KATIA LEITE AGOSTINHO

ESTUDO DO NITROGÊNIO E DO FÓSFORO (N E P) NO SETOR NORTE DO COMPLEXO ESTUARINO-LAGUNAR DE CANANÉIA-IGUAPE (SP)

CONSIDERANDO AS CONDIÇÕES NATURAIS DO SISTEMA E A INFLUÊNCIA DOS APORTES ANTRÓPICOS

Dissertação apresentada ao Instituto Oceanográfico da Universidade de São Paulo, como parte dos requisitos para obtenção do título de Mestre em Ciências, área de Oceanografia Química.

Orientadora: Prof ${ }^{\mathrm{a}}$. Dr ${ }^{\mathrm{a}}$. Elisabete de Santis Braga da Graça Saraiva 


\title{
ESTUDO DO NITROGÊNIO E DO FÓSFORO (N E P) NO SETOR NORTE DO \\ COMPLEXO ESTUARINO-LAGUNAR DE CANANÉIA-IGUAPE (SP) \\ CONSIDERANDO AS CONDIÇÕES NATURAIS DO SISTEMA E A INFLUÊNCIA DOS APORTES ANTRÓPICOS
}

\begin{abstract}
Dissertação apresentada ao Instituto Oceanográfico da Universidade de São Paulo, como parte dos requisitos para obtenção do título de Mestre em Ciências, área de Oceanografia Química.
\end{abstract}

Julgada em 03/07/2015

VERSÃO CORRIGIDA

Prof(a). Dr(a). Elisabete de Santis Braga da Graça Saraiva Conceito

Prof. Dr. Leandro José Grava de Godoy Conceito

Prof. Dr Jose Juan Barrera Alba

Conceito 


\section{Sumário}

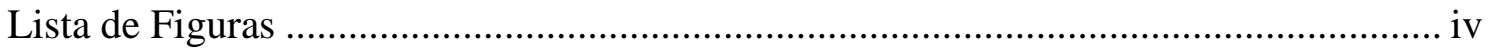

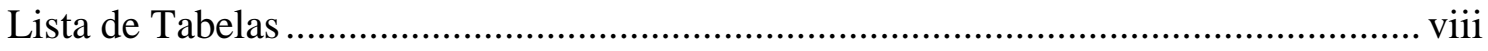

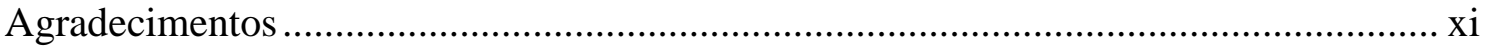

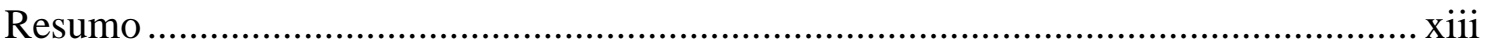

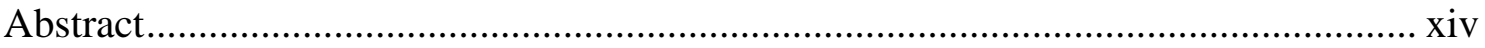

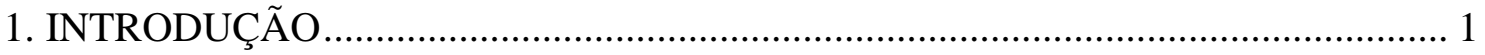

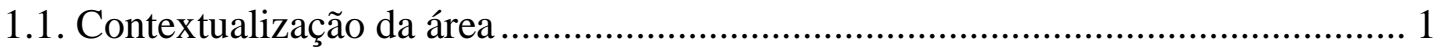

1.2. Nutrientes $\mathrm{N}$-nitrato e $\mathrm{P}$-fosfato .......................................................................... 5

1.3. Características da produção da banana- Bananicultura na área estudada.............. 7

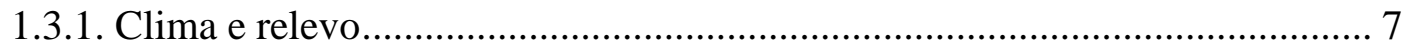

1.3.2. Tipo de Solo, formação vegetal natural, uso da terra................................... 8

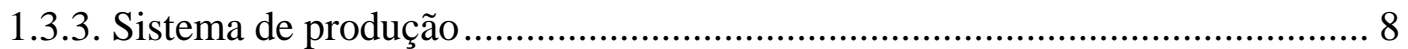

1.4. Características do Rio Ribeira desde a sua nascente e cidades que o margeiam. 10

1.5. Características do afluente Jacupiranga e as cidades à margem deste ................. 12

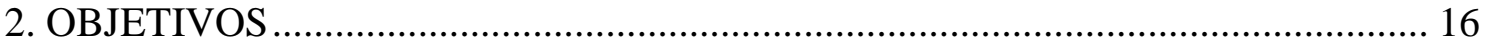

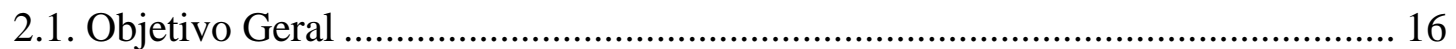

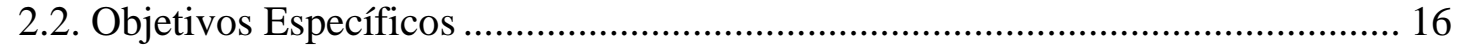

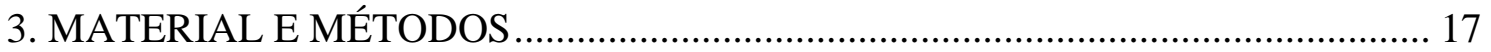

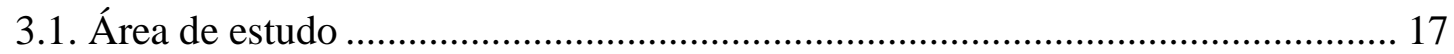

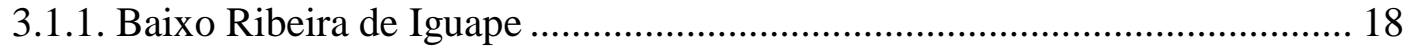

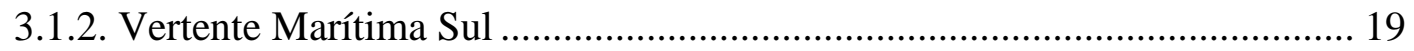

3.1.3. Vertente Marítima Norte .............................................................................. 19

3.1.4. Afluente ao rio Ribeira de Iguape - entre Registro e Iguape- Rio Jacupiranga

3.1.5. Regime hidrológico da bacia ..................................................................... 20

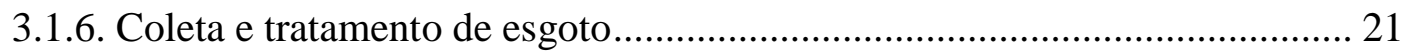

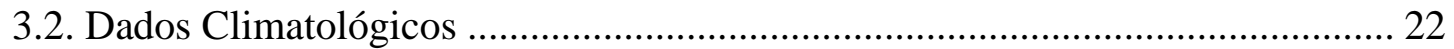

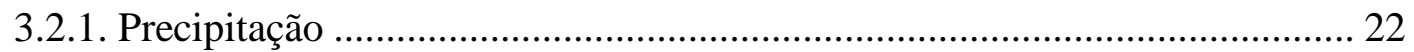

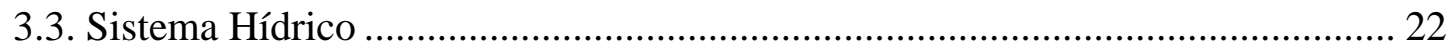

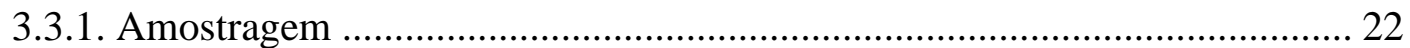

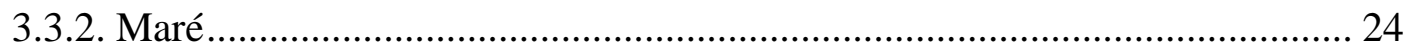

3.3.3. Turbidez e penetração da luz ..................................................................... 24

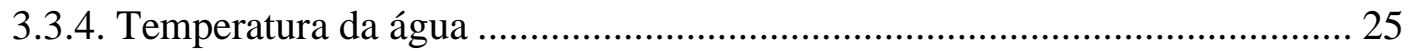

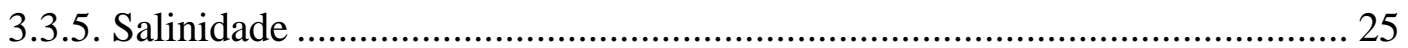




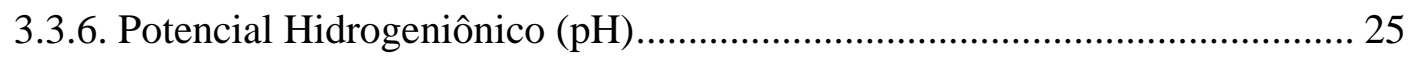

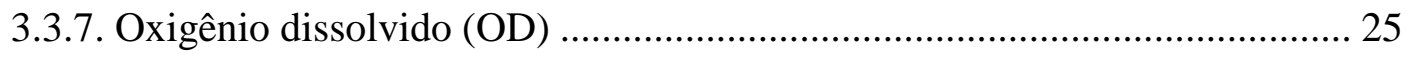

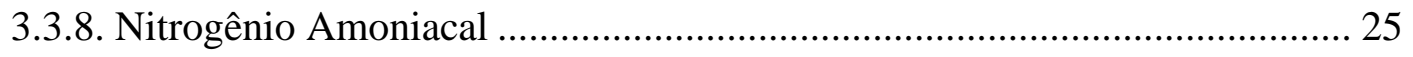

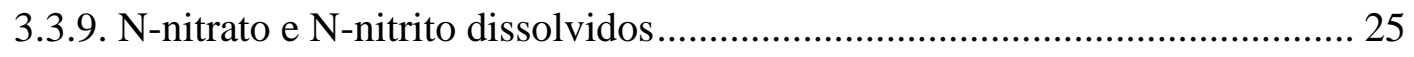

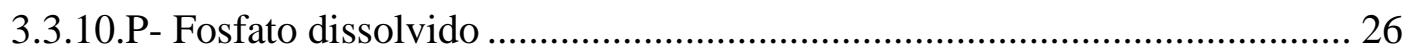

3.3.11. Material em Suspensão (MES) ……….................................................... 26

3.3.12. Material Orgânico em Suspensão (MOS).................................................. 26

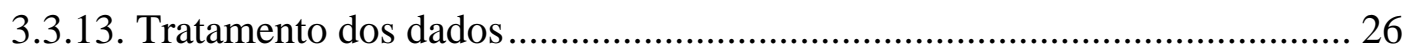

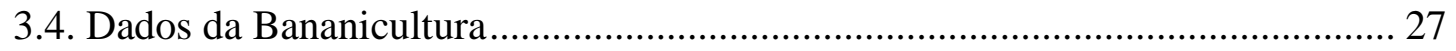

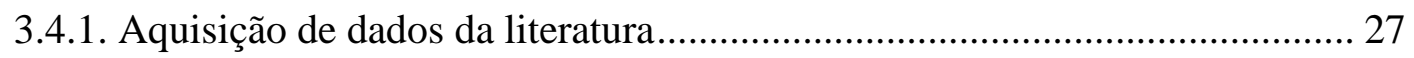

3.4.2. Aquisição de dados via tratamento de imagens ............................................ 27

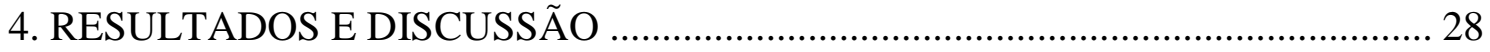

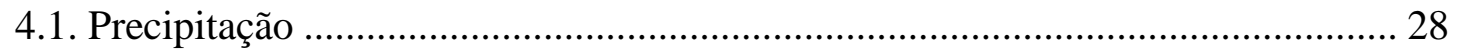

4.2. Condições hidroquímicas com destaque ao N-nitrato e ao P-fosfato................. 30

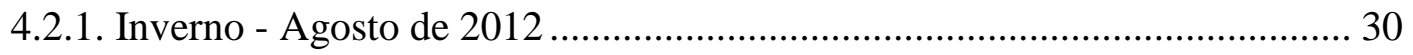

4.2.1.1. Rio Ribeira de Iguape - estações R1 a R6 .......................................... 31

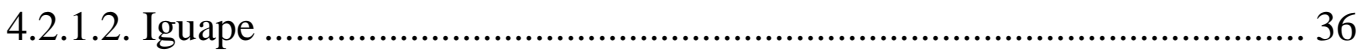

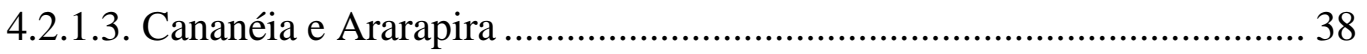

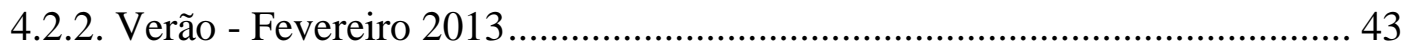

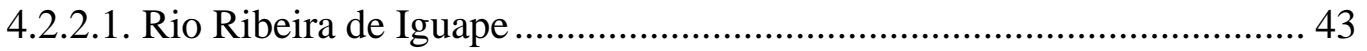

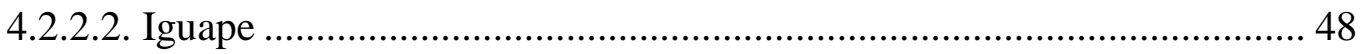

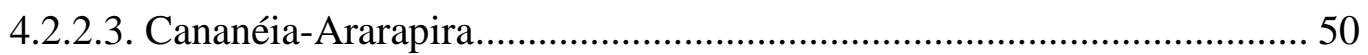

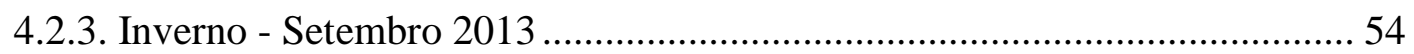

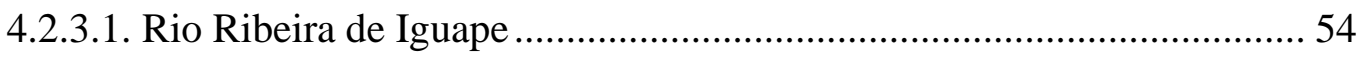

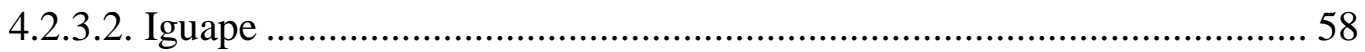

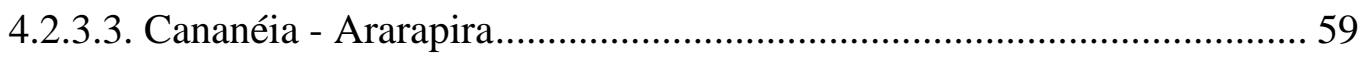

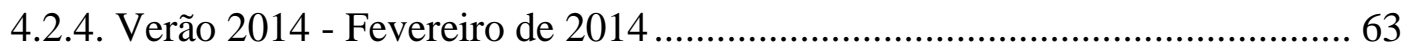

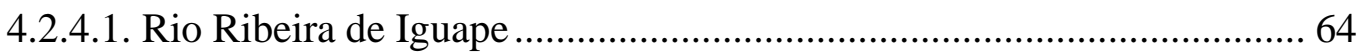

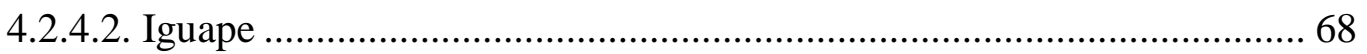

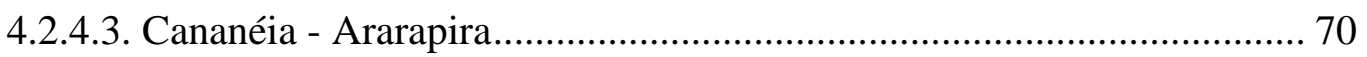

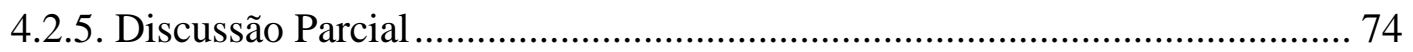

4.3. Aspectos indicativos de contribuições antrópicas no Baixo Ribeira ................... 81

4.3.1. Área estimada da bananicultura nas margens do Rio (Registro - Iguape) ... 81

4.3.1.1. Caracterização de cada área/lote........................................................ 83 
4.3.2. Cultivo da banana e potencial de lixiviação de N-nitrato e P-fosfato ao Rio

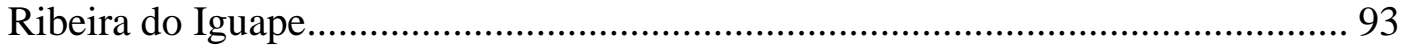

4.3.3. Perda de N-nitrato e P-fosfato no solo, sob o cultivar de bananas ............... 94

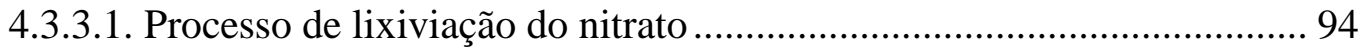

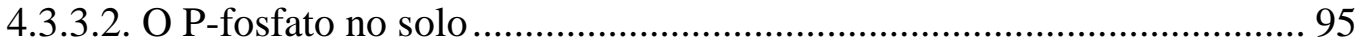

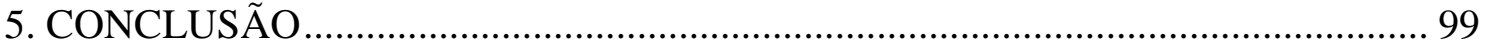

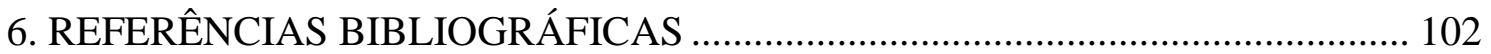




\section{Lista de Figuras}

Figura 1. Cultivo de banana nas margens do Rio Ribeira de Iguape. (Fonte: camiloaparecido-blog.terra.com.br, acesso em 04/07/2013)........................................ 1

Figura 2. Região administrativa de Registro (Fonte: www.igc.gov.br/portal//igc) (a); destaque do final do curso do Rio Ribeira de Iguape (b) com localização do Valo Grande (seta; fonte: the-rioblog.blogspot.com, acesso em 04/07/2013).

Figura 3. Distribuição geográfica da área de cultivo de banana, no estado de São Paulo (Pino et al., 2000.).

Figura 4. Búfalos ao longo das margens do Rio Ribeira de Iguape (SP) na região de Iguape (Foto: E. S. Braga).

Figura 5. Pontos de coleta no complexo estuarino-lagunar de Cananéia-Iguape (a) com ênfase nas estações realizadas no Rio Ribeira de Iguape e Valo Grande (b) no Projeto Febiogeoquim/ INCT-TMCOcean em agosto/2012, fevereiro/2013, setembro/2013 e fevereiro/2014.

Figura 6. Precipitação mensal nos anos de 2012 (a), 2013 (b) e 2014 (c), com base nos dados de Pariquera-Açú divulgados em CIIAGRO, www.diagro.sp.gov.br, acesso em 20/02/2015. 28

Figura 7. Precipitação mensal de janeiro, fevereiro, julho, agosto, setembro e outubro de 2012, 2013 e 2014 com base na precipitação total anual dos anos 2012 a 2014, CIIAGRO, www.diagro.sp.gov.br, acesso em 20/02/2015.

Figura 8. Curvas de maré construídas com dados do LABDADOS-IOUSP nos dias 28, 29, 30 e 31 de Agosto de 2012, destacando os momentos de realização das estações na região de Cananéia e Iguape (SP).

Figura 9. Distribuição espacial de temperatura (a) e salinidade (b) a jusante do Rio Ribeira de Iguape (SP), Agosto de 2012.

Figura 10. Distribuição espacial de oxigênio dissolvido (a) e $\mathrm{pH}$ (b) a jusante do Rio Ribeira de Iguape (SP), Agosto de 2012.

Figura 11. Distribuição espacial de compostos nitrogenados no Rio, $\mathrm{N}$-amoniacal (a), nitrito (b), nitrato (c), NID (d), Agosto de 2012.

Figura 12. Distribuição espacial dos valores de $\mathrm{PO}_{4}{ }^{-3}$ (a) e NID/PO $4{ }^{3-}(\mathrm{b})$, nos pontos do

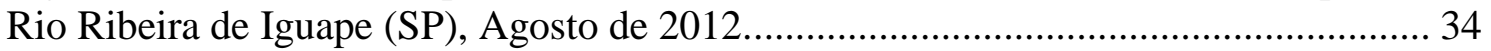

Figura 13. Distribuição espacial dos valores de material em suspensão (a), matéria orgânica (b) e porcentagem de matéria orgânica (c) no Rio Ribeira de Iguape, em agosto de 2012. 35

Figura 14. Distribuição de fosfato, nitrato e $\mathrm{N}$-amoniacal $\left(\mu \mathrm{mol} \mathrm{L} \mathrm{L}^{-1}\right)$ versus salinidade. Rio Ribeira do Iguape, Agosto de 2012 . ....................................................................... 36

Figura 15. Distribuição de fosfato, nitrato e amônio pela Salinidade. Iguape, agosto 2012.

Figura 16. Fosfato, Nitrato e Amônio versus Salinidade. Cananéia, agosto de 2012 ... 41

Figura 17. Fosfato, Nitrato e Amônio versus Salinidade. Ararapira, agosto 2012 ......... 41 
Figura 18. Curvas de maré construídas com dados do LABDADOS-IOUSP nos dias 23, 24 e 25de Fevereiro de 2013, destacando os momentos de realização das estações na região de Cananéia e Iguape (SP). 43

Figura 19. Distribuição espacial da temperatura (a) e salinidade (b) a jusante do Rio Ribeira do Iguape, Fevereiro de 2013.

Figura 20. Distribuição espacial de oxigênio dissolvido (a) e $\mathrm{pH}$ (b) a jusante do Rio Ribeira de Iguape, Fevereiro de 2013.

Figura 21. Distribuição espacial de compostos nitrogenados no Rio Ribeira de Iguape, Namoniacal (a), nitrito (b), nitrato (c) e NID (d), Fevereiro 2013.

Figura 22. Distribuição espacial dos valores de $\mathrm{PO}_{4}{ }^{3}$ (a) e NID/PO ${ }_{4}{ }^{3}$ (b) nos pontos do Rio Ribeira de Iguape, Fevereiro de 2013

Figura 23. Distribuição espacial dos valores de MES (a), MO (b) e \% de MO (c) no Ribeira de Iguape em fevereiro de 2013.

Figura 24. Distribuição de Fosfato, Nitrato e Amônio versus Salinidade. Rio Ribeira do Iguape, fevereiro de 2013. 48

Figura 25. Distribuição de Fosfato, Nitrato e Amônio versus Salinidade. Iguape, Fevereiro de 2013. 50

Figura 26. Distribuição de Fosfato, Nitrato e Amônio versus Salinidade. Cananéia, Fevereiro de 2013.

Figura 27. Distribuição de Fosfato, Nitrato e Amônio versus Salinidade. Ararapira, Fevereiro de 2013. 52

Figura 28. Curvas de maré construídas com dados do LABDADOS-IOUSP nos dias 13, 14, 15 e 16 de Setembro de 2013, destacando os momentos de realização das estações na região de Cananéia e Iguape (SP).

Figura 29. Distribuição espacial de temperatura (a) e salinidade a jusante do Rio Ribeira de Iguape, Setembro de 2013.

Figura 30. Distribuição espacial de oxigênio dissolvido (a) e pH (b) a jusante do Rio Ribeira de Iguape, Setembro de 2013.

Figura 31. Distribuição espacial de compostos nitrogenados no Rio, N-amoniacal (a), nitrito (b), nitrato (c) e NID (d), Setembro de 2013.

Figura 32. Distribuição espacial do fosfato (a) e da relação NID/PO ${ }_{4}^{-3}$ (b). Setembro de

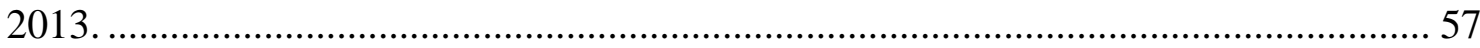

Figura 33. Distribuição espacial de MES (a), MO (b) e \%MO (c), Setembro 2013...... 58

Figura 34. Distribuição de fosfato, nitrato, nitrito e amônio versus salinidade, Cananéia, Setembro de 2013.

Figura 35. Distribuição de fosfato, nitrato, nitrito e amônio versus salinidade, Ararapira, Setembro de 2013.

Figura 36. Curvas de maré construídas com dados do LABDADOS-IOUSP nos dias 13, 14, 15 e 16 de Setembro de 2014, destacando os momentos de realização das estações na região de Cananéia e Iguape (SP).

Figura 37. Distribuição espacial da temperatura $\left({ }^{\circ} \mathrm{C}\right.$ ) (a) e salinidade (b) no Rio Ribeira de Iguape (SP), em Fevereiro 2014. 
Figura 38. Distribuição espacial de OD ( $\mathrm{ml} \mathrm{L}^{-1}$ ) (a) e pH (b) no Rio Ribeira de Iguape, em Fevereiro 2014.

Figura 39. Distribuição espacial de N-amoniacal (a), nitrito (b), nitrato (c) e NID (d), no Rio Ribeira de Iguape, em Fevereiro de 2014. 66

Figura 40. Distribuição espacial de $\mathrm{PO}_{4}{ }^{-3}$ (a) e NID/ $\mathrm{PO}_{4}^{-3}$ (b), nos pontos do Rio Ribeira de Iguape, em Fevereiro de 2014.

Figura 41. Distribuição espacial do material em suspensão (a), matéria orgânica (b) e porcentagem de matéria orgânica (c) no Rio Ribeira de Iguape, em Fevereiro de 2014.

Figura 42. Distribuição de Fosfato, Nitrato e Amônio versus Salinidade, Iguape, em Fevereiro de 2014.

Figura 43. Distribuição de Fosfato, Nitrato e Amônio versus Salinidade, Cananéia, em Fevereiro de 2014.

Figura 44. Distribuição de Fosfato, Nitrato e Amônio versus Salinidade. Ararapira, em Fevereiro de 2014. 72

Figura 45. Valores médios dos parâmetros salinidade, temperatura, $\mathrm{pH}$ e OD nos diferentes anos, no setor Rio(a), Iguape (b) e Cananéia-Ararapira (c). 75

Figura 46. Valores médios dos parâmetros N-amoniacal, nitrito, nitrato, NID, fosfato e razão N/P nos diferentes anos, no setor Rio (a), Iguape (b) e Cananéia-Ararapira (c). . 76

Figura 47. Mapa referente ao indicador E.01 (1) - Fósforo total. Fonte: CETESB ,2013

Figura 48. Desenho amostral das áreas/setores de bananiculturas localizadas nas margens do Rio Ribeira entre as cidades de Registro e Iguape (SP) (GOOGLE EARTH PRO$11 / 01 / 2015)$.

Figura 49. Localização e delimitação da área A de plantação de banana na região entre Registro e Iguape (SP), (utilização do GOOGLE EARTH PRO-11/01/2015). 83

Figura 50. Localização e delimitação das áreas B e C (utilização do GOOGLE EARTH PRO-11/01/2015)

Figura 51. Localização e delimitação das áreas D e E (utilização do GOOGLE EARTH PRO-11/01/2015).

Figura 52. Localização e delimitação das áreas F, G, H e I (utilização do GOOGLE EARTH PRO-11/01/2015).

Figura 53. Localização e delimitação das áreas J, K, L e M (utilização do GOOGLE EARTH PRO-07/02/2015) 86

Figura 54. Localização e delimitação das áreas N, O e Q (utilização do GOOGLE EARTH $-07 / 02 / 2014)$.

Figura 55. Localização e delimitação das áreas $\mathrm{P}$ e R, margem direita do Rio (utilização do GOOGLE EARTH -07/02/2014).

Figura 56. Localização e delimitação das áreas S, T, U e W à margem esquerda do Rio (utilização do GOOGLE EARTH PRO-07/02/2014).

Figura 57. Localização e delimitação da área V à margem direita do Rio (utilização do GOOGLE EARTH PRO -07/02/2014).... 
Figura 58. Localização e delimitação das áreas X e X' nas margens direita e esquerda do Rio (utilização do GOOGLE EARTH PRO -07/02/2014).......................................... 90

Figura 59. Localização e delimitação das áreas Y e Z às margens direita e esquerda do Rio respectivamente (utilização do GOOGLE EARTH PRO -07/02/2014).................. 91

Figura 60. Localização e delimitação da área BR2 margem direita do Rio (utilização do

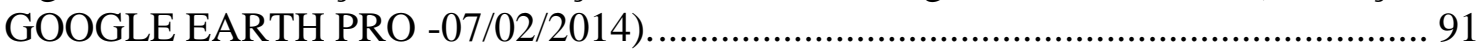

Figura 61. Localização e delimitação da área BR1, à margem esquerda do Rio (utilização do GOOGLE EARTH PRO -07/02/2014).

Figura 62. Localização e delimitação da área BR1, chegada do afluente Jacupiranga e pontos de coleta no Rio Ribeira do Iguape - Projeto FEBIOGEOQUIM e INCTTMCOcean (utilização do GOOGLE EARTH PRO -07/02/2014).

Figura 63. Tamanho das áreas ocupadas pela bananicultura delimitadas neste estudo entre Registo e Iguape (SP). 


\section{Lista de Tabelas}

Tabela 1. Levantamento Censitário das principais Unidades de Produção Agropecuária dos municípios de Cananéia, Iguape, Registro e Jacupiranga (CATI, 2008).

Tabela 2. Tipos de adubos comercializados no Vale do Ribeira, SP (Godoy et al., 2006).

Tabela 3. Quadro Sub Bacias do Rio Ribeira do Iguape e litoral Sul (SSRH, 2009)..... 18

Tabela 4. Valores relacionados à população, atendimento e coleta de esgoto/tratado, eficiência, carga poluidora kg DBO/dia, ICETEM, corpo receptor (CETESB, 2013).... 22

Tabela 5. Precipitação total anual ds anos 2012 a 2014. CIIAGRO, disponível em

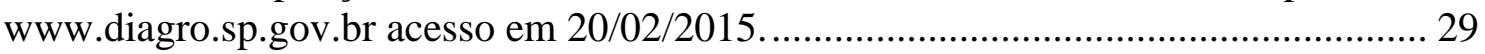

Tabela 6. Precipitação total mensal (mm) dos meses de coleta de 2012 a 2014. CIIAGRO,

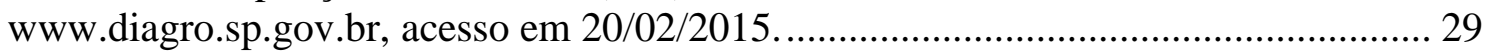

Tabela 7. Dados hidrológicos e hidroquímicos $(0 \mathrm{~m})$ das águas a jusante do Rio Ribeira

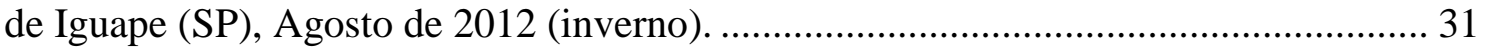

Tabela 8. Concentrações de material em suspensão, material orgânico em suspensão, porcentagem de material orgânico em suspensão, turbidez, e profundidade do disco de Secchi nas águas do Rio Ribeira de Iguape, em Agosto de 2012 …............................. 34

Tabela 9. Valores de temperatura, salinidade, oxigênio dissolvido, $\mathrm{pH}, \mathrm{N}$-amoniacal, $\mathrm{N}$ nitrito, N-nitrato, nitrogênio inorgânico dissolvido, P-fosfato e relação nitrogênio inorgânico dissolvido e P-fosfato referentes ao sistema norte, incluindo o Valo Grande (estações 4 e 4A) e a estação intermediária(6), em agosto de 2012 (inverno). 37

Tabela 10. Concentrações de material em suspensão (MES), material orgânico em suspensão (MO), porcentagem de material orgânico em suspensão e turbidez, nas águas de Iguape, Valo Grande e estação intermediária, em Agosto de 2012.

Tabela 11. Valores de temperatura, salinidade, oxigênio dissolvido, $\mathrm{pH}, \mathrm{N}$-amoniacal, $\mathrm{N}$ nitrito,N- nitrato e nitrogênio inorgânico dissolvido, em Cananéia e Ararapira, sul do sistema, em Agosto de 2012.

Tabela 12. Concentrações de material em suspensão, material orgânico em suspensão, porcentagem de material orgânico em suspensão e turbidez, nas águas Cananéia e Ararapira, em Agosto de 2012

Tabela 13. Quadro sinóptico da situação do sistema Rio-Valo Grande-Iguape-CananéiaArarapira (SP), em Agosto de 2012.

Tabela 14. Dados hidrológicos e hidroquímicos $(0 \mathrm{~m})$ das águas a jusante do Rio Ribeira de Iguape, Fevereiro de 2013. 44

Tabela 15. Concentrações de material em suspensão, material orgânico em suspensão, porcentagem de material orgânico em suspensão, turbidez e profundidade do disco de Secchi nas águas do Rio Ribeira de Iguape, em Fevereiro de 2013 .............................. 46

Tabela 16. Valores de temperatura, salinidade, oxigênio dissolvido, $\mathrm{pH}, \mathrm{N}$-amoniacal, $\mathrm{N}$ nitrito, N-nitrato, nitrogênio inorgânico dissolvido,P-fosfato e relação NID/P-fosfato no norte do sistema, incluindo o Valo Grande (estações 4 e 4A) e a estação intermediária (6), em fevereiro de 2013. 
Tabela 17. Concentrações de material em suspensão, material orgânico em suspensão, porcentagem de material orgânico em suspensão e turbidez, nas águas Cananéia e Ararapira, em Agosto de 2012.

Tabela 18. Valores de temperatura, salinidade, oxigênio dissolvido, $\mathrm{pH}, \mathrm{N}$-amoniacal, $\mathrm{N}$ nitrito, N-nitrato e nitrogênio inorgânico dissolvido, em Cananéia e Ararapira, sul do sistema, em Fevereiro de 2013.

Tabela 19. Valores de material em suspensão, matéria orgânica, porcentagem de matéria orgânica e turbidez, em Cananéia e Ararapira, sul do sistema, em Fevereiro de 2013. . 51

Tabela 20. Quadro sinóptico da situação do sistema em Fevereiro de 2013. 53

Tabela 21. Dados hidrológicos e hidroquímicos $(0 \mathrm{~m})$ das águas a jusante do Rio Ribeira de Iguape, Setembro 2013.

Tabela 22. Valores de material em suspensão, matéria orgânica, porcentagem de MO, turbidez e profundidade do disco de Secchi das águas a jusante do Rio Ribeira de Iguape, Setembro 2013

Tabela 23. Valores de temperatura, salinidade, oxigênio dissolvido, $\mathrm{pH}, \mathrm{N}$-amoniacal, $\mathrm{N}$ nitrito,N- nitrato e nitrogênio inorgânico dissolvido, em Iguape, no Valo Grande e na estação 6, em Setembro de 2013. 59

Tabela 24. Valores de material em suspensão, matéria orgânica, porcentagem de matéria orgânica e turbidez, em Iguape, no Valo Grande no setor intermediário em Setembro de 2013.

Tabela 25. Valores de temperatura, salinidade, oxigênio dissolvido, $\mathrm{pH}, \mathrm{N}$-amoniacal, Nnitrito, N-nitrato, nitrogênio inorgânico dissolvido e relação NID/P-fosfato, Setembro de 2013.

Tabela 26. Valores de material em suspensão, matéria orgânica, porcentagem de matéria orgânica e turbidez, em Cananéia e Ararapira, sul do sistema, em setembro de 2013... 60

Tabela 27. Quadro sinóptico da situação do sistema em Setembro de 2013.

Tabela 28. Dados hidrológicos e hidroquímicos $(0 \mathrm{~m})$ das águas a jusante do Rio Ribeira de Iguape, Fevereiro de 2014.

Tabela 29. Dados hidrológicos e hidroquímicos (0m) das águas a jusante do Rio Ribeira de Iguape, Fevereiro 2014.

Tabela 30. Valores de temperatura, salinidade, $\mathrm{pH}$, oxigênio dissolvido, $\mathrm{N}$-amoniacal, $\mathrm{N}$ nitrito, N-nitrato, P- fosfato, nitrogênio inorgânico dissolvido, relação entre nitrogênio inorgânico dissolvido e P-fosfato em Iguape, no Valo Grande e na estação 6, em Fevereiro de 2014.

Tabela 31. Valores de material em suspensão, matéria orgânica, \% de matéria orgânica e turbidez, em Iguape, no Valo Grande e no setor intermediário, em Fevereiro de 2014. 70

Tabela 32. Valores de temperatura, salinidade, $\mathrm{pH}$, oxigênio dissolvido, $\mathrm{N}$-amoniacal, $\mathrm{N}$ nitrito,N- nitrato, P-fosfato , nitrogênio inorgânico dissolvido,relação entre nitrogênio inorgânico dissolvido e P-fosfato em Cananéia - Ararapira, em fevereiro de 2014..... 71

Tabela 33. Concentrações de material em suspensão, material orgânico em suspensão, porcentagem de material orgânico em suspensão e turbidez, nas águas de Cananéia -

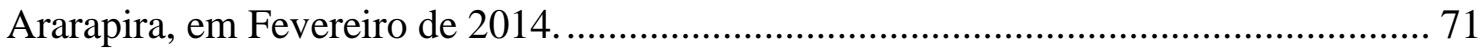

Tabela 34. Quadro sinóptico da situação do sistema em Fevereiro de 2014.................. 74 
Tabela 35. Concentrações de fosfato e nitrato em rios com base no trabalho de Meybeck, 1982.

Tabela 36. Valores de $\mathrm{pH}$, oxigênio dissolvido, N-amoniacal, N-nitrito, N-nitrato, N-total, P-fósforo, P-fósforo total em Registro e no Canal do Valo Grande, Novembro de 2006. Fonte: BRASIL DAS ÁGUAS (2007) e estudo atual.

Tabela 37. Área plantada total, densidade de plantas/ha, total de plantas, quantidade de $\mathrm{N}$ aplicado por planta, total de $\mathrm{N}$ aplicado, perda estimada (30\%) de $\mathrm{N} /$ ano.................... 93

Tabela 38. Densidade de plantas e estimativa de perda de P (fosfato)........................... 94

Tabela 39. Estimativa da perda de nutrientes (N-nitrato e P-fosfato) da bananeira por enxurrada, drenagem e adubação (tabela adaptada de Godefroy et al., 1970; 1975).... 96

Tabela 40. Estimativa de transporte de $\mathrm{N}$-nitrato e $\mathrm{P}$-fosfato pelos rios no inverno e verão, de acordo com as concentrações determinadas na estação Rio mais a Jusante, R3 e em Registro (Novembro, 2013). Apresentam-se também resultados de Cunha, 2010, obtidos no Rio Jacupiranga. 


\section{Agradecimentos}

Tenho muito a agradecer a todos, mas caso esqueça de agradecer a alguém, espero perpetuar o que tenha aprendido com esta pessoa, creio que isso seja uma boa forma de agradecer.

Agradeço a Deus pela vida, pela saúde, por me dar força sempre de persistir com meus ideais e pela linda família que me deu. Meus pais maravilhosos Augusto e Silvia, companheiros, exemplos que segui para trilhar meus caminhos, e que, quando errei, pois sim são os erros que nos levam a aprender, suas mãos lá estavam, me dando amor, conforto e me ensinando a continuar na luta. Meus amados irmãos, Adriana, Henrique e Ricardo, companheiros de casa, de crescimento, de carro apertado na hora de viajar, de muita risada e parceria nas difíceis horas da vida.

Ao meu marido, companheiro e amigo Silvio, que cuidou e cuida muito dos nossos filhos quando não estou presente, obrigada pela paciência, amor e dedicação prestados sempre a mim e aos nossos filhos Gabriela e Vitor.

À querida professora Elisabete de Santis Braga, por me ouvir (desde a nossa primeira conversa ao telefone em 2009). Saiba que escutar as pessoas é um dos maiores dons de um bom comunicador. Obrigada por me ensinar, me guiar neste trabalho, por toda a orientação científica prestada, pela amizade e confiança, pelas subidas e descidas de rio, pelas alegrias, pela oportunidade de acompanhar o grupo de pesquisa em campos tão especiais. Vou poder um dia falar aos meus netos “- Vocês sabiam que a vovó já viu baleia e golfinho no mar?" Quero continuar a fazer pesquisa com a senhora.

Ao suporte financeiro prestado a essa pesquisa que se integra no âmbito dos projetos: UNIVERSAL FEOBIOGEOQUIM-CNPq 478890/2011-7 e ao Instituto Nacional de Ciência e Tecnologia Transferência de Material Continente-Oceano INCTTMCOcean - Proc. 573.601/2008-9.

Ao instituto Oceanográfico (IO-USP) e aos Laboratórios de Nutrientes, Micronutrientes e Traços nos Oceanos (LABNUT).

Aos companheiros do Labnut: Ana Teresa Bastos, Ana Maria Souza, Beatriz Scigliano, Caio Hirakawa, Chiara Machado, Esther Oliveira, Glaucia Berbel, João Maluf, Leonardo Bertini, Lilian Seiler, Livia Coelho, Natalia Garrido, Samara Eschrique, Vitor Chiozzini. Obrigada pela companhia nos campos, pela ajuda nas análises, pelos ensinamentos, pela troca de ideias, pelas alegrias. 
Aos professores e funcionários do IO. Aos professores responsáveis pelas disciplinas cursadas no mestrado que muito contribuíram na consolidação das informações e reflexões necessárias para a realização deste trabalho. À doce companhia da professora Sueli S. Godoi e do Wilson N. de Oliveira em nossos trabalhos de campo .

À tripulação do Barco de Pesquisa Oceanográfica "Albacora" e a todos os funcionários da Base Sul de Pesquisa "Dr. João de Paiva Carvalho", situada na cidade de Cananéia, pelo apoio e consideração durante as atividades de campo desta dissertação.

Ao pessoal do Cepema - Cubatão, em especial Osmar e Rafaela pelo apoio nas análises de agrotóxicos, na busca de uma metodologia adequada, para análise destes em água, que servirão para trabalhos futuros e ao Prof. Claudio Oller.

Ao professor Dr. Leandro Godoy da Unesp - Registro por ter me recebido e me auxiliado nos cálculos do aporte de nutrientes da cultura de banana.

Muito obrigada a todos. 


\section{Resumo}

O Rio Ribeira nasce no estado do Paraná e tem sua foz no município de Iguape estado de São Paulo. Possui 470 km de extensão e recebe o nome de Ribeira de Iguape em sua porção final, onde existe uso intensivo do solo para a agricultura (bananicultura), atividades industriais como mineração, eliminação de esgoto e um pouco de pecuária. Estas atividades contribuem com o aporte de nutrientes nitrogenados e fosfatados para o corpo hidrológico, atingindo o Complexo Estuarino-Lagunar de Cananéia-Iguape por meio do Canal do Valo Grande, em Iguape. O presente trabalho caracterizou o sistema hídrico por meio de parâmetros hidrológicos e hidroquímico como: temperatura da água, salinidade, $\mathrm{pH}$, oxigênio dissolvido, material em suspensão, teores de nitrogênio e de fósforo, matéria orgânica em suspensão e turbidez. Foi realizado um diagnóstico do setor norte do sistema em relação às condições estuarinas naturais presentes no setor sul, correlacionando os valores observados de componentes nitrogenados e fosfatados com a carga estimada de fertilizante empregada nos cultivos de banana, principal cultura da área estudada. Entre Registro e Iguape, a bananicultura localizada na região marginal ao rio foi estimada, com o uso de imagens, em aproximadamente 744 hectares. Foram feitas quatro coletas (invernos 2012 e 2013, verões 2013 e 2014) com 20 estações ao longo do Rio-Valo Grande-Sistema Estuarino Lagunar de Cananéia Iguape. No setor norte foram obtidos os mais altos teores de nitrato, $15,72 \mu \mathrm{mol} \mathrm{L}{ }^{-1}$ no rio e $14,59 \mu \mathrm{mol} \mathrm{L}^{-1}$ no Valo Grande indicando o grande aporte deste nutriente via rio e com contribuição significativa da adubação da cultura da banana. Quanto ao fosfato, os valores foram extremamente altos em toda a amostragem no setor norte, sobretudo no Inverno de 2012, onde o máximo teor foi de $12,45 \mu \mathrm{mol} \mathrm{L}^{-1}$ no Rio. Este aporte alto é contínuo e deve receber contribuição suplementar via afluentes, com forte indicativo da proveniência da exploração de rochas fosfatadas, na região de Cajati, cujos efluentes podem atingir o Rio Ribeira de Iguape por meio do Rio Jacupiranga. As cargas de $\mathrm{N}$ e $\mathrm{P}$ provenientes da agricultura foram de 44,22 $\mathrm{t}$ ano $^{-1}$ para $\mathrm{N}\left(1,6 \%\right.$ da carga total do rio) e $5,36 \mathrm{t} \mathrm{ano}^{-1}$, para $\mathrm{P}(0.12 \%$ da carga total do rio). O desbalanceamento da entrada de $\mathrm{P}$ na relação N:P mostra esta entrada suplementar de P no norte do sistema indicando a forte influência antrópica na região em relação aos dois nutrientes, mas com maior carga para $\mathrm{P}$ e uma diluição em relação ao sul que deve ser monitorada.

Palavras chaves: nutrientes, fósforo, nitrogênio, bananicultura, fertilizantes, sistema estuarino, influência antrópica. 


\section{Abstract}

The Ribeira River rises in the state of Paraná- Brazil and outfalls in Iguape, state of São Paulo (Brazil). The river is $470 \mathrm{~km}$ long, and in its final portion, which is aproximately $70 \mathrm{~km}$ long, is called Ribeira de Iguape River. In this area an intense use of the soil can be found regarding the growth of bananas crops, there are also industrial mining activities, sewage disposal and some livestock. These activities contribute to the supply of nitrogenous and phosphate nutrients input for the hydrological body, which further reaches Cananéia-Iguape Estuary-Lagoon Complex through Valo Grande Channel, in Iguape. This study characterized the water system through hydrological and hydrochemical parameters such as water temperature, salinity, $\mathrm{pH}$, dissolved oxygen, suspended matter and turbidity. It was conducted a diagnosis of the northern sector of the system in relation to the natural estuarine conditions present in the south sector. The observed values of nitrogen and phosphate were correlated with the estimated load of fertilizer used in banana plantations, which is the main crop in the study area. The banana plantation located in the river's margins, between the cities of Registro and Iguape, was estimated with the use of images, and resulted in approximately 744 hectares. Four campaigns of water sampling were made: winter of 2012 and 2013; summers 2013 ,2014) with 19 stations along the River - Valo Grande channel - Cananéia Iguape Estuarine Lagoon System. Highest levels of nitrate were obtained in the river sample of $15.72 \mu \mathrm{mol}$ $\mathrm{L}^{-1}$, and $14.59 \mu \mathrm{mol} \mathrm{L}^{-1}$ in the Channel, indicating the great contribution of this nutrient via river and significant contribution of the banana crop fertilization. Regarding the phosphate levels, they were extremely high throughout the sampling in the northern sector, especially in winter 2012, where the maximum level was $12.45 \mu \mathrm{mol} \mathrm{L}^{-1}$ in the River. This high contribution is ongoing and might receive additional contribution via tributaries, with strong indication of provenance from exploiting phosphate rocks, in the region of Cajati- SP, where effluent can reach the Ribeira de Iguape River through Jacupiranga River. The agricultural load of $\mathrm{N}$ and $\mathrm{P}$ were estimated in $44.22 \mathrm{t} \mathrm{N}$ year ${ }^{-1}$ (1.62\% of total river load) and $5.36 \mathrm{t}^{\text {year }} \mathrm{r}^{-1} \mathrm{P}(0.15 \%$ of total river load $)$. The imbalance of $\mathrm{P}$ input in $\mathrm{N}$ : $\mathrm{P}$ shows this additional input of $\mathrm{P}$ - Phosphate in the north of the system, indicating the strong anthropogenic influence in the region in the two nutrients, but with higher load for $\mathrm{P}$ and a dilution towards south, which should be monitored.

Key words: phosphorus, nitrogen, banana plantations, fertilizers, estuarine system, anthropogenic influence. 


\section{INTRODUÇÃO}

\subsection{Contextualização da área}

A região costeira constitui uma zona de interface entre o continente e o mar, apresentando características diferenciadas devido à influência dos processos atuantes em cada segmento de costa, sendo também uma região sede ou destino de muitas atividades antrópicas e/ou de seus efeitos.

De acordo com Mommaerts et al. (1987), a otimização dos múltiplos usos em região costeira requer a acomodação de conflitos de interesses dentro de um quadro regulatório que assegure que os distúrbios sejam mínimos, ou reversíveis, e que os recursos marinhos sejam conservados.

O Complexo Estuarino-Lagunar de Cananéia-Iguape (SP) é uma região de alta complexidade hidrológica e, atualmente, apresenta distinção nas atividades e ocupação das regiões norte e sul do sistema. A região Norte, junto à cidade de Iguape, recebe aportes de águas trazidas pelo Rio Ribeira de Iguape, que inserem materiais no sistema, fazendo com que a porção norte seja mais fragilizada pelo excesso de nutrientes provenientes da fertilização das áreas utilizadas pela agricultura nas margens do rio, além do material em suspensão e também, de agrotóxicos oriundos de áreas de cultivo implantadas ao longo do Rio (Fig. 1). Outras atividades antrópicas também contribuem ao aporte de material no Rio Ribeira e consequente transporte para o estuário. Como por exemplo a exploração mineral e a pecuária.
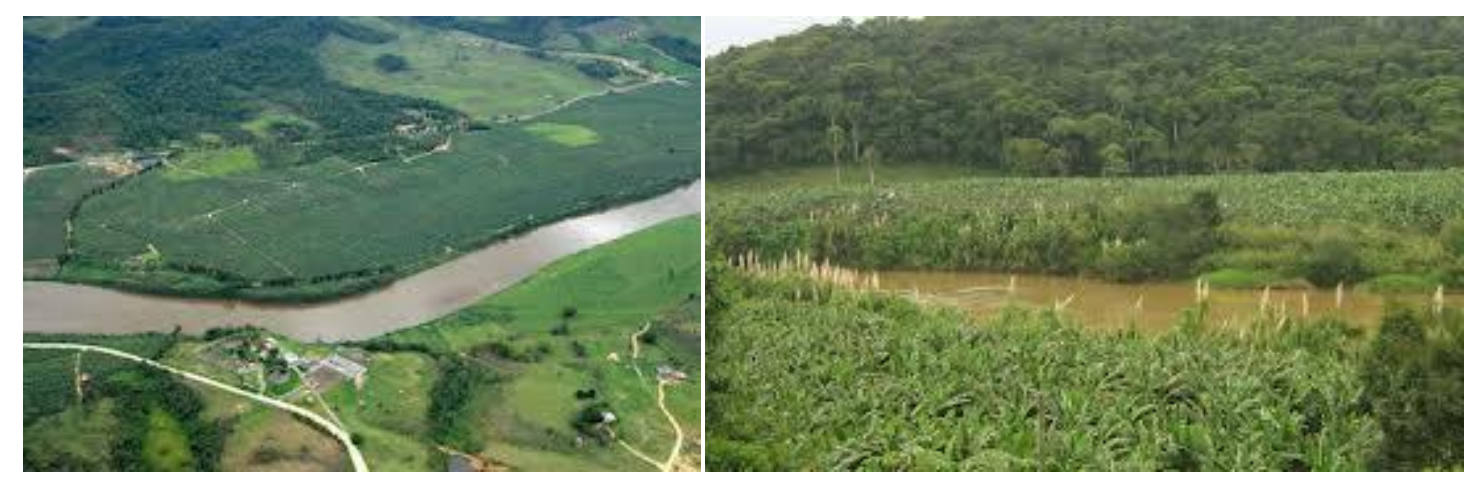

Figura 1. Cultivo de banana nas margens do Rio Ribeira de Iguape. (Fonte: camiloaparecido blog.terra.com.br, acesso em 04/07/2013). 
A região norte do complexo estuarino-lagunar de Cananéia-Iguape é mais suscetível à introdução de material proveniente da ocupação das margens do Rio Ribeira, que nasce no estado do Paraná e vem rumo à região costeira de Iguape (SP) (Fig. 2).
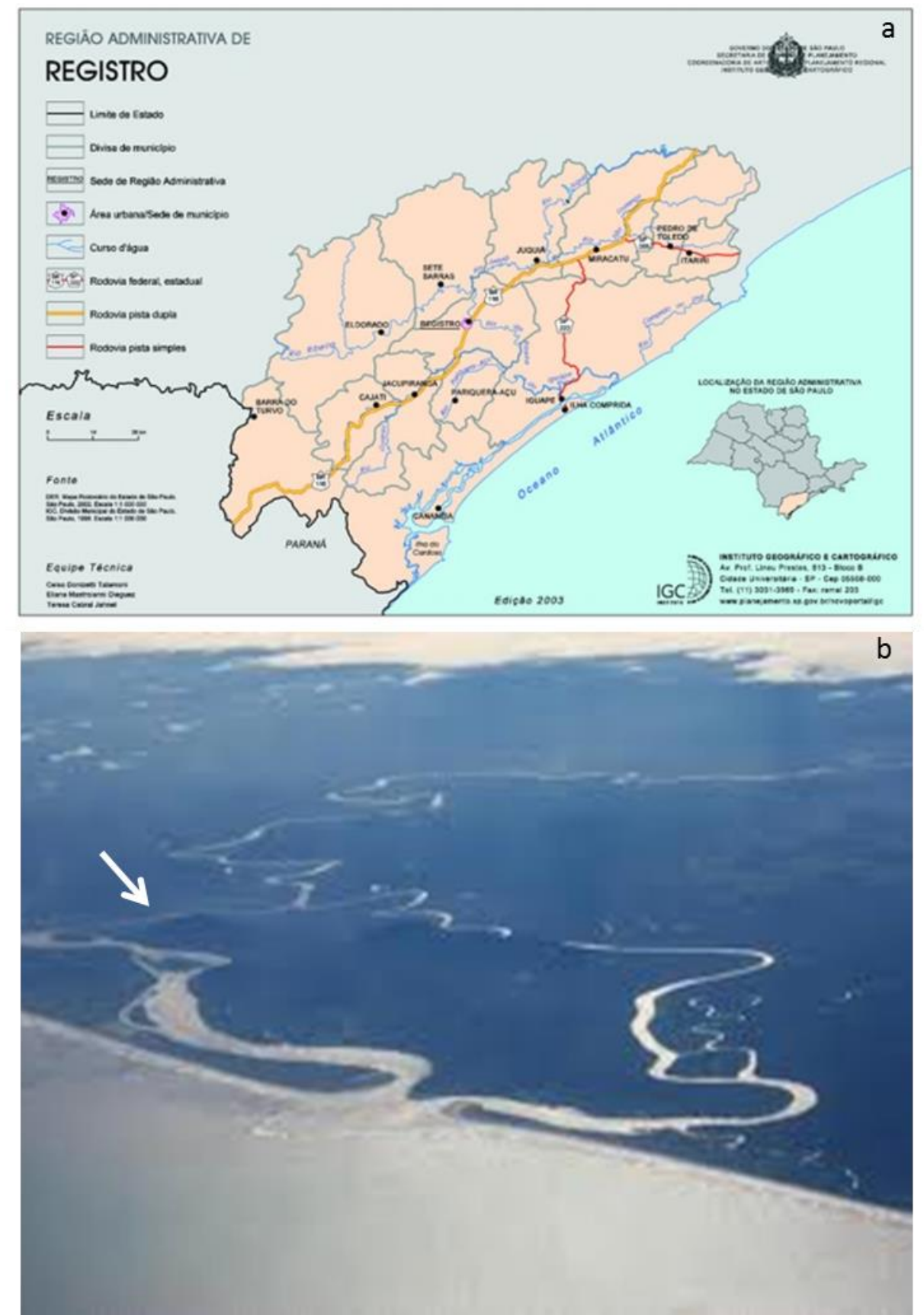

Figura 2. Região administrativa de Registro (Fonte: www.igc.gov.br/portal//igc) (a); destaque do final do curso do Rio Ribeira de Iguape (b) com localização do Valo Grande (seta; fonte: therioblog.blogspot.com, acesso em 04/07/2013).

O Vale do Ribeira abriga uma população de aproximadamente 400 mil habitantes, sendo $71,2 \%$ população urbana e 28,8\% rural, distribuída nos seus 23 municípios no estado de São Paulo; ocupado pela agricultura, pecuária, indústrias e uma área de Mata 
Atlântica em sua porção serrana em direção ao mar (Disponível em: www.valedoribeiraufpr.br/vale.htm; SEADE, 2010).

Esta região abriga uma área com grande fragilidade natural em relação aos processos de ocupação urbana, devido às características de relevo plano, solos arenosos e inconsolidados, lençol freático próximo à superfície e riqueza em biodiversidade, sendo berçário para reprodução de inúmeras espécies animais. A área está praticamente toda delimitada por Unidades de Conservação Ambiental e sob o controle dos órgãos gestores ambientais aos níveis federal e estadual. Constitui, portanto, uma Unidade de Preservação Ambiental de absoluto interesse (Ross, 2002).

Quanto à ocupação agrícola, no alto Vale há a predominância da bananicultura; a cultura do chá, que outrora fora significativa tem sido substituída por pupunha e espécies de plantas ornamentais. A mineração permanece de forma residual, a ocupação urbana e as atividades ao longo do Vale remetem sua influência para a porção final do Rio Ribeira do Iguape, que tem aproximadamente $70 \mathrm{~km}$ de extensão (Registro - Iguape). O Rio Ribeira tem por volta de $470 \mathrm{~km}$ de extensão de a sua nascente à foz.

O Brasil está entre os cinco maiores produtores mundiais de bananas. No estado de São Paulo, a produção de bananas está concentrada no Vale do Ribeira e litoral sul, sendo responsável por mais de $60 \%$ da produção agrícola estadual (Fig. 3).

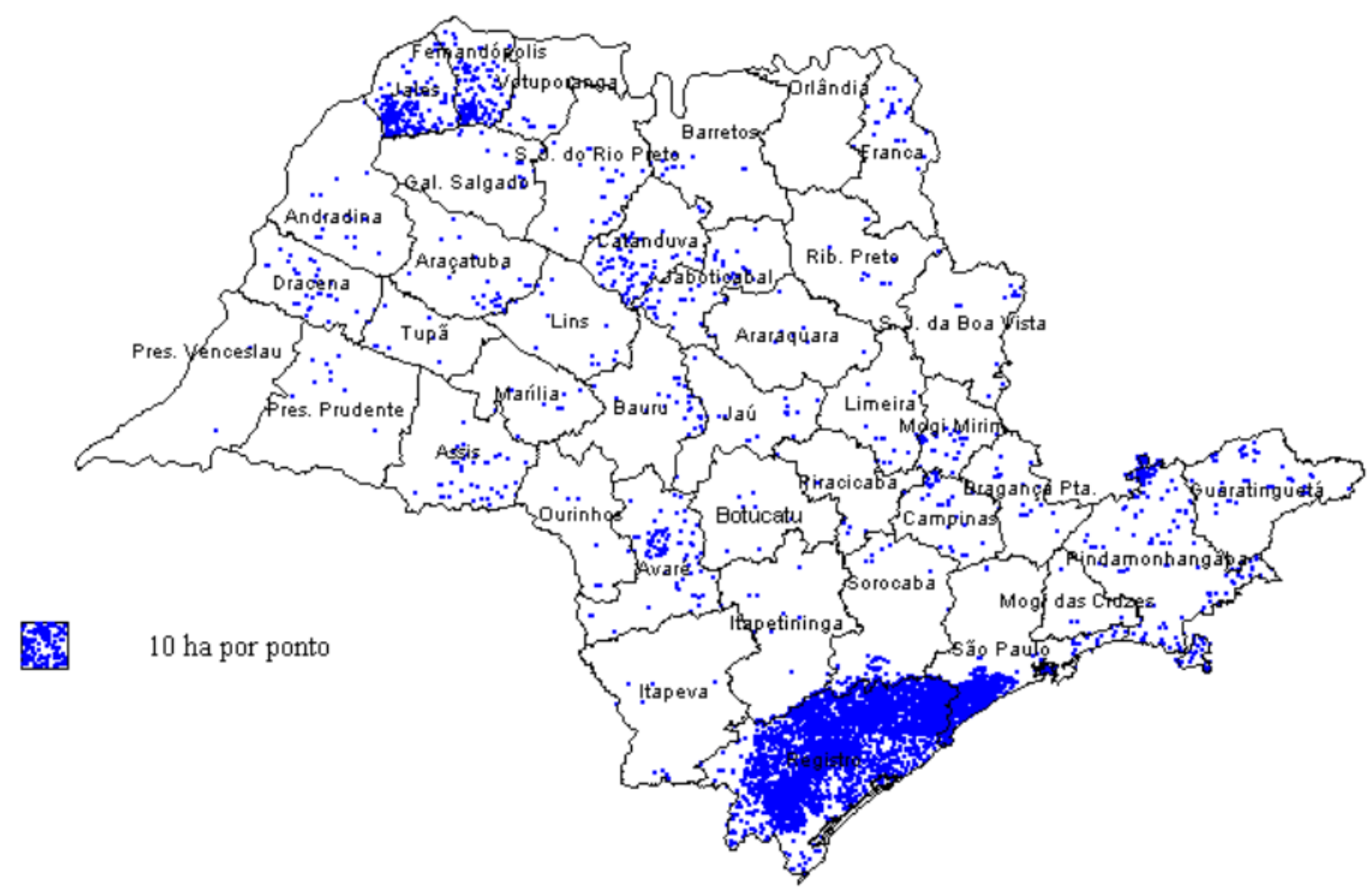

Figura 3. Distribuição geográfica da área de cultivo de banana, no estado de São Paulo (Pino et al., 2000.) 
Atualmente, a produção de bananas do Vale do Ribeira cobre uma área plantada de aproximadamente 30 mil hectares. A produção concentra-se na mão de pequenos produtores, cujas propriedades variam entre 10 e 20 hectares. Em 2011, a produção no Brasil foi de 7.329.471 toneladas de bananas. Desse total, o Estado de São Paulo produziu 1.354.528 toneladas de bananas (EMBRAPA, 2011), o que correspondeu a 18,5\%.

As práticas agrícolas como: adubação (aplicação de N, P, K), controle de pragas e/ou ervas daninhas via aplicação de fertilizantes, pesticidas e herbicidas respectivamente, que por um lado visam contribuir de forma significativa à produção, por outro lado também aumentam a poluição do corpo hídrico situado nas áreas adjacentes às plantações, especialmente quando não há controle destas práticas.

Outras práticas também são observadas à jusante do Rio Ribeira, na região de Iguape, como a pecuária, tendo como exemplo a criação de búfalo (Fig. 4).

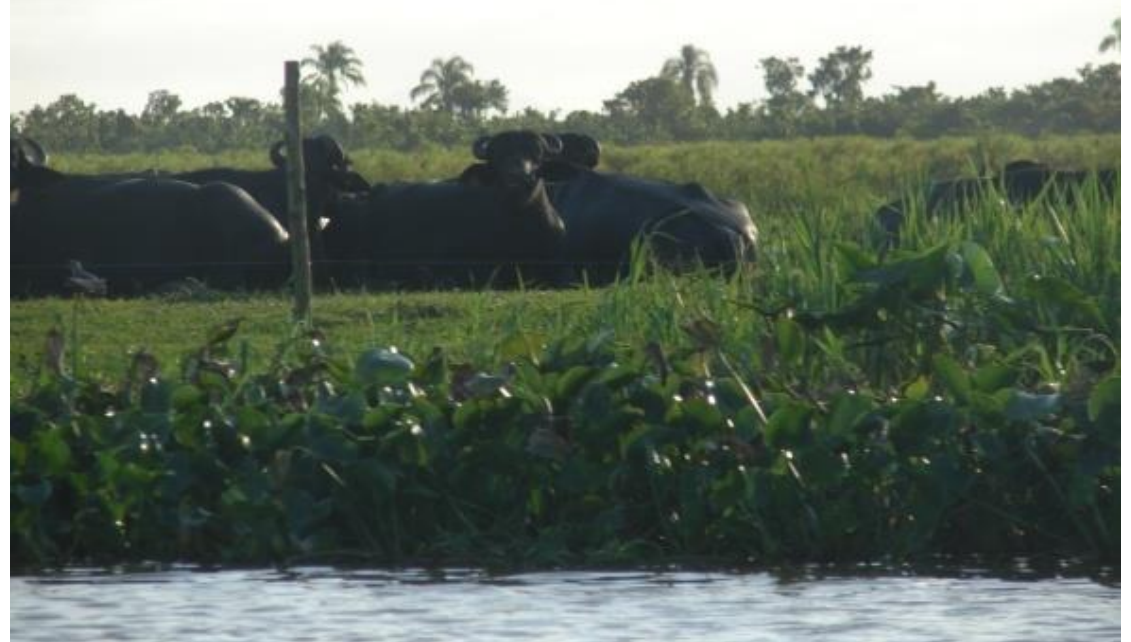

Figura 4. Búfalos ao longo das margens do Rio Ribeira de Iguape (SP) na região de Iguape (Foto: E. S. Braga).

Historicamente, no século XVII, após a decadência da exploração da mineração na região de Iguape, foi iniciada a agricultura do arroz. Havia nessa época uma demanda cada vez maior do arroz de alta qualidade, produzido na região, pelos mercados europeus (Braga, 1998). Com o objetivo de um escoamento maior deste produto, em 1825 foi iniciada a construção do canal do Valo Grande, interligando assim o Rio Ribeira de Iguape e o Mar Pequeno, obra que foi concluída em 1852 (Diegues, 1973).

Inicialmente, o Valo Grande tinha 20m de largura e hoje, devido ao efeito da erosão, tem mais de 300 m de largura (Berbel, 2008; Maluf, 2009; Eschrique, 2011; 
Kuniyhoshi, 2011; Stein, 2011). Desta forma, parte das águas do Rio Ribeira de Iguape vertem no interior do sistema estuarino, alterando a qualidade da água do sistema, sobretudo no setor norte do complexo.

Calcula-se que a descarga média anual de água doce para o sistema estuarino seja de $773,56 \mathrm{~m}^{3} / \mathrm{s}$ com valor mínimo de $99 \mathrm{~m}^{3} / \mathrm{s}$ em agosto, e máximo de $1751 \mathrm{~m}^{3} / \mathrm{s} \mathrm{em} \mathrm{março}$ (Bérgamo, 2000). E ainda, a carga de material sólido em suspensão (sedimentos finos) é da ordem de $1.000 .000 \mathrm{~m}^{3} /$ ano (GEOBRAS, 1966).

No caso dos agrotóxicos, o uso é comum na região norte, sendo que informações sobre as quantidades e manuseio são raras e devem ser incrementadas ao longo desta pesquisa. No entanto, já é possível informar que, segundo o Centro de Referência em Saúde do Trabalhador Regional do Vale do Ribeira (CBH-RB, 2008-2011), um grande problema de saúde observado na região provém da aplicação excessiva e mal executada de agrotóxicos, fazendo com que o Vale do Ribeira ocupe o quarto lugar em casos notificados de intoxicação por agrotóxicos, com um grande percentual de mortes por essa causa.

Na década de 30, Cajati ganhou vulto com atividade de extrativismo mineral, sendo que esta atividade tem introduzido grande quantidade de fosfato no rio Jacupiranguinha, que se une ao Jacupiranga e despeja suas águas no Rio Ribeira de Iguape, no meio do trecho entre Iguape e Registro (Cunha, 2010; CETESB, 2013).

As cidades instaladas ao longo do Rio Ribeira também contribuem com a entrada de esgoto no sistema hídrico aumentando a carga de N e P do Rio.

\subsection{Nutrientes ( $N$ - nitrato e $P$-fosfato)}

O excesso de fertilizantes nitrogenados e fosfatados pode causar a eutrofização (proliferação de algas de forma descontrolada) e isto pode comprometer a disponibilidade de oxigênio devido à oxidação da excessiva biomassa, prejudicando os demais organismos da biota, o que constitui um problema iminente na região.

A adubação nitrogenada para a cultura de banana exige 3 fases ao longo do seu crescimento que são: a fase de plantio, formação e produção (EMBRAPA, 2003).

Para a fase de plantio pode-se usar o $\mathrm{N}$ de fonte orgânica, pois trará benefícios químicos, físicos e biológicos à planta. As fontes orgânicas a serem aplicadas nas covas de plantio, principalmente em solos arenosos (solo típico da região estudada) e de baixos nutrientes dependem da sua disponibilidade, em geral recomenda-se 30 litros de esterco por cova (EMBRAPA, 2003). 
Na fase de formação usa-se o (N) nitrogênio mineral, após 30 dias e até 360 dias após o plantio. A ureia (44\% de N) e o sulfato de amônio (20\% de N e $30 \%$ de S) são os mais utilizados. Podem-se usar também adubos verdes, como em algumas leguminosas. Os estercos, resíduos de agroindústrias, palhadas quando presentes na propriedade também podem ser usados, em quantidade calculada de acordo com a necessidade (EMBRAPA, 2003).

A adubação de produção é feita em função da produção esperada, também recomenda-se para a banana cultivada em solos arenosos, a utilização de 20 litros de esterco curtido por touceira, a cada 4 meses (EMBRAPA, 2003).

A adubação nitrogenada é muito importante, geralmente recomenda-se de 160 a $400 \mathrm{~kg}$ de $\mathrm{N}$ mineral/ha/ano (EMBRAPA, 2003).

Quanto à adubação fosfatada, o P, fósforo favorece o desenvolvimento vegetativo e radicular, é praticamente imóvel no solo por isso deve ser aplicado na cova de plantio, a recomendação após a análise de solo pode variar de 40 a $120 \mathrm{~kg}$ de $\mathrm{P}_{2} \mathrm{O}_{5}$ /ha (EMBRAPA, 2003).

As fontes de fosfato, recomendadas geralmente, são os superfosfatos simples (18\% de $\mathrm{P}_{2} \mathrm{O}_{5}, 20 \%$ de $\mathrm{Ca}$ e $11 \%$ de $\mathrm{S}$ ). O superfosfato triplo ( $42 \%$ de $\mathrm{P}_{2} \mathrm{O}_{5}$ e $14 \%$ de $\mathrm{Ca}$ ), ou o termofosfato magnesiano ( $17 \%$ de $\mathrm{P}_{2} \mathrm{O}_{5}, 18 \%$ de $\mathrm{Ca}$ e $7 \%$ de $\mathrm{Mg}$ ). Para solos com teores de $\mathrm{P}$ acima de $30 \mathrm{mg} \mathrm{dm}^{-3}$, a adubação fosfatada não é necessária (EMBRAPA, 2003).

No aspecto relativo à caracterização das propriedades bananicultoras, elas são relativamente homogêneas, caracterizando-se por terem a área ocupada por bananicultura e reservas florestais, como mostra a tabela 1, com dados de 1995. 
Tabela 1. Levantamento Censitário das principais Unidades de Produção Agropecuária dos municípios de Cananéia, Iguape, Registro e Jacupiranga (CATI, 2008).

\begin{tabular}{|lccccc|}
$\begin{array}{l}\text { CULTURA } \\
\text { *A(hectare=ha) }\end{array}$ & $\begin{array}{c}\text { Cananéia } \\
\text { (ha) }\end{array}$ & $\begin{array}{c}\text { Iguape } \\
\text { (ha) }\end{array}$ & $\begin{array}{c}\text { Registro } \\
\text { (ha) }\end{array}$ & $\begin{array}{c}\text { Cajati } \\
\text { (ha) }\end{array}$ & $\begin{array}{c}\text { Jacupira } \\
\text { (ha) }\end{array}$ \\
\hline Banana & 291,90 & 1086,40 & 3178,9 & 5042 & 3678,3 \\
Reflorestamento & 1 & 107 & 203,3 & 1393,2 & 2638 \\
Maracujá & 0,3 & 354 & 50,7 & 34,8 & 30,8 \\
Fruticultura & - & 622 & - & - & - \\
Arroz & 22 & 104 & 272,8 & - & 149,5 \\
Pastagem & 2662 & 15261 & 19770.9 & 9898,9 & 12700 \\
Palmito & - & 8490 & 432,8 & 168,6 & 111,1 \\
Feijão & 7 & 13 & 12,9 & 3,9 & 22,4 \\
Milho & 17 & 8 & 24 & 6,3 & 9,9 \\
Olerícola & 3 & 547 & - & - & - \\
Florestamento & - & 30 & 12,5 & 15,6 & - \\
ornamental & & - & 1422,5 & - & - \\
Chá & - & & & &
\end{tabular}

\section{Pecuária}

Número de cabeças

Bovinocultura

\begin{tabular}{lccccc} 
Corte & 1010 & 3490 & 2236 & 3410 & 6201 \\
Leite & - & 179 & 836 & 417 & 794 \\
Mista & 573 & 2816 & 6023 & 316 & 2128 \\
& & & & & \\
Bubalinocultura & 200 & 2116 & 3464 & 50 & 103 \\
$\begin{array}{l}\text { Avicultura } \\
\text { corte cab/ano }\end{array}$ & 380 & 1199 & 180 & 480 & 8655 \\
\hline *Área=A em hectares (ha) & & & & \\
Fonte:Projeto CATI (2008) & & & & \\
\end{tabular}

\subsection{Características da produção da banana- Bananicultura na área estudada}

\subsubsection{Clima e relevo}

A bananeira é uma cultura plantada sob o clima tropical e subtropical. De acordo com Medina et al. (1978), a planta se desenvolve bem num clima de temperatura média elevada (igual ou maior que $22^{\circ} \mathrm{C}$ ), com precipitações pluviométricas anuais abundantes e bem distribuídas (maior que $1200 \mathrm{~mm}$ ) e com uma elevada umidade relativa do ar, por volta de $80 \%$. Além disso, é importante a baixa incidência de ventos fortes e ausência de ventos frios, geada e granizo. Tais características conferem à planta um ciclo de crescimento e/ou produção mais curto.

As temperaturas de $15^{\circ} \mathrm{C}$ e $35^{\circ} \mathrm{C}$, são limítrofes para o crescimento deste cultivo (Moreira,1979; Brunini, 1984; ITAL, 1990). A umidade do solo é fundamental para o ciclo vegetativo dos frutos. Quando chove em excesso, há a necessidade da drenagem e 
controle da erosão do solo, podendo também haver a lavagem dos fertilizantes que foram aplicados proximamente à inundação (Moreira, 1987).

Em períodos de seca, o desenvolvimento da bananeira é interrompido, as folhas ficam amarelas e o ciclo vegetativo aumenta, há uma diminuição no tamanho dos cachos e os frutos apresentam qualidade inferior (Medina et al., 1978). O suprimento de água para a planta está relacionado às propriedades físicas e mecânicas do solo e às características do clima, que devem ser monitorados para uma irrigação efetiva. Quanto à necessidade hídrica, a precipitação ideal é de 100 mm/mês com uma boa distribuição anual.

O tipo de relevo encontrado nessas áreas é de morro e vale. Tais fatores determinam o sistema de cultivo adotado na região do Vale do Ribeira, pois terrenos planos e levemente ondulados são favoráveis para a produção da cultura.

\subsubsection{Tipo de Solo, formação vegetal natural, uso da terra.}

Segundo Ross (2002), na região de Cananéia-Iguape, predominam os solos do tipo Podzol Hidromórfico de textura arenosa e solos orgânicos tiomórficos que apresentam altos teores de enxofre em sua composição, por isso exalam um mau cheiro característico, sobretudo nas áreas interiores da planície costeira, onde também são encontradas turfeiras.

Na região de Registro, destacam-se os solos do tipo Cambissolos eutróficos, apresentando características morfogenéticas diferenciadas das encontradas na área mais a jusante do rio. Estes solos apresentam a relação silte/argila maior e/ou maior proporção de minerais intemperizáves, também apresentam diferenças significativas quanto à cobertura vegetal natural. Na área de Cananéia-Iguape prevalece a vegetação hidrófila, associada à formações pioneiras herbáceas e trechos mais enxutos com mata galeria, hoje convertidas em pastagem. Nas regiões de Registro, Eldorado e Sete Barras prevalecem as matas galerias quase que totalmente substituídas por plantações de bananas, pois possuem o solo com melhor drenagem facilitando assim a atividade da bananicultura.

\subsubsection{Sistema de produção}

Um sistema de produção adequado é representado por tratos culturais, manejo na colheita e pós colheita, de acordo com as condições edafoclimáticas da região.

No Brasil, para cultivos comerciais tecnicamente conduzidos, os espaçamentos mais utilizados vão de 2,0 x 2,0 m a 2,0 x 2,5 m para os cultivares de Nanica e Nanicão. Para as condições do Estado de São Paulo, as densidades entre 2000 e 2500 plantas por 
hectare, proporcionam boa colheita com bons rendimentos e frutos de boa qualidade (Moreira, 1987).

A bananeira é uma planta de crescimento rápido e que necessita, para o seu desenvolvimento e produção normais, concentrações elevadas de nutrientes no solo, os quais podem ser fornecidos em parte pelo solo e pelo sistema de reciclagem, solo-planta. No entanto, para a obtenção de produtos economicamente viáveis, tais fontes não são suficientes, sendo fundamental a aplicação de fertilizantes em quantidades e proporções adequadas para suprir os nutrientes exigidos pela cultura (Soto, 1992; Lahav \& Turner, 1983; Teixeira, 2005).

As exigências nutricionais da cultura dependem da variedade e do seu potencial produtivo (Soto, 1992). Segundo a literatura, é unânime a exigência nutricional do cultivo para a adubação nitrogenada e potássica. $\mathrm{O} N$ tem papel fundamental para o crescimento e desenvolvimento da cultura, determinando em grande parte, o porte e rendimento dos frutos. $\mathrm{O}$ suprimento de $\mathrm{N}$ é quase sempre deficitário, até mesmo em solos férteis cultivados com bananeira na América Central. Em quantidade acumulada na biomassa, o $\mathrm{N}$ é superado pelo $\mathrm{K}$, que é considerado o elemento chave na nutrição das bananeiras, interferindo na fotossíntese, translocação de fotossintetizados, equilíbrio hídrico das plantas e dos frutos, entre outras funções. O suprimento insuficiente de potássio afeta a qualidade e quantidade dos frutos, assim como, a resistência das plantas a estresses bióticos (pragas e doenças) e abióticos como o frio e a seca (Teixeira, 2005).

Além dos nutrientes exportados para as frutas, as perdas dos nutrientes foram contabilizadas no manejo da fertilidade do solo numa série de trabalhos de Godefroy et al. (1975), onde os autores determinaram perdas entre 60 e $85 \%$ dos fertilizantes aplicados, exceto para $\mathrm{P}$, sendo N, K, Ca e Mg perdidos predominantemente (85\% a 95\%) por lixiviação.

A Tabela 2 confere os tipos de adubos comercializados na região do Vale do Ribeira, Registro (SP) de 2003 a 2006. 
Tabela 2. Tipos de adubos comercializados no Vale do Ribeira, SP (Godoy et al., 2006).

\begin{tabular}{c|cccc|}
$\begin{array}{c}\text { ADUBOS } \\
\text { FORMULADOS } \\
\text { N- P-K }\end{array}$ & $\begin{array}{c}\text { Ano } \\
\%\end{array}$ & $\begin{array}{c}\text { Ano } \\
\%\end{array}$ & $\begin{array}{c}\text { Ano } \\
\%\end{array}$ & $\begin{array}{c}\text { Ano } \\
\%\end{array}$ \\
\hline $14-07-28$ & 36,3 & 41,4 & 39,1 & 36,6 \\
$13-13-28$ & 19,1 & 15,7 & 22,0 & 28,0 \\
$11-07-35$ & 15,3 & 13,1 & 17,2 & 16,8 \\
$12-06-30$ & 18,2 & 24,2 & 20,0 & 16,5 \\
$12-06-24$ & 11,1 & 5,6 & 1,7 & 2,1
\end{tabular}

Em relação aos nutrientes nitrogênio e fósforo, vários trabalhos (Kato, 1966; Teixeira, 1980; Braga, 1989) e os mais recentes (Maluf, 2009; Eschrique, 2011; Kuniyoshi, 2011; Stein, 2011) mostram valores com o Valo Grande fechado e aberto que indicam oscilações nos valores de nutrientes considerando a participação ou não do Valo no complexo ao longo de sua história.

Atualmente são observados altos valores de nutrientes principais dissolvidos ( $\mathrm{Ne}$ P) no setor norte do sistema, sendo atribuídos como fonte: o aporte de água do Rio Ribeira de Iguape, a drenagem das áreas terrestres e, sobretudo das áreas agriculturáveis que contribuem com os nutrientes. A atividade industrial e os despejos de esgotos podem contribuir de sobremaneira a estes valores, como é o caso de despejos industriais que ocorrem rio acima, pois o Rio Ribeira que tem sua nascente nos municípios de Cerro Azul e Rio Branco do Sul no estado do Paraná, passa por muitas cidades que o margeiam como: Adrianópolis, Itaoca, Iporanga, Eldorado, Sete Barras, Registro, Iguape ao longo de seu percurso de $470 \mathrm{~km}$.

\subsection{Características do Rio Ribeira desde a sua nascente e cidades que o margeiam}

Segundo o relatório publicado por Brasil das Águas (2007) o curso do Rio Ribeira começa no encontro dos rios Ribeirinha e Açunguí, no estado do Paraná. Esta área apresenta-se desmatada, fazendo com que já no início do Rio as águas desçam barrentas e carreguem toneladas de terra levadas pelo Rio.

O Rio tem o seu leito bem encaixado cheio de pedras, no entanto o desmatamento na sua proximidade dá à água uma coloração mais barrenta (Brasil das Águas, 2007). São dose os municípios contíguos ao rio, sendo 4 cidades pertencentes ao estado do Paraná 
(Rio Branco do Sul, Cerro Azul, Doutor Ulysses, Adrianópolis) e 8 cidades pertencentes ao estado se São Paulo sendo estas: Itapirapuã Paulista, Ribeira, Itapioca, Iporanga, Eldorado, Sete Barras, Registro e Iguape.

Seguem abaixo algumas características de parte destas cidades que margeiam o Rio (Brasil das Águas, 2007).

- Cerro Azul (PR) - Microrregião do Paraná, localizada a 92 km da capital do Estado. A atividade econômica dessa cidade baseia-se na criação de gado e no cultivo da laranja, tangerina, além do cultivo de hortaliças, feijão e milho. A proximidade da lavoura às margens do rio pode causar poluição como aporte de agrotóxicos e fertilizantes. Casas próximas ao rio, despejam o esgoto diretamente nele. A partir de 1988, a Companhia Brasileira de Alumínio (CBA) comprou muitas terras nesta região.

- Adrianópolis (PR) - No passado a economia municipal estava ligada à exploração mineral, com a atuação da empresa Plumbum na extração de chumbo. Atualmente a economia baseia-se na atividade pecuária, cultivo de Pinus e agricultura familiar de feijão, milho, arroz e cana de açúcar

- Ribeira (SP): O município de Ribeira localiza-se no alto do Vale, a $340 \mathrm{~km}$ da capital paulista e a $130 \mathrm{~km}$ de Curitiba, esta cidade desenvolveu-se à margem esquerda do Rio Ribeira. A economia local baseia-se na agricultura familiar do feijão, milho, mandioca, cana-de-açúcar, atividade pecuarista de gado de leite e de corte, pequenas minerações e comércio varejista.

- Iporanga (SP) - Situada no coração da Mata Atlântica, junto à margem do Rio Ribeira e em uma região montanhosa, localizado a $331 \mathrm{~km}$ da capital paulista, o município de Iporanga tem como sua principal fonte econômica o turismo, pois está localizado próximo ao Parque Estadual e Turístico do Alto Ribeira (PETAR). Há nessa área também agricultura familiar para a extração do palmito, inclusive plantio sustentável no interior da floresta.

- Eldorado (SP) - Localizada numa região mais plana do Vale, no sul do Estado de São Paulo e a $50 \mathrm{~km}$ da cidade de Registro, a economia desta cidade se fundamenta com a agricultura da banana, maior plantação do Vale e do Estado com aproximadamente 10 milhões de pés de bananeiras distribuídas em uma área plantada de 5711,6 ha (CATI, 2008). Há também o cultivo da pupunha e do maracujá voltados à agricultura familiar (Brasil das Águas, 2007). 
- Registro (SP): A cidade de Registro, localiza-se na região do litoral sul do Estado de São Paulo, a $185 \mathrm{~km}$ da Capital, o município faz limite com Iguape, Juquiá, Jacupiranga, Sete Barras, Eldorado e Pariquera-açú, o acesso a esta cidade dá-se pela BR116. A base da economia local são a pecuária, a agricultura e a indústria de beneficiamento de alimentos e de comércio. Registro é responsável por mais de $50 \%$ da produção de banana do estado de São Paulo, com mais ou menos 7 milhões de pés de bananas ocupando uma área de 3.178,90 ha (CATI, 2008). A cultura de chá da Índia no Brasil, concentra-se na região do Vale do Ribeira, principalmente nos municípios de Registro e Pariquera-açú. A criação de búfalos tem crescido nesta região (Brasil das Águas, 2007).

Entre as cidades de Registro e Iguape, o Rio Ribeira de Iguape recebe o afluente Jacupiranga (que recebe efluente de uma indústria de fertilizantes) e o Pariquera-Açú. Este trata-se de um rio com aproximadamente $31 \mathrm{~km}$ de extensão, cujo entorno é preservado, com mata ciliar em diversos trechos e aparentemente não recebe efluente industrial. Deságua no Rio Ribeira do Iguape a aproximadamente $1500 \mathrm{~m}$ abaixo do afluente Jacupiranga. Ambos os rios, no entanto são receptores de efluentes de lagoas de estabilização que tratam o esgoto doméstico dos municípios de Cajati e de Pariquera-Açú (Cunha \& Calijuri, 2008).

\subsection{Características do afluente Jacupiranga e as cidades à margem deste}

O Rio Jacupiranga é longo com aproximadamente $52 \mathrm{~km}$ de extensão e meândrico. É formado pela junção dos Rios Guaraú e Jacupiranguinha, desaguando na margem direita do Rio Ribeira de Iguape. Quanto à demanda hídrica de acordo com o uso da água da sub-bacia do Rio Jacupiranga, a maior utilização é industrial com demanda de 1,628

$\mathrm{m}^{3} / \mathrm{s}$, seguida pela demanda do uso de irrigação de $0,714 \mathrm{~m}^{3} / \mathrm{s}$ e, por último, a demanda representada pelo uso urbano com 0,206 m³/s (CETEC, 1999).

No entorno do Rio Jacupiranga são observados diferentes tipos de uso e ocupação do solo, como propriedades rurais destinadas à agricultura, em especial à bananicultura e à pecuária de corte e de leite (criação de bovinos e bubalinos), além de moradias ribeirinhas da área rural e urbana (Cunha, 2010). 
A maioria das propriedades rurais e o desenvolvimento urbano não respeitam o limite de preservação das matas ciliares, disposto pela Lei 4771 do código florestal (BRASIL, 1965).

Rio Jacupiranga possui ao longo de sua extensão grandes porções marginais desprovidas de mata ciliar, apresentando em certos locais, solo sujeito à erosão e exposto com barrancos de areia superiores a $2 \mathrm{~m}$ de altura. Além de estar vulnerável ao escoamento das áreas agrícolas e das cidades, o rio recebe o efluente da estação de tratamento do esgoto do município de Jacupiranga e lançamentos de esgoto doméstico bruto (Cunha, 2010).

Segundo o relatório de águas superficiais da CETESB (2013), os pontos amostrais de coleta de água no Rio Jacupiranguinha (município Cajati) e Rio Jacupiranga (município de Jacupiranga) mostraram valores de ruim a péssimo para o parâmetro de fósforo total.

$\mathrm{O}$ rio Jacupiranga-Jacupiranguinha atravessa as cidades de Jacupiranga, Jacupiranguinha e Cajati que apresentam as seguintes características:

- Jacupiranga (SP) - O município foi criado no território de Iguape, no fim do século XVIII, na época da exploração de ouro do Vale do Ribeira, atraindo assim novos moradores para a região. Em 1870, o povoado passou a categoria de vila, e em 1963, município emancipado, embora possuísse terras férteis o município teve um desenvolvimento muito lento, devido à dificuldade de comunicação e transporte, na época o acesso era apenas via fluvial. Sua atividade esteve sempre baseada na agricultura, em especial na cultura de banana (SEADE, 2010; Cunha, 2010). Dados do CATI (2008), conferem a essa área a presença de aproximadamente 6 milhões de plantas distribuídas em 3680 hectares.

- Iguape (SP) - Está localizada na desembocadura do Rio Ribeira de Iguape, no distrito da Barra do Ribeira, a base da economia é a agricultura em especial da banana, algumas outras frutíferas como o maracujá, há também a criação de búfalos e a pesca.

- Ilha Comprida (SP) - Atualmente abriga um número crescente de habitantes em função da construção de uma ponte entre a cidade de Iguape e a Ilha, o que contribui com o impacto ambiental no mesmo setor.

- Cananéia (SP): Situada no setor sul, é uma região bastante preservada, apresentando valores de nutrientes em faixas normais para sistemas estuarinos como mostram os trabalhos de vários autores (Braga, 1995; Berbel, 2008; Braga \& Chiozzini, 
2008; Maluf, 2009; Eschrique, 2011; Kuniyoshi, 2011; Stein, 2011). Entretanto, praticamente inexistem pesquisas sobre o teor de agrotóxicos na água deste setor, pois a atividade agrícola da região é apenas de subsistência.

- Cajati (SP): Localizada a $13 \mathrm{~km}$ da cidade de Jacupiranga, a $44 \mathrm{~km}$ da cidade de Registro e a $230 \mathrm{~km}$ da capital paulista, esta cidade que se tornou independente do município de Jacupiranga em dezembro de 1991, tem como principal atividade econômica, a bananicultura e o extrativismo mineral. É considerada como o principal polo Industrial de Minérios do Vale do Ribeira.

A atividade de mineração na região de Cajati teve seus primórdios na época de exploração aurífera no Brasil, mas foi em 1930 que as primeiras atividades de lavra de apatita foram iniciadas sob a responsabilidade do Grupo Moinho Santista, que com o direito de lavra adquirido em 1938, deteve a patente para a produção do cimento pozolônico, e então fundou-se a companhia Serrana S/A de mineração.

Um dos resíduos de aproveitamento do minério fosfático de baixo teor é a calcita, que passou a ser utilizada como matéria prima para a fabricação de cimento. A própria Serrana construiu uma fábrica para esse fim em 1972. Nos anos subsequentes, entraram em operação as fábricas de ácido sulfúrico e de ácido fosfórico, que tinham como objetivo a importação de produtos químicos e adubos, atividades estas também sob responsabilidade da Serrana S/A (Sanchez \& Sanchez, 2011).

No ano de 2000, a multinacional Bunge e fertilizantes, sucessora da Serrana S/A de mineração, passou a ser detentora dos direitos de lavra do minério fosfático da região. Este grupo já havia criado em 1985 uma outra empresa em Cajati, a FosfBrasil que foi o primeiro produtor de ácido fosfórico purificado por via úmida do hemisfério Sul, a qual começou a funcionar em 1987, produzindo ácido fosfórico nos graus alimentício, agrícola e industrial. Desde então o parque industrial de Cajati constitui um complexo integrado com produção de rocha fosfática, calcário para cimento, calcário agrícola, cimento, ácido sulfúrico, ácido fosfórico, superfosfato simples (SSP) e fosfato bicálcico. Finalmente em, maio de 2010 a Vale adquiriu os ativos da Bunge no Brasil referentes à mina de Cajati que agora pertencem a Vale Fosfatados (Sanchez \& Sanchez, 2011).

A bananicultura também é bem expressiva nesta região com aproximadamente 8 milhões e oitocentos mil pés de bananeiras distribuídos em 5.042 hectares (CATI, 2008).

Neste percurso fluvial o rio recebe esgoto doméstico, aportes de fertilizantes de áreas agriculturáveis e também despejos industriais localizados ao longo do rio. Deixando de lado, neste estudo, os registros deixados pelas pretéritas atividades de mineração e 
pelos pesticidas que atingem o corpo hídrico, esta proposta de estudo volta-se ao acompanhamento da carga de nutrientes nitrogenados e fosfatados que podem estar atingindo o Rio, e consequentemente, o complexo estuarino-lagunar.

Uma vez que o sistema hídrico é contínuo entre norte e sul, o acompanhamento da evolução das caraterísticas tróficas do sistema deve ser continuado, e também, o estudo das concentrações de agrotóxicos deve ser implantado desde a região de jusante, junto ao Valo Grande e um pouco acima, no curso normal do rio, até o sistema sul, em Cananéia e no Canal do Ararapira.

De um modo geral, de acordo com o Comitê da Bacia Hidrográfica do Ribeira de Iguape e Litoral Sul no Relatório de Situação dos Recursos Hídricos da UGRHI 11 (CBHRB, 2011), na região há uma tendência ao aumento do número de áreas contaminadas contabilizadas, mas ainda é muito inferior ao das áreas que compõem a Bacia.

Em 2011 foram cadastradas no banco de dados da CETESB, 25 áreas classificadas como Áreas Contaminadas Sob Investigação (AI) pertencentes à UGRHI-11, ou seja, foi confirmada a existência de contaminantes no solo ou água subterrânea, porém não foram realizados estudos mais detalhados. Contudo, existem quantidades significativas de Áreas Potenciais (AP) e suspeitas que ainda não foram cadastradas no banco de dados da CETESB (2013).

Desta forma, a quantificação e distribuição de agentes eutrofizantes devem ser estudados no complexo Estuarino-Lagunar de Cananéia-Iguape (SP), destacando-se o papel do setor norte como maior agente perturbador do equilíbrio do sistema em função da ação antrópica representada pelo Valo Grande e pela ausência de cuidados com o corpo hídrico do Rio Ribeira de Iguape. Este deveria ter programas de monitoramento e controle dos compostos nitrogenados e fosfatados, e também outros importantes agentes, como pesticidas, fármacos, coliformes fecais, que escoam para o corpo hídrico e alteram sua condição natural, com impactos importantes ao ecossistema, ameaçando o santuário que ainda existe na região sul deste sistema.

Esta pesquisa visa contribuir com informações sobre componentes nitrogenados e fosfatados que atingem o norte do Complexo Estuarino-Lagunar de Cananéia-Iguape por meio do Valo Grande e também conhecer o quanto as regiões centrais e sul do sistema encontram-se afetadas por estes componentes. 


\section{OBJETIVOS}

\subsection{Objetivo Geral}

Avaliar o aporte de nitrogênio e fósforo dissolvidos no Complexo EstuarinoLagunar de Cananéia-Iguape (SP) pelo Rio Ribeira de Iguape, via Valo Grande (setor norte) e sua diluição em sentido sul no sistema, considerando as contribuições antrópicas associadas ao aporte.

\subsection{Objetivos Específicos}

- Caracterizar o sistema hídrico por meio de parâmetros hidrológicos e hidroquímicos (temperatura da água, salinidade, $\mathrm{pH}$, oxigênio dissolvido e material em suspensão) de modo a estabelecer um diagnóstico do setor norte do sistema (Rio Ribeira de Iguape, Canal do Valo Grande, Iguape) em relação às condições naturais estuarinas do setor sul do sistema.

- Avaliar os valores de componentes nitrogenados (N-amoniacal,N-nitrito, Nnitrato) e fosfatados (P-fosfato) dissolvidos no setor norte do complexo modo a identificar aportes (anomalia positiva) que possam ser atribuídos ao excesso de fertilizantes inseridos pela zona agrícola ou outras fontes.

- Estimar a carga de aporte de material nitrogenado e fosfatado no complexo via setor norte, considerando o regime sazonal (inverno e verão) segundo a carga estimada do Rio Ribeira de Iguape, via Valo Grande.

- Correlacionar os valores observados de componentes nitrogenados e fosfatados com a carga estimada de fertilizante empregados nos cultivos nas margens do Rio Ribeira e também com o aporte industrial de fontes urbanas ao sistema. 


\section{MATERIAL E MÉTODOS}

\section{1. Área de estudo}

A área de estudo insere-se na bacia Hidrográfica do Rio Ribeira de Iguape e Litoral Sul do Estado de São Paulo. Segundo DAEE/IPT-SIBH (2004) e o Plano Regional Integrado de Saneamento Básico da Secretaria de Saneamento e Energia do Estado de São Paulo (SSRH, 2009), a área da Bacia Hidrográfica do Rio Ribeira do Iguape e litoral Sul é de 17.067,92 km² e corresponde à Unidade de Gerenciamento de Recursos Hídricos n. 11 (UGRHI-11).

Nesta Bacia, há uma complexidade do ambiente natural que envolve o ambiente urbano dos municípios que a integram com uma rede hidrográfica indissociável. Os principais rios da Bacia são o Ribeira, na sua parte inferior denominado Ribeira de Iguape e seus afluentes Açungui, Capivari, Pardo, Turvo, Juquiá, São Lourenço, Jacupiranga, Una da Aldeia e Itariri.

A Bacia está localizada na porção mais ao sul do Estado de São Paulo, delimitando-se a sudoeste com o Estado do Paraná; ao norte com as UGRHIs 14, Alto Paranapanema, e 10, Sorocaba e Médio Tietê; a nordeste com a 6, Alto Tietê e 7, Baixada Santista; e a leste, somente com o Oceano Atlântico Sul. As sub-bacias do Rio Ribeira encontram-se na tabela 3.

A disponibilidade hídrica da bacia é muito maior que as demandas atuais, pois a demanda total não chega a $1 \%$ da vazão média. Ao mesmo tempo, a vazão máxima e as enchentes excepcionais constituem um desafio crescente para a população ribeirinha e mesmo para a produção agrícola situada nas várzeas.

As maiores cidades localizadas na UGRHI 11 são: Registro, Cajati, Iguape e Apiaí. Apenas a cidade de Registro, que é o maior polo regional, apresenta uma população próxima a 50.000 habitantes.

Com características complexas e severas restrições ambientais, a região apresenta desempenho econômico tímido, com alguma atividade de mineração concentradas em areia e calcário e atividades agrícolas concentradas na cultura da banana e do chá. Vêm ganhando importância as atividades de turismo especialmente as voltadas ao ecoturismo e aos esportes radicais. 
Tabela 3. Quadro Sub Bacias do Rio Ribeira do Iguape e litoral Sul (SSRH, 2009).

\begin{tabular}{lcl}
\hline Sub Bacia & $\begin{array}{c}\text { Área de drenagem } \\
\text { km }{ }^{2}\end{array}$ & \\
\hline 1 - Alto Ribeira & $1.781,44$ & $\begin{array}{l}\text { Marra do Chapéu, ItapirapuãPaulista, Apiaí, } \\
\text { Itaoca, Iporanga, Ribeira }\end{array}$ \\
$\mathbf{2}$ - Baixo Ribeira & $3.115,63$ & Apiaí, Iporanga, Eldorado, Sete Barras \\
$\mathbf{3}$ - Rio Ribeira de Iguape & $1.184,94$ & Registro, Pariquera-Açu, Iguape \\
$\mathbf{4}$ - Alto Juquiá & $1.493,46$ & São Lourenço da Serra, Juquitiba, Tapiraí \\
\hline $\mathbf{5}$ - Médio Juquiá & $1.166,59$ & Tapiraí, Juquiá, Miracatu \\
$\mathbf{6}$ - Baixo Juquiá & $1.059,20$ & Juquiá, Tapiraí, Sete Barras \\
$\mathbf{7}$ - Rio São Lourenço & $1.240,80$ & Miracatu, Pedro de Toledo, Juquiá \\
$\mathbf{8}$ - Rio Itariri & 511,83 & Itariri, Pedro de Toledo \\
$\mathbf{9}$ - Rio Una da Aldeia & 950,42 & Iguape \\
$\mathbf{1 0}$ - Rio Pardo & $1.082,03$ & Barra do Turvo \\
$\mathbf{1 1}$ - Rio Jacupiranga & $1.469,93$ & Jacupiranga, Cajati, Registro, Pariquera-Açu \\
\hline 12 - Vertente Marítima Sul & $1.544,15$ & Cananéia, Ilha Comprida \\
\hline 13 - Vertente Marítima Norte & 539,67 & Iguape \\
\hline
\end{tabular}

\subsubsection{Baixo Ribeira de Iguape}

Os municípios de Registro e Iguape situam-se às margens do rio Ribeira. A rede hídrica que atravessa a área urbana de Registro é formada pelo rio Ribeira do Iguape e pelos seus afluentes, com destaque para o rio Carapiranga, o córrego São Francisco e o ribeirão de Registro, todos afluentes pela margem direita do rio Ribeira do Iguape e os principais responsáveis pelos eventos de inundações na cidade.

Iguape situa-se na margem direita do Rio Ribeira de Iguape, e não possui contribuintes na área urbana. A seção do rio onde se localiza a cidade corresponde praticamente ao exutório da bacia, com uma área total de drenagem aproximadamente igual a $25.681 \mathrm{~km}^{2}$.

Em 1997, houve inundação das áreas rurais a montante de Iguape e da barragem do Valo Grande, indicando que a capacidade do antigo leito do Rio Ribeira de Iguape a jusante do Valo está muito prejudicada por causa do assoreamento. Assim, o Valo Grande age como um tipo de extravasor, mas submetido a limitado controle de vazão, pois não há comportas na sua seção de controle (SSRH, 2009).

Tanto a área urbana de Registro como a de Iguape ficam sujeitas às consequências dos fenômenos que acontecem a montante da bacia hidrográfica, sendo que Iguape ainda 
sofre com os complexos comportamentos hidráulicos provenientes da variação da maré ao longo do canal do Mar Pequeno.

\subsubsection{Vertente Marítima Sul}

Os municípios de Cananéia e Ilha Comprida encontram-se na porção do território da UGRHI 11 conhecida como Vertente Marítima Sul e recebem os efeitos indiretos do regime hidrológico do Rio Ribeira do Iguape.

Cananéia situa-se numa ilha às margens do Mar de Fora ou de Cananéia. Não há corpos d'água doces como rios próximos da área urbana, exceto pequenos córregos que nascem na própria ilha e afluem aos canais marítimos que a ladeiam a oeste, o Mar de Itapitangui, e a leste, o Mar de Cananéia. Este último, mais ao norte é também conhecido como Mar de Iguape ou Pequeno. São esses os corpos receptores das águas pluviais urbanas (SSRH, 2009).

A Ilha Comprida possui, a oeste o Mar Pequeno e a leste o Oceano Atlântico, logo é exposta ao denominado mar aberto e todas as suas variações usuais. Não existem grandes rios próximos à mancha urbana ou na própria ilha, exceto valas de drenagem para propiciar a expansão urbana ou pequenos corpos d'água doces que nascem na própria ilha e com foz no mar.

O rio perene mais próximo é o Ribeira do Iguape de domínio federal e não há contribuintes seus na área urbana do município. Esse rio tem sua foz natural no norte da ilha, mas o canal do Valo Grande aflui ao Mar Pequeno numa margem oposta àquela onde se situa a ilha (SSRH, 2009).

Esse complexo sistema de corpos d'água influencia a dinâmica do escoamento superficial nos terrenos da ilha.

\subsubsection{Vertente Marítima Norte}

Iguape situa-se na margem direita do Rio Ribeira de Iguape, curso d'água de domínio federal, que não possui contribuintes na área urbana. A seção do rio onde se localiza a cidade corresponde praticamente ao exutório da bacia, com uma área total de drenagem aproximadamente igual a $25.681 \mathrm{~km}^{2}$.

Por estar na porção mais a jusante da bacia, recebe as consequências de todos os fenômenos que de alguma forma se relacionam com o regime hidrológico do rio Ribeira do Iguape. Assim, canalizações a montante e crescente impermeabilização do solo tendem a tornar mais agudos os efeitos em Iguape (SSRH, 2009). 
Além disso, por estar às margens do Valo Grande e junto ao Mar Pequeno, a complexidade dos escoamentos também contribui para que os efeitos das cheias na sua área urbana. As águas doces que chegam ao Mar Pequeno através do Valo Grande acabaram por alterar o ecossistema aquático natural, modificando inclusive a presença e a quantidade de espécies.

\subsubsection{Afluente ao rio Ribeira de Iguape - entre Registro e Iguape- Rio Jacupiranga}

Cajati é atravessada pelo Rio Jacupiranguinha, a jusante denominada Jacupiranga, contribuinte à margem direita do Rio Ribeira do Iguape. A seção do rio a jusante da cidade corresponde à área de drenagem de $381 \mathrm{~km}^{2}$; já a bacia correspondente à seção a montante tem área de $372 \mathrm{~km}^{2}$. A população urbana se espalha por uma área com 1.142,92 ha e perímetro de $22,89 \mathrm{~km}$. Inserido nesse perímetro a planície aluvional possui uma extensão de $5 \mathrm{~km}$ e largura média de $250 \mathrm{~m}$, perfazendo área de 125 ha, logo em torno de $10 \%$ da área urbana é formada por terrenos naturalmente submetidos à inundação, mesmo que ainda hoje estejam em parte ocupados.

A área urbana de Jacupiranga está situada à margem direita do Rio Jacupiranga, porém afastada de suas várzeas. Este rio contribui pela margem direita ao rio Ribeira do Iguape mais a jusante, com uma área de drenagem de $534 \mathrm{~km}^{2}$. A área urbana consolidada submetida à inundação é de cerca de 20 ha, logo significativa e toda situada na planície aluvional ao longo das margens do Rio Jacupiranga. A área urbana de ambos os municípios, em termos de macro-drenagem, fica sujeita às consequências dos fenômenos que acontecem na porção montante da bacia hidrográfica.

O município de Pariquera-Açu situa-se junto ao rio Turvo e próximo à confluência deste com o rio Pariquera-Açu. A seção do rio Pariquera-Açu corresponde a uma área de drenagem de aproximadamente $58 \mathrm{~km}^{2}$, sendo que mais a jusante este contribui à margem direita do Rio Ribeira do Iguape, em plena depressão tectônica do Baixo Ribeira a 1500 m sul de onde o Rio Jacupiranga deságua no Ribeira do Iguape.

\subsubsection{Regime hidrológico da bacia}

O clima e o regime hidrológico dos cursos d'água que compõem a rede hídrica da bacia do rio Ribeira do Iguape são importantes condicionantes, principalmente para as infra-estruturas de drenagem urbana.

Segundo o Relatório de Situação da URGHI-11 (CBH-RB, 2008) na classificação dos tipos climáticos, feita com base no sistema de Köppen: 
Há o tipo Af, tropical úmido sem estação seca que cobre $5 \%$ da bacia; o tipo Cfa, subtropical úmido com verão quente, que por sua vez, cobre $50 \%$ da bacia, e os restantes $45 \%$ são do tipo Cfb, subtropical úmido com verão fresco. Este último abrange as encostas das serras que incluem as áreas do norte e oeste da UGRHI. A umidade se faz presente em todos os tipos climáticos pertinentes à bacia.

\subsubsection{Coleta e tratamento de esgoto}

Uma das principais causas da poluição das águas do Rio Ribeira de Iguape é o lançamento de esgoto in natura, ou coletado e não tratado. Um dos principais indicadores de lançamento de esgoto é o aumento da presença de coliformes termotolerantes na água. O consequente aumento da concentração de matéria orgânica e a sua decomposição pelos micro-organismos causam a redução dos níveis de oxigênio dissolvido no meio aquático podendo chegar à anoxia.

Com o lançamento indevido de esgoto doméstico há o aumento da turbidez, e concentração de surfactantes e sólidos totais. A decomposição da matéria orgânica presente no esgoto leva também ao acréscimo de nitrogênio e fósforo no sistema contribuindo aos processos de eutrofização.

Segundo dados do relatório da CETESB (2013) a UGRHI- 11, com uma população urbana de 269.704 habitantes, tem em média $65 \%$ do esgoto coletado e $61 \%$ tratado, a carga remanescente é de $7760 \mathrm{~kg} /$ dia e apresenta o Índice de Coleta e Tratabilidade de Esgotos da População Urbana de Municípios (ICTEM) de 5,79. Os valores para os municípios de Iguape e Cananéia, segundo relatório da CETESB (2013), são mostrados na tabela 4 . 
Tabela 4. Valores relacionados à população, atendimento e coleta de esgoto/tratado, eficiência, carga poluidora $\mathrm{kg} \mathrm{DBO/dia,} \mathrm{ICETEM,} \mathrm{corpo} \mathrm{receptor} \mathrm{(CETESB,2013).}$

\begin{tabular}{|c|c|c|c|c|c|c|c|}
\hline Município & Concessão & $\begin{array}{l}\text { População } \\
\text { Urbana }\end{array}$ & $\begin{array}{c}\text { Atendimento } \\
\text { Coleta/ } \\
\text { Tratamento } \\
(\%)\end{array}$ & Eficiência & $\begin{array}{c}\text { Carga } \\
\text { poluidora (kg } \\
\text { DBO/dia)/ } \\
\text { potencial } \\
\text { remanescente }\end{array}$ & ICETEM & $\begin{array}{c}\text { Corpo } \\
\text { receptor }\end{array}$ \\
\hline Iguape & SABESP & 25785 & $53 / 100$ & 76,16 & $1392 / 732$ & 5,98 & $\begin{array}{l}\text { Rio Ribeira de } \\
\text { Iguape }\end{array}$ \\
\hline Cananéia & SABESP & 10754 & $60 / 100$ & 79 & $581 / 346$ & 5,42 & Mar Pequeno \\
\hline Registro & SABESP & 49800 & $81 / 100$ & 69,9 & $2690 / 1183$ & 6,86 & $\begin{array}{l}\text { Rio Ribeira de } \\
\text { Iguape }\end{array}$ \\
\hline Cajati & SABESP & 21222 & $69 / 100$ & 75,10 & $1146 / 552$ & 6,40 & $\begin{array}{l}\text { Rio } \\
\text { Jacupiranguinha }\end{array}$ \\
\hline Jacupiranga & SABESP & 9692 & $92 / 91$ & 88,01 & $523 / 183$ & 8,03 & Rio Jacupiranga \\
\hline $\begin{array}{l}\text { Pariquera- } \\
\text { Açú }\end{array}$ & SABESP & 13205 & $75 / 100$ & 69 & $713 / 344$ & 6,49 & $\begin{array}{l}\text { Rio Pariquera- } \\
\text { Açú }\end{array}$ \\
\hline
\end{tabular}

FONTE: RELATÓRIO CETESB-2013

\subsection{Dados Climatológicos}

\subsubsection{Precipitação}

Os dados de precipitação foram retirados da internet, com dados disponibilizados pelo Centro Integrado de Informações Agrometeorológicas (www.ciagro.sp.gov.br). As condições meteorológicas: valores de temperatura do ar e pluviosidade nas épocas de coleta, dados mensais e anuais, fornecidos pelo Centro de Previsão de Tempo e Estudos Climáticos (CPETEC) do Instituto nacional de Pesquisas Espaciais (INPE) foram obtidos no site www.cpetec.gov.br.

\subsection{Sistema Hídrico}

\subsubsection{Amostragem}

Este projeto está vinculado ao Projeto do edital Universal "Estudo ambiental de sistemas expostos a importantes ações antrópicas na região sudeste por meio de ferramentas biogeoquímicas" (FEBIOGEOQUIM - CNPq 47 8890/2011-7) sob a coordenação da Prof ${ }^{a}$. Dr ${ }^{\mathrm{a}}$. Elisabete de Santis Braga e ao INCT-TMCOcean (CNPq 573.601/2008-9) sob a coordenação geral do Prof. Dr. Luiz Drude de Lacerda.

As campanhas de amostragem dos parâmetros hidrológicos e hidroquímicos foram realizadas nos seguintes períodos: agosto/2012, fevereiro/2013, setembro/2013 e 
fevereiro/2014. Foram observadas algumas características referentes à agricultura para algumas amostragens pontuais levando em conta a cultura da banana, que é a principal cultura na região amostrada, uma estimativa da área ocupada por esta no trecho entre Registro e Iguape, estimativa da adubação anual de N e P na área plantada, a provável interferência da adubação nas épocas de amostragem do corpo hídrico e sua associação com a sazonalidade.

Foram realizadas quatro campanhas: inverno (2012 e 2013), verão (2013 e 2014) nos pontos indicados na figura 5a, com destaque dos pontos do Rio Ribeira de Iguape está na figura 5b. A nomenclatura das estações tem a seguinte classificação por área:

i) Porção final do Rio Ribeira (R1 a R6);

ii) Sistema Estuarino região de Iguape, incluindo o Valo Grande (estações 1 a 5);

iii) Região intermediária, entre Cananéia e Iguape, estação 6);

iv) Região de Cananéia (estações 7, 8, 9)

v) Canal do Ararapira (estações 10, 11 e 12)

Na coleta de água de superfície foram utilizadas garrafas hidrográficas tipo go-flo da Hydrobios seguindo a sequência: oxigênio dissolvido, $\mathrm{pH}$, nutrientes (nitrato e fosfato) e salinidade. 


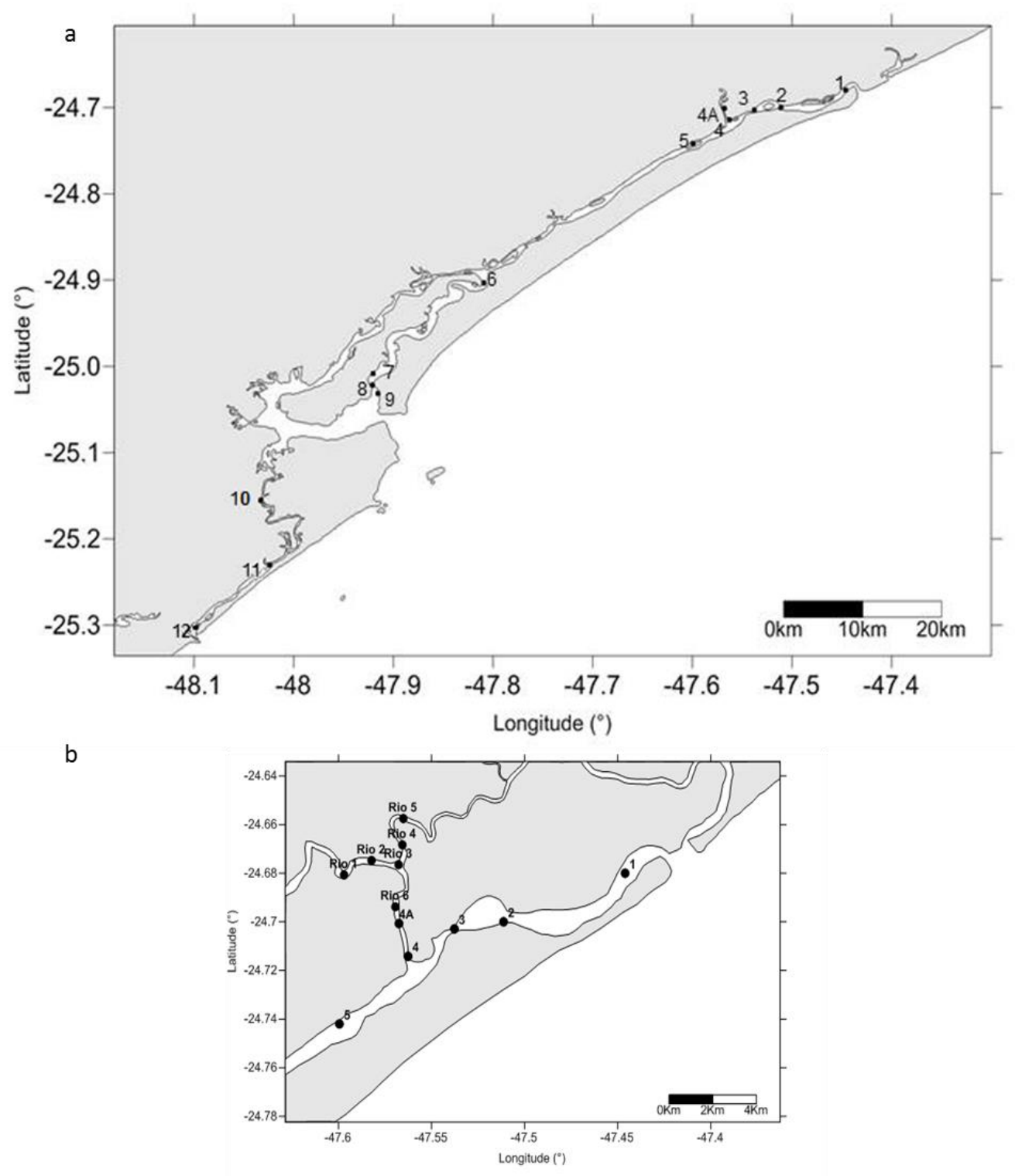

Figura 5. Pontos de coleta no complexo estuarino-lagunar de Cananéia-Iguape (a) com ênfase nas estações realizadas no Rio Ribeira de Iguape e Valo Grande (b) no Projeto Febiogeoquim/ INCT-TMCOcean em agosto/2012, fevereiro/2013, setembro/2013 e fevereiro/2014.

\subsubsection{Maré}

Os dados de maré foram obtidos das tábuas de maré fornecidas pelo MAPTOLAB- Laboratório de Marés e Processos Temporários Oceânicos do Instituto Oceanográfico da USP (www.mares.io.usp.br/tabua), com posterior validação dos dados para elaborar as curvas de maré nos dias de estudo.

\subsubsection{Turbidez e penetração da luz}

Os dados de turbidez foram obtidos com o uso de um turbidímetro Hatch ${ }^{\circledR}$, enquanto a penetração da luz foi medida com o uso do disco de Secchi. 


\subsubsection{Temperatura da água}

A temperatura da água in situ foi avaliada utilizando termômetros de reversão protegidos, calibrados em graus centígrados e acondicionados em cartuchos contendo termômetros auxiliares, agregados a garrafa coletora. Precisão de $\pm 0,02{ }^{\circ} \mathrm{C}$.

\subsubsection{Salinidade}

As amostras de água para determinação da salinidade foram armazenadas em frascos de âmbar de $250 \mathrm{ml}$. As leituras foram realizadas em salinômetro indutivo da marca Beckman, RS10, com precisão de $\pm 0,005$, sendo as unidades apresentadas em unidade de salinidade prática (USP).

\subsubsection{Potencial Hidrogeniônico (pH)}

$\mathrm{O}$ pH foi obtido em amostras coletadas em frasco de vidro com boca larga e medidas com o auxílio do pHmetro Orion P210A, com precisão de $\pm 0,001$, seguindo as recomendações de Aminot \& Chaussepied (1983).

\subsubsection{Oxigênio dissolvido (OD)}

A subamostragem foi a primeira a ser realizada, em frascos tipo Erlenmeyer, com tampas mergulhadoras e volume calibrado, desta forma é garantido que não haja a formação de bolhas. A análise foi feita antes de completar 8 horas de coleta. A metodologia seguida foi a de Winkler, como apresentada por Grasshoff et al. (1983), utilizando um titulador Metrohm automático em um Kit Hydrobios/Kiel. O método apresenta precisão de $\pm 0,02 \mathrm{~cm}^{3} \mathrm{dm}^{-3}$ para teores de $2 \mathrm{~cm}^{3} \mathrm{dm}^{-3} \mathrm{e} \pm 0,04 \mathrm{~cm}^{3} \mathrm{dm}^{-3}$ para teores superiores.

\subsubsection{Nitrogênio Amoniacal}

Essas amostras foram retiradas diretamente da garrafa, sendo os reagentes adicionados durante a coleta. As amostras foram armazenadas ao abrigo da luz. A metodologia utilizada é a descrita por Tréguer \& Le Corre (1975), apresentando uma precisão de $\pm 0,05 \mu \mathrm{mol} \mathrm{L} \mathrm{L}^{-1}$.

\subsubsection{Nitrato e Nitrito dissolvidos}

Os teores de nitrato e nitrito foram determinados segundo a análise de fluxo contínuo com arraste por bolhas baseada em Grasshoff et al. (1983); Tréguer \& Le Corre (1975) e Braga (1997), utilizando equipamento automático AutoAnalyzer II (BranLuebbe ${ }^{\circledR)}$ ). A determinação do nitrato envolve o uso de coluna de cádmio cuperizado para a redução do nitrato a nitrito. $\mathrm{O}$ valor de nitrito total (nitrito + nitrato reduzido) menos o 
valor do nitrito fornece o valor de nitrato. A precisão do método para nitrito é de 0,01 $\mu \mathrm{mol} \mathrm{L} \mathrm{L}^{-1}$ e para nitrato é de $0,02 \mu \mathrm{mol} \mathrm{L} \mathrm{L}^{-1}$.

\subsubsection{Fosfato dissolvido}

O fosfato foi determinado por espectrofotometria, utilizando a metodologia proposta em Grasshoff et al. (1983). As leituras foram realizadas em espectrofotômetro Genesys 2 (Bausch \& Lomb) e a precisão é de $0,01 \mu \mathrm{mol} \mathrm{L}{ }^{-1}$.

\subsubsection{Material em Suspensão (MES)}

A determinação do material em suspensão (MES) seguiu o método proposto por Strickland \& Parsons (1968), no qual a diferença de peso do filtro, antes (P1) e depois da filtragem da amostra (P2), apresentou a quantidade de material em suspensão presente no volume filtrado. Os filtros de porosidade nominal de $0,45 \mu \mathrm{m}$ de fibra de vidro $\mathrm{GF} / \mathrm{F}$ Whatman ${ }^{\circledR}$ foram previamente lavados em água destilada, calcinados por $4 \mathrm{~h} 30 \mathrm{~min}$ a 450 ${ }^{\circ} \mathrm{C}$, em mufla para eliminação de impurezas e tiveram seus pesos registrados em balança analítica BEL Engineering ${ }^{\circledR}$, modelo MARK 210A, com precisão de $\pm 0,0001$ g. Após a filtração de um volume de amostra, entre 450 e $600 \mathrm{~mL}$, os filtros foram acondicionados em embalagens individuais, identificadas e mantidos em frascos com sílica gel para redução da umidade e conservados em freezer $\left(-20^{\circ} \mathrm{C}\right)$.

\subsubsection{Material Orgânico em Suspensão (MOS)}

Após a determinação do MES os filtros foram calcinados por 4h30min em mufla a $450^{\circ} \mathrm{C}$ e pesados novamente (P3). A diferença entre os pesos P2 e P3 dividido pelo volume de água filtrado determina a concentração do material orgânico, expressa em mg $\mathrm{L}^{-1}$ seguindo a fórmula apresentada por Strickland \& Parsons (1968).

\subsubsection{Tratamento dos dados}

As informações sobre o uso e ocupação do solo foram tabeladas e os dados obtidos da parte hídrica foram dispostos na forma planilhas do programa Excel 7.0, geraram gráficos e tabelas que permitiram visualizar a distribuição espacial e temporal dos parâmetros medidos na área estudada. Os dados foram tratados e analisados em conjunto com as informações de uso e ocupação do solo, vazão do Rio, vazão no Valo Grande e carga doméstica e industrial de nitrogenados e fosfatados. O acoplamento entre as informações pode auxiliar a gestão ambiental na região. 


\subsection{Dados da Bananicultura}

\subsubsection{Aquisição de dados da literatura}

A partir de pesquisa bibliográfica, compilação de dados pretéritos, coleta de imagens (fotografias aéreas, satélite, etc.) foi composto um quadro preliminar de informações sobre uso e ocupação atual do solo, sinalizando as possíveis áreas de origem de poluição. Foram identificados o uso e a quantidade de fertilizantes consumidos na região. A relação entre a qualidade e ocupação do solo foi avaliada confrontando os registros de qualidade do solo obtidos de outros autores. Os índices e referenciais apresentados na legislação ambiental foram tomados para avaliar os dados.

\subsubsection{Aquisição de dados via tratamento de imagens}

A utilização de fotos aéreas da região visou a identificação da ocupação geral da área e das regiões com cultivo de bananas ao longo da margem do Rio Ribeira de Iguape, no trecho entre os municípios de Registro e Iguape. O tratamento de imagens foi realizado utilizando o Programa Google-Earth Pro @ que permitiu o cálculo das áreas com o cultivo de bananas a partir de polígonos identificados individualmente sobre a imagem, considerando apenas as plantações com interface ou proximidade com o rio. No cálculo foi considerada a área integral de cada plantação. Para tomada de maiores informações sobre o plantio de banana no Vale do Ribeira, foi consultado o Prof. Dr Leandro Godoy da UNESP de Registro que confirmou as doses de adubos, os períodos e a densidade de pés por área na região de estudo a partir dos dados pesquisados em literatura. 


\section{RESULTADOS E DISCUSSÃO}

\subsection{Precipitação}

A região de estudo é conhecida pelo alto índice pluviométrico nos meses de verão e por apresentar um inverno seco. No entanto, existem diferenças anuais que podem ser observadas considerando os três anos quando foram realizadas as coletas de estudo. A precipitação mensal nos anos de 2012, 2013 e 2014 encontra-se na figura 6. O ano de 2012 (Fig. 6a) apresentou um perfil de precipitação com valores altos nos meses de verão chegando até os meses de junho e julho, e portanto, mostrando parte do inverno com um alto valor de precipitação e valores mínimos em agosto e setembro.

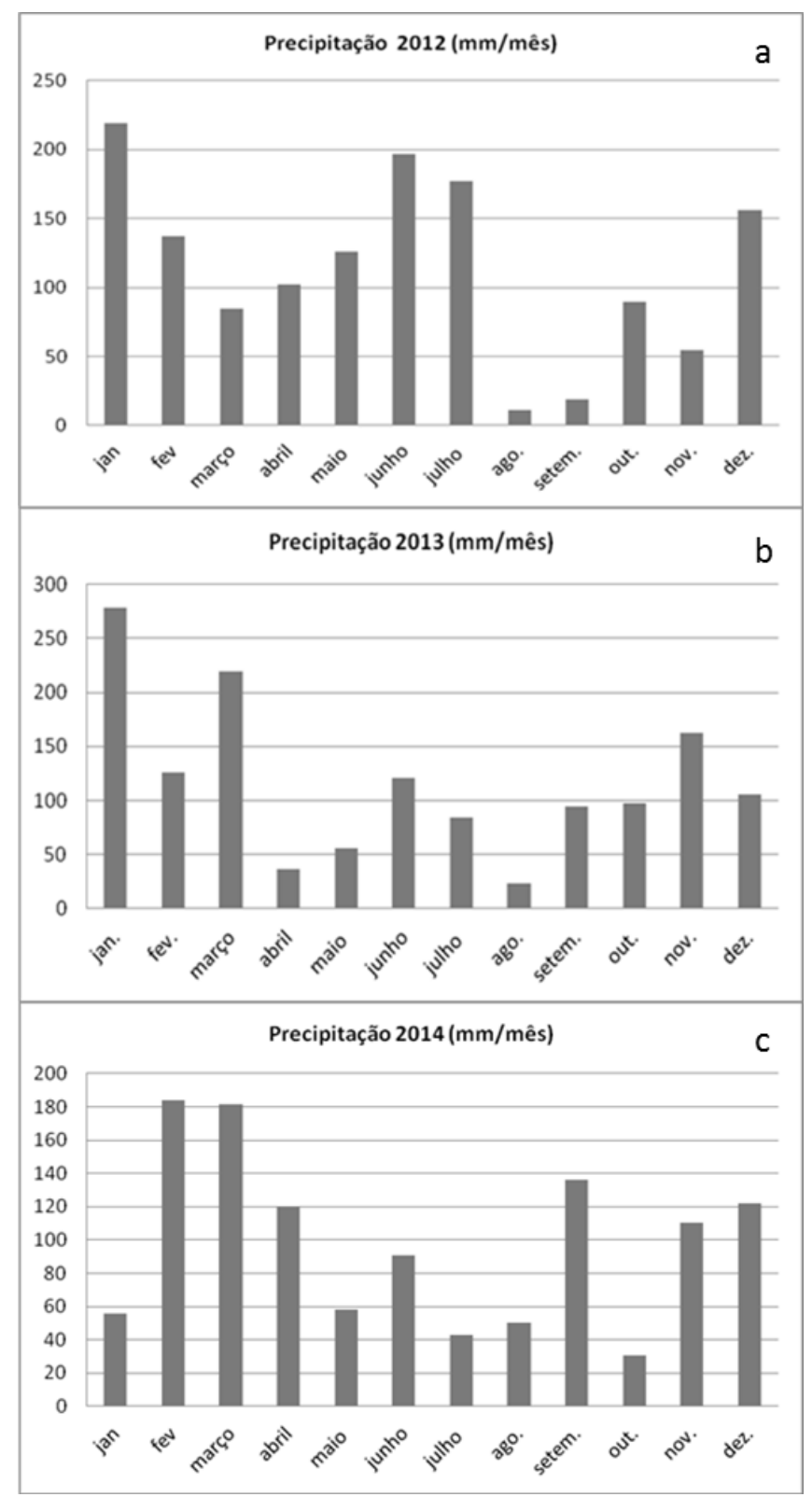

Figura 6. Precipitação mensal nos anos de 2012 (a), 2013 (b) e 2014 (c), com base nos dados de Pariquera-Açú divulgados em CIIAGRO, www.diagro.sp.gov.br, acesso em 20/02/2015. 
No caso do ano 2013 (Fig. 6b), os mais altos valores de precipitação se mantiveram nos meses de verão e o mínimo, mais uma vez ocorreu no mês de agosto. No ano 2014, o mês de janeiro não foi tão chuvoso, o que ocorreu nos meses de fevereiro e março, e o mês de outubro foi o mais seco do ano, aspecto muito diferenciado (Fig. 6c). A tabela 5 mostra, que o ano 2013 foi aquele que apresentou maior volume de precipitação e o ano 2014 foi o mais seco, apresentando valores de precipitação mensal sempre abaixo de 200mm (Fig. 6). A precipitação nos meses de coleta evidencia o apecto mais chuvoso no mês de fevereiro e um agosto mais seco. O mês de sembro de 2012 foi bastante diferente daquele de 2013 (Tab. 6).

Tabela 5. Precipitação total anual ds anos 2012 a 2014. CIIAGRO, disponível em www.diagro.sp.gov.br acesso em 20/02/2015.

\begin{tabular}{cc}
\hline Ano & $\begin{array}{c}\text { Precipitação Total } \\
\text { (mm) }\end{array}$ \\
\hline 2012 & 1372,8 \\
\hline 2013 & 1403,3 \\
\hline 2014 & 1182,9 \\
\hline
\end{tabular}

Tabela 6. Precipitação total mensal (mm) dos meses de coleta de 2012 a 2014. CIIAGRO, www.diagro.sp.gov.br, acesso em 20/02/2015.

\begin{tabular}{c|cccc}
\hline \multicolumn{5}{c}{ Precipitação total nos meses de coleta $(\mathrm{mm})$} \\
\hline Ano & Fevereiro & Agosto & Setembro & Outubro \\
\hline 2012 & 137 & 11 & 19 & 89 \\
2013 & 125 & 23 & 94 & 97 \\
2014 & 184 & 50 & - & - \\
\hline
\end{tabular}

A figura 7 mostra que o ano de 2012 apresentou um período de seca com um índice pluviométrico relativamente alto no mês de julho, porém o mês de agosto foi bastante representativo do período de seca. No ano de 2013, o mês de janeiro foi bastante representativo do período de chuva e agosto, mais uma vez, representou o mínimo de chuva. O ano de 2014 foi considerado o mais seco e a maior pluviosidade se deslocou para o mês de janeiro, sendo que agosto e setembro foram relativamente mais chuvosos que nos anos anteriores. 


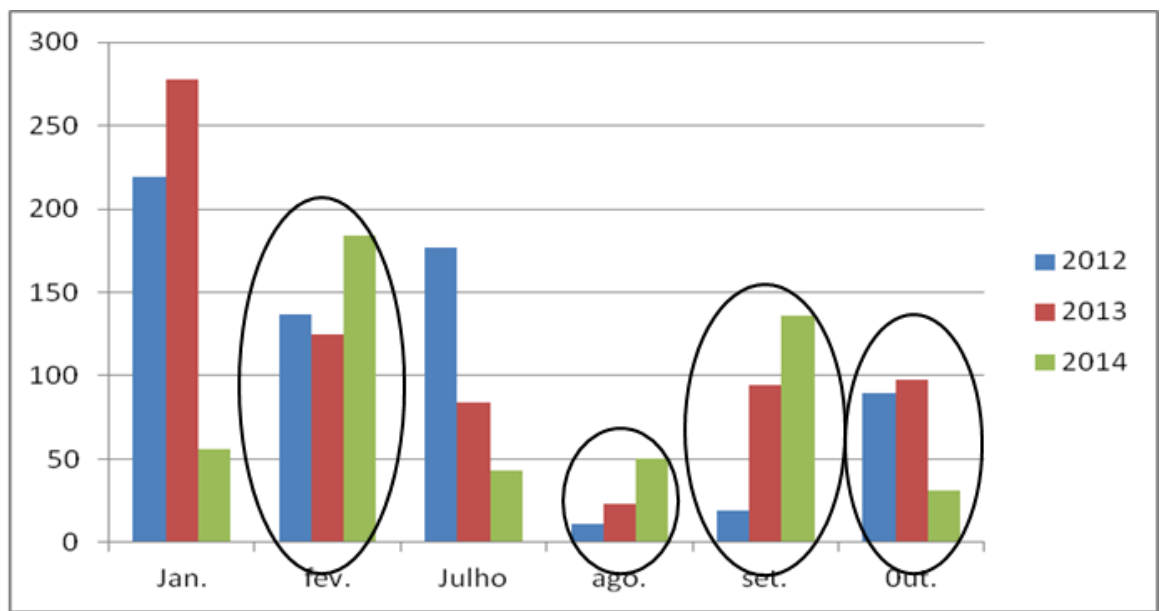

Figura 7. Precipitação mensal de janeiro, fevereiro, julho, agosto, setembro e outubro de 2012, 2013 e 2014 com base na precipitação total anual dos anos 2012 a 2014, CIIAGRO, www.diagro.sp.gov.br, acesso em 20/02/2015.

No caso das coletas de fevereiro de 2014, elas acabaram refletindo um período de seca anterior, que foi marcado com um verão seco, atípico na região sudeste de um modo geral, sendo assim, a drenagem continental foi diminuída neste período e, consequentemente, também foram diminuídos os aportes ao sistema hídrico por lixiviação continental, passando a ocorrer mais intensamente no mês de fevereiro.

As coletas no mês de agosto de 2012 ocorreream dos dias 28 a 31, enquanto no mês de fevereiro de 2013 ocorreram de 23 a 26, no mês de setembro de 2013 foram feiras nos dias 13 a 17, no mês de fevereiro de 2014 nos dias 07 a 11 .

\subsection{Condições hidroquímicas com destaque ao nitrogênio ( $\mathbf{N}$-amoniacal, $N$-nitrito, $\mathrm{N}$-nitrato ) e ao fósforo (P-fosfato)}

\subsubsection{Inverno - Agosto de 2012}

A curva de maré construída com dados da Base de Pesquisa Sul "Prof. Dr. João de Paiva Carvalho" fornecida pelo LABDADOS-IOUSP para o período de amostragem (Fig. 8). A curva apresentou vales e picos bem definidos com feições de sizígia, sendo que a maioria dos pontos de amostragem estiveram em condição de enchente $(1,2,3,4$, 7, 8 e 9), alguns em vazante (6 e 10) e outros em estofa de maré alta (4A, 5, 11, 12 e as estações do Rio). 


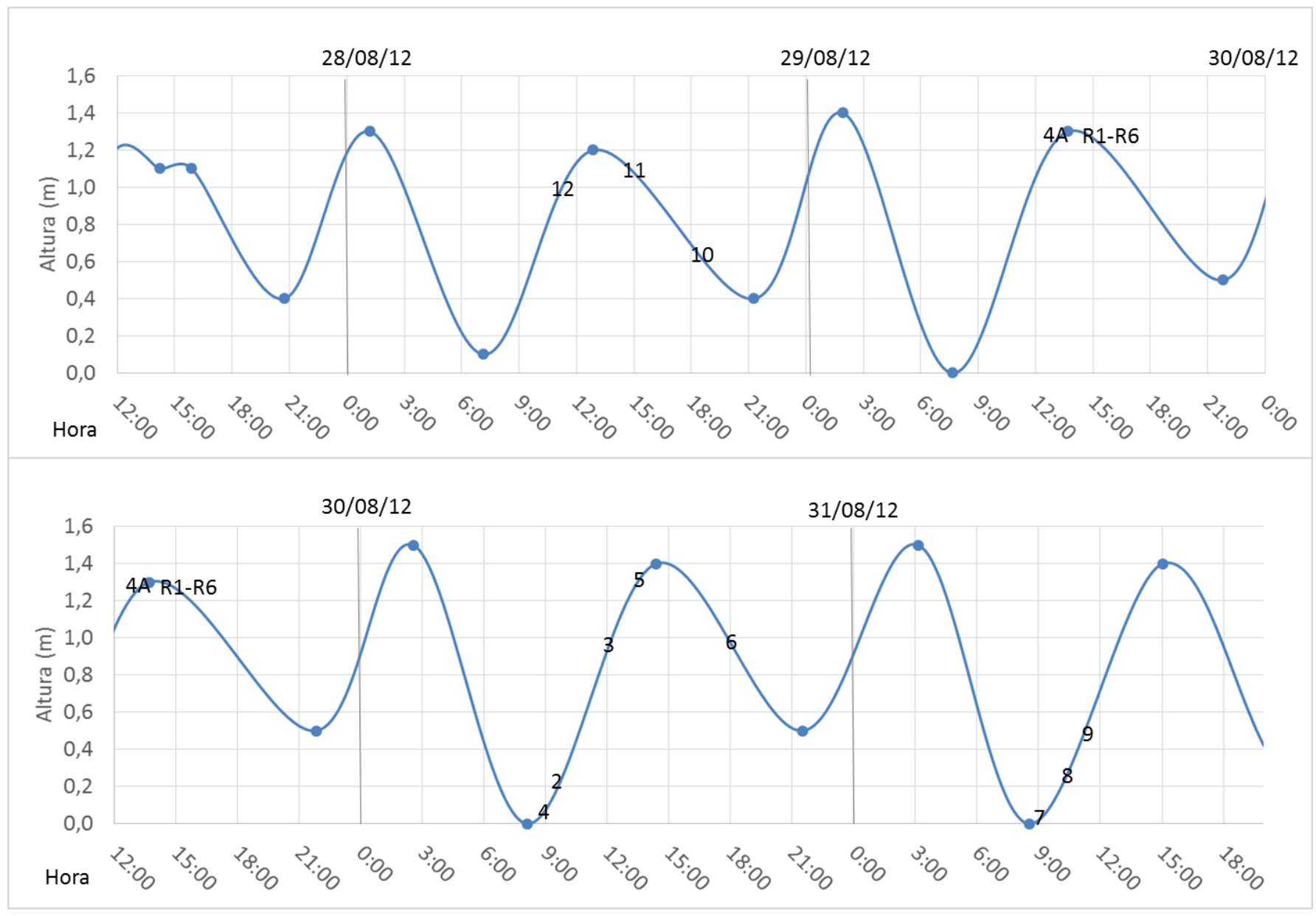

Figura 8. Curvas de maré construídas com dados do LABDADOS-IOUSP nos dias 28, 29, 30 e 31 de Agosto de 2012, destacando os momentos de realização das estações na região de Cananéia e Iguape (SP).

\subsubsection{Rio Ribeira de Iguape - estações R1 a R6}

Os dados de água de rio nesta campanha foram amostrados em superfície e os valores obtidos encontram-se na tabela 7.

Tabela 7. Dados hidrológicos e hidroquímicos $(0 \mathrm{~m})$ das águas a jusante do Rio Ribeira de Iguape (SP), Agosto de 2012 (inverno).

\begin{tabular}{|c|c|c|c|c|c|c|c|c|c|c|c|}
\hline $\begin{array}{l}\text { Ago. } \\
2012\end{array}$ & Est. & $\begin{array}{c}\text { Temp. } \\
\left({ }^{\circ} \mathrm{C}\right)\end{array}$ & Salin. & pH & $\begin{array}{c}\text { OD } \\
(\mathrm{mL} / \mathrm{L})\end{array}$ & $\begin{array}{c}\text { N- am. } \\
\left(\mu \mathrm{mol} \mathrm{L} \mathbf{L}^{-1}\right)\end{array}$ & 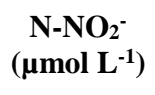 & 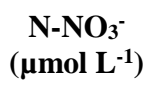 & $\begin{array}{c}\text { NID } \\
\left(\mu \mathrm{mol} \mathrm{L}^{-1}\right)\end{array}$ & $\begin{array}{c}\left.{\mathrm{P}-\mathrm{PO}_{4}{ }^{3-}}_{(\mu \mathrm{mol} \mathrm{L}}^{-1}\right)\end{array}$ & $\begin{array}{l}\mathrm{NID/} \\
\mathrm{PO}_{4}{ }^{3-}\end{array}$ \\
\hline \multirow{6}{*}{$\begin{array}{c}\text { Rio } \\
\text { Ribeira } \\
\text { de } \\
\text { Iguape }\end{array}$} & $\mathrm{R} 1$ & 21,3 & 0,03 & - & 5,58 & 1,71 & 0,09 & 10,08 & 11,88 & 6,12 & 1,95 \\
\hline & $\mathrm{R} 2$ & 21,2 & 0,03 & 6,96 & 5,74 & 1,74 & 0,10 & 9,97 & 11,81 & 11,17 & 1,06 \\
\hline & R3 & 21,2 & 0,03 & 6,84 & 5,54 & 2,26 & 0,10 & 10,07 & 12,43 & 11,95 & 1,04 \\
\hline & $\mathrm{R} 4$ & 21,1 & 0,03 & 6,91 & 5,56 & 2,06 & 0,11 & 10,06 & 12,23 & 10,90 & 1,12 \\
\hline & R5 & 21,2 & 0,04 & 6,82 & 5,71 & 1,91 & 0,11 & 10,16 & 12,18 & 9,03 & 1,35 \\
\hline & R6 & 21,3 & 0,04 & 6,85 & 5,56 & 2,55 & 0,10 & 10,37 & 13,02 & 12,45 & 1,05 \\
\hline
\end{tabular}

Considerando as estações de rio, os valores de temperatura foram bastante estáveis (Fig. 9a) ficando em torno de $21^{\circ} \mathrm{C}$. Os valores de salinidade, de modo geral, foram 
bastante baixos, próximos a zero, caracterizando o aporte de água doce $(S<5)$ com um valor levemente maior na estação R6, mais próxima ao Valo Grande (Fig. 9b) e, portanto, à conexão com o sistema estuarino.
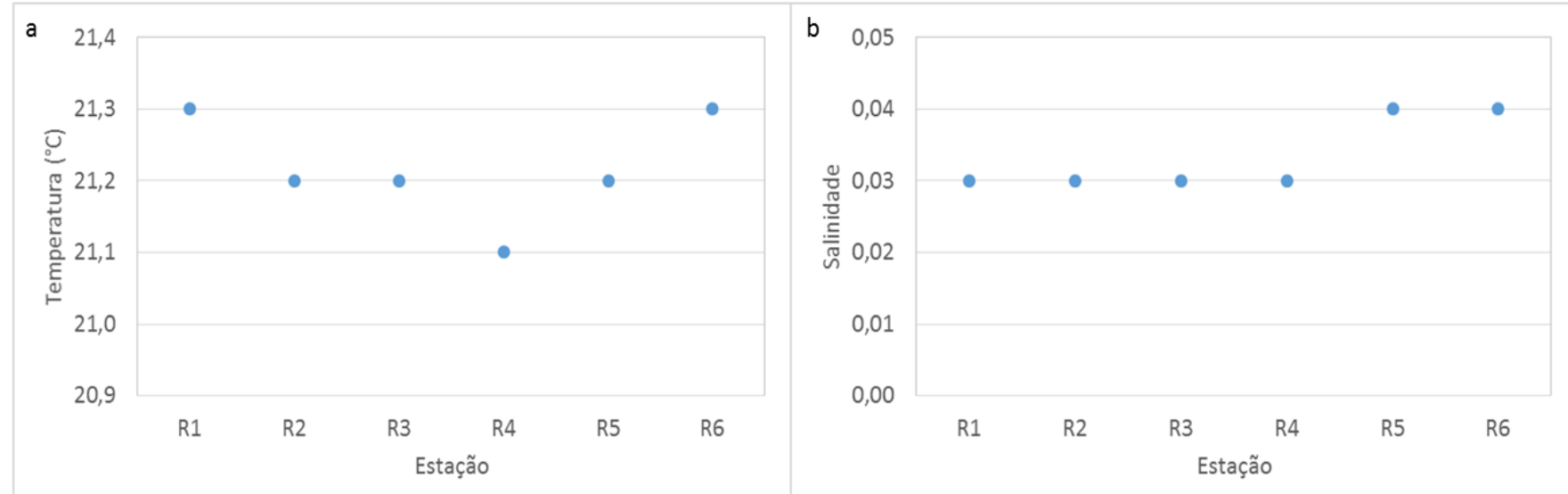

Figura 9. Distribuição espacial de temperatura (a) e salinidade (b) a jusante do Rio Ribeira de Iguape (SP), Agosto de 2012.

Todos os valores de oxigênio dissolvido (OD) estiveram acima de $5,5 \mathrm{ml} \mathrm{L}^{-1}$ (Fig.

10a) mostrando uma condição bem oxigenada nas águas amostradas, enquanto os valores de pH (Fig. 10b) estiveram todos um pouco abaixo de 7, indicando uma condição ligeiramente ácida, como encontrado na maioria das águas de rios.

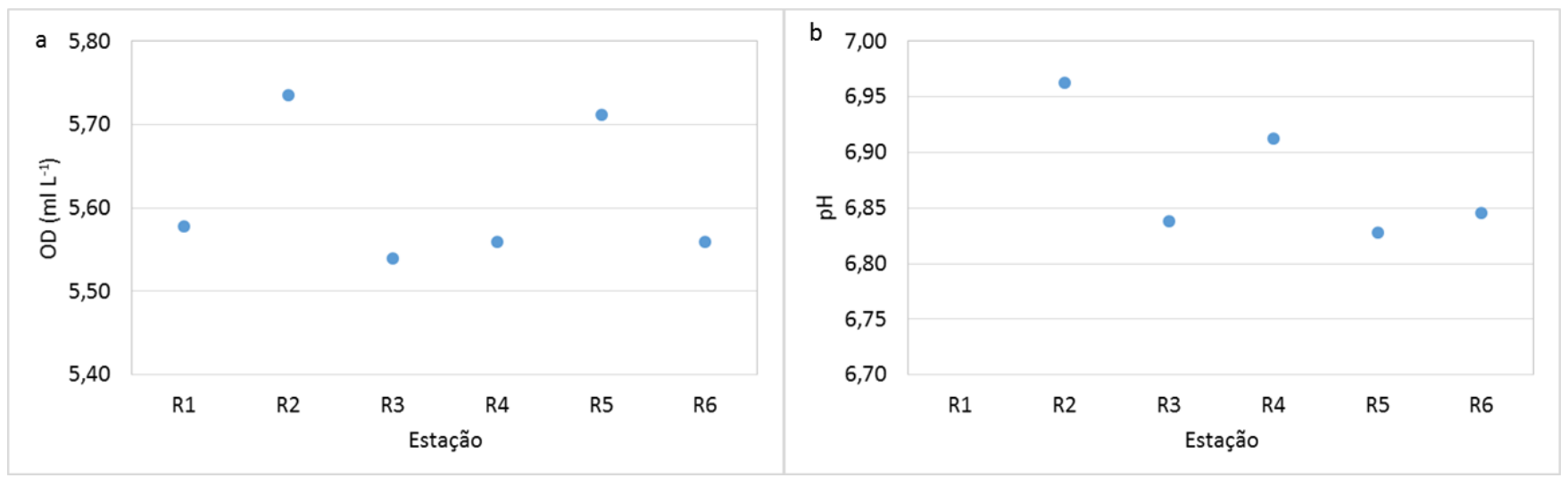

Figura 10. Distribuição espacial de oxigênio dissolvido (a) e pH (b) a jusante do Rio Ribeira de Iguape (SP), Agosto de 2012.

Em relação aos nutrientes dissolvidos, os valores de $\mathrm{N}$-amoniacal estiveram todos acima de $1,50 \mu \mathrm{mol} \mathrm{L} \mathrm{L}^{-1}$ sendo que o maior valor foi observado na estação mais a jusante (R6) com 2,55 $\mu \mathrm{mol} \mathrm{L}^{-1}$ (Fig. 11a). As concentrações de N-nitrito estiveram todas baixas $(\sim 0,10)$ com maior valor nas estações R4 e R5, próximas ao Valo Grande (Fig.11b). O Nnitrato mostrou concentrações com valores relativamente altos $\left(\sim 10 \mu \mathrm{mol} \mathrm{L}^{-1}\right)$ o que pode estar revelando contribuições antrópicas somadas aos aportes naturais, com destaque do valor mais alto também no ponto R6 (Fig. 11c). Os valores de Nitrogênio Inorgânico 
Dissolvido (NID) foram bem altos, apresentando o valor mínimo de $11,81 \mu \mathrm{mol} \mathrm{L}^{-1}$ na estação R1 e máximo valor de 13,02 $\mu \mathrm{mol} \mathrm{L}^{-1}$ na estação R6 (Fig.11d).

Considerando os valores de Nitrogênio Inorgânico Dissolvido (NID), o N-nitrato foi a forma de nitrogênio que mostrou maiores concentrações, sendo a forma mais importante no rio e que pode indicar a participação de aporte de fertilizantes ao sistema. $\mathrm{O} \mathrm{N}$-amoniacal foi o segundo contribuinte, muito provavelmente tendo parte de sua origem em esgoto doméstico, além da introdução natural.
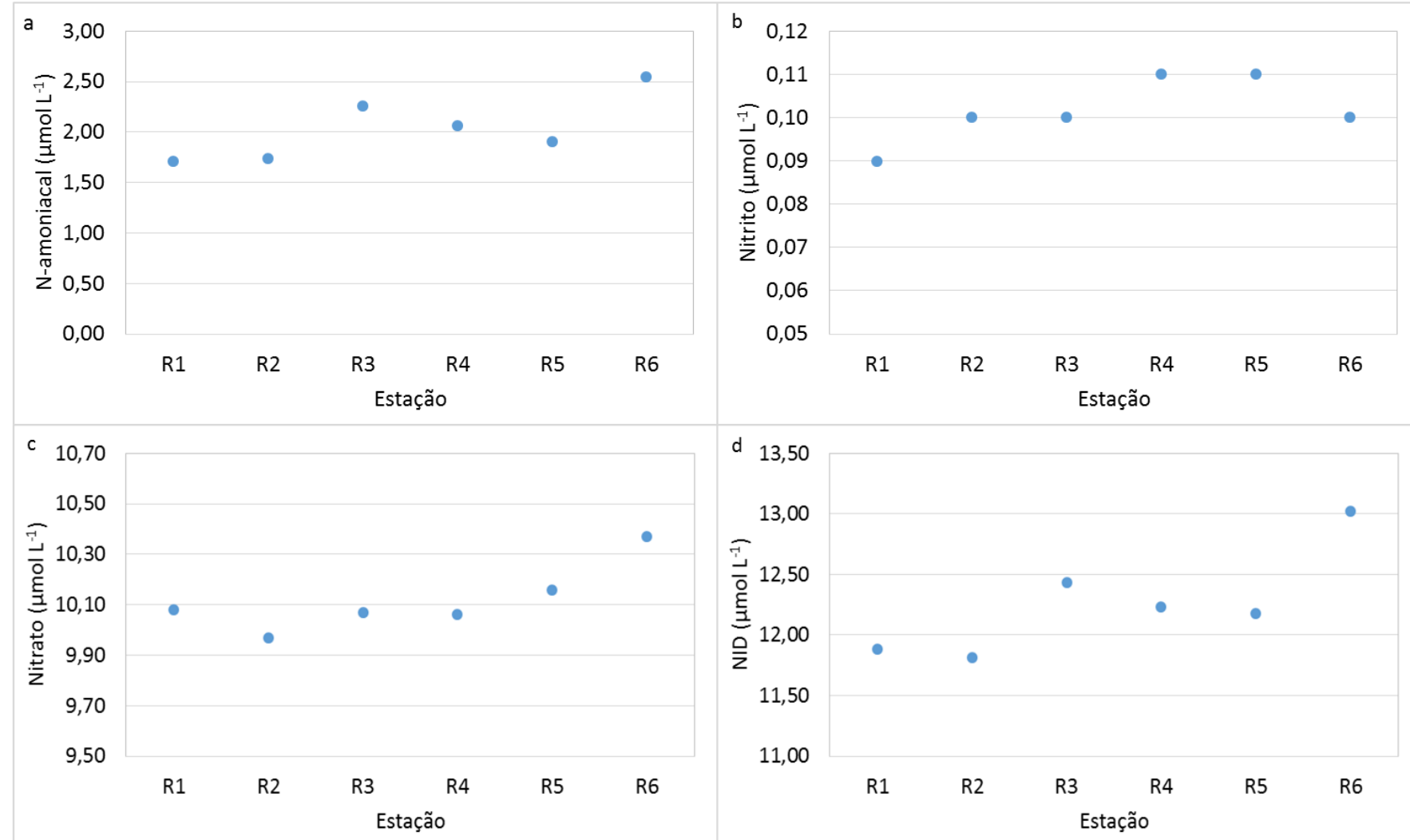

Figura 11. Distribuição espacial de compostos nitrogenados no Rio, N-amoniacal (a), N-nitrito (b),N- nitrato (c), NID (d), Agosto de 2012.

Os valores de fosfato $\left(\mathrm{PO}_{4}{ }^{3-}\right)$ também foram bem altos, revelando provável aporte do sistema industrial localizado a montante, apresentando um valor máximo na estação R6 de 12,45 $\mu \mathrm{mol} \mathrm{L} \mathrm{L}^{-1}$ e um valor mínimo de 6,12 $\mu \mathrm{mol} \mathrm{L}^{-1}$ na R1 (Fig. 12a). A relação $\mathrm{NID} / \mathrm{PO}_{4}{ }^{3-}$ foi menor que 2 para todas as estações, confirmando o intenso aporte dos dois nutrientes ( $\mathrm{Ne} \mathrm{P}$ ) assim como o alto valor de $\mathrm{PO}_{4}^{-3}$ (Fig. 12b). 


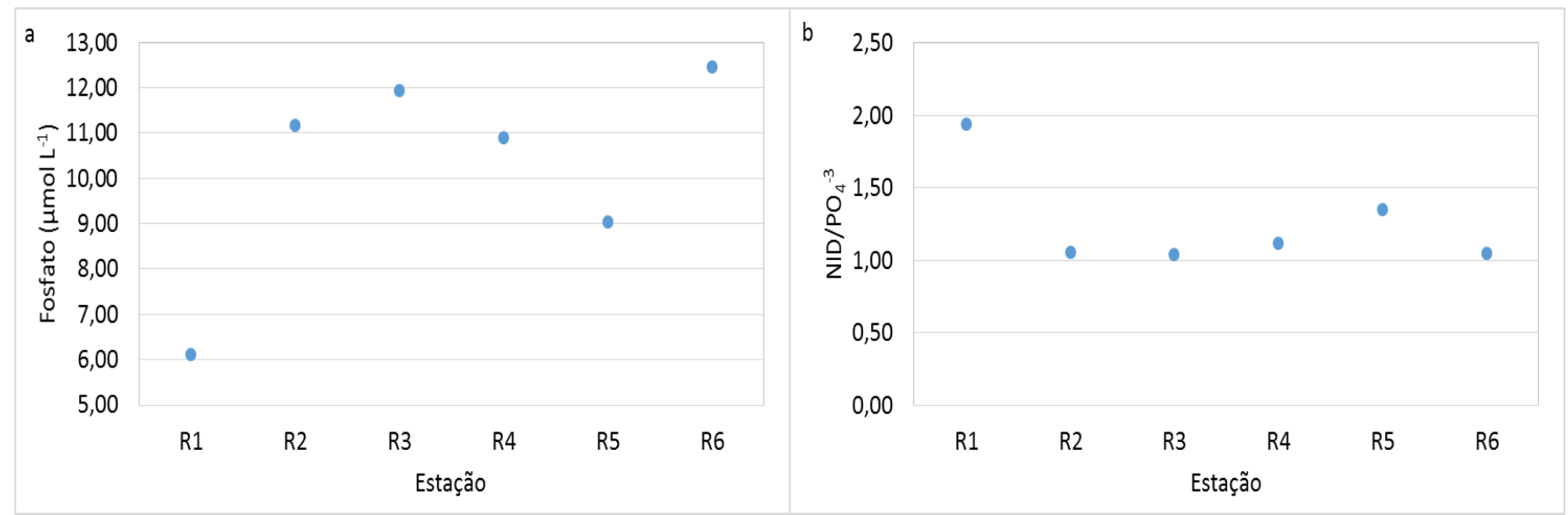

Figura 12. Distribuição espacial dos valores de $\mathrm{P}-\mathrm{PO}_{4}{ }^{-3}$ (a) e NID/P-PO ${ }_{4}{ }^{3-}(\mathrm{b})$, nos pontos do Rio Ribeira de Iguape (SP), Agosto de 2012.

Os valores de material em suspensão (Tab. 8) foram moderados, e as observações mostraram a presença de aporte de material em suspensão de qualidade fina, associado aos altos valores de turbidez. A porcentagem de material orgânico foi considerada com valores relativamente medianos para a região, entre $14 \%$ a $36 \%$, que pode estar contribuindo ao sistema com formas de $\mathrm{N}$-amoniacal, no processo de degradação do $\mathrm{N}$.

Tabela 8. Concentrações de material em suspensão, material orgânico em suspensão, porcentagem de material orgânico em suspensão, turbidez, e profundidade do disco de Secchi nas águas do Rio Ribeira de Iguape, em Agosto de 2012.

\begin{tabular}{cccccccc}
\hline $\begin{array}{c}\text { Ago. } \\
\mathbf{2 0 1 2}\end{array}$ & Est. & $\begin{array}{c}\text { Prof. } \\
(\mathbf{m})\end{array}$ & $\begin{array}{c}\text { MES } \\
\left(\mathbf{m g ~ L}^{-\mathbf{1}}\right)\end{array}$ & $\begin{array}{c}\text { MO } \\
\left(\mathbf{m g ~ L}^{-\mathbf{1}}\right)\end{array}$ & $\% \mathbf{M O}$ & $\begin{array}{c}\text { Turb. } \\
(\mathbf{n t u})\end{array}$ & $\begin{array}{c}\text { Secchi } \\
(\mathbf{m})\end{array}$ \\
\hline & R1 & 0 & 5,50 & 2,00 & 36,36 & 40,40 & 1,2 \\
$\begin{array}{c}\text { Rio } \\
\text { Ribeira } \\
\text { de }\end{array}$ & R2 & 0 & 5,83 & 1,17 & 20,00 & 41,90 & 1,2 \\
Iguape & R4 & 0 & 7,17 & 1,00 & 13,95 & 41,00 & 1,2 \\
& R5 & 0 & 5,67 & 1,33 & 23,53 & 41,20 & 1,2 \\
& R6 & 0 & 4,83 & 1,67 & 34,48 & 41,50 & 1,0 \\
\hline
\end{tabular}

A turbidez mostrou valores bastante altos que corroboram com a baixa entrada de luz no sistema, como mostra os valores de visualização do Disco de Secchi.

O valor mais alto do MES foi observado no ponto R3 (7,17 $\mathrm{mg} \mathrm{L}^{-1}$ ) (Fig. 13a), sendo que no ponto mais a montante (R1) a quantidade de matéria orgânica foi de 2,00 $\mathrm{mg} \mathrm{L}^{-1}$ (Fig. 13b). A porcentagem de MO foi maior no ponto $\mathrm{R} 1 \mathrm{com}$ o valor de $36,36 \%$, 
seguido pelo ponto R6 de $34,48 \%$ que é o ponto do rio mais próximo ao Canal do Valo Grande (Fig. 13c).

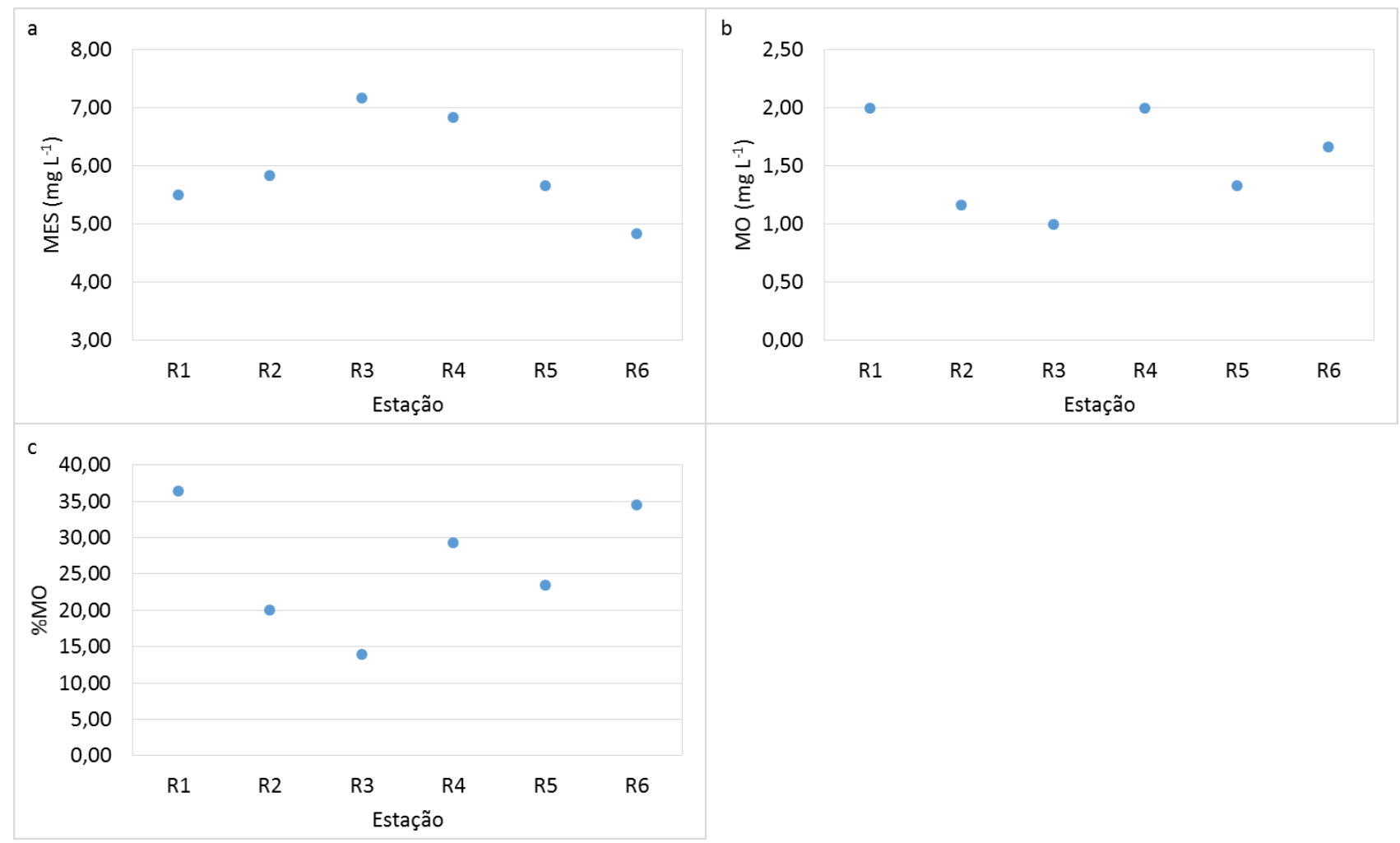

Figura 13. Distribuição espacial dos valores de material em suspensão (a), matéria orgânica (b) e porcentagem de matéria orgânica (c) no Rio Ribeira de Iguape, em agosto de 2012.

Segundo o Relatório de Situação dos Recursos Hídricos da Bacia Hidrográfica do Rio Ribeira do Iguape e litoral Sul, da unidade de gerenciamento - UGRHI11, do ano de 2013, referindo-se ao ano base de 2012 (CBH-RB, 2013), nos pontos monitorados pela CETESB (RIG02500, RIG02900, RIG02950) verifica-se que a qualidade para abastecimento (IQA) encontra-se predominantemente boa com valores em média de 0,15 $\mathrm{mg} \mathrm{L}^{-1}\left(4,8 \mu \mathrm{mol} \mathrm{L}{ }^{-1}\right)$ de fosfato, valores médios de 0,24 a $0,26 \mathrm{mg} \mathrm{L}^{-1}$ (16,4 a 18,5 $\mu \mathrm{mol}$ $\mathrm{L}^{-1}$ ) de nitrato. No entanto, o Rio Jacupiranga ainda apresenta situação de criticidade devido ao lançamento de efluentes líquidos finais da Vale Fertilizantes. O valore de fosfato neste rio (pontoJAPI02100) é de 3,8 $\mathrm{mg} \mathrm{L}^{-1}\left(122,5 \mu \mathrm{mol} \mathrm{L}^{-1}\right)$. Nesta área há a exploração de minerais (Jacupiranguitos, Carbonatitos) que apresentam $\mathrm{P}_{2} \mathrm{O}_{5}$ em sua composição (Bonás, 2007).

As estações de Rio apresentaram um alto teor de nutrientes, tanto para o nitrato que teve seu valor máximo de $10,37 \mu \mathrm{mol} \mathrm{L}^{-1}$ como para o fosfato que teve o seu maior, e bastante alto, valor de $12,45 \mu \mathrm{mol} \mathrm{L} \mathrm{L}^{-1}$. 
O maior valor de $\mathrm{N}$ - amoniacal foi de $2,55 \mu$ mol $\mathrm{L}^{-1}$, todos os altos valores estão associados à estação 6, mais próxima ao Valo Grande, corroborando com o fato que $70 \%$ da vazão do rio (Fig. 14) é vertida para esta área, sendo assim, a salinidade é típica de água fluvial ficando entre 0,03-0,04.

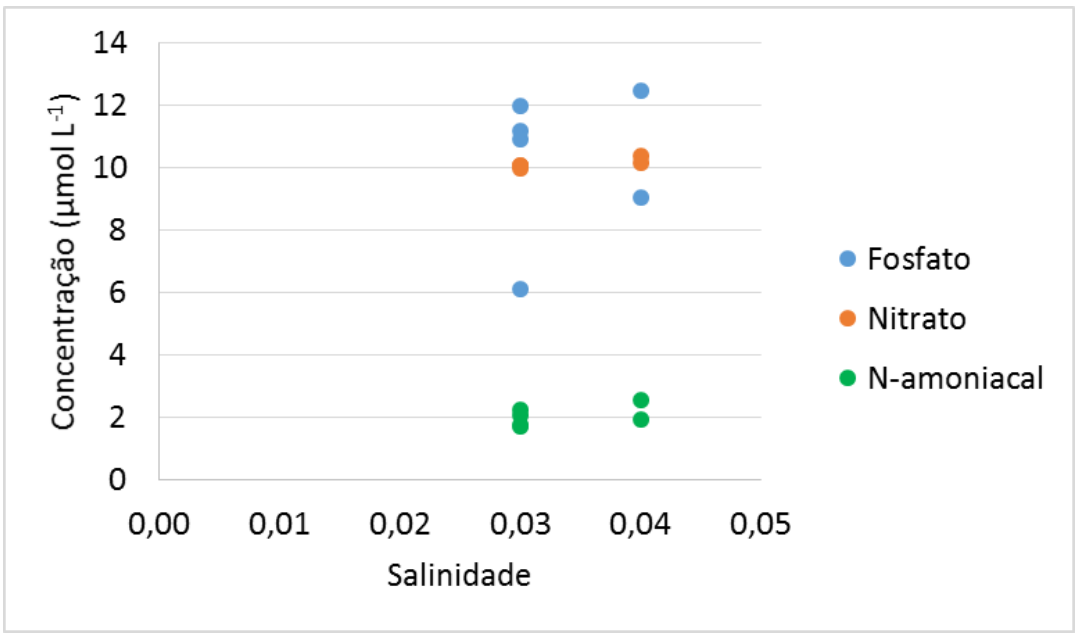

Figura 14. Distribuição de $\mathrm{P}$-fosfato, $\mathrm{N}$-nitrato e $\mathrm{N}$-amoniacal $\left(\mu \mathrm{mol} \mathrm{L} \mathrm{L}^{-1}\right)$ versus salinidade. Rio Ribeira do Iguape, Agosto de 2012.

\subsubsection{Iguape}

A região do sistema estuarino junto à Iguape, representada pelas estações de 1 a 5 apresentou valores das propriedades transitórios entre os valores do rio e do sistema estuarino, alterado pelo aumento do aporte de água doce. Os valores das estações 4 e 4A representam o Canal do Valo Grande. A estação 6, já está próxima ao início da Ilha de Cananéia, ou seja na porção intermediária do sistema indo para Sul (Tab. 9).

Os valores de temperatura mostram que as águas do Rio e do Valo Grande estavam mais frias, enquanto a estação próxima à Barra de Icapara (est.1) e a intermediária (est. 6) apresentam valores maiores, o que é acompanhado pela salinidade, $\mathrm{pH}$ e OD. Os nutrientes nitrogenados ainda exibiram valores altos no setor norte, diminuindo apenas na estação intermediária. Em relação aos valores de fosfato, eles permanecem altos no setor norte e diminuíram significativamente na estação 6, em direção ao sul do sistema.

\begin{tabular}{|c|c|c|c|c|c|c|c|c|c|c|c|c|}
\hline $\begin{array}{c}\text { Agosto } \\
2012\end{array}$ & Est. & $\begin{array}{l}\text { Prof } \\
\text { (m) }\end{array}$ & $\begin{array}{c}\text { Temp } \\
\left({ }^{\circ} \mathbf{C}\right)\end{array}$ & Salin. & pH & $\begin{array}{c}\text { OD } \\
\left(\mathbf{m L} \mathbf{L}^{-1}\right)\end{array}$ & $\underset{(\mu \mathrm{mol} \mathrm{L}}{\mathrm{N}-\mathbf{a m})}$ & $\left|\begin{array}{c}\mathrm{N}_{-} \mathrm{NO}_{2}^{-} \\
\left(\mu \mathrm{mol} \mathrm{L} \mathbf{L}^{-1}\right)\end{array}\right|$ & $\begin{array}{c}\left.\mathrm{N}^{-\mathrm{NO}_{3}}{ }_{(\mu \mathrm{mol} \mathrm{L}}^{-1}\right)\end{array}$ & $\begin{array}{c}\text { NID } \\
\left(\mu \mathrm{mol} \mathrm{L} \mathbf{L}^{-1}\right)\end{array}$ & $\begin{array}{c}\text { P-PO4}_{4}^{3-} \\
\left(\mu \mathrm{mol} \mathrm{L}{ }^{-1}\right)\end{array}$ & $\begin{array}{c}\mathrm{NID} / \mathrm{P}- \\
\mathrm{PO}_{4}{ }^{3-}\end{array}$ \\
\hline \multirow{2}{*}{ Iguape } & 1 & 0 & 24,00 & 6,73 & 7,86 & 5,40 & 4,73 & 0,11 & 7,87 & 12,71 & 6,92 & 1,83 \\
\hline & 2 & 0 & 24,00 & 1,43 & 7,26 & 1,14 & 3,35 & 0,11 & 9,46 & 12,92 & 7,18 & 1,80 \\
\hline
\end{tabular}




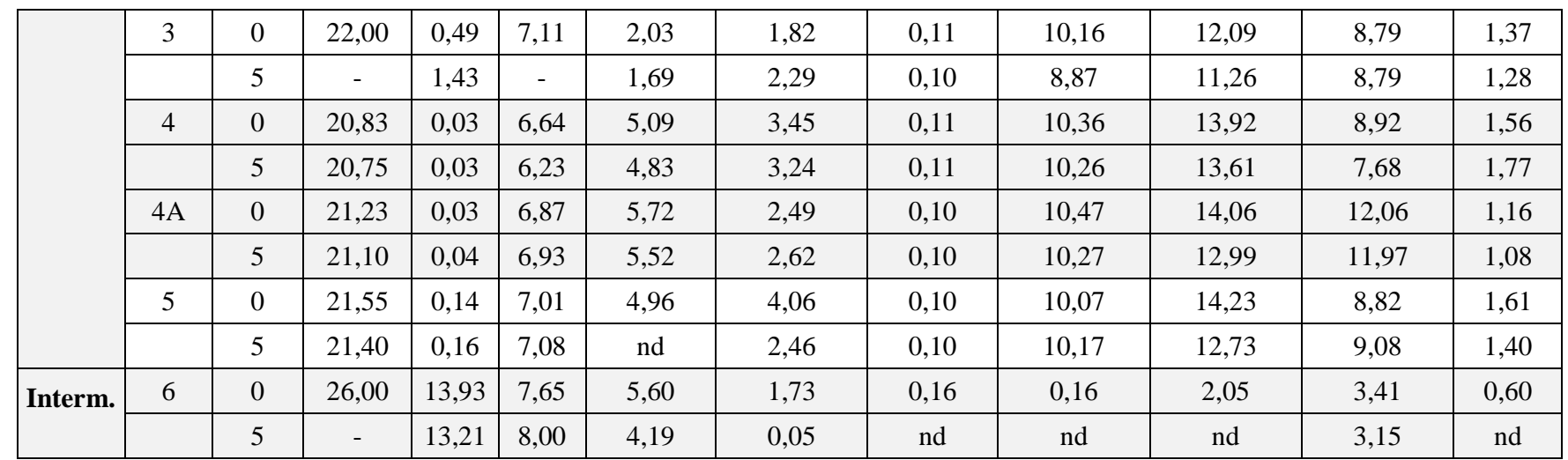

Tabela 9. Valores de temperatura, salinidade, oxigênio dissolvido, $\mathrm{pH}, \mathrm{N}$-amoniacal, nitrito, nitrato, nitrogênio inorgânico dissolvido, fosfato e relação nitrogênio inorgânico dissolvido e fosfato referentes ao sistema norte, incluindo o Valo Grande (estações 4 e 4A) e a estação intermediária(6), em agosto de 2012 (inverno).

No que se refere ao MES, o maior valor foi encontrado no setor intermediário acompanhado pelo maior valor de $\mathrm{MO}$ e de \%MO. A turbidez diminui sensivelmente na estação intermediária (Tab.10).

Tabela 10. Concentrações de material em suspensão (MES), material orgânico em suspensão (MO), porcentagem de material orgânico em suspensão e turbidez, nas águas de Iguape, Valo Grande e estação intermediária, em Agosto de 2012.

\begin{tabular}{|c|c|c|c|c|c|c|}
\hline Agosto 2012 & Est. & $\begin{array}{c}\text { Prof. } \\
(\mathbf{m})\end{array}$ & $\begin{array}{c}\text { MES } \\
\left(\mathbf{m g ~ L}^{-\mathbf{1}}\right)\end{array}$ & $\begin{array}{c}\text { MO } \\
\left(\mathbf{m g ~ L}^{-\mathbf{1}}\right)\end{array}$ & \% MO & $\begin{array}{c}\text { Turb. } \\
(\mathbf{n t u})\end{array}$ \\
\hline \multirow{5}{*}{ Iguape } & 1 & 0 & 33,33 & 8,33 & 25,00 & 17,70 \\
\cline { 2 - 7 } & 2 & 0 & 28,33 & 6,33 & 22,35 & 41,50 \\
\cline { 2 - 7 } & 3 & 0 & 39,00 & 9,00 & 23,08 & 50,00 \\
\cline { 2 - 7 } & & 5 & 25,33 & 6,33 & 25,00 & 60,60 \\
\cline { 2 - 7 } & 4 & 0 & 6,80 & 1,60 & 23,53 & 11,70 \\
\cline { 2 - 7 } & $4 \mathrm{~A}$ & 0 & 4,20 & 1,60 & 38,10 & $\mathrm{nd}$ \\
\cline { 2 - 7 } & & 5 & 7,17 & 1,33 & 18,60 & nd \\
\cline { 2 - 7 } & 5 & 0 & $\mathrm{nd}$ & 2,00 & 17,07 & 12,90 \\
\cline { 2 - 7 } & & 5 & 26,00 & 5,33 & 20,51 & 18,40 \\
\hline \multirow{4}{*}{ Interm. } & 6 & 0 & 38,00 & 9,00 & 23,68 & 3,19 \\
\cline { 2 - 7 } & & 5 & 42,67 & 11,33 & 26,56 & 3,29 \\
\hline
\end{tabular}

$\mathrm{Na}$ região de Iguape, na primeira campanha, observou-se que os teores de nutrientes foram bastante altos, em especial a concentração de P-fosfato que esteve extremamente alta quando observado em relação aos valores de nitrato, isto ocorre nesta área sob maior influência da água fluvial. Observa-se também que conforme a salinidade aumenta (Fig. 15), as concentrações diminuem, sendo que por volta da salinidade 7, o teor de nitrato esteve em torno de $8 \mu \mathrm{mol} \mathrm{L}^{-1}$ e o de fosfato foi de aproximadamente 7 $\mu \mathrm{mol} \mathrm{L}{ }^{-1}$. A concentração de fosfato passa a ser menor que $4 \mu \mathrm{mol} \mathrm{L}^{-1}$ quando a salinidade 
está por volta de 14, enquanto o nitrato fica extremamente baixo nesta salinidade. O teor de amônio foi menor que os dois outros parâmetros na área sob influência do Rio, mostrando valores entre 2 e $4 \mu \mathrm{mol} \mathrm{L}^{-1}$ em salinidade $<5$ e valores em torno de $5 \mu \mathrm{mol} \mathrm{L}{ }^{-}$ ${ }^{1}$ em salinidade intermediária (água salobra).

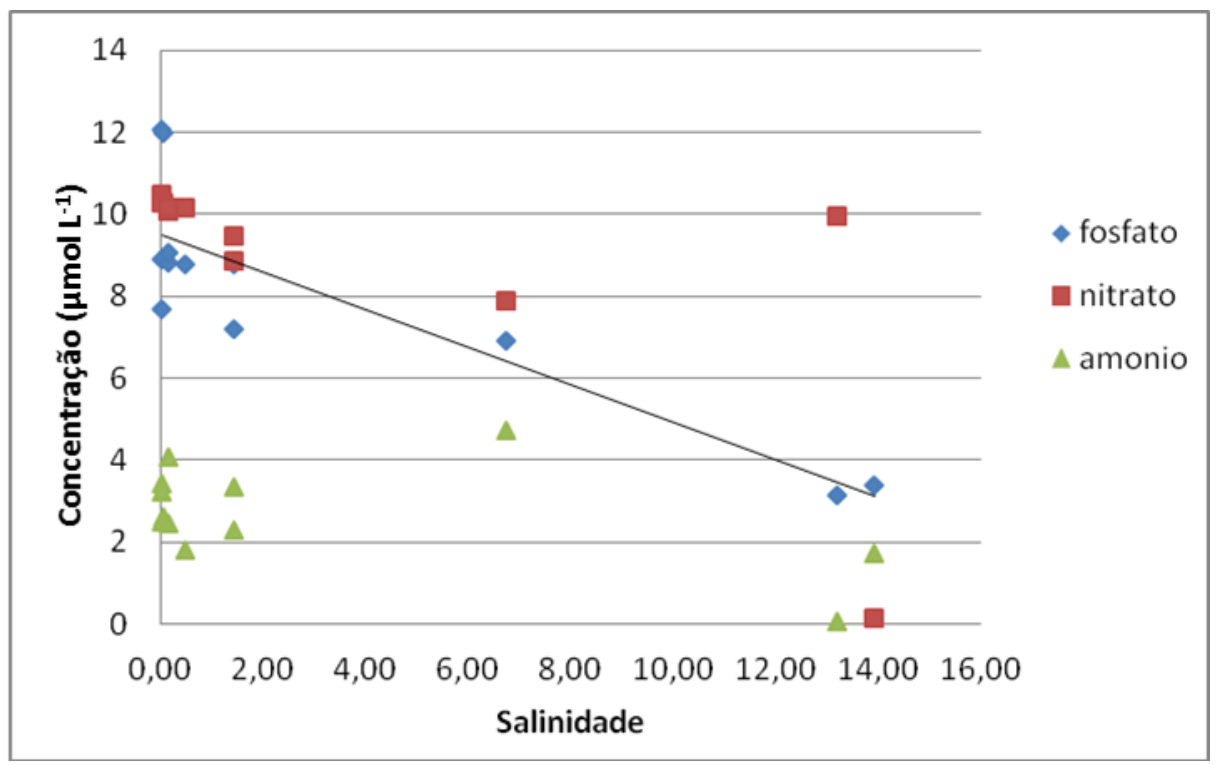

Figura 15. Distribuição de P-fosfato, N-nitrato e N-amônio pela Salinidade. Iguape, agosto 2012.

Este comportamento evidencia o importante aporte de N-nitrato e P-fosfato pelas águas fluviais no setor norte do sistema em estudo.Trabalho pretérito realizado na região do Canal do Valo encontrou valores médios de P-fosfato de 4,26 $\mu \mathrm{mol} \mathrm{L} \mathrm{L}^{-1}$ e valores máximos de 5,24 $\mu \mathrm{mol} \mathrm{L}{ }^{-1}$ (Barrera-Alba,2004).

Outros autores (Meybeck, 1982; Balls, 1994; Sonal \& Kataria, 2012) indicam que $\mathrm{o}$ alto teor de $\mathrm{N}$-nitrato pode estar associado às atividades de agricultura. Assim, a concentração de nutrientes em rios e estuários está ligada ao uso da terra em sua adjacência.

\subsubsection{Cananéia e Ararapira}

Os valores das propriedades hidrológicas e hidroquímicas de Cananéia-Ararapira se encontram na tabela 11. Pode-se notar que os valores de temperatura foram menores no setor de Ararapira, mais ao sul do Complexo. Os valores de salinidade estiveram todos na casa da categoria de águas salobras em Cananéia e atingiram valores superiores a 30 no canal do Ararapira, ou seja, de águas salinas. Os valores de $\mathrm{pH}$ estiveram todos acima de 8,0 e os maiores valores de OD foram encontrados junto à Barra do Ararapira e na superfície da estação 8. 
Os nutrientes nitrogenados estiveram presentes em quantidades bem menores quando comparados aos valores encontrados no Rio, Iguape e porção intermediária, assinalando o decréscimo destes ao longo do sistema, em direção ao setor sul. O menor valor de NID foi constatado na estação 12 , profundidade $5 \mathrm{~m}$ com valor de $0,86 \mu \mathrm{mol} \mathrm{L} \mathrm{L}^{-1}$, sendo que a maioria dos demais pontos apresentaram valores entre $2 \mu \mathrm{mol} \mathrm{L}^{-1}$ e $4,5 \mu \mathrm{mol}$ $\mathrm{L}^{-1}$. A estação 9 na profundidade de $5 \mathrm{~m}$ apresentou valores de $8,89 \mu \mathrm{mol} \mathrm{L} \mathrm{L}^{-1}$. Os valores de P-fosfato no setor sul foram bem mais baixos que no setor norte. Em Cananéia os

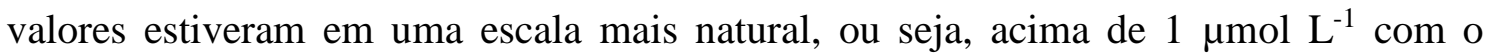
máximo de 2,06 $\mu \mathrm{mol} \mathrm{L}{ }^{-1}$ na estação 7. Nos pontos de Ararapira os teores de P-fosfato ficaram entre $0,25 \mu \mathrm{mol} \mathrm{L}{ }^{-1}$ e $0,49 \mu \mathrm{mol} \mathrm{L}^{-1}$. A razão $\mathrm{NID} / \mathrm{PO}_{4}{ }^{-3}$ teve seu menor valor no ponto $8,0 \mathrm{~m}$ de profundidade com 1,98 , e máximo no ponto 10 a $0 \mathrm{~m}$ com $14,78 \mu \mathrm{mol} \mathrm{L}^{-1}$ (Tab. 11).

De um modo geral, os valores de salinidade, temperatura e $\mathrm{pH}$ aumentaram do setor norte para o setor sul e as propriedades químicas como nutrientes diminuíram, sendo que, os nutrientes, sobretudo o $\mathrm{P}$ - fosfato e o $\mathrm{N}$-nitrato apresentam valores altos no rio e no setor norte de um modo geral, sofrendo diluição em direção ao sul (Tab. 11).

Tabela 11. Valores de temperatura, salinidade, oxigênio dissolvido, $\mathrm{pH}, \mathrm{N}$-amoniacal, nitrito, nitrato e nitrogênio inorgânico dissolvido, em Cananéia e Ararapira, sul do sistema, em Agosto de 2012.

\begin{tabular}{|c|c|c|c|c|c|c|c|c|c|c|c|c|}
\hline Agosto 2012 & Est. & $\begin{array}{c}\text { Prof. } \\
\text { (m) }\end{array}$ & $\underset{{ }^{\circ} \mathrm{C}}{\text { Temp. }}$ & Salin. & $\mathbf{p H}$ & $\underset{\left(\mathrm{ml} \mathrm{L} \mathbf{L}^{-1}\right)}{\text { OD }}$ & $\begin{array}{c}\mathrm{N} \text {-am. } \\
(\mu \mathrm{mol} \mathrm{L} \\
\left.\mathbf{L}^{-1}\right)\end{array}$ & $\begin{array}{c}\mathrm{N}-\mathrm{NO}_{2}{ }^{-} \\
\left(\mu \mathrm{mol} \mathbf{L}^{-1}\right)\end{array}$ & 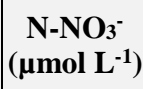 & $\begin{array}{c}\text { NID } \\
\left(\mu \mathrm{mol} \mathrm{L} \mathbf{L}^{-1}\right)\end{array}$ & $\begin{array}{c}\mathrm{P}_{-\mathrm{PO}_{4}{ }^{3-}} \\
\left(\mu \mathrm{mol} \mathrm{L}{ }^{-1}\right)\end{array}$ & $\begin{array}{c}\text { NID/ } \\
\text { P-PO4 }_{4}{ }^{3-}\end{array}$ \\
\hline \multirow{6}{*}{ Cananéia } & 7 & 0 & 21,58 & 20,21 & 8,04 & 4,82 & 3,94 & 0,11 & 0,46 & 4,51 & 2,06 & 2,18 \\
\hline & & 5 & 21,50 & 20,32 & 8,16 & 4,78 & 3,20 & 0,27 & 0,59 & 4,06 & 1,76 & 2,31 \\
\hline & 8 & 0 & 21,70 & 20,76 & 8,05 & 5,62 & 3,30 & 0,13 & 0,48 & 3,91 & 1,97 & 1,98 \\
\hline & & 5 & 21,48 & 20,97 & 8,13 & 4,70 & 4,12 & 0,15 & 0,53 & 4,80 & 1,85 & 2,59 \\
\hline & 9 & 0 & 22,18 & 23,01 & 8,22 & 4,94 & 3,52 & 0,15 & 0,57 & 4,24 & 1,59 & 2,66 \\
\hline & & 5 & 21,20 & 27,43 & 8,35 & 4,94 & 4,40 & 0,20 & 4,29 & 8,89 & 1,31 & 6,79 \\
\hline \multirow{6}{*}{ Ararapira } & 10 & 0 & 21,10 & 28,87 & 8,30 & 4,46 & 3,88 & 0,07 & 0,19 & 4,14 & 0,28 & 14,78 \\
\hline & & 5 & 20,45 & 29,43 & 8,10 & 4,28 & 2,27 & 0,06 & 0,26 & 2,59 & 0,25 & 10,36 \\
\hline & 11 & 0 & 20,50 & 32,75 & 8,43 & 4,50 & 1,43 & 0,05 & 0,11 & 1,59 & 0,30 & 5,30 \\
\hline & & 5 & 20,55 & 32,67 & 8,63 & 4,66 & 0,72 & 0,05 & 0,09 & 0,86 & 0,35 & 2,46 \\
\hline & 12 & 0 & 20,25 & 32,41 & 8,62 & 5,31 & 1,88 & 0,23 & 0,67 & 2,78 & 0,49 & 5,67 \\
\hline & & 5 & 20,30 & 32,35 & 8,39 & 5,36 & 2,07 & 0,22 & 0,62 & 2,91 & 0,44 & 6,61 \\
\hline
\end{tabular}

O MES e a MO foram maiores no setor sul, aumentando junto às Barras de Cananéia e do Ararapira, em função da hidrodinâmica. A porcentagem de MO sempre esteve com valores entre $19 \%$ e $28 \%$. A turbidez no canal do Ararapira foi maior que em 
Cananéia, talvez em função do aporte de material húmico mais intenso neste setor (Tab.12).

Tabela 12. Concentrações de material em suspensão, material orgânico em suspensão, porcentagem de material orgânico em suspensão e turbidez, nas águas Cananéia e Ararapira, em Agosto de 2012.

\begin{tabular}{|c|c|c|c|c|c|c|}
\hline $\begin{array}{c}\text { Agosto } \\
\mathbf{2 0 1 2}\end{array}$ & Est. & $\begin{array}{c}\text { Prof. } \\
(\mathbf{m})\end{array}$ & $\begin{array}{c}\text { MES } \\
\left(\mathbf{m g ~ L}^{-\mathbf{1}}\right)\end{array}$ & $\begin{array}{c}\text { MO } \\
\left(\mathbf{m g ~ L}^{-\mathbf{1}}\right)\end{array}$ & \% MO & $\begin{array}{c}\text { Turb. } \\
(\mathbf{n t u})\end{array}$ \\
\hline \multirow{4}{*}{ Cananéia } & 7 & 0 & 33,80 & 9,20 & 27,27 & 3,50 \\
\cline { 2 - 7 } & & 5 & 45,56 & 12,00 & 27,34 & 4,63 \\
\cline { 2 - 7 } & 8 & 0 & 43,00 & 10,75 & 25,00 & 3,84 \\
\cline { 2 - 7 } & & 5 & 43,20 & 10,20 & 23,61 & 5,30 \\
\cline { 2 - 7 } & 9 & 0 & 44,60 & 10,60 & 23,77 & 3,80 \\
\cline { 2 - 7 } & & 5 & 82,75 & 17,25 & 20,85 & 6,77 \\
\hline \multirow{4}{*}{ Ararapira } & 10 & 0 & 25,90 & 7,10 & 27,41 & 1,62 \\
\cline { 2 - 7 } & & 5 & 26,10 & 7,50 & 27,74 & 1,30 \\
\cline { 2 - 7 } & 11 & 0 & 37,75 & 7,62 & 20,20 & 14,75 \\
\cline { 2 - 7 } & 12 & 5 & 41,00 & 9,75 & 23,78 & 10,00 \\
\cline { 2 - 7 } & & 5 & 68,44 & 17,11 & 25,00 & 23,40 \\
\hline
\end{tabular}

Chiozzini et al. (2008) obtiveram valores de concentração de nitrato na região de Cananéia de 0,14 a $0,31 \mu \mathrm{mol} \mathrm{L} \mathrm{L}^{-1}$, no inverno de 2005 , e de 0,05 a $1,93 \mu \mathrm{mol} \mathrm{L}{ }^{-1}$, no verão de 2006. Braga (1995) com o Valo Grande fechado, observou valores de nitrato em 1992 na região de Cananéia, variando de 1,07 a 7,69 $\mu \mathrm{mol} \mathrm{L}^{-1}$ no verão, e de 0,05 a 1,46 $\mu$ mol $\mathrm{L}^{-1}$ no inverno. Braga \& Chiozzini (2008) observaram teores de $\mathrm{N}$-nitrato, no estuário de Cananéia em 2005, de 0,47 a 4,37 $\mu \mathrm{mol} \mathrm{L}^{-1}$ no verão, e de 0,12 a $0,32 \mu \mathrm{mol} \mathrm{L} \mathrm{L}^{-1}$ no inverno.

Com relação aos teores de P-fosfato, N-nitrato e N-amônio em função da salinidade, na região de Cananéia (Fig. 16), observa-se que próximo à salinidade 21, o fosfato esteve entre $1,76 \mu \mathrm{mol} \mathrm{L}-1$ e $2,06 \mu \mathrm{mol} \mathrm{L}^{-1}$; o nitrato esteve entre $0,46 \mu \mathrm{mol} \mathrm{L}^{-1} \mathrm{e}$ 0,57 $\mu$ mol L $\mathrm{L}^{-1}$ e o amônio entre $3,30 \mu \mathrm{mol} \mathrm{L}^{-1}$ e $4,12 \mu \mathrm{mol} \mathrm{L}^{-1}$. Com o aumento da salinidade, em torno de 23, o teor de P-fosfato diminui chegando ao menor valor de 1,31 $\mu$ mol L $\mathrm{L}^{-1}$ quando a salinidade atingiu 27 na profundidade de $5 \mathrm{~m}$ (estação 9). O nitrato manteve valores baixos e estáveis entre salinidade de 21 e 23, no entanto, observou-se um valor maior que $4 \mu \mathrm{mol} \mathrm{L} \mathrm{L}^{-1}$ que está associado à estação $9(5 \mathrm{~m})$. O amônio apresentou valores maiores que $3 \mu \mathrm{mol} \mathrm{L} \mathrm{L}^{-1}$ em todos os pontos analisados neste setor, com um máximo de 4,40 $\mu \mathrm{mol} \mathrm{L}{ }^{-1}$, associado à estação $9(5 \mathrm{~m})$. 


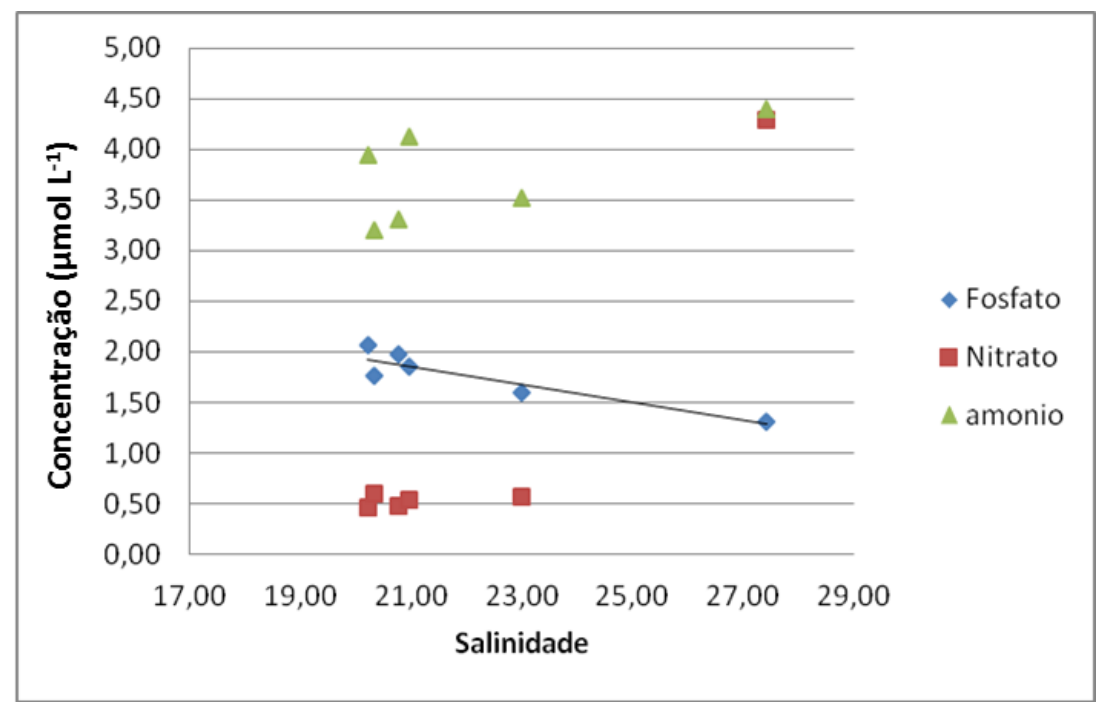

Figura 16. P-fosfato, N-nitrato e N-amônio versus Salinidade. Cananéia, agosto de 2012.

Na região do Canal do Ararapira, onde a salinidade variou de 28 (água salobra) a 33 (água salina) (Fig. 17), o P-fosfato mostrou valores de $0,25 \mu \mathrm{mol} \mathrm{L} \mathrm{L}^{-1}$ a $0,44 \mu \mathrm{mol} \mathrm{L} \mathrm{L}^{-1}$. $\mathrm{O}$ nitrato variou de 0,26 a $0,67 \mu \mathrm{mol} \mathrm{L} \mathrm{L}^{-1}$. O N-amônio apresentou valores entre 0,72 e

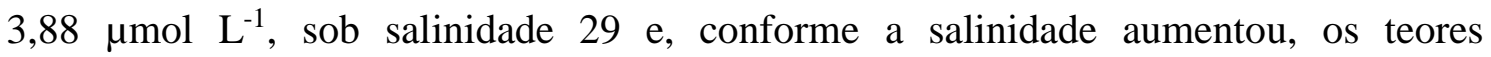
decresceram obtendo-se o mínimo valor de $0,72 \mu \mathrm{mol} \mathrm{L}^{-1}$ na estação 17 , profundidade $5 \mathrm{~m}$.

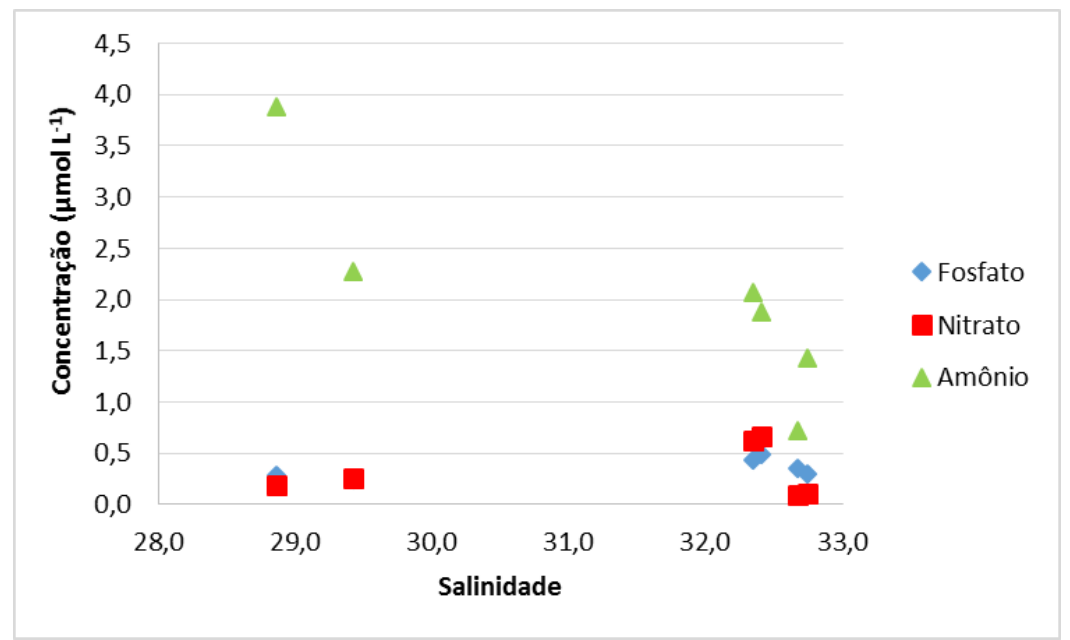

Figura 17.P- fosfato, N-nitrato e N- Amônio versus Salinidade. Ararapira, agosto 2012.

A Campanha de Agosto de 2012 (Tab. 13), apresentou temperaturas que variaram entre $20,5^{\circ} \mathrm{C}$ e $26,0^{\circ} \mathrm{C}$ no sistema, a salinidade esteve próxima a zero no setor Norte, porção final do Rio Ribeira e Canal do Valo Grande, que estão sob influência da água fluvial. A salinidade aumenta em direção ao setor sul, o setor intermediário apresentou salinidade igual a 14, mostrando assim um valor de água salobra. Em Cananéia a salinidade chegou a aproximadamente 27,5 e na porção do Ararapira foram observados 
valores maiores que 30, ou seja, de água salina. O pH também aumentou com a salinidade, mostrando o valor mínimo de 6,23 em água doce e 8,63 em água salina. O oxigênio dissolvido mostrou-se praticamente homogêneo ao longo de todo o sistema, exceto no setor Iguape, especificamente na estação 2, onde foi verificado um valor muito baixo indicando episódio de hipoxia. O material em suspensão mostrou um incremento crescente em direção ao setor sul, com o valor mínimo de 4,20 mg L $\mathrm{L}^{-1}$ no Valo Grande e com os maiores valores encontrados em Cananéia com 82,75 $\mathrm{mg} \mathrm{L}^{-1}$. A porcentagem de matéria orgânica mostrou-se maior na porção Norte do sistema, apresentando seu maior teor de $38,10 \%$ no Valo Grande e $36,4 \%$ no Rio Ribeira, que por sua vez apresentou o maior valor de turbidez encontrado em todo o sistema, com 41,3 ntu e, o valor mínimo encontrado foi de 1,30 ntu, no setor de Ararapira.

Tabela 13. Quadro sinóptico da situação do sistema Rio-Valo Grande-Iguape-CananéiaArarapira (SP), em Agosto de 2012.

\begin{tabular}{|c|c|c|c|c|c|c|}
\hline Agosto-2012 & Rio Ribeira & Valo Grande & Iguape & Inter. & Cananéia & Ararapira \\
\hline $\mathbf{T}\left({ }^{\circ} \mathbf{C}\right)$ & $21,1-21,3$ & $20,75-21,23$ & $21,40-24,00$ & 26,00 & $21,20-22,18$ & $20,25-20,50$ \\
\hline Salinidade & $0,03-0,04$ & $0,03-0,04$ & $0,14-6,73$ & $13,21-13,93$ & $20,21-27,43$ & $28,87-32,75$ \\
\hline pH & $6,83-6,96$ & $6,23-6,93$ & $7,01-7,86$ & $7,65-8,00$ & $8,04-8,35$ & $8,10-8,63$ \\
\hline $\mathrm{OD}\left(\mathrm{mL} \mathrm{L}^{-1}\right)$ & $5,54-5,74$ & $4,84-5,72$ & $1,14-5,40$ & $4,19-5,60$ & $4,70-5,62$ & $4,28-5,36$ \\
\hline MES (mg L L $\left.{ }^{-1}\right)$ & $4,83-7,17$ & $4,20-12,00$ & $25,33-39,00$ & $38,00-42,67$ & $33,80-82,75$ & $25,90-68,44$ \\
\hline $\operatorname{MO}\left(\mathrm{mg} \mathrm{L}^{-1}\right)$ & $1,00-2,00$ & $1,33-2,80$ & $2,00-9,00$ & $9,00-11,33$ & $9,20-7,25$ & $7,10-17,11$ \\
\hline$\% \mathrm{MO}$ & $14,0-36,4$ & $18,60-38,10$ & $17,07-25,00$ & $23,68-26,56$ & $20,85-27,34$ & $19,58-27,74$ \\
\hline Turbidez (ntu) & $40,40-41,90$ & $11,70-17,40$ & $12,90-60,60$ & $3,19-3,29$ & $3,50-6,77$ & $1,30-23,40$ \\
\hline $\mathrm{N}$-am. $\left(\mu \mathrm{mol}-\mathrm{L}^{-1}\right)$ & $1,71-2,55$ & $2,49-3,45$ & $1,82-4,73$ & $0,05-1,73$ & $3,20-4,40$ & $0,72-3,88$ \\
\hline $\begin{array}{c}\mathrm{N}^{-\mathrm{NO}_{2}^{-}}{ }^{-}\left(\mu \mathrm{mol}-\mathrm{L}^{-}\right. \\
\end{array}$ & $0,09-0,11$ & $0,10-0,11$ & $0,10-0,11$ & 0,16 & $0,11-0,27$ & $0,05-0,23$ \\
\hline $\begin{array}{c}\mathrm{N}-\mathrm{NO}_{3}{ }^{-}\left(\mu \mathrm{mol}-\mathrm{L}^{-}\right. \\
{ }_{1}^{-}\end{array}$ & $9,97-10,37$ & $10,26-10,47$ & $7,87-10,17$ & nd & $0,46-4,29$ & $0,09-0,67$ \\
\hline NID $\left(\mu \mathrm{mol}-\mathrm{L}^{-1}\right)$ & $9,97-10,37$ & $12,99-14,06$ & $11,76-14,23$ & 2,05 & $3,91-8,71$ & $0,86-4,14$ \\
\hline 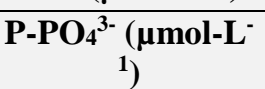 & $11,81-13,02$ & $7,68-12,06$ & $6,92-9,08$ & $3,15-3,41$ & $1,31-2,06$ & $0,25-0,49$ \\
\hline NID/P-PO 4 & $0,60-1,83$ & $1,08-1,77$ & $1,08-1,83$ & 0,60 & $1,98-6,79$ & $2,46-14,78$ \\
\hline
\end{tabular}

Quanto aos nutrientes nitrogenados, o $\mathrm{N}$-amoniacal mostrou seus maiores teores em Iguape com 4,73 $\mu \mathrm{mol} \mathrm{L}{ }^{-1}$ e em Cananéia com 4,40 $\mu$ mol L ${ }^{-1}$. O N-nitrito mostrou seu maior valor em Cananéia com $0,27 \mu \mathrm{mol} \mathrm{L}^{-1}$. O N-nitrato apresentou os maiores teores no setor Norte, os maiores teores registrados foram de $10,47 \mu \mathrm{mol} \mathrm{L}^{-1}$, no Valo Grande, e de $10,37 \mu \mathrm{mol} \mathrm{L} \mathrm{L}^{-1}$ no Rio Ribeira, tais teores diminuem drasticamente no setor Sul, mostrando valores de $0,46 \mu \mathrm{mol} \mathrm{L} \mathrm{L}^{-1}$ em Cananéia e teor de $0,09 \mu \mathrm{mol} \mathrm{L} \mathrm{L}^{-1}$ em Ararapira. O P-fosfato também apresentou um alto teor encontrado no Setor Norte, com teor de fosfato maior que o teor de nitrato, registrando $13,02 \mu \mathrm{mol} \mathrm{L}^{-1}$ de P-fosfato na porção do 
Rio Ribeira. Este nutriente também decresce no sentido Sul. A relação NID/P-PO 4 de maior valor encontrado foi em Ararapira, com 14,78.

\subsubsection{Verão - Fevereiro 2013}

A curva de maré apresentou vales e picos bem definidos com feições de sizígia (Fig. 18), sendo que os pontos de amostragem 1, 2, 3, 5, 11 e 12 estiveram em condição de enchente, os pontos R2, R3, R6, 4A, 4, 7, 8 e 10 em vazante, R1 e 9 em estofa de maré alta e 6 em estofa de maré baixa.

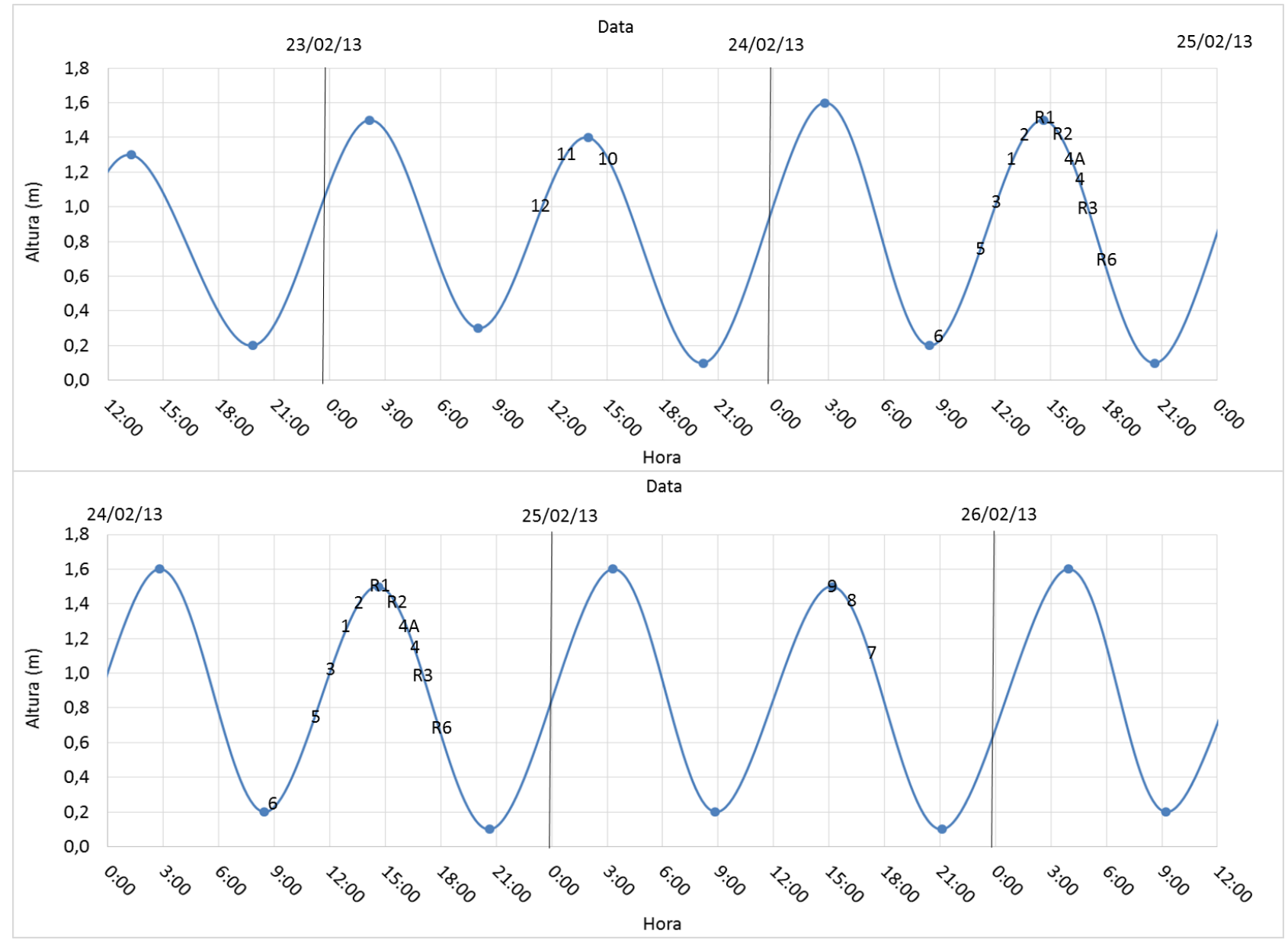

Figura 18. Curvas de maré construídas com dados do LABDADOS-IOUSP nos dias 23, 24 e 25de Fevereiro de 2013, destacando os momentos de realização das estações na região de Cananéia e Iguape (SP).

\subsubsection{Rio Ribeira de Iguape}

Os valores de temperatura, salinidade, $\mathrm{pH}$, oxigênio dissolvido, $\mathrm{N}$-amoniacal, Nnitrito, N-nitrato, nitrogênio inorgânico dissolvido (NID), P-fosfato e a relação NID/P$\mathrm{PO}_{4}{ }^{-3}$ obtidos na amostragem de fevereiro de 2013 encontram-se na tabela 14.

O valor de temperatura foi maior na estação Rio 2. De um modo geral, a salinidade foi baixa $(<0,04)$. Os valores de OD foram menores que no inverno, provavelmente 
devido à presença de uma carga maior de matéria orgânica sendo decomposta no período, de modo que também houve maiores valores de $\mathrm{N}$-amoniacal. O N-nitrito apresentou valores baixos similares ao inverno e o $\mathrm{N}$-nitrato continuou alto sendo ainda um pouco maior, quando comparados à Campanha anterior. De um modo geral, a disponibilidade de $\mathrm{N}$-inorgânico aumentou no verão nas amostras de rio.

Tabela 14. Dados hidrológicos e hidroquímicos (0m) das águas a jusante do Rio Ribeira de Iguape, Fevereiro de 2013.

\begin{tabular}{|c|c|c|c|c|c|c|c|c|c|c|c|c|}
\hline $\begin{array}{l}\text { Fev. } \\
2013\end{array}$ & Est. & $\begin{array}{c}\text { Prof. } \\
\text { (m) }\end{array}$ & $\begin{array}{c}\text { Temp. } \\
\left({ }^{\circ} \mathrm{C}\right)\end{array}$ & Salin. & pH & $\underset{\left(\mathbf{m l ~ L} \mathbf{L}^{-1}\right)}{\text { OD }}$ & $\begin{array}{l}\mathrm{N} \text { - amon. } \\
\left(\mu \mathrm{mol} \mathrm{L} \mathbf{L}^{-1}\right)\end{array}$ & $\begin{array}{c}\text { N-NO }{ }_{2}^{-} \\
\left.(\mu \mathrm{mol} \mathrm{L})^{-}\right)^{1}\end{array}$ & 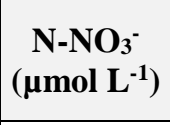 & $\underset{\left(\mu \mathrm{mol} \mathrm{L} \mathbf{L}^{-1}\right)}{\operatorname{NID}}$ & $\begin{array}{c}\mathbf{P}_{-} \mathbf{P O}_{4}{ }^{3} \\
(\mu \mathrm{mol} \mathrm{L})^{-1}\end{array}$ & $\begin{array}{c}\mathrm{NID} / \\
\mathrm{P}- \\
\mathrm{PO}_{4}{ }^{3}\end{array}$ \\
\hline \multirow{5}{*}{$\begin{array}{c}\text { Rio } \\
\text { Ribeira } \\
\text { de } \\
\text { Iguape }\end{array}$} & R1 & 0 & 27,3 & 03 & 6,80 & 4,16 & 3,35 & 0,10 & 12,65 & 16,10 & 5,60 & 2,87 \\
\hline & $\mathrm{R} 2$ & 0 & 28,6 & 0,02 & 6,88 & 4,11 & 2,41 & 0,13 & 12,63 & 15,17 & 5,78 & 2,62 \\
\hline & R3 & 0 & 27,3 & 0,03 & 6,75 & 4,11 & & 0,0 & nd & nd & 6,45 & nd \\
\hline & R5 & 0 & 27,4 & 0,02 & 6,73 & 4,06 & 2,91 & 0,12 & 12,87 & 15,90 & 5,73 & 2,77 \\
\hline & R6 & 0 & 27,3 & 0,03 & 6,61 & 4,05 & 3,20 & 0,12 & 12,40 & 15,72 & 5,45 & 2,88 \\
\hline
\end{tabular}

A distribuição da temperatura no rio mostrou o valor mais alto no ponto $\mathrm{R} 2 \mathrm{com}$ $28,6^{\circ} \mathrm{C}$, enquanto os valores de salinidade foram maiores nos pontos R1, R3 e R6 (Fig. 19 a e b).

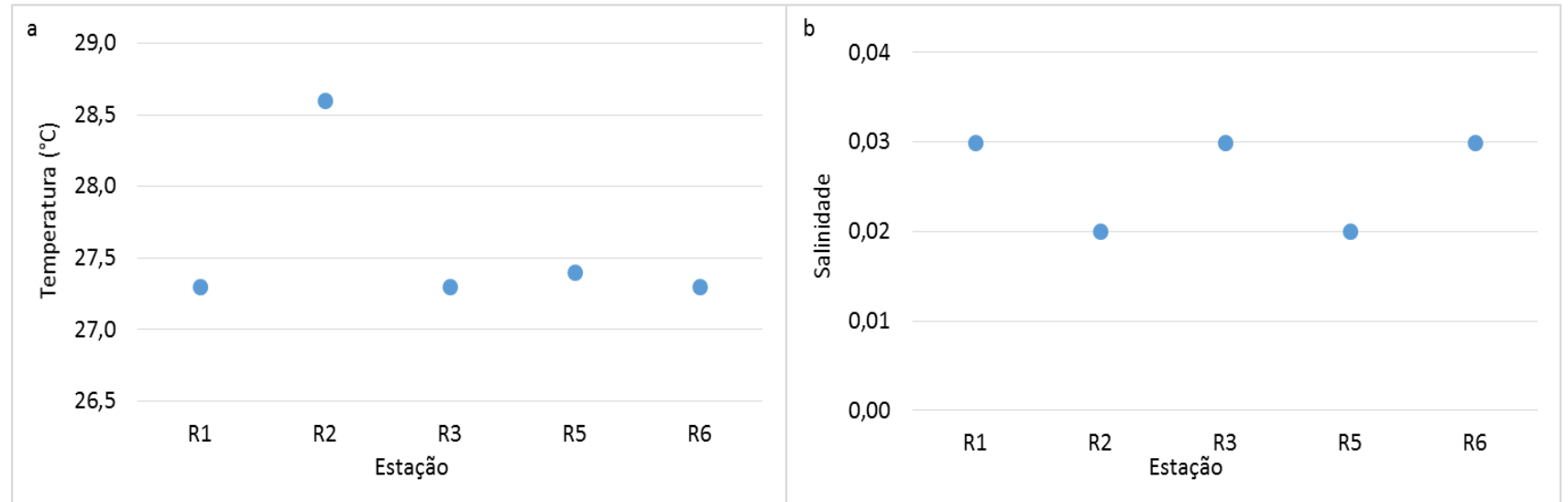

Figura 19. Distribuição espacial da temperatura (a) e salinidade (b) a jusante do Rio Ribeira do Iguape, Fevereiro de 2013.

A distribuição de oxigênio dissolvido mostrou maior valor na estação R1, ponto mais a montante do Rio (Fig. 20a). O maior valor de $\mathrm{pH}$ foi de 6,88 observado no R2 (Fig. 20b). 


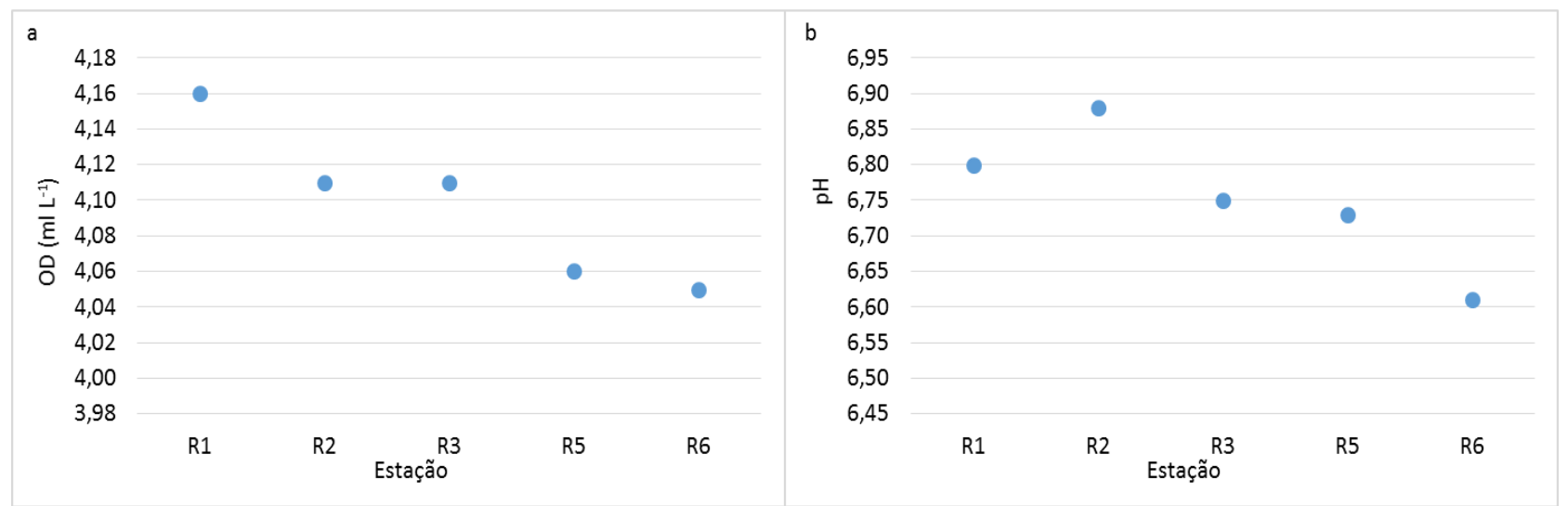

Figura 20. Distribuição espacial de oxigênio dissolvido (a) e pH (b) a jusante do Rio Ribeira de Iguape, Fevereiro de 2013.

Quanto aos nutrientes, o N-amoniacal (Fig. 21a), mostrou o menor valor no R3. Os valores de N- nitrito (Fig. 21b) estiveram todos baixos. Os valores de N-nitrato (Fig. 21c) estiveram bastante altos nas águas amostradas do Rio Ribeira de Iguape. Sem dúvida alguma, a forma de $\mathrm{N}$-nitrato foi a mais significante no rio, também no verão, sendo mais altas do que no inverno anterior. Quanto aos valores de NID, estes foram bem altos, apresentando o valor mínimo de $15,17 \mu \mathrm{mol} \mathrm{L}^{-1}$ na estação $\mathrm{R} 2$ e máximo valor de 16,10 $\mu$ mol L ${ }^{-1}$ no ponto R1, mais montante ao Rio (Fig. 21d).

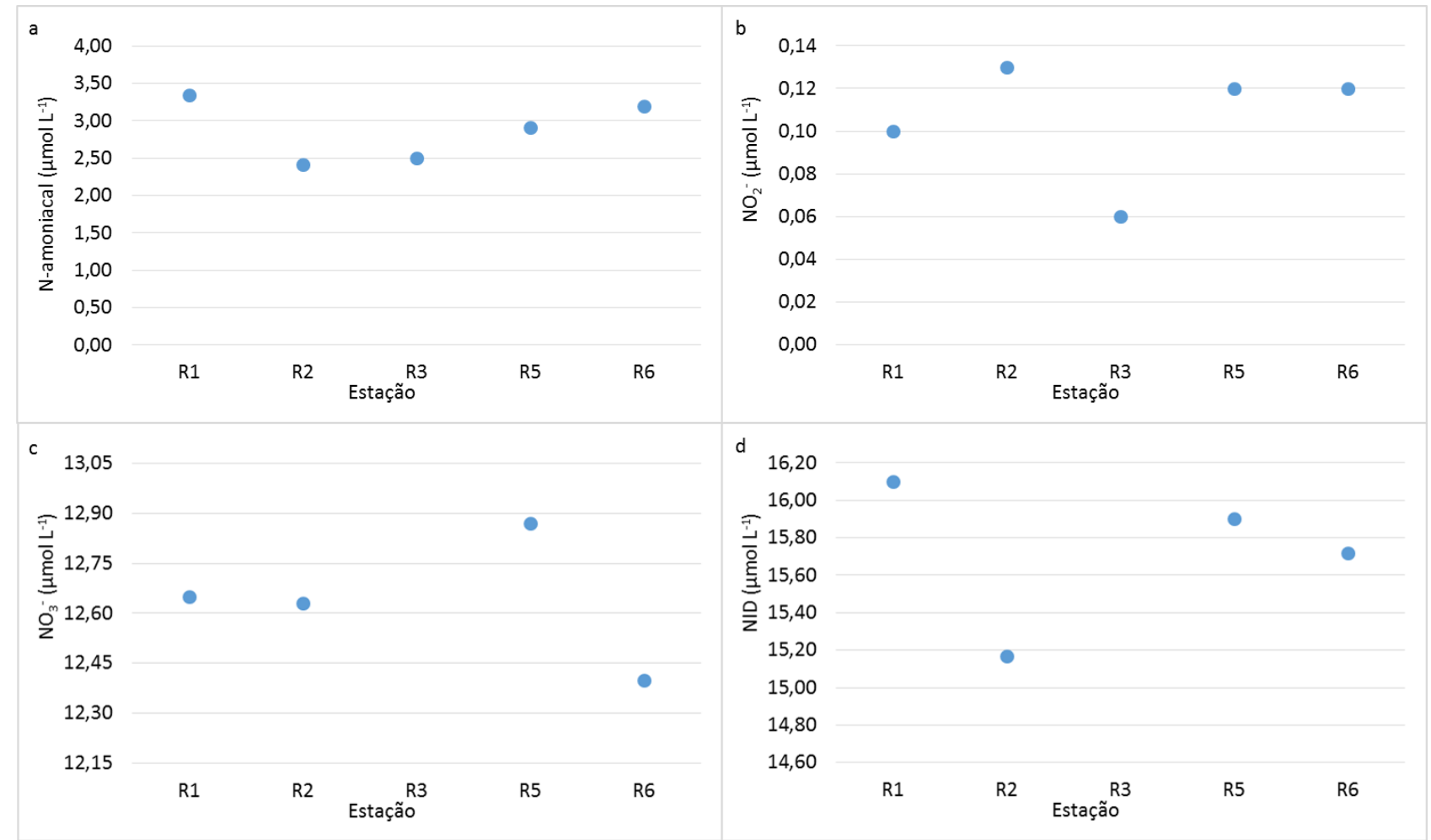

Figura 21. Distribuição espacial de compostos nitrogenados no Rio Ribeira de Iguape, Namoniacal (a), nitrito (b), nitrato (c) e NID (d), Fevereiro 2013. 
Os valores de P-fosfato $\left(\mathrm{PO}_{4}{ }^{3-}\right)$ foram cerca da metade dos valores encontrados na primeira Campanha, revelando a provável continuidade do aporte industrial ao sistema porém com diferença sazonal ou no aporte ou na diluição. $\mathrm{O}$ valor máximo ocorreu no ponto $\mathrm{R} 3$ de $6,45 \mu \mathrm{mol} \mathrm{L} \mathrm{L}^{-1}$ e um valor mínimo de 5,45 $\mu \mathrm{mol} \mathrm{L} \mathrm{L}^{-1}$ no R6 (Fig. 22a). A relação NID/P-PO4 calculada teve maior valor no ponto R6 (Fig. 22b).

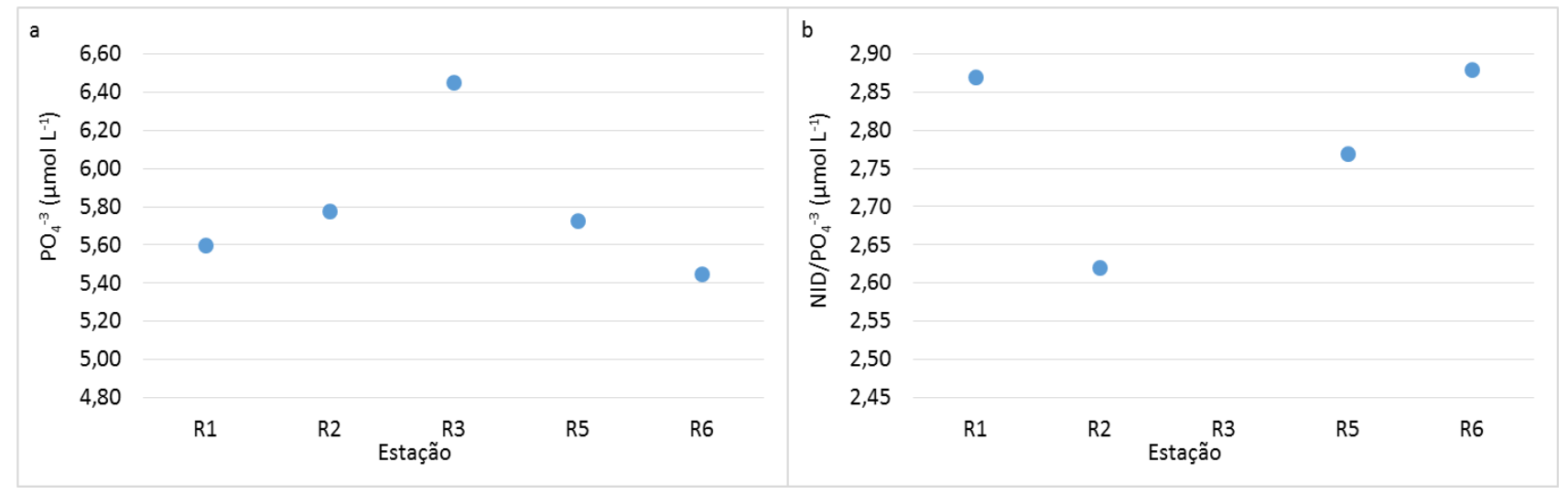

Figura 22. Distribuição espacial dos valores de $\mathrm{PO}_{4}{ }^{3}(\mathrm{a})$ e $\mathrm{NID} / \mathrm{PO}_{4}{ }^{3}$ (b) nos pontos do Rio Ribeira de Iguape, Fevereiro de 2013.

As concentrações de MES (Tab. 15) foram muito maiores neste período do ano, os valores máximos foram observados em R2 e R6 (Fig. 23a), ambos com valores de $155,00 \mathrm{mg} \mathrm{L}^{-1}$, na campanha anterior o maior valor ficou um pouco acima de $7 \mathrm{mg} \mathrm{L}^{-1}$. Os valores de MO também foram maiores nos pontos R2 e R6 com valores de 15,00 mg L $\mathrm{m}^{-1}$ e 14,40 $\mathrm{mg} \mathrm{L}^{-1}$, respectivamente (Fig. 23b). A porcentagem de MO foi maior nos pontos R2 e R3, ambos com 10\% (Fig.23c). O disco de Secchi teve seu maior valor a 0,20m, devido à grande presença de MES.

Tabela 15. Concentrações de material em suspensão, material orgânico em suspensão, porcentagem de material orgânico em suspensão, turbidez e profundidade do disco de Secchi nas águas do Rio Ribeira de Iguape, em Fevereiro de 2013.

\begin{tabular}{|c|c|c|c|c|c|c|c|}
\hline \multirow{2}{*}{$\begin{array}{c}\text { Fev. } \\
\mathbf{2 0 1 3}\end{array}$} & Est. & $\begin{array}{c}\text { Prof. } \\
(\mathbf{m})\end{array}$ & $\begin{array}{c}\text { MES } \\
\left(\mathbf{m g ~ L}^{-\mathbf{1}}\right)\end{array}$ & $\begin{array}{c}\text { MO } \\
\left(\mathbf{m g ~ L}^{-\mathbf{1}}\right)\end{array}$ & $\mathbf{\%} \mathbf{M O}$ & $\begin{array}{c}\text { Turb. } \\
\text { ntu }\end{array}$ & $\begin{array}{c}\text { Disco de } \\
\text { Secchi } \\
(\mathbf{m})\end{array}$ \\
\hline \multirow{2}{*}{$\begin{array}{c}\text { Rio } \\
\text { Ribeira } \\
\text { De }\end{array}$} & R1 & 0 & 127,00 & 11,50 & 9 & $\mathrm{nd}$ & 0,20 \\
\cline { 2 - 8 } Iguape & R2 & 0 & 155,00 & 15,00 & 10 & nd & 0,20 \\
\cline { 2 - 8 } & R3 & 0 & 114,00 & 10,80 & 10 & nd & 0,20 \\
\cline { 2 - 8 } & R5 & 0 & 134,00 & 12,70 & 9 & nd & 0,20 \\
\cline { 2 - 8 } & R6 & 0 & 155,00 & 14,40 & 9 & nd & 0,15 \\
\hline
\end{tabular}




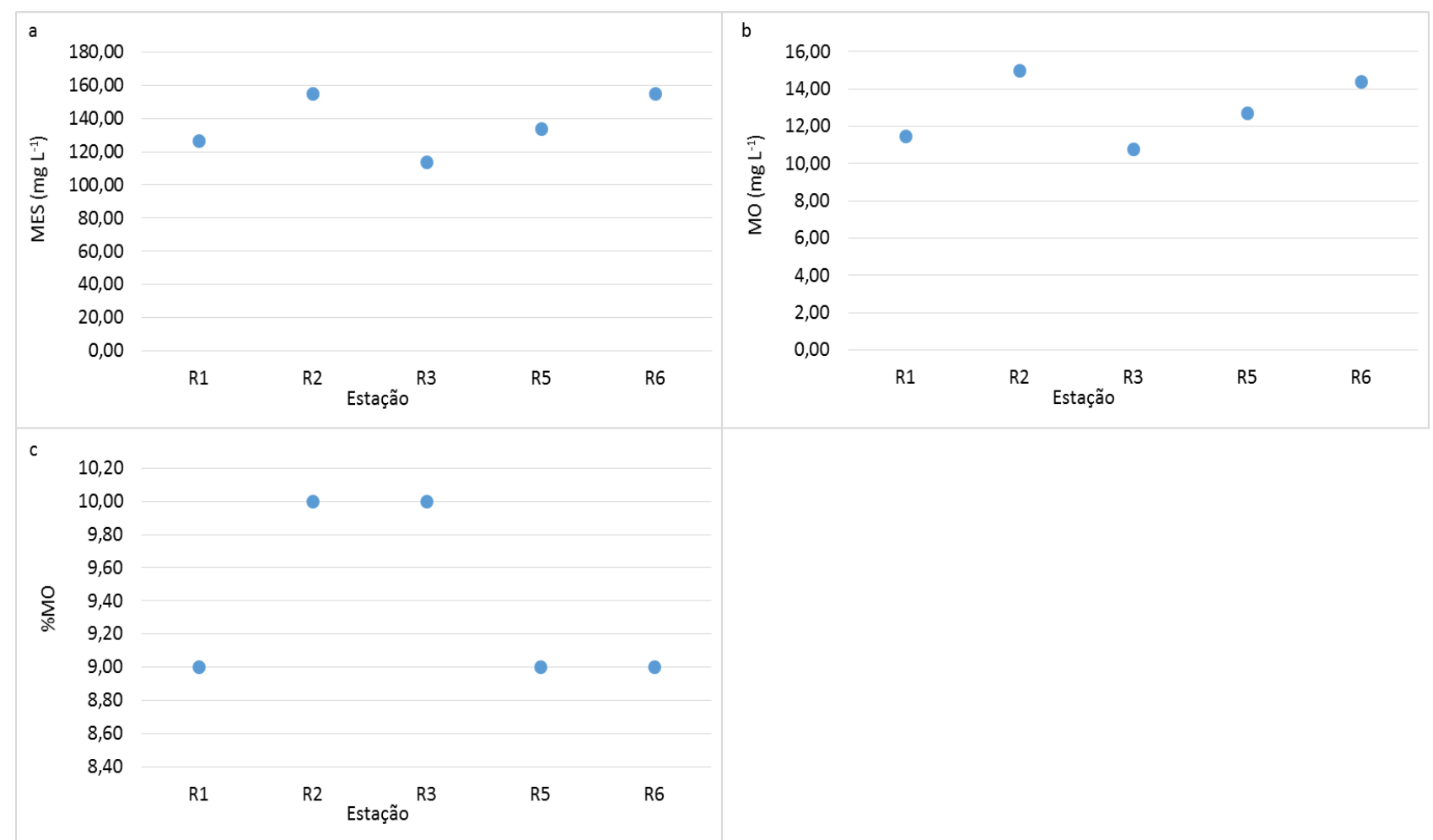

Figura 23. Distribuição espacial dos valores de MES (a), MO (b) e \% de MO (c) no Ribeira de Iguape em fevereiro de 2013.

$\mathrm{Na}$ Campanha de fevereiro de 2013 a relação dos nutrientes em função da salinidade (Fig. 24) mostrou o alto teor de nitrato acima de $12 \mu \mathrm{mol} \mathrm{L}^{-1} \mathrm{o}$ fosfato obteve seu maior teor registrado de $6,45 \mu \mathrm{mol} \mathrm{L}-1$ e todos os demais valores acima de $5 \mu \mathrm{mol} \mathrm{L}-$ 1 , o amônio mostrou-se com teores acima de $2 \mu \mathrm{mol} \mathrm{L} \mathrm{L}^{-1}$ para praticamente todos os pontos analisados. Para a salinidade maior que 0,30 os teores de P-fosfato e N-nitrato tem uma leve queda. Comparados à Campanha anterior os valores de P-fosfato foram bem menores, praticamente a metade dos encontrados na Campanha de agosto de 2012, os teores de $\mathrm{N}$-nitrato estão em média $2 \mu \mathrm{mol} \mathrm{L} \mathrm{L}^{-1}$ maiores que os teores de $\mathrm{N}$-nitrato assinalados na Campanha anterior, o mesmo aconteceu com os teores de amônio, pois na primeira Campanha tais valores não passaram de $2,50 \mu \mathrm{mol} \mathrm{L}{ }^{-1}$. 


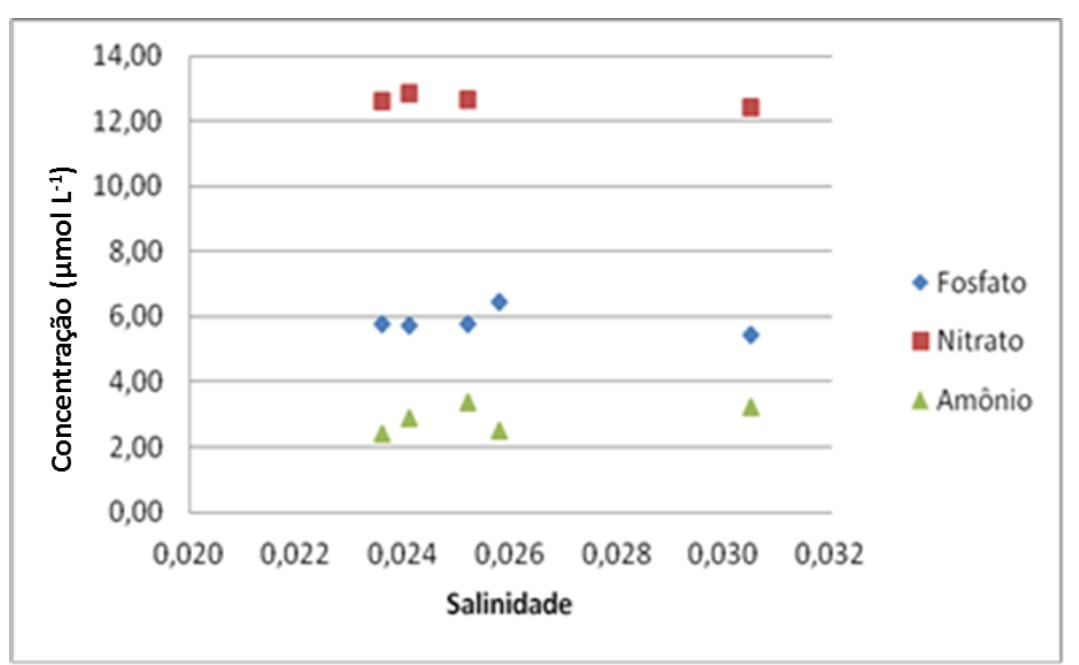

Figura 24. Distribuição de P- Fosfato, N-nitrato e N-amônio versus Salinidade. Rio Ribeira do Iguape, fevereiro de 2013.

\subsubsection{Iguape}

Os valores de temperatura mostraram que as águas de Iguape estavam mais quentes que a Campanha anterior, $3^{\circ} \mathrm{C}$ (em média), a estação próxima à Barra de Icapara (1) apresentou o maior valor de temperatura encontrado, o que foi acompanhado também pelos maiores valores de salinidade e $\mathrm{pH}$ (Tab. 16).

A região de Iguape, estações de 1 a 5 (Tab.16) apresentou valores relativamente baixos de OD no norte do sistema, aumentando na região do Valo Grande e diminuindo em direção a Cananéia. A região intermediária apresentou os maiores valores de Namoniacal. Os valores das estações 4 e 4A representam valores do Canal do Valo Grande e a estação 6, já está junto ao início da Ilha de Cananéia, ou seja na porção intermediária do sistema (Tab. 16). Os valores de N-nitrato foram altos, diminuindo apenas na estação intermediária, onde os valores de $\mathrm{N}$-amoniacal foram mais representativos que os de nitrato. Em relação aos valores de P-fosfato (Tab.16), eles estiveram mais altos nos pontos localizados no Canal do Valo Grande e diminuíram em direção à barra do Icapara (est. 1) e também em direção à estação 6 , ao sul do sistema. A relação $\mathrm{NID} / \mathrm{PO}_{4}{ }^{3-}$ foi maior no ponto $2(0 \mathrm{~m})$ no setor Iguape e no ponto 5 , tendo o seu mínimo na estação intermediária 6. 
Tabela 16. Valores de temperatura, salinidade, oxigênio dissolvido, $\mathrm{pH}, \mathrm{N}$-amoniacal, $\mathrm{N}$ - nitrito, $\mathrm{N}$-nitrato, nitrogênio inorgânico dissolvido, P-fosfato e relação NID/P-fosfato no norte do sistema, incluindo o Valo Grande (estações 4 e 4A) e a estação intermediária (6), em fevereiro de 2013.

\begin{tabular}{|c|c|c|c|c|c|c|c|c|c|c|c|c|}
\hline $\begin{array}{l}\text { Fev. } \\
2013 \\
\end{array}$ & Est. & $\begin{array}{c}\text { Prof. } \\
(\mathbf{m})\end{array}$ & $\begin{array}{c}\text { Temp. } \\
\left({ }^{\circ} \mathrm{C}\right)\end{array}$ & Salin. & pH & $\begin{array}{c}\text { OD } \\
\left(\mathbf{m l ~ L}^{-1}\right)\end{array}$ & $\left.\begin{array}{c}\mathrm{N}-\mathrm{am} . \\
(\mu \mathrm{mol} \mathrm{L} \\
-1\end{array}\right)$ & 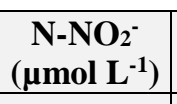 & $\begin{array}{c}\text { N-NO }{ }^{-} \\
\left(\mu \mathrm{mol} \mathrm{L}{ }^{-1}\right)\end{array}$ & $\begin{array}{c}\text { NID } \\
\left(\mu \mathrm{mol} \mathrm{L}^{-1}\right) \\
\end{array}$ & $\begin{array}{c}\text { P-PO4 }{ }^{3-} \\
\left(\mu \mathrm{mol} \mathrm{L}^{-1}\right)\end{array}$ & $\begin{array}{c}\mathrm{NID} / \\
{\mathrm{P}-\mathrm{PO}_{4}}^{3-}\end{array}$ \\
\hline \multirow{10}{*}{ Iguape } & 1 & 0 & 28,90 & 20,59 & 8,05 & 3,34 & 3,92 & 0,16 & 4,45 & 8,53 & 1,88 & 4,5 \\
\hline & 2 & 0 & 29,50 & 0,54 & 7,08 & 3,98 & 4,12 & 0,14 & 11,20 & 15,46 & 3,26 & 4,7 \\
\hline & 3 & 0 & 27,77 & 1,61 & 6,76 & 3,93 & 3,55 & 0,12 & 11,45 & 15,12 & 3,79 & 4,0 \\
\hline & & 5 & 27,50 & 0,07 & 6,72 & 3,90 & 3,54 & 0,13 & 11,44 & 15,11 & 3,81 & 4,0 \\
\hline & 4 & 0 & 27,18 & 0,23 & 6,92 & 4,19 & 2,68 & 0,09 & 10,77 & 13,54 & 5,41 & 2,5 \\
\hline & & 5 & 27,18 & 0,03 & 6,97 & 4,13 & 2,56 & 0,09 & 11,10 & 13,66 & 5,15 & 2,7 \\
\hline & $4 \mathrm{~A}$ & 0 & 27,20 & 0,03 & 6,77 & 4,14 & 2,56 & 0,09 & 10,54 & 13,19 & 5,13 & 2,6 \\
\hline & & 5 & 27,10 & 0,03 & 6,68 & 4,14 & 2,53 & 0,13 & 10,73 & 13,39 & 5,16 & 2,6 \\
\hline & 5 & 0 & 27,17 & 0,04 & 6,76 & 3,74 & 4,02 & 0,12 & 10,50 & 14,64 & 3,17 & 4,6 \\
\hline & & 5 & 27,10 & 0,04 & 6,70 & 3,70 & 3,87 & 0,09 & 11,25 & 15,21 & 3,44 & 4,4 \\
\hline \multirow{2}{*}{ Interm. } & 6 & 0 & 27,50 & 4,26 & 7,03 & 4,04 & 5,08 & 0,20 & 3,51 & 8,79 & 3,63 & 2,4 \\
\hline & & 5 & 27,87 & 3,94 & 7,11 & 3,78 & 4,91 & 0,10 & 3,51 & 8,60 & 3,44 & 2,5 \\
\hline
\end{tabular}

No que se refere ao MES, os maiores valores foram encontrados nas estações $2 \mathrm{e}$

3. Esta foi a Campanha que apresentou o maior valor de MES, quando comparado às demais Campanhas e, as estações com maiores valores de turbidez foram a 3 (135 ntu 0m) e a 5 (164 ntu - 5m). O setor intermediário (est. 6) apresentou a maior \%MO. De um modo geral, a turbidez diminui sensivelmente na estação intermediária (Tab.17).

Tabela 17. Concentrações de material em suspensão, material orgânico em suspensão, porcentagem de material orgânico em suspensão e turbidez, nas águas Cananéia e Ararapira, em Agosto de 2012.

\begin{tabular}{|c|c|c|c|c|c|c|}
\hline $\begin{array}{c}\text { Fev. } \\
\mathbf{2 0 1 3}\end{array}$ & Est. & $\begin{array}{c}\text { Prof. } \\
(\mathbf{m})\end{array}$ & $\begin{array}{c}\text { MES } \\
\left(\mathbf{m g ~ L}^{-\mathbf{1}}\right)\end{array}$ & $\begin{array}{c}\text { MO } \\
\left(\mathbf{m g ~ L}^{-\mathbf{1}}\right)\end{array}$ & $\mathbf{\%} \mathbf{M O}$ & $\begin{array}{c}\text { Turb. } \\
(\mathbf{n t u})\end{array}$ \\
\hline \multirow{7}{*}{ Iguape } & 1 & 0 & 64,25 & 21,10 & 33 & nd \\
\cline { 2 - 7 } & 2 & 0 & 133,33 & 17,80 & 13 & nd \\
\cline { 2 - 7 } & 3 & 0 & 111,43 & 15,10 & 14 & 135,0 \\
\cline { 2 - 7 } & & 5 & 112,78 & 18,80 & 17 & 134,0 \\
\cline { 2 - 7 } & 4 & 0 & 85,00 & 7,70 & 9 & 73,8 \\
\cline { 2 - 7 } & $4 \mathrm{~A}$ & 0 & 82,00 & 8,10 & 10 & 74,1 \\
\cline { 2 - 7 } & 4 & 5 & 72,00 & 6,60 & 9 & 73,9 \\
\cline { 2 - 7 } & 5 & 0 & 109,00 & 20,40 & 19 & 133,0 \\
\cline { 2 - 7 } & & 5 & 187,27 & 19,60 & 10 & 164,0 \\
\hline \multirow{4}{*}{ Interm. } & 6 & 0 & 38,57 & 12,20 & 32 & 11,75 \\
\cline { 2 - 7 } & & 5 & 42,50 & 14,30 & 34 & 21,75 \\
\hline
\end{tabular}

Na região de Iguape os nutrientes tendem a mostrar altos valores sob influência da água fluvial, quando a salinidade é próxima à zero, mantendo assim as concentrações em coformidade aos teores encontrados nos pontos do Rio desta mesma Campanha. A 
medida que a salinidade aumenta, em torno da salinidade 5, os valores dos teores de Pfosfato e $\mathrm{N}$-nitrato ficam abaixo de $4 \mu \mathrm{mol} \mathrm{L}^{-1}$, os teores de $\mathrm{N}$-nitrato se mantiveram mais estáveis mesmo sob influência de uma salinidade maior. Na salinidade 20,59 o teor de fosfato encontrado foi de $1,88 \mu \mathrm{mol} \mathrm{L}{ }^{-1}$ e o de N-nitrato de $4,45 \mu \mathrm{mol} \mathrm{L}^{-1}$ (Fig. 25).

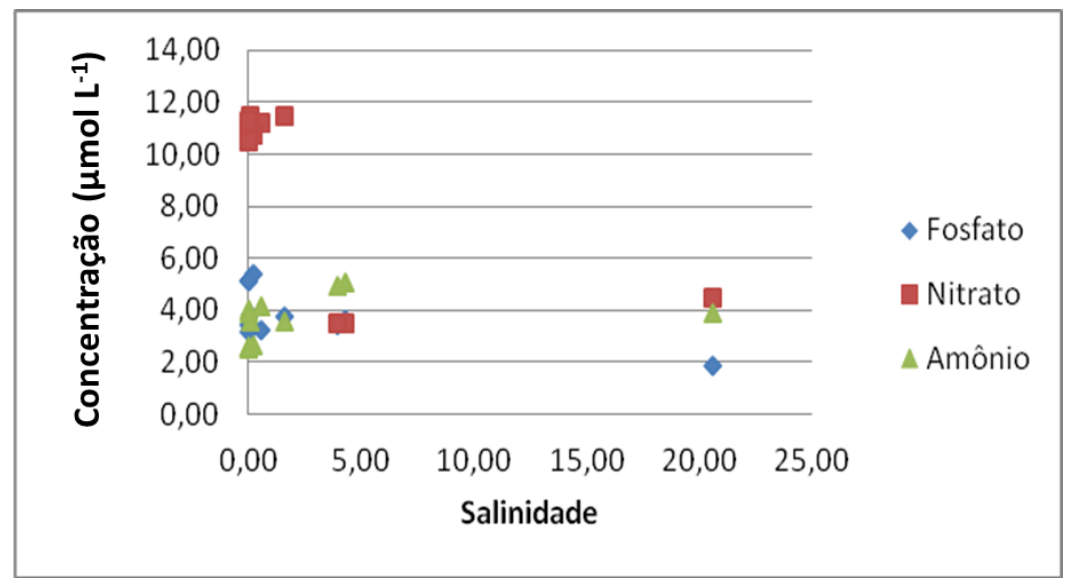

Figura 25. Distribuição de P-fosfato, N-nitrato e N-Amônio versus Salinidade. Iguape, Fevereiro de 2013.

\subsubsection{Cananéia-Ararapira}

Os valores das propriedades hidrológicas e hidroquímicas de Cananéia-Ararapira se encontram na tabela 18. Pode-se notar que os valores de temperatura estiveram menores no setor de Ararapira, mais ao sul do Complexo. Os valores de salinidade estiveram todos na casa da categoria de águas salobras em Cananéia e atingiram valores superiores a 30 no Canal do Ararapira. Os valores de $\mathrm{pH}$ variaram entre 7,36 e 8,43 e os maiores valores de OD foram encontrados junto à Barra do Ararapira, no fundo da estação 12.

Tabela 18. Valores de temperatura, salinidade, oxigênio dissolvido, $\mathrm{pH}, \mathrm{N}$-amoniacal, $\mathrm{N}$ - nitrito, $\mathrm{N}$-nitrato e nitrogênio inorgânico dissolvido, em Cananéia e Ararapira, sul do sistema, em Fevereiro de 2013.

\begin{tabular}{|c|c|c|c|c|c|c|c|c|c|c|c|c|}
\hline $\begin{array}{l}\text { Fev. } \\
2013 \\
\end{array}$ & Est. & $\begin{array}{l}\text { Prof. } \\
\text { (m) }\end{array}$ & $\begin{array}{c}\text { Temp. } \\
\left({ }^{\circ} \mathbf{C}\right)\end{array}$ & Salin. & pH & $\begin{array}{c}\text { OD } \\
\left(\mathrm{ml} \mathrm{L}^{-1}\right)\end{array}$ & $\begin{array}{c}\mathrm{N} \text {-am } \\
\left.(\mu \mathrm{mol} \mathrm{L})^{-1}\right)\end{array}$ & $\left.\begin{array}{c}\mathrm{N}_{-} \mathrm{NO}_{2}^{-} \\
(\mu \mathrm{mol} \mathrm{L} \\
-1\end{array}\right)$ & $\begin{array}{c}\mathrm{N}_{-\mathrm{NO}_{3}}^{-} \\
(\mu \mathrm{mol} \mathrm{L}\end{array}$ & $\begin{array}{c}\text { NID } \\
\left.(\mu \mathrm{mol} \mathrm{L})^{-1}\right)\end{array}$ & $\begin{array}{c}\left.{\mathrm{P}-\mathrm{PO}_{4}{ }^{3-}}_{(\mu \mathrm{mol} \mathrm{L}}^{-1}\right) \\
(\end{array}$ & \begin{tabular}{|c|}
$\mathrm{NID} /$ \\
$\mathrm{P}_{-}-\mathrm{PO}_{4}{ }^{3-}$ \\
\end{tabular} \\
\hline \multirow{6}{*}{ Cananéia } & 7 & 0 & 28,55 & 23,88 & 8,14 & 4,79 & 2,11 & 0,21 & 0,50 & 2,82 & 2,06 & 1,36 \\
\hline & & 5 & 28,45 & 26,39 & 8,25 & 4,78 & 1,47 & 0,15 & 0,34 & 1,96 & 1,76 & 1,11 \\
\hline & 8 & 0 & nd & 28,14 & 8,33 & 4,51 & 1,67 & 0,10 & 0,30 & 2,07 & 1,97 & 1,05 \\
\hline & & 5 & nd & 30,12 & 8,38 & 4,74 & 1,46 & 0,05 & 0,40 & 1,91 & 1,88 & 1,01 \\
\hline & 9 & 0 & 28,55 & 30,31 & 8,41 & 4,35 & 1,29 & 0,03 & 0,18 & 1,50 & 1,59 & 0,94 \\
\hline & & 5 & 28,60 & 31,09 & 8,28 & 4,37 & 1,34 & 0,02 & 0,12 & 1,48 & 1,31 & 1,13 \\
\hline \multirow{6}{*}{ Ararapira } & 10 & 0 & 27,53 & 13,91 & 7,36 & 3,34 & 3,87 & 0,05 & 0,66 & 4,58 & 0,28 & 16,35 \\
\hline & & 5 & 27,53 & 14,11 & 7,49 & 3,31 & 5,83 & 0,05 & 0,61 & 6,02 & 0,25 & 24,08 \\
\hline & 11 & 0 & 28,07 & 23,26 & 8,10 & 4,37 & 1,37 & 0,06 & 0,10 & 1,53 & 0,30 & 5,10 \\
\hline & & 5 & 27,95 & 25,00 & 8,12 & 4,39 & 0,96 & 0,06 & 0,06 & 1,12 & 0,35 & 3,20 \\
\hline & 12 & 0 & 27,27 & 31,50 & 8,14 & 4,84 & 0,85 & 0,06 & 0,11 & 0,97 & 0,49 & 1,97 \\
\hline & & 3 & 27,20 & 31,51 & 8,31 & 4,90 & 3,05 & 0,05 & 0,11 & 3,21 & 0,44 & 7,26 \\
\hline
\end{tabular}


As concentrações de P-fosfato no setor sul tiveram valores bem mais baixos que no setor norte, e no Canal do Ararapira apresentou os valores mais baixos (mais naturais). De um modo geral, o MES foi bem menor no setor sul, mas aumentou junto à Barra do Ararapira, em função da hidrodinâmica. A porcentagem de MO sempre esteve com valores entre 20 e 30. A turbidez no Canal do Ararapira é maior que em Cananéia, em especial nos pontos 11 e 12 talvez em função do aporte de material húmico mais intensamente neste setor (Tab.19).

Tabela 19. Valores de material em suspensão, matéria orgânica, porcentagem de matéria orgânica e turbidez, em Cananéia e Ararapira, sul do sistema, em Fevereiro de 2013.

\begin{tabular}{|c|c|c|c|c|c|c|}
\hline Fev. 2013 & Est. & $\begin{array}{c}\text { Prof. } \\
(\mathbf{m})\end{array}$ & $\begin{array}{c}\text { MES } \\
\left(\mathbf{m g ~ L}^{-1}\right)\end{array}$ & $\begin{array}{c}\text { MO } \\
\left(\mathbf{m g ~ L}^{-\mathbf{1}}\right)\end{array}$ & \% MO & $\begin{array}{c}\text { Turb. } \\
(\mathbf{n t u})\end{array}$ \\
\hline \multirow{5}{*}{ Cananéia } & 7 & 0 & 33,80 & 9,20 & 27,27 & 3,50 \\
\cline { 2 - 7 } & & 5 & 45,56 & 12,00 & 27,34 & 4,63 \\
\cline { 2 - 7 } & 8 & 0 & 43,00 & 10,75 & 25,00 & 3,84 \\
\cline { 2 - 7 } & & 5 & 43,20 & 10,20 & 23,61 & 5,30 \\
\cline { 2 - 7 } & 9 & 0 & 44,60 & 10,60 & 23,77 & 3,80 \\
\hline & & 5 & 82,75 & 17,25 & 20,85 & 6,77 \\
\hline \multirow{5}{*}{ Ararapira } & 14 & 0 & 25,90 & 7,10 & 27,41 & 1,62 \\
\cline { 2 - 7 } & & 5 & 26,10 & 7,50 & 28,74 & 1,30 \\
\cline { 2 - 7 } & 17 & 0 & 37,75 & 7,62 & 20,20 & 14,75 \\
\cline { 2 - 7 } & & 5 & 41,00 & 9,75 & 23,78 & 10,00 \\
\cline { 2 - 7 } & 18 & 0 & 68,44 & 17,11 & 25,00 & 23,40 \\
\cline { 2 - 6 } & & 3 & 67,46 & 13,20 & 19,58 & 13,30 \\
\hline
\end{tabular}

De um modo geral, as temperaturas apresentaram valores muito próximos ao longo de todo o sistema. A salinidade aumentou no sentido Sul, caracterizando a porção norte como sob maior influência fluvial e o sul de característica de estuário, o pH esteve abaixo de 7 até o setor de Iguape e, a partir daí encontram-se valores maiores que 7. Os valores de N-nitrato e P-fosfato sofrem diminuição em direção às Barras de Icapara e Ararapira, os maiores valores de MES foram registrados em Iguape, bem como o maior valor para turbidez.

Em Cananéia, na Campanha de fevereiro de 2013, os teores de nutrientes diminuíram em função do aumento da salinidade, o P-fosfato foi o nutriente que teve teores mais altos, com o mínimo de $1,31 \mu \mathrm{mol} \mathrm{L}{ }^{-1}$ em água salina e máximo de 2,06 $\mu$ mol $\mathrm{L}^{-1}$ em água salobra. $\mathrm{O} \mathrm{N}$-nitrato em água salobra apresentou teores em torno de $0,5 \mu \mathrm{mol}$ $\mathrm{L}^{-1}$ que decresce para $0,12 \mu \mathrm{mol} \mathrm{L}-1$ em água salina (salinidade maior que 30) (Fig. 26). 


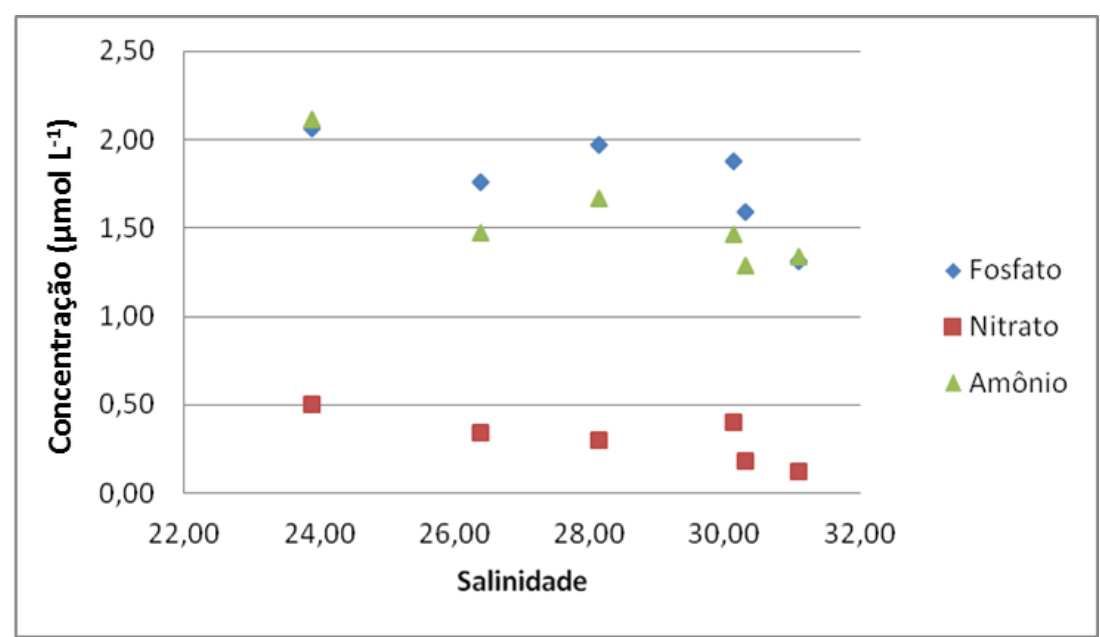

Figura 26. Distribuição de P-fosfato, N-nitrato e N-amônio versus Salinidade. Cananéia, Fevereiro de 2013.

Na região do Ararapira, em fevereiro de 2013 (Fig. 27) os parâmetros nitrogenados, em especial o N-nitrato, diminuem em função do aumento da salinidade. Sob salinidade em torno de 14 o teor de P-fosfato foi de $0,25 \mu \mathrm{mol} \mathrm{L}^{-1}$ e sob salinidade de 31,51 este parâmetro revelou um valor um pouco mais alto de $0,44 \mu \mathrm{mol} \mathrm{L}^{-1}$ (na estação $12,5 \mathrm{~m})$. O amônio diminuiu de forma substancial entre a salinidade 15 e 25 , caindo de $5,83 \mu \mathrm{mol} \mathrm{L}{ }^{-1}$ para $0,96 \mu \mathrm{mol} \mathrm{L}{ }^{-1}$, e em salinidade maior que 30 , apresentou um teor de 3,05 associado ao ponto $12(5 \mathrm{~m})$.

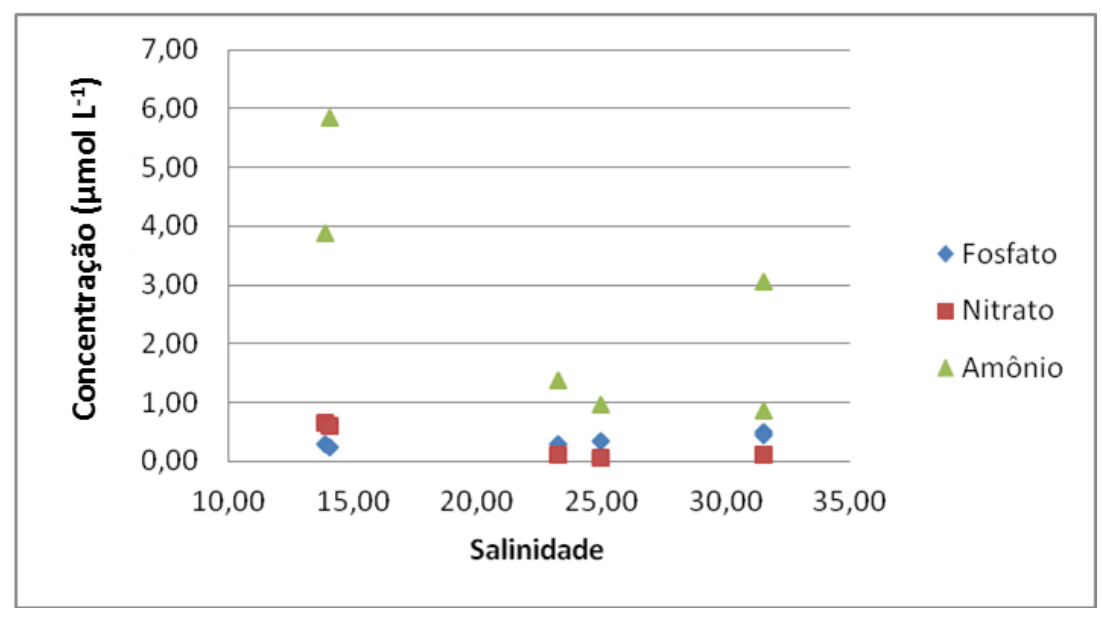

Figura 27. Distribuição de P -Fosfato, N-Nitrato e N-amônio versus Salinidade. Ararapira, Fevereiro de 2013.

$\mathrm{Na}$ Campanha de fevereiro de 2013 (Tab. 20), a temperatura foi de $27,20{ }^{\circ} \mathrm{C}$ a $28,45{ }^{\circ} \mathrm{C}$. A salinidade mostrou-se próxima a zero no setor Norte na porção do Rio Ribeira, no Canal do Vale, na estação 1 de Iguape ela mostra-se salobra pois há influência da entrada de água salina pela Barra de Icapara, a partir da estação intermediária a salinidade cresce em sentido ao setor sul apresentando pontos de água salobra e salina em Cananéia e Ararapira. $\mathrm{O}$ pH aumenta com o aumento da salinidade. O oxigênio dissolvido 
(OD), mostrou-se bem homogêneo ao longo de todo o sistema, com o valor mínimo encontrado de $3,31 \mathrm{ml} \mathrm{L}^{-1}$ e máximo de $4,90 \mathrm{ml} \mathrm{L}^{-1}$ ambos valores registrados em Ararapira. Os maiores teores encontrados de material em suspensão foram na porção do Rio com $155 \mathrm{mg} \mathrm{L}^{-1}$ e o menor valor encontrado foi em Ararapira com $34 \mathrm{mg} \mathrm{L}^{-1}$.O maior valor encontrado de matéria orgânica (MO) foi em Ararapira com 31,90 mg L $\mathrm{m}^{-1}$. A maior porcentagem de matéria orgânica encontrada foi em Cananéia com 60\% de MO. Iguape registrou a maior turbidez com $135 \mathrm{ntu}$.

Quanto aos nutrientes nitrogenados, o maior teor de $\mathrm{N}$-amoniacal foi encontrado na estação intermediária, com 4,91 $\mu \mathrm{mol} \mathrm{L} \mathrm{L}^{-1}$. O N-nitrito apresentou maior teor registrado em Cananéia com 0,21 $\mu \mathrm{mol} \mathrm{L} \mathrm{L}^{-1}$, o N-nitrato, assim como na Campanha anterior, apresentou valores bem altos na porção do Rio, com teor máximo encontrado de 12,87 $\mu \mathrm{mol} \mathrm{L} \mathrm{L}^{-1}$, dimibuindo em direção ao setor sul apresentando teores de $0,66 \mu \mathrm{mol} \mathrm{L}{ }^{-1} \mathrm{em}$ Ararapira. O NID também é maior na porção do Rio $\left(16,10 \mu \mathrm{mol} \mathrm{L}^{-1}\right)$ e decresce em direção à porção Sul apresentando valor mínimo de $0,97 \mu \mathrm{mol} \mathrm{L} \mathrm{L}^{-1}$ em Ararapira. O Pfosfato apresentou um alto teor na porção do Rio, máximo de 6,45, mas com teores bem mais baixos que aos encontrados na Campanha anterior. A relação NID/PO $4^{-3}$ apresentou seu maior valor $(24,1)$ em Ararapira.

Tabela 20. Quadro sinóptico da situação do sistema em Fevereiro de 2013.

\begin{tabular}{|c|c|c|c|c|c|c|}
\hline Fevereiro 2013 & Rio Ribeira & Valo Grande & Iguape & Inter. & Cananéia & Ararapira \\
\hline $\mathbf{T}\left({ }^{\circ} \mathbf{C}\right)$ & $27,30-28,60$ & $27,10-27,20$ & $27,20-29,50$ & $27,37-27,50$ & $28,45-28,60$ & $27,20-27,95$ \\
\hline Salinidade & $0,02-0,03$ & $0,02-0,03$ & $0,02-20,50$ & $3,93-4,29$ & $23,87-31,00$ & $13,91-31,90$ \\
\hline $\mathrm{pH}$ & $6,61-6,88$ & $6,68-6,97$ & $6,74-8,04$ & $7,03-7,09$ & $8,14-8,42$ & $7,36-8,30$ \\
\hline $\mathrm{OD}\left(\mathrm{ml} \mathrm{L}^{-}\right)^{1}$ & $4,04-4,11$ & $4,14-4,64$ & $3,34-4,19$ & $3,78-4,04$ & $4,35-4,79$ & $3,31-4,90$ \\
\hline MES $\left(\mathrm{mg} \mathrm{L}^{-1}\right)$ & $127,00-155,00$ & $72,00-85,00$ & $82,00-139,33$ & $38,57-42,50$ & $44,93-77,20$ & $34,00-66,60$ \\
\hline MO $\left(\mathrm{mg} \mathrm{L}^{-1}\right)$ & $10,80-15,00$ & $6,60-8,10$ & $7,70-21,10$ & $12,20-14,40$ & $27-34,60$ & $16,30-31,90$ \\
\hline$\% \mathrm{MO}$ & $9-10$ & $9-10$ & $9-33$ & $32-34$ & $39-60$ & $44-58$ \\
\hline Turb. (ntu) & nd & $73,5-74,1$ & $73,8-135,0$ & $11,75-21,75$ & $4,41-9,19$ & $5,38-11,1$ \\
\hline $\mathrm{N}$-am. $\left(\mu \mathrm{mol} \mathrm{L}^{-1}\right)$ & $2,41-3,35$ & $2,53-2,68$ & $2,68-4,12$ & $4,91-5,08$ & $1,29-2,11$ & $0,85-5,83$ \\
\hline $\begin{array}{c}\mathrm{N}^{-\mathrm{NO}_{2}}{ }^{-}\left(\mu \mathrm{mol} \mathrm{\textrm {L } ^ { - }}\right. \\
\left.{ }_{1}\right)\end{array}$ & $0,06-0,13$ & $0,09-0,13$ & $0,09-0,16$ & $0,18-0,20$ & $0,02-0,21$ & $0,05-0,06$ \\
\hline $\begin{array}{c}\mathrm{N}^{-\mathrm{NO}_{3}-}{ }^{-}(\mu \mathrm{mol} \mathrm{L} \\
{ }^{-}\end{array}$ & $12,40-12,87$ & $10,54-11,10$ & $4,45-11,10$ & 3,51 & $0,18-0,50$ & $0,06-0,66$ \\
\hline $\left.\operatorname{NID}(\mu \mathrm{mol} \mathrm{L})^{-1}\right)$ & $15,72-16,10$ & $13,39-13,54$ & $8,53-15,43$ & $8,60-8,79$ & $1,48-2,82$ & $0,97-4,58$ \\
\hline $\begin{array}{c}\mathrm{P}_{-} \mathrm{PO}_{4}^{3-}\left(\mu \mathrm{mol} \mathrm{L}{ }^{-}\right. \\
{ }_{1}^{-}\end{array}$ & $5,73-6,45$ & $5,13-5,41$ & $1,88-5,41$ & $3,44-3,64$ & $0,50-0,88$ & $0,46-2,51$ \\
\hline $\mathrm{NID} / \mathrm{P}-\mathrm{PO}_{4}{ }^{3-}$ & $2,6-2,9$ & $2,5-2,7$ & $4,0-4,7$ & $2,4-2,5$ & $0,9-1,4$ & $2,0-24,1$ \\
\hline
\end{tabular}




\subsubsection{Inverno - Setembro 2013}

A curva de maré apresentou uma situação de transição entre as fases de quadratura e sizígia (Fig. 28), sendo que os pontos de amostragem 5, 8, 9 e 12 estiveram em condição de enchente, os pontos 1, 2, 3, 4 e 10 em vazante, R1 a R6, 4A, 6 e 11 em estofa de maré alta e 7 em estofa de maré baixa.

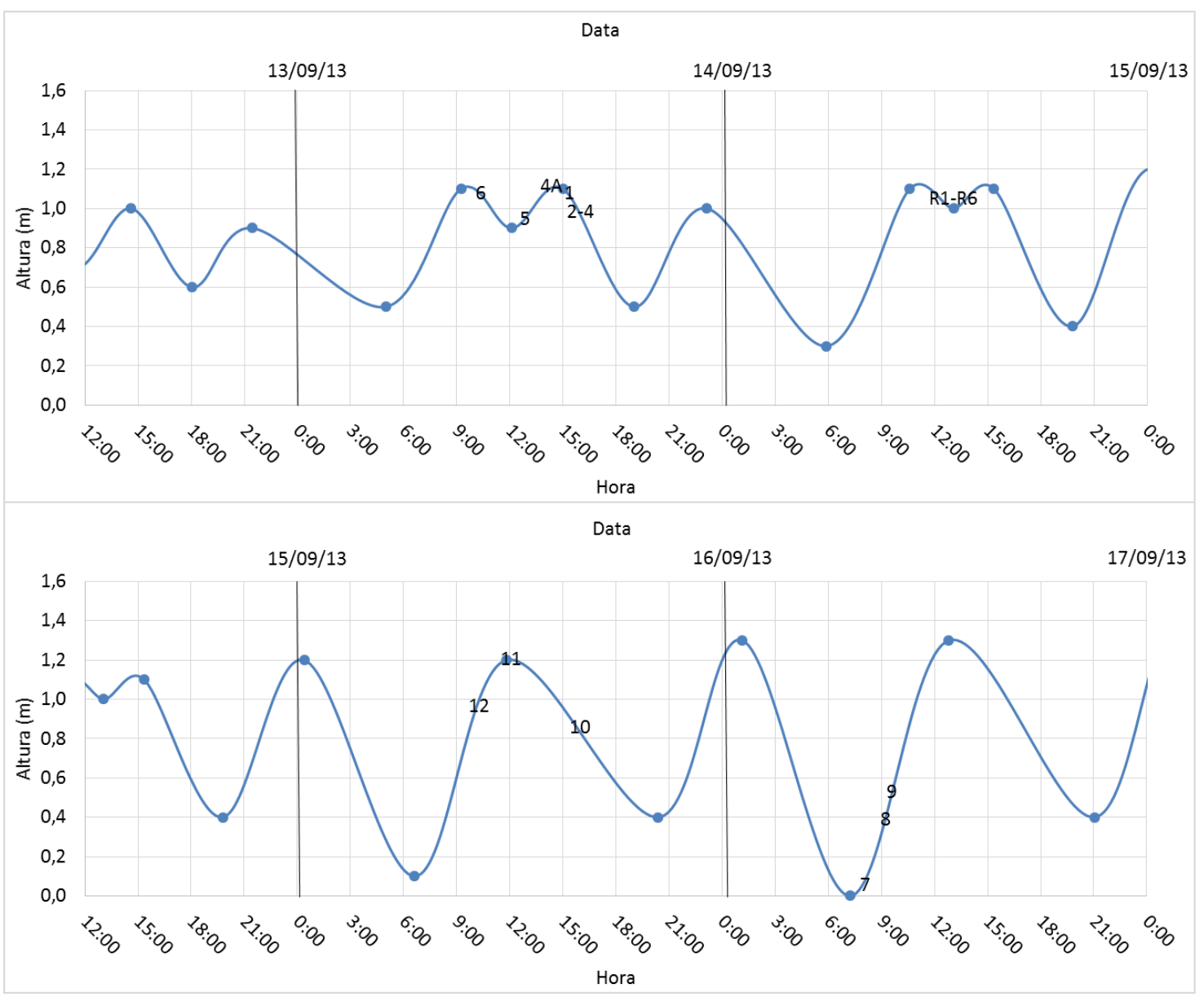

Figura 28. Curvas de maré construídas com dados do LABDADOS-IOUSP nos dias 13, 14, 15 e 16 de Setembro de 2013, destacando os momentos de realização das estações na região de Cananéia e Iguape (SP).

\subsubsection{Rio Ribeira de Iguape}

Os valores de temperatura, salinidade, $\mathrm{pH}$, oxigênio dissolvido, $\mathrm{N}$-amoniacal, $\mathrm{N}$ nitrito, N-nitrato e NID obtidos na amostragem de Setembro de 2013 encontram-se na tabela 21. 
Tabela 21. Dados hidrológicos e hidroquímicos (0m) das águas a jusante do Rio Ribeira de Iguape, Setembro 2013.

\begin{tabular}{|c|c|c|c|c|c|c|c|c|c|c|c|c|}
\hline $\begin{array}{l}\text { Set. } \\
2013\end{array}$ & Est. & $\begin{array}{l}\text { Prof. } \\
\text { (m) }\end{array}$ & $\begin{array}{l}\text { Temp. } \\
\left({ }^{\circ} \mathbf{C}\right)\end{array}$ & Salin. & pH & $\begin{array}{c}\mathbf{O D} \\
\left(\mathrm{mL} \mathrm{L} \mathrm{L}^{-1}\right)\end{array}$ & $\begin{array}{c}\text { N-am. } \\
\left(\mu \mathrm{mol} \mathrm{L} \mathbf{L}^{-1}\right)\end{array}$ & $\begin{array}{c}\mathrm{N}^{\mathrm{N} \mathrm{NO}_{2}^{-}} \\
\left(\mu \mathrm{mol} \mathrm{L}^{-1}\right)\end{array}$ & $\begin{array}{c}\mathrm{N}-\mathrm{NO}_{3}^{-} \\
\left(\mu \mathrm{mol} \mathrm{L} \mathbf{L}^{-1}\right)\end{array}$ & $\begin{array}{c}\text { NID } \\
\left(\mu \mathrm{mol} \mathrm{L}^{-1}\right)\end{array}$ & $\begin{array}{c}\text { P-PO } 4^{3-} \\
\left.(\mu \mathrm{mol} \mathrm{L})^{-1}\right)\end{array}$ & \begin{tabular}{|l}
$\mathrm{NID/} /$ \\
$\mathrm{PO}_{4}{ }^{3-}$
\end{tabular} \\
\hline \multirow{6}{*}{$\begin{array}{c}\text { Rio } \\
\text { Ribeira } \\
\text { De } \\
\text { Iguape }\end{array}$} & R1 & 0 & 24,20 & 0,04 & 7,82 & 5,98 & 0,75 & 0,23 & 14,17 & 15,15 & 6,22 & 2,43 \\
\hline & R2 & 0 & 25,10 & 0,04 & 7,21 & 5,91 & 0,96 & 0,22 & 13,88 & 15,06 & 6,26 & 2,41 \\
\hline & R3 & 0 & 23,60 & 0,04 & 7,62 & 5,71 & 2,3 & 0,23 & 14,17 & 16,70 & 5,82 & 2,87 \\
\hline & R4 & 0 & 23,50 & 0,04 & 7,25 & 5,82 & 1,31 & 0,23 & 14,62 & 16,16 & 5,96 & 2,71 \\
\hline & R5 & 0 & 23,50 & 0,04 & 7,19 & 5,87 & 0,81 & 0,25 & 15,72 & 16,78 & 6,11 & 2,75 \\
\hline & R6 & 0 & 23,60 & 0,04 & 7,28 & 5,90 & 1,31 & 0,23 & 14,62 & 16,16 & 5,73 & 2,82 \\
\hline
\end{tabular}

Os valores de temperatura variaram entre $23,50^{\circ} \mathrm{C}$ e $25,10^{\circ} \mathrm{C}$ (Fig. 29a), com os maiores valores nas estações mais a montante do rio. Os valores de salinidade foram todos próximos a zero $(0,04)$ nas estações R1 a R6 (Fig. 29b).

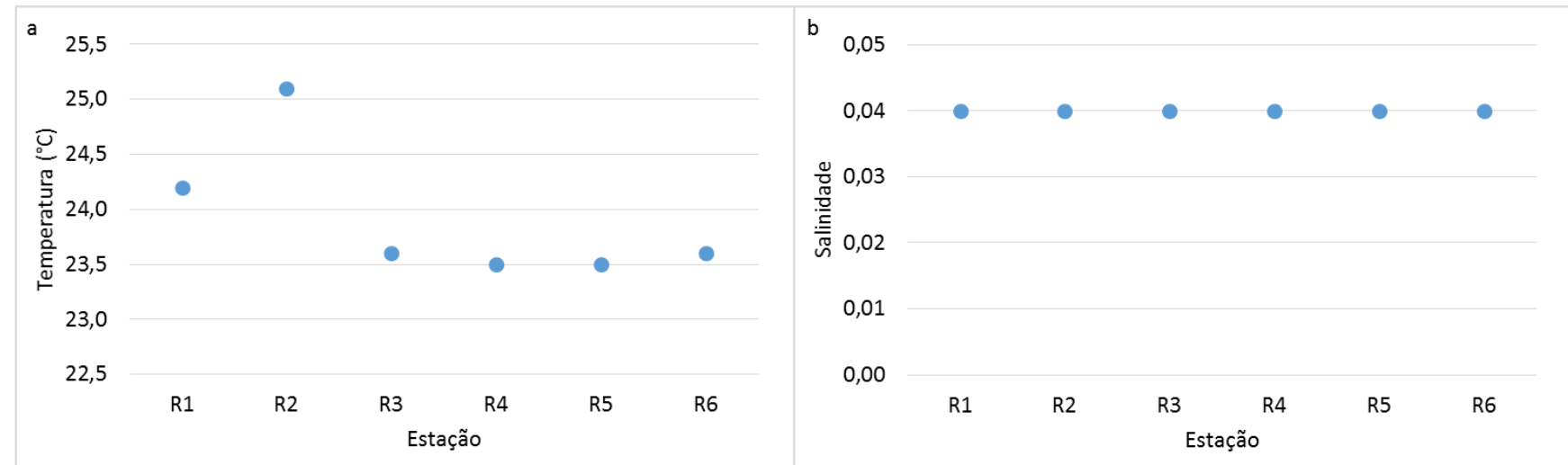

Figura 29. Distribuição espacial de temperatura (a) e salinidade a jusante do Rio Ribeira de Iguape, Setembro de 2013.

Os valores de oxigênio dissolvido (OD) variaram entre 5,71 e 5,90 $\mathrm{ml} \mathrm{L}^{-1}$ (Fig 30a), mostrando valores maiores que na Campanha anterior, enquanto os valores de $\mathrm{pH}$ (Fig. 30b) estiveram entre 7,19 na estação R5 e 7,82 na estação R1, mais montante ao Rio, que também apresentou o maior valor de OD. Todos os valores de $\mathrm{pH}$ estiveram abaixo de 8,00.

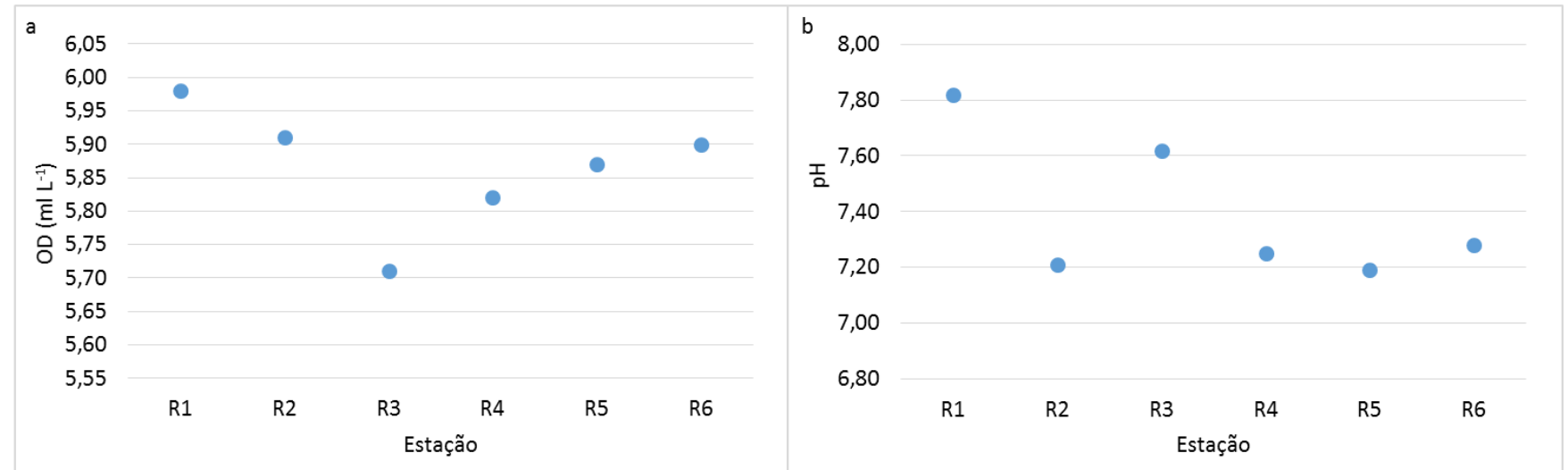

Figura 30. Distribuição espacial de oxigênio dissolvido (a) e pH (b) a jusante do Rio Ribeira de Iguape, Setembro de 2013. 
Em relação aos nutrientes nitrogenados, os valores de $\mathrm{N}$-amoniacal $\left(\mu \mathrm{mol} \mathrm{L} \mathrm{L}^{-1}\right)$ estiveram entre $0,75 \mu \mathrm{mol} \mathrm{L}{ }^{-1}$ na estação R1 e 1,31 $\mu \mathrm{mol} \mathrm{L}{ }^{-1}$ nas estações R4 e R6 (Fig. 31a). Os valores de $\mathrm{N}^{-\mathrm{NO}_{2}}{ }^{-}$tiveram mínima variação entre 0,22 e $0,25 \mu \mathrm{mol} \mathrm{L}{ }^{-1}$, com o

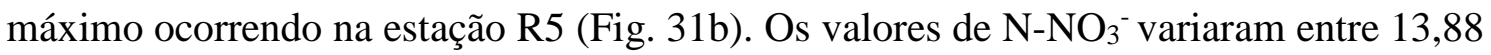
$\mu \mathrm{mol} \mathrm{L} \mathrm{L}^{-1}$ na R2 e 15,72 $\mu \mathrm{mol} \mathrm{L} \mathrm{L}^{-1}$ também na R5 (Fig. 31c), que deve estar associado a excesso de fertilizantes. O maior valor de NID foi constatado no R5, por ser a estação com maior valor dos parâmetros nitrogenados, em especial o $\mathrm{N}$ - nitrato e o N- nitrito (Fig. 31d). Os valores NID foram bem altos, apresentando o valor mínimo de 15,06 $\mu$ mol L-1 na estação R2 e máximo valor de $16,78 \mu \mathrm{mol} \mathrm{L}^{-1}$ na estação $\mathrm{R} 5$, estes valores foram maiores que as duas campanhas anteriores.

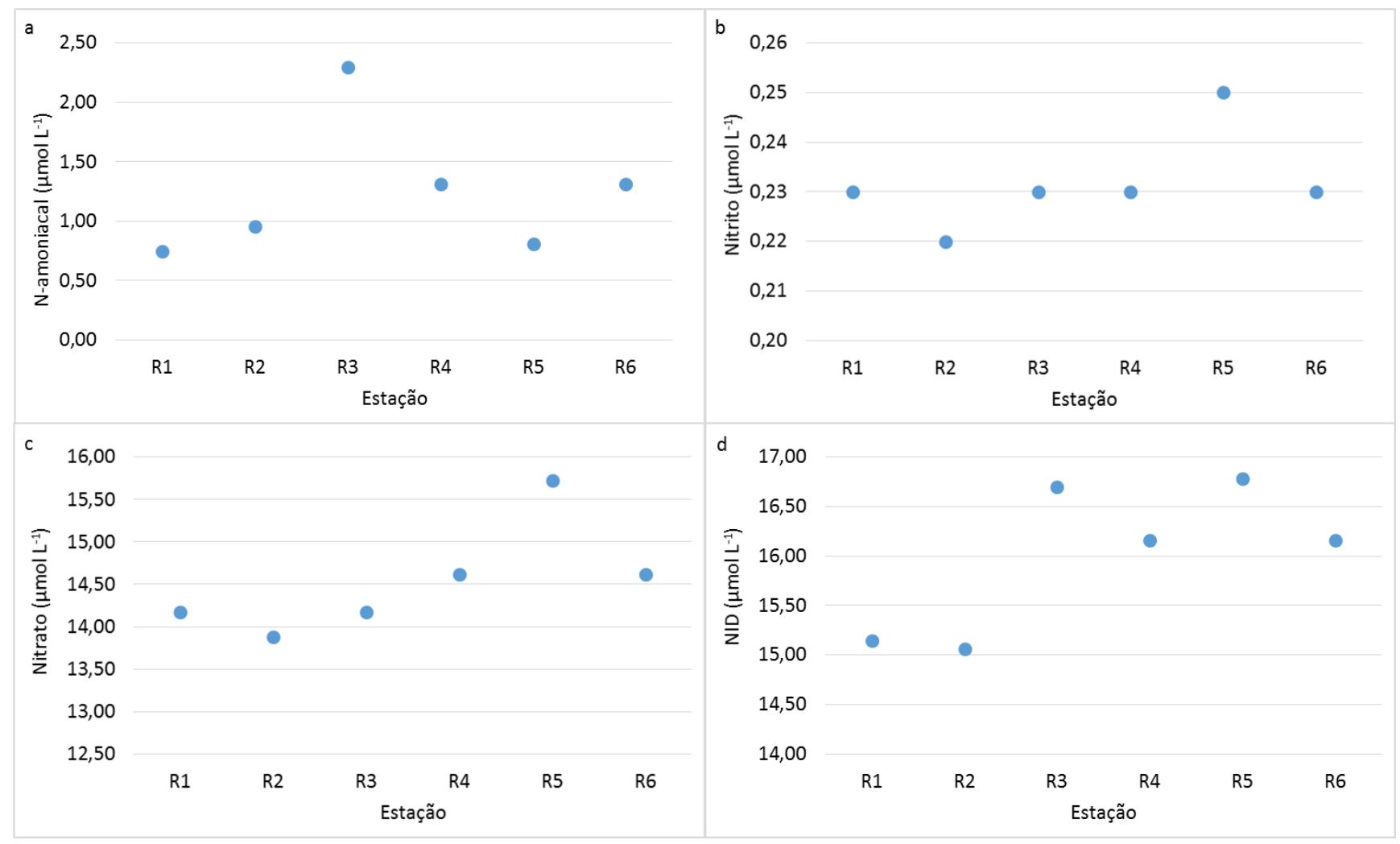

Figura 31. Distribuição espacial de compostos nitrogenados no Rio, N-amoniacal (a), nitrito (b), nitrato (c) e NID (d), Setembro de 2013.

Os valores de P-fosfato $\left(\mathrm{PO}_{4}{ }^{3-}\right)$, com um mínimo de 5,73 $\mu \mathrm{mol} \mathrm{L}^{-1}$ em R6 e máximo de 6,26 $\mu \mathrm{mol} \mathrm{L}^{-1}$ no ponto R2 (Fig. 32a), foram bem semelhantes aos encontrados na Campanha anterior e relativamente a metade dos valores encontrados na primeira Campanha. De toda forma, também revelaram provável aporte do sistema industrial. A relação NID/PO ${ }_{4}{ }^{3}$ teve os maiores valores encontrados no ponto $\mathrm{R} 3$, com um valor de 2,87 $\mu \mathrm{mol} \mathrm{L}{ }^{-1}$ (ponto do Rio que bifurca em direção à Barra do Icapara e ao Canal), e no 
ponto R6 (sentido ao Canal do Valo Grande), com o valor de 2,82 $\mu \mathrm{mol} \mathrm{L}{ }^{-1}$, mostrando assim o alto e crescente valor de NID desta Campanha (Fig. 32b).

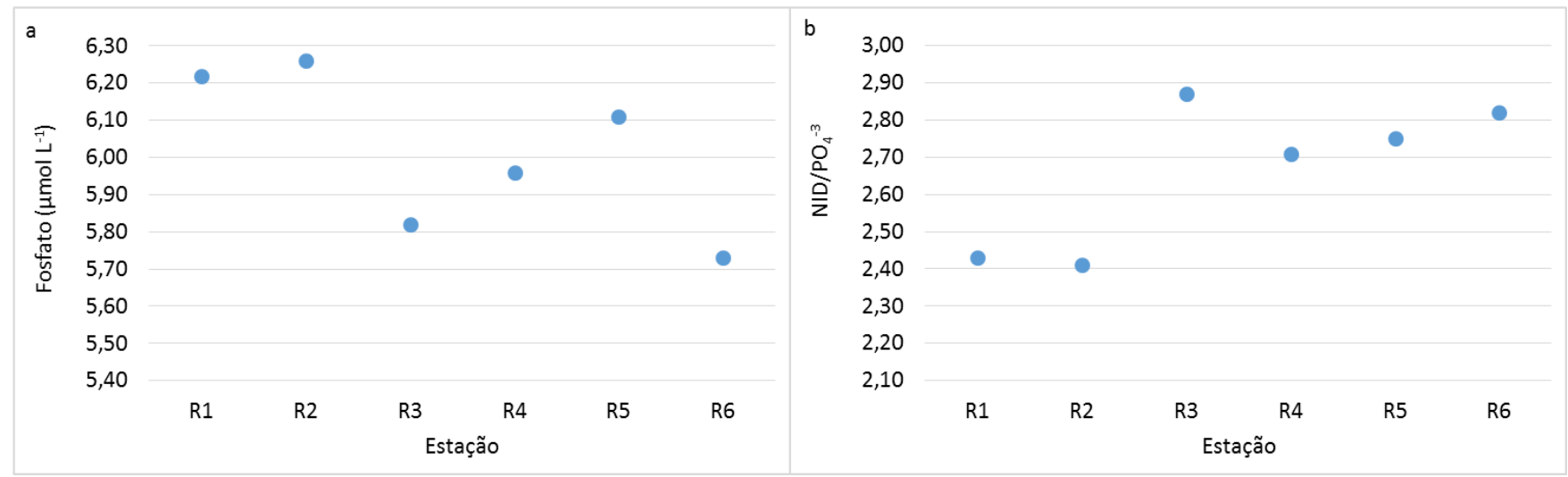

Figura 32. Distribuição espacial do fosfato (a) e da relação NID/PO ${ }_{4}^{-3}$ (b). Setembro de 2013.

Os valores de material em suspensão, material orgânico, porcentagem de material orgânico, turbidez e profundidade do disco de Secchi encontram-se na tabela 22.

Tabela 22. Valores de material em suspensão, matéria orgânica, porcentagem de MO, turbidez e profundidade do disco de Secchi das águas a jusante do Rio Ribeira de Iguape, Setembro 2013.

\begin{tabular}{|c|c|c|c|c|c|c|c|}
\hline $\begin{array}{c}\text { Set. } \\
\mathbf{2 0 1 3}\end{array}$ & Est. & $\begin{array}{c}\text { Prof. } \\
(\mathbf{m})\end{array}$ & $\begin{array}{c}\text { MES } \\
\left(\mathbf{m g ~ L}^{-\mathbf{1}}\right)\end{array}$ & $\begin{array}{c}\text { MO } \\
\left(\mathbf{m g ~ L}^{-\mathbf{1}}\right)\end{array}$ & \%MO & $\begin{array}{c}\text { Turb. } \\
(\mathbf{n t u})\end{array}$ & $\begin{array}{c}\text { Disco de } \\
\text { Secchi } \\
(\mathbf{m})\end{array}$ \\
\hline \multirow{4}{*}{$\begin{array}{c}\text { Rio } \\
\text { Ribeira } \\
\text { de }\end{array}$} & $\mathrm{R} 1$ & 0 & 6,80 & 3,20 & 47,06 & 9,96 & 1,0 \\
\cline { 2 - 8 } Iguape & $\mathrm{R} 2$ & 0 & 5,64 & 3,27 & 58,06 & 8,00 & 1,0 \\
\cline { 2 - 8 } & $\mathrm{R} 3$ & 0 & 10,14 & 3,71 & 36,62 & 7,04 & 1,1 \\
\cline { 2 - 8 } & $\mathrm{R} 4$ & 0 & 5,71 & 3,00 & 52,50 & 5,78 & 1,2 \\
\cline { 2 - 8 } & $\mathrm{R} 5$ & 0 & 5,43 & 2,71 & 50,00 & 5,26 & 1,5 \\
\hline
\end{tabular}

Os valores de material em suspensão (Fig. 31a) foram moderados e bem semelhantes aos encontrados na primeira Campanha, com o valor mínimo de 5,43 mg L${ }^{1}$ em R5 e máximo valor encontrado na R3 de 10,14 $\mathrm{mg} \mathrm{L}^{-1}$, revelando o aporte de material em suspensão fino pelo Rio.

A quantidade de matéria orgânica também mostrou valores bem próximos aos encontrados na primeira Campanha com um mínimo de 2,67 $\mathrm{mg} \mathrm{L}^{-1}$ em R6 e de 3,71 mg $\mathrm{L}^{-1}$ em R3, ponto intermediário em relação aos pontos que divergem para a Barra do Icapara (R4, R5) e a estação R6 que vai em direção ao Canal do Valo Grande (Fig. 31b). A porcentagem de material orgânico apresentou valor mínimo de 37,21 \% encontrado em R6 e máximo valor encontrado em R2 de 58,06\% (Fig. 31c), revelando a presença de matéria orgânica, que pode estar contribuindo com formas de $\mathrm{N}$-amoniacal ao sistema. 
A turbidez revelou valores baixos, menores que os valores encontrados na primeira Campanha, com um valor mínimo de 4,94 ntu (R6) e 9,96 ntu (R1) que corroboram com a boa entrada de luz no sistema, como mostra os valores de visualização do Disco de Secchi.

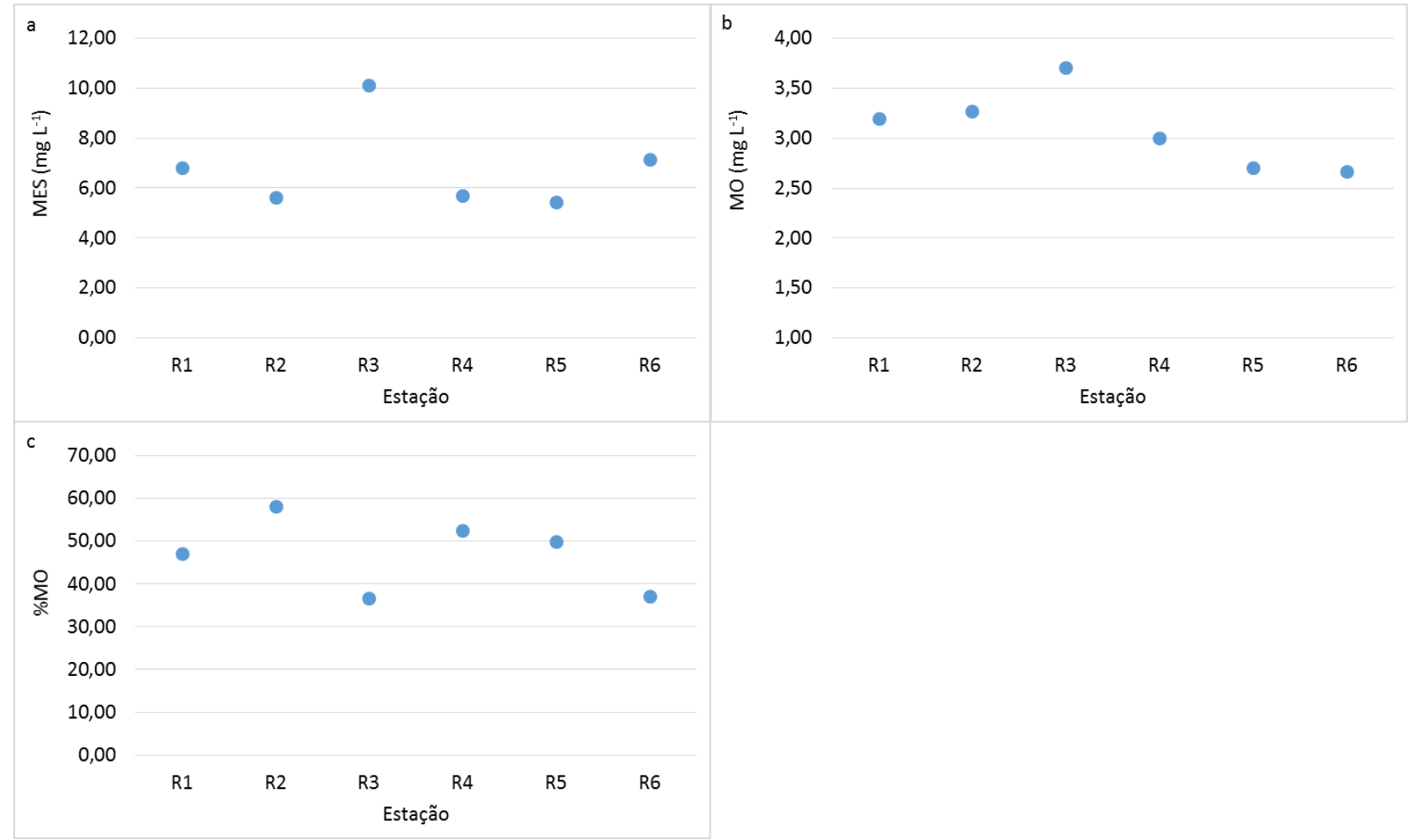

Figura 33. Distribuição espacial de MES (a), MO (b) e \%MO (c), Setembro 2013.

\subsubsection{Iguape}

Os valores hidrográficos e hidroquímicos do período encontram-se na tabela 23 . Os valores de temperatura mostram que as águas do rio e do Valo Grande estiveram mais frias que nas estações próximas à Barra de Icapara (ests. 1 e 2). A estação intermediária (6) apresentou valores maiores de salinidade e pH. A salinidade foi menor nas junto à Barra de Icapara. Os valores de $\mathrm{pH}$ estiveram todos abaixo de 8. Os teores de oxigênio foram altos, sobretudo nas estações 1 e 5 .

Os nutrientes nitrogenados exibiram valores altos no setor norte, diminuindo apenas na estação intermediária. As concentrações de $\mathrm{N}$-amoniacal foram baixas, sendo ligeiramente maiores no Valo Grande. O nitrito foi baixo e o nitrato foi bastante alto no Valo Grande. O P-fosfato continuou com valores altos no setor norte, em especial nos pontos do Valo Grande e foram diminuindo até a estação intermediária 6 (Tab. 23). 
Tabela 23. Valores de temperatura, salinidade, oxigênio dissolvido, $\mathrm{pH}, \mathrm{N}$-amoniacal, $\mathrm{N}$ - nitrito, $\mathrm{N}$-nitrato e nitrogênio inorgânico dissolvido, em Iguape, no Valo Grande e na estação 6, em

Setembro de 2013.

\begin{tabular}{|c|c|c|c|c|c|c|c|c|c|c|c|c|}
\hline $\begin{array}{l}\text { Set. } \\
2013\end{array}$ & Est. & $\begin{array}{c}\text { Prof. } \\
\text { (m) }\end{array}$ & $\begin{array}{c}\text { Temp. } \\
\left({ }^{\circ} \mathbf{C}\right)\end{array}$ & Salin. & pH & $\underset{\left(\mathbf{m L ~ L} \mathbf{L}^{-1}\right)}{\text { OD }}$ & $\underset{(\mu \mathrm{mol} \mathrm{L}}{\mathrm{N}-\mathrm{am}})$ & $\begin{array}{c}\mathrm{N}-\mathrm{NO}_{2}^{-} \\
\left(\mu \mathrm{mol} \mathrm{L} \mathbf{L}^{-1}\right)\end{array}$ & $\mid \begin{array}{c}\mathrm{N}^{-\mathrm{NO}_{3}^{-}} \\
\left(\mu \mathrm{mol} \mathrm{L} \mathbf{L}^{-1}\right)\end{array}$ & $\frac{\text { NID }}{\left(\mu \mathrm{mol} \mathrm{L} \mathbf{L}^{-1}\right)}$ & 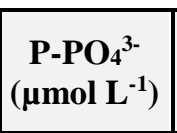 & $\begin{array}{l}\mathrm{NID} / \\
\mathrm{P}- \\
\mathrm{PO}_{4}{ }^{3-}\end{array}$ \\
\hline \multirow{9}{*}{ Iguape } & 1 & 0 & 23,60 & 0,04 & 7,48 & 6,22 & 0,29 & 0,14 & 5,86 & 6,29 & 3,35 & 1,88 \\
\hline & 2 & 0 & 24,20 & 3,75 & 7,76 & 6,31 & 0,63 & 0,17 & 8,83 & 9,63 & 4,14 & 2,33 \\
\hline & 3 & 0 & 23,10 & 1,82 & 7,76 & 4,81 & 0,88 & 0,17 & 9,43 & 10,48 & 4,53 & 2,31 \\
\hline & 4 & 0 & 22,87 & 0,04 & 7,49 & nd & 1,86 & 0,22 & 14,59 & 16,67 & 6,10 & 2,73 \\
\hline & & 5 & 22,89 & 0,04 & 7,50 & nd & 2,20 & 0,22 & 14,59 & 17,01 & 6,32 & 2,69 \\
\hline & $4 \mathrm{~A}$ & 0 & 22,89 & 0,04 & 7,44 & 5,69 & 3,21 & 0,22 & 13,39 & 16,82 & 6,38 & 2,64 \\
\hline & & 5 & 22,86 & 0,04 & 7,56 & 5,72 & 2,22 & 0,22 & 13,84 & 16,28 & 6,34 & 2,57 \\
\hline & 5 & 0 & 22,75 & 0,06 & 7,59 & 6,41 & 1,10 & 0,17 & 10,97 & 12,25 & 5,27 & 2,32 \\
\hline & & 5 & 22,51 & 0,06 & 7,59 & 6,28 & 0,15 & 0,14 & 11,26 & 11,55 & 5,33 & 2,17 \\
\hline \multirow[t]{2}{*}{ Interm. } & 6 & 0 & 22,25 & 11,89 & 7,55 & 5,62 & 0,10 & 0,02 & 0,13 & 0,25 & 1,25 & 0,20 \\
\hline & & 5 & 22,19 & 14,28 & 7,60 & 5,37 & 0,32 & 0,01 & 0,11 & 0,44 & 0,96 & 0,46 \\
\hline
\end{tabular}

O MES apresentou uma variação entre $4,50 \mathrm{mg} \mathrm{L}^{-1}$, no Valo Grande (4A-5m), e $23,00 \mathrm{mg} \mathrm{L}^{-1}$ no fundo da estação 6. A matéria orgânica variou de $2,10 \mathrm{mg} \mathrm{L}^{-1}$, na superfície da estação 6 , a $6,50 \mathrm{mg} \mathrm{L}^{-1}$, no fundo da mesma. Estes parâmetros e a turbidez foram menores do que os valores observados nas duas Campanhas anteriores. Já a porcentagem de MO foi mais alta neste período (Tab. 24).

Tabela 24. Valores de material em suspensão, matéria orgânica, porcentagem de matéria orgânica e turbidez, em Iguape, no Valo Grande no setor intermediário, em Setembro de 2013.

\begin{tabular}{|c|c|c|c|c|c|c|}
\hline $\begin{array}{c}\text { Set. } \\
\mathbf{2 0 1 3}\end{array}$ & Est. & $\begin{array}{c}\text { Prof. } \\
(\mathbf{m})\end{array}$ & $\begin{array}{c}\text { MES } \\
\left(\mathbf{m g ~ L}^{-1}\right)\end{array}$ & $\begin{array}{c}\text { MO } \\
\left(\mathbf{m g ~ L}^{-\mathbf{1}}\right)\end{array}$ & \% MO & $\begin{array}{c}\text { Turb. } \\
(\mathbf{n t u})\end{array}$ \\
\hline \multirow{5}{*}{} & 1 & 0 & 17,8 & 5,8 & 32,58 & 5,15 \\
\cline { 2 - 7 } & 2 & 0 & 12,8 & 4,8 & 37,5 & 9,61 \\
\cline { 2 - 7 } & 3 & 0 & 11,2 & 4,4 & 39,29 & 9,74 \\
\cline { 2 - 7 } Iguape & 4 & 0 & 7,43 & 2,86 & 38,46 & 4,91 \\
\cline { 2 - 7 } & & 5 & 7 & 2,83 & 40,48 & 10,5 \\
\cline { 2 - 7 } & $4 \mathrm{~A}$ & 0 & 4,5 & 3 & 66,67 & 8,44 \\
\cline { 2 - 7 } & 4 & 5 & 7 & 3,14 & 44,9 & 11,9 \\
\cline { 2 - 7 } & 5 & 0 & 6,87 & 3,25 & 47,27 & 5,72 \\
\cline { 2 - 7 } & & 5 & $\mathrm{nd}$ & $\mathrm{nd}$ & $\mathrm{Nd}$ & 7,46 \\
\hline \multirow{3}{*}{ Interm. } & 6 & 0 & 5,9 & 2,1 & 35,59 & 1,30 \\
\cline { 2 - 7 } & & 5 & 23 & 6,5 & 28,26 & 1,52 \\
\hline
\end{tabular}

\subsubsection{Cananéia - Ararapira}

Os valores de temperatura na Campanha de setembro 2013 (Tab.25) oscilaram entre $20,20{ }^{\circ} \mathrm{C}$ e $24,16{ }^{\circ} \mathrm{C}$, sendo a estação 10 , setor Ararapira com a temperatura mais alta. A salinidade no setor de Cananéia variou entre 20,91 e 23,51. Na estação 10, a salinidade apresentou valores próximos a 26 e, nas estações 11 e 12 os valores foram maiores que 30. O pH mostrou um gradiente crescente, notando-se que da estação 7-10 
(0 m) o pH foi menor que 8 e, a partir da $10(5 \mathrm{~m})$ o pH aumenta, com o máximo de 8,14 para a estação $12(0 \mathrm{~m})$. O OD também apresentou valores crescentes no sentido Sul do setor Cananéia - Ararapira. Os nutrientes apresentaram valores baixos, sendo o maior valor de P-fosfato observado na estação $9(5 \mathrm{~m})$, de $1,23 \mu \mathrm{mol} \mathrm{L}{ }^{-1}$, enquanto os valores de NID foram maiores que $1 \mu \mathrm{mol} \mathrm{L}{ }^{-1}$ na estação 7 (0m) e nas estações 10 e 12 (5m) (Tab.25).

Tabela 25. Valores de temperatura, salinidade, oxigênio dissolvido, $\mathrm{pH}, \mathrm{N}$-amoniacal, nitrito, nitrato, nitrogênio inorgânico dissolvido e relação NID/fosfato, Setembro de 2013.

\begin{tabular}{|c|c|c|c|c|c|c|c|c|c|c|c|c|}
\hline $\begin{array}{l}\text { Set. } \\
2013\end{array}$ & Est. & $\begin{array}{l}\text { Prof. } \\
\text { (m) }\end{array}$ & $\begin{array}{c}\text { Temp. } \\
\left({ }^{\circ} \mathbf{C}\right)\end{array}$ & Salin. & pH & $\begin{array}{c}\text { OD } \\
\left(\mathbf{m L} \mathbf{L}^{-1}\right)\end{array}$ & $\begin{array}{c}\mathrm{N}-\mathrm{am} . \\
\left(\mu \mathrm{mol} \mathrm{L} \mathbf{L}^{-1}\right)\end{array}$ & $\begin{array}{c}\text { N-NO }{ }_{2}^{-} \\
\left(\mu \mathrm{mol} \mathrm{L}^{-1}\right)\end{array}$ & $\begin{array}{c}\mathrm{N}^{-\mathrm{NO}_{3}^{-}} \\
\left(\mu \mathrm{mol} \mathrm{L}^{-1}\right)\end{array}$ & $\begin{array}{c}\text { NID } \\
\left(\mu \mathrm{mol} \mathrm{L}^{-1}\right)\end{array}$ & $\begin{array}{c}\mathrm{P}_{-\mathrm{PO}_{4}{ }^{3-}} \\
\left(\mu \mathrm{mol} \mathrm{L} \mathrm{L}^{-1}\right)\end{array}$ & $\begin{array}{l}\mathrm{NID/} / \\
\mathrm{PO}_{4}{ }^{3}\end{array}$ \\
\hline \multirow{6}{*}{ Cananéia } & 7 & 0 & 22,54 & 20,91 & 7,94 & 5,28 & 0,22 & 0,02 & 0,13 & 0,37 & 0,77 & 0,48 \\
\hline & & 5 & 22,55 & 20,91 & 7,92 & 5,29 & 0,94 & 0,02 & 0,16 & 1,12 & nd & nd \\
\hline & 8 & 0 & 21,10 & 21,96 & 7,95 & 5,33 & 0,38 & 0,04 & 0,10 & 0,52 & 0,86 & 0,60 \\
\hline & & 5 & 21,10 & 23,51 & 7,96 & 5,19 & 0,02 & 0,05 & 0,13 & 0,20 & 0,87 & 0,23 \\
\hline & 9 & 0 & nd & nd & 7,98 & 5,20 & 0,29 & 0,20 & 0,04 & 0,53 & 0,80 & 0,66 \\
\hline & & 5 & nd & nd & 7,99 & 5,39 & 0,29 & 0,20 & 0,04 & 0,53 & 1,23 & 0,43 \\
\hline \multirow{6}{*}{ Ararapira } & 10 & 0 & 24,16 & 25,15 & 7,94 & 5,37 & 0,22 & 0,08 & 0,17 & 0,47 & 0,33 & 1,42 \\
\hline & & 5 & 23,07 & 25,95 & 8,01 & 5,39 & 0,93 & 0,08 & 0,17 & 1,18 & 0,34 & 3,47 \\
\hline & 11 & 0 & 22,70 & 30,04 & 8,07 & 5,36 & 0,32 & 0,05 & 0,11 & 0,48 & 0,14 & 3,43 \\
\hline & & 5 & 22,33 & 30,20 & 8,08 & 5,33 & 0,12 & 0,04 & 0,11 & 0,27 & 0,30 & 0,90 \\
\hline & 12 & 0 & 22,31 & 30,97 & 8,14 & 5,36 & 0,87 & 0,07 & 0,15 & 1,09 & 0,45 & 2,42 \\
\hline & & 5 & 20,20 & 31,04 & 8,14 & 5,45 & 0,44 & 0,08 & 0,18 & 0,7 & 0,36 & 1,94 \\
\hline
\end{tabular}

O maior valor de MES encontrado foi na estação $12(0 \mathrm{~m})$, e o maior valor MO encontrado também foi na estação 12. A porcentagem de MO foi maior na estação 7 de Cananéia $(0 \mathrm{~m})$, os maiores valores de turbidez foram encontrados nos extremos deste sistema sendo de 11,8 na estação 7 de Cananéia e 16,25 para a estação 12 de Ararapira (Tab. 26).

Tabela 26. Valores de material em suspensão, matéria orgânica, porcentagem de matéria orgânica e turbidez, em Cananéia e Ararapira, sul do sistema, em setembro de 2013.

\begin{tabular}{|c|c|c|c|c|c|c|}
\hline $\begin{array}{c}\text { Setembro } \\
2013 \\
\end{array}$ & Est. & $\begin{array}{c}\text { Prof. } \\
\text { (m) }\end{array}$ & $\begin{array}{c}\text { MES } \\
\left(\mathrm{mg} \mathrm{L}^{-1}\right)\end{array}$ & $\begin{array}{c}\text { MO } \\
\left(\mathrm{mg} \mathrm{L}^{-1}\right) \\
\end{array}$ & \% МO & $\begin{array}{l}\text { Turb. } \\
\text { (ntu) }\end{array}$ \\
\hline \multirow{6}{*}{ Cananéia } & 7 & 0 & 21,70 & 4,90 & 72,56 & 11,80 \\
\hline & & 5 & 34,67 & 8,11 & 23,40 & 4,04 \\
\hline & 8 & 0 & 21,71 & 6,29 & 28,95 & 3,52 \\
\hline & & 5 & 31,33 & 7,87 & 25,11 & 3,91 \\
\hline & 9 & 0 & 22,70 & 6,29 & 24,67 & 3,60 \\
\hline & & 5 & 30,33 & 7,87 & 23,44 & 4,85 \\
\hline \multirow{6}{*}{ Ararapira } & 14 & 0 & 26,30 & 6,37 & 24,17 & 1,37 \\
\hline & & 5 & 32,25 & 8,12 & 25,19 & 2,27 \\
\hline & 17 & 0 & 37,57 & 7,29 & 19,39 & 2,32 \\
\hline & & 5 & 29,40 & 6,40 & 21,37 & 2,62 \\
\hline & 18 & 0 & 112,73 & 23,03 & 20,43 & 8,05 \\
\hline & & 5 & 56,81 & 10,67 & 20,55 & 16,25 \\
\hline
\end{tabular}


Em Cananéia, na Campanha de setembro de 2013, os teores de nutrientes diminuíram em função do aumento da salinidade (Fig. 34), o fosfato foi o nutriente que teve teores mais altos, com o mínimo de $0,77 \mu \mathrm{mol} \mathrm{L}^{-1}$ em água salobra e máximo de 1,23 $\mu \mathrm{mol} \mathrm{L} \mathrm{L}^{-1}$. O nitrato apresentou valor máximo de $0,16 \mu \mathrm{mol} \mathrm{L} \mathrm{L}^{-1}$. O N-amoniacal mostrou valores baixos, porém os mais representativos na composição do NID.

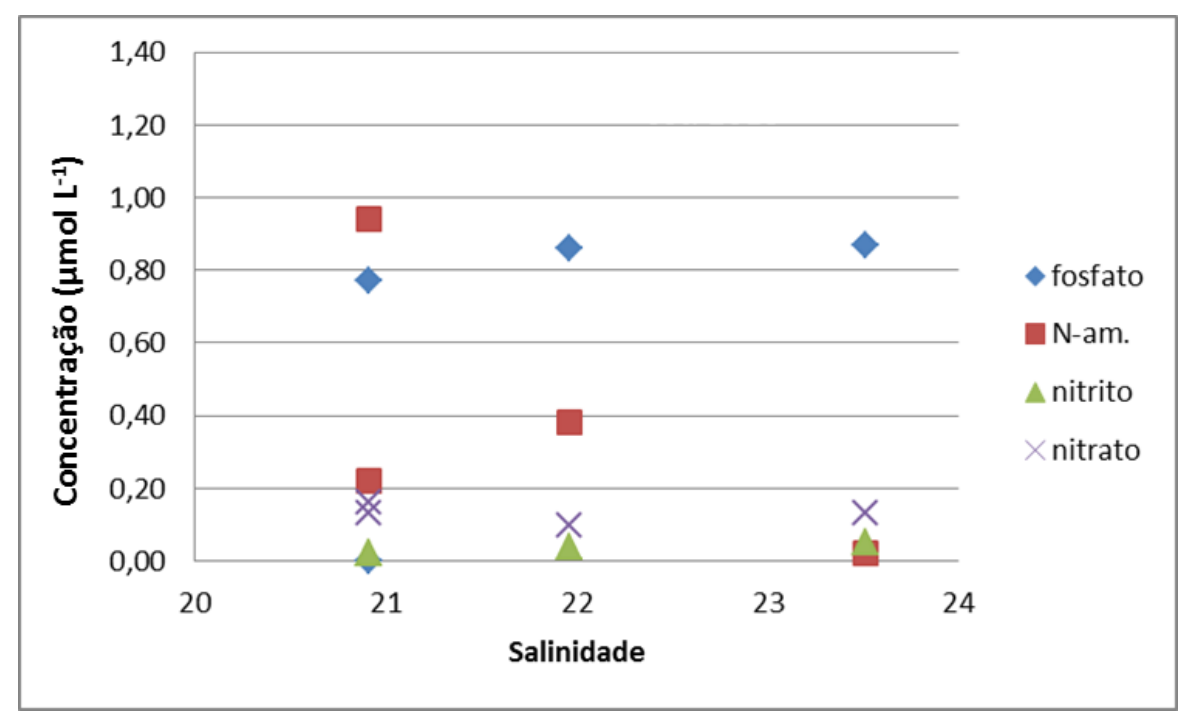

Figura 34. Distribuição de fosfato, nitrato, nitrito e amônio versus salinidade, Cananéia, Setembro de 2013.

Na região do Ararapira, em setembro de 2013, os parâmetros nitrogenados, em especial o nitrato apresentou valores baixos $\left(<0,20 \mu \mathrm{mol} \mathrm{L}^{-1}\right)$ todos em água salobra (Fig 35). Os valores de $\mathrm{N}$-amoniacal foram os mais representativos dentro do NID. Os valores de fosfatos foram típicos da região.

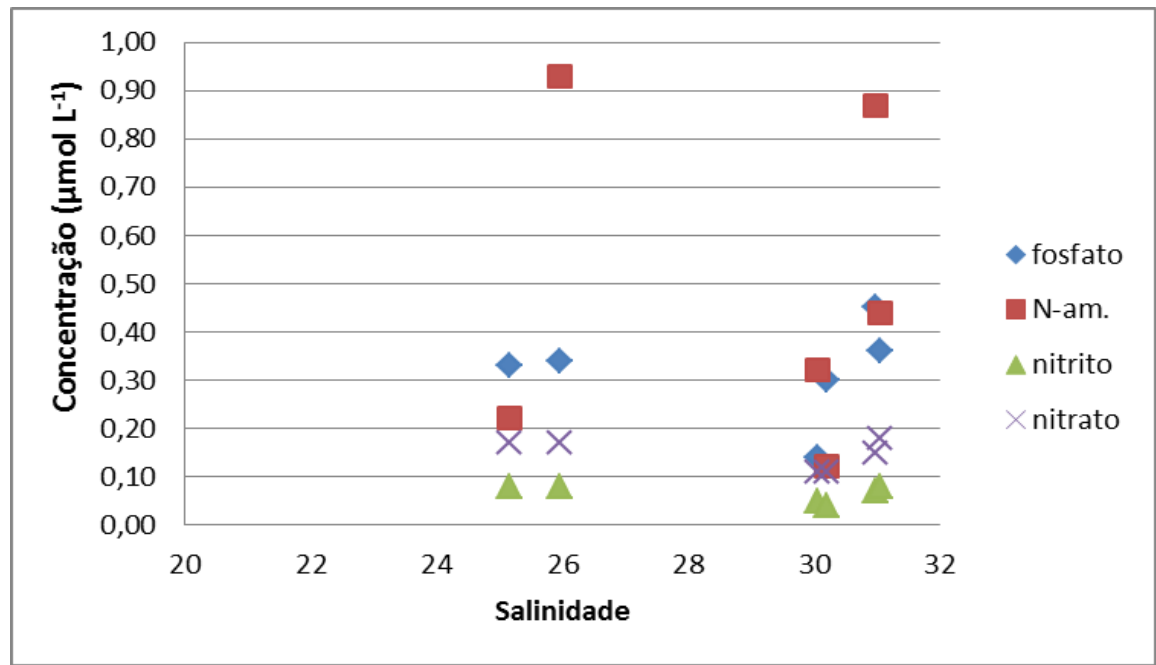

Figura 35. Distribuição de fosfato, nitrato, nitrito e amônio versus salinidade, Ararapira, Setembro de 2013. 
Na Campanha de setembro de 2013 (Tab.27), a temperatura ficou entre $20,30^{\circ} \mathrm{C}$ e $25,10{ }^{\circ} \mathrm{C}$, a salinidade foi próxima a zero nas áreas do Rio Ribeira, Valo Grande e estações 1 e 5 na porção de Iguape, que estão sob influência da água fluvial. A partir da estação intermediária a salinidade registrada foi maior do que 10, retratando assim uma água salobra. A salinidade continua a aumentar e no setor de Ararapira ela passa de água salobra com salinidade igual a 25,14 para água salina, com salinidade de 31,04. O oxigênio dissolvido ficou entre 4,81 $\mathrm{ml} \mathrm{L}^{-1}$ e $6,40 \mathrm{ml} \mathrm{L}^{-1}$, ambos registrados no setor de Iguape. O material em suspensão encontrado na porção Sul (Cananéia, Ararapira), com teores entre $21,70 \mathrm{mg} \mathrm{L}^{-1}$ e $112,73 \mathrm{mg} \mathrm{L}^{-1}$ foi bem maior do que o MES encontrado na porção Norte que registrou teores entre 4,50 $\mathrm{mg} \mathrm{L}^{-1}$ e 17,80 $\mathrm{mg} \mathrm{L}^{-1}$. Quanto ao teor de matéria orgânica, este apresentou-se maior na porção sul, com o máximo teor registrado de 23,03 $\mathrm{mg} \mathrm{L}^{-1}$ em Arapira. A porcentagem de MO foi maior na porção Norte do que na porção Sul com máximo valor de 66,67\% no Valo Grande e mínimo de 28,95\% em Cananéia. A turbidez esteve acima de 10 ntu no Valo Grande e em Cananéia, atingindo o máximo valor encontrado no setor de Ararapira, com 16,25 ntu.

Com relação aos nutrientes nitrogenados, o $\mathrm{N}$-amoniacal apresentou teores maiores que $5 \mu \mathrm{mol} \mathrm{L} \mathrm{L}^{-1}$, no setor do Rio, e decresce em direção ao setor sul, apresentando o mínimo teor registrado na porção intermediária do sistema, com $0,10 \mu \mathrm{mol} \mathrm{L}-1$ e teores menores que $1 \mu \mathrm{mol} \mathrm{L}{ }^{-1}$ nas regiões de Cananéia e Ararapira. O nitrito apresentou seu maior valor encontrado na porção do Rio com $0,25 \mu \mathrm{mol} \mathrm{L}^{-1}$ e menor na porção intermediária, com 0,01 $\mu \mathrm{mol} \mathrm{L} \mathrm{L}^{-1}$; em Cananéia e Ararapira os teores encontrados foram menores que $0,20 \mu \mathrm{mol} \mathrm{L}{ }^{-1}$. O N-nitrato apresentou teores bem maiores na porção Norte do sistema com o máximo teor registrado de $15,72 \mu \mathrm{mol} \mathrm{L} \mathrm{L}^{-1}$ na porção do Rio, este parâmetro decresce em direção à porção Sul do sistema, apresentando teores menores que $0,2 \mu \mathrm{mol} \mathrm{L}{ }^{-1}$ nos setores que conferem as estações da porção Sul (Cananéia e Ararapira) e a estação intermediária. O NID foi maior na porção Norte que na porção Sul do sistema, como era esperado apresentando assim teores máximos no Valo Grande $(17,01 \mu \mathrm{mol} \mathrm{L}-$ $\left.{ }^{1}\right)$ e Rio Ribeira $\left(16,78 \mu \mathrm{mol} \mathrm{L}{ }^{-1}\right)$. Os teores de P-fosfato também são maiores na porção do Rio e do Valo Grande com teores entre $5,73 \mu \mathrm{mol} \mathrm{L}{ }^{-1}$ e $6,38 \mu \mathrm{mol} \mathrm{L}^{-1}$, e na porção Sul do sistema este parâmetro apresentou valores menores que $0,75 \mu \mathrm{mol} \mathrm{L} \mathrm{L}^{-1}$. A relação $\mathrm{NID} / \mathrm{PO}_{4}{ }^{-3}$ foi maior na porção Sul do sistema com máximo valor de 3,47 registrado em Ararapira; o Norte do sistema, apresentou valor máximo de 2,82 no Rio e o mínimo teor registrado foi na área intermediária com 0,20. 
Tabela 27. Quadro sinóptico da situação do sistema em Setembro de 2013.

\begin{tabular}{|c|c|c|c|c|c|c|}
\hline Setembro -2013 & Rio Ribeira & Valo Grande & Iguape & Intermediária & Cananéia & Ararapira \\
\hline $\mathrm{T}\left({ }^{\circ} \mathrm{C}\right)$ & $23,50-25,10$ & $22,86-22,89$ & $22,19-24,20$ & $22,19-22,25$ & $21,10-22,54$ & $20,30-24,16$ \\
\hline Salinidade & $0,03-0,04$ & 0,04 & $0,04-3,78$ & $11,88-14,27$ & $20,91-23,50$ & $25,14-31,04$ \\
\hline pH & $7,19-7,82$ & $7,44-7,56$ & $7,48-7,60$ & $7,55-7,60$ & 7,94-7,98 & $7,94-8,14$ \\
\hline $\mathrm{OD}\left(\mathrm{ml} \mathrm{L}^{-1}\right)$ & $5,71-5,90$ & $5,69-5,72$ & $4,81-6,40$ & $5,37-5,62$ & $5,19-5,39$ & $5,33-5,45$ \\
\hline MES mg L $\mathbf{~ L}^{-1}$ & $5,64-10,14$ & $4,50-7,43$ & $6,87-17,8$ & $5,90-23,00$ & $21,70-34,67$ & $29,40-112,73$ \\
\hline MO $\mathrm{mg} \mathrm{L}^{-1}$ & $2,67-3,71$ & $2,83-3,14$ & $3,25-5,8$ & $2,10-6,50$ & $4,90-7,87$ & $8,12-23,03$ \\
\hline$\%$ MO & $36,62-52,50$ & $38,46-66,67$ & $32,58-47,27$ & $28,26-35,59$ & $21,67-28,95$ & $19,39-25,19$ \\
\hline Turbidez ntu & $4,94-8,00$ & $8,44-11,90$ & $5,15-9,74$ & $1,30-1,52$ & $3,52-11,80$ & $1,35-16,25$ \\
\hline $\mathrm{N}$-am. $\left(\mu \mathrm{mol} \mathrm{L}{ }^{-1}\right)$ & $0,75-2,30$ & $2,22-3,21$ & $0,15-2,20$ & $0,10-0,32$ & $0,22-0,94$ & $0,22-0,88$ \\
\hline $\begin{array}{c}\mathrm{N}^{-\mathrm{NO}_{2-}}\left(\boldsymbol{\mu \mathrm { mol } \mathrm { L }} \mathrm{L}^{-}\right. \\
{ }^{-}\end{array}$ & $0,22-0,25$ & 0,22 & $0,14-0,17$ & $0,01-0,02$ & $0,02-0,20$ & $0,04-0,08$ \\
\hline 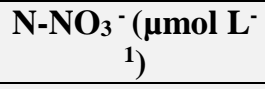 & $13,88-15,72$ & $13,39-14,59$ & $5,86-11,26$ & $0,11-0,13$ & $0,04-0,16$ & $0,11-0,18$ \\
\hline NID $\left(\mu \mathrm{mol} \mathrm{L}^{-1}\right)$ & $15,15-16,78$ & $16,28-17,01$ & $6,29-12,55$ & $0,25-0,44$ & $0,20-1,12$ & $0,47-1,18$ \\
\hline 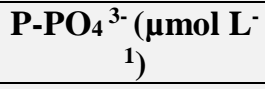 & $5,73-6,22$ & $6,10-6,38$ & $3,35-5,33$ & $0,96-1,25$ & $0,73-1,23$ & $0,14-0,45$ \\
\hline $\mathrm{NID} / \mathrm{PO}_{4}{ }^{3-}$ & $2,41-2,82$ & $2,57-2,69$ & $1,88-2,33$ & $0,20-0,46$ & $0,08-0,66$ & $0,90-3,47$ \\
\hline
\end{tabular}

\subsubsection{Verão 2014 - Fevereiro de 2014}

A curva de maré apresentou uma situação de transição entre as fases de quadratura e sizígia (Fig. 29), sendo que os pontos de amostragem R1 a R6, 9 e 12 estiveram em condição de enchente, os pontos 1, 2, 3, 4, 7 e 10 em vazante, 5, 8 e 11 em estofa de maré alta e 6 em estofa de maré baixa. 


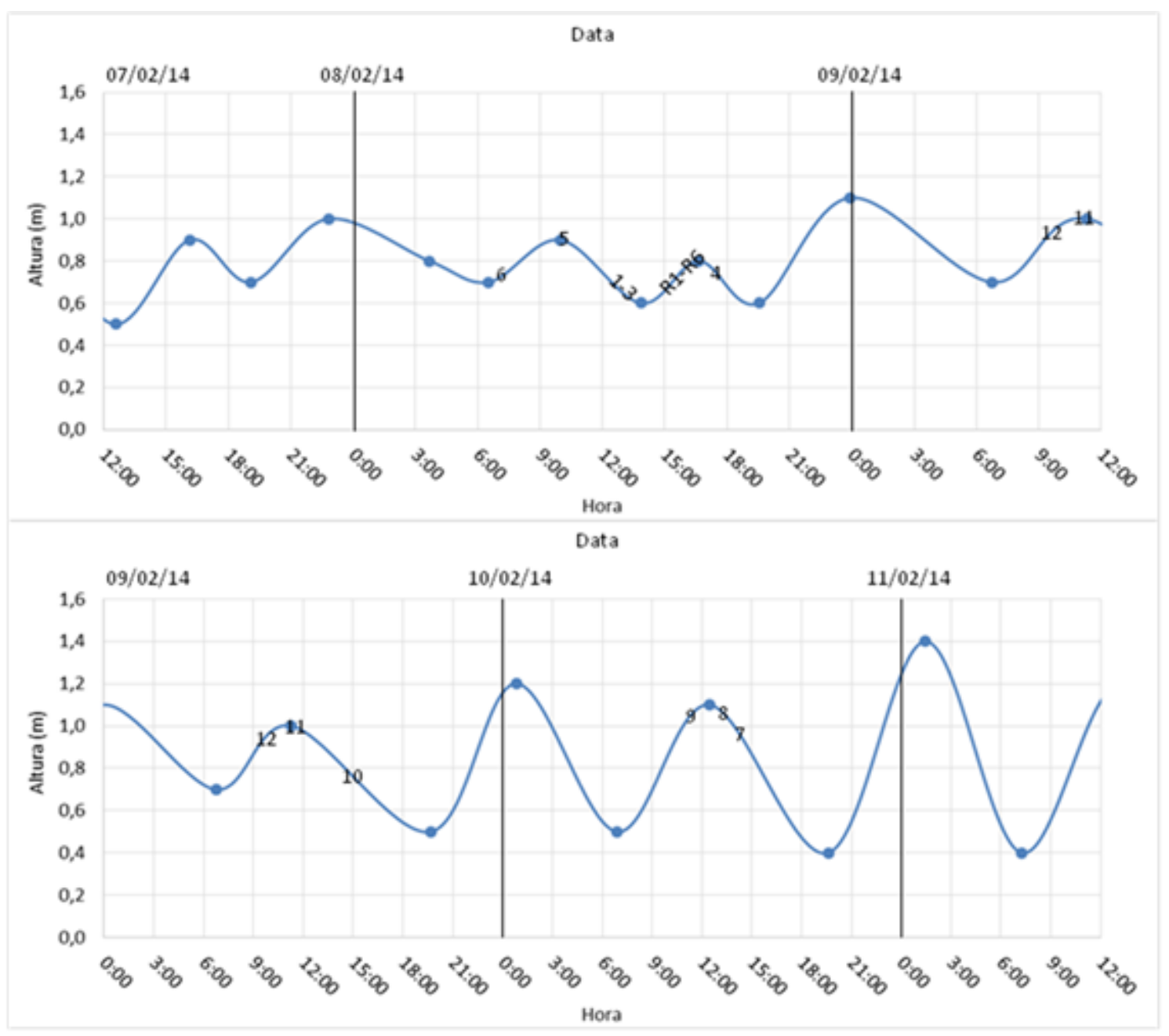

Figura 36. Curvas de maré construídas com dados do LABDADOS-IOUSP nos dias 13, 14, 15 e 16 de Setembro de 2014, destacando os momentos de realização das estações na região de Cananéia e Iguape (SP).

\subsubsection{Rio Ribeira de Iguape}

Os valores de temperatura, salinidade, $\mathrm{pH}$, oxigênio dissolvido, $\mathrm{N}$-amoniacal, nitrito, nitrogênio inorgânico dissolvido (NID), fosfato e a relação NID/PO ${ }_{4}^{-3}$, obtidos na amostragem de fevereiro de 2014 encontram-se na tabela 28.

Tabela 28. Dados hidrológicos e hidroquímicos (0m) das águas a jusante do Rio Ribeira de Iguape, Fevereiro de 2014.

\begin{tabular}{|c|c|c|c|c|c|c|c|c|c|c|c|c|}
\hline $\begin{array}{l}\text { Fev. } \\
2014\end{array}$ & Est. & $\begin{array}{l}\text { Prof. } \\
\text { (m) }\end{array}$ & $\begin{array}{c}\text { Temp. } \\
\left({ }^{\circ} \mathbf{C}\right)\end{array}$ & Salin. & pH & $\begin{array}{c}\text { OD } \\
\left(\mathrm{ml} \mathrm{L}^{-1}\right)\end{array}$ & $\begin{array}{l}\text { N-amon. } \\
\left(\mu \mathrm{mol} \mathrm{L}^{-1}\right)\end{array}$ & $\begin{array}{c}\mathrm{N}-\mathrm{NO}_{2}^{-} \\
\left(\mu \mathrm{mol} \mathrm{L}^{-1}\right)\end{array}$ & $\begin{array}{c}\mathrm{N}^{-\mathrm{NO}_{3}^{-}} \\
\left(\mu \mathrm{mol} \mathrm{L} \mathrm{L}^{-1}\right)\end{array}$ & $\begin{array}{c}\text { NID } \\
\left(\mu \mathrm{mol} \mathrm{L}^{-1}\right)\end{array}$ & $\begin{array}{c}\mathbf{P}_{-P_{4}{ }^{3-}} \\
\left.(\mu \mathrm{mol} \mathrm{L})^{-1}\right)\end{array}$ & \begin{tabular}{|c|} 
NIID/ \\
P-PO4
\end{tabular} \\
\hline \multirow{6}{*}{$\begin{array}{c}\text { Rio } \\
\text { Ribeira } \\
\text { de } \\
\text { Iguape }\end{array}$} & R1 & 0 & 33,20 & 0,05 & 7,74 & 7,26 & 0,29 & 0,21 & 10,33 & 10,83 & 3,08 & 3,52 \\
\hline & R2 & 0 & 33,20 & 0,05 & 7,62 & 6,40 & 1,06 & 0,22 & 12,52 & 13,80 & 3,06 & 4,51 \\
\hline & R3 & 0 & 32,90 & 0,04 & 7,65 & 6,52 & 1,19 & 0,21 & 12,28 & 13,68 & 3,18 & 4,30 \\
\hline & $\mathrm{R} 4$ & 0 & 32,80 & 0,04 & 7,49 & 6,16 & 1,69 & 0,21 & 13,78 & 15,68 & 3,36 & 4,66 \\
\hline & $\mathrm{R} 5$ & 0 & 32,50 & 0,04 & 7,43 & 6,04 & 1,20 & 0,21 & 13,78 & 15,90 & 3,21 & 4,97 \\
\hline & R6 & 0 & 32,50 & 0,05 & 7,45 & 6,09 & 2,88 & 0,21 & 13,53 & 15,62 & 3,24 & 4,82 \\
\hline
\end{tabular}


A temperatura nessa campanha foi bem alta, em média 5 graus a mais que a campanha de verão do ano anterior e, cerca de 7 a 9 graus mais altos que a campanha de inverno de 2013, evidenciando um verão bem quente em 2014.

Os valores de temperatura variaram de $32,50{ }^{\circ} \mathrm{C}$ nas estações R5 e R6 a 33,20 ${ }^{\circ} \mathrm{C}$ nas estações R1 e R2 (Fig. 37a). Os valores de salinidade foram bastante baixos, próximos a zero, caracterizando um valor típico de água doce com valores entre 0,04 e 0,05 (Fig. $37 b)$.

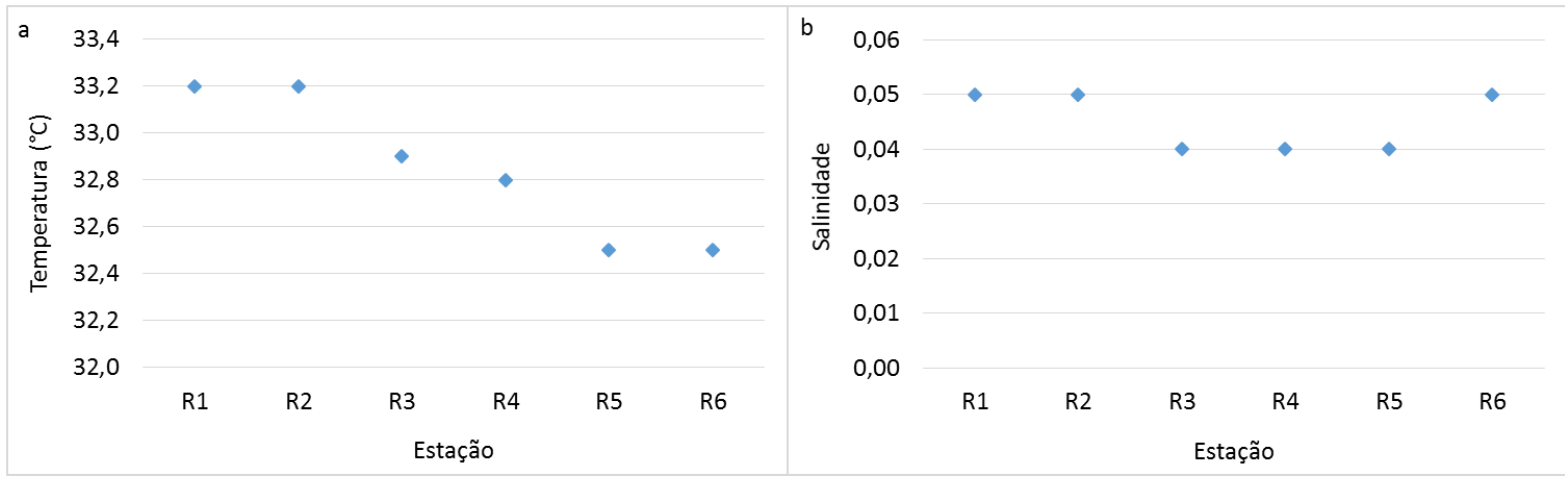

Figura 37. Distribuição espacial da temperatura $\left({ }^{\circ} \mathrm{C}\right)(\mathrm{a})$ e salinidade (b) no Rio Ribeira de Iguape (SP), em Fevereiro 2014.

Os valores de oxigênio dissolvido (OD) variaram entre 6,04 $\mathrm{ml} \mathrm{L}^{-1}$ (R5) e 7,26 ml $\mathrm{L}^{-1}(\mathrm{R} 1)$, sendo este o valor máximo encontrado considerando todas as Campanhas (Fig. 38a), quanto aos valores de $\mathrm{pH}$, todos foram acima de 7, variando entre 7,43 (R5) e 7,74 (R1) (Fig. 38b).

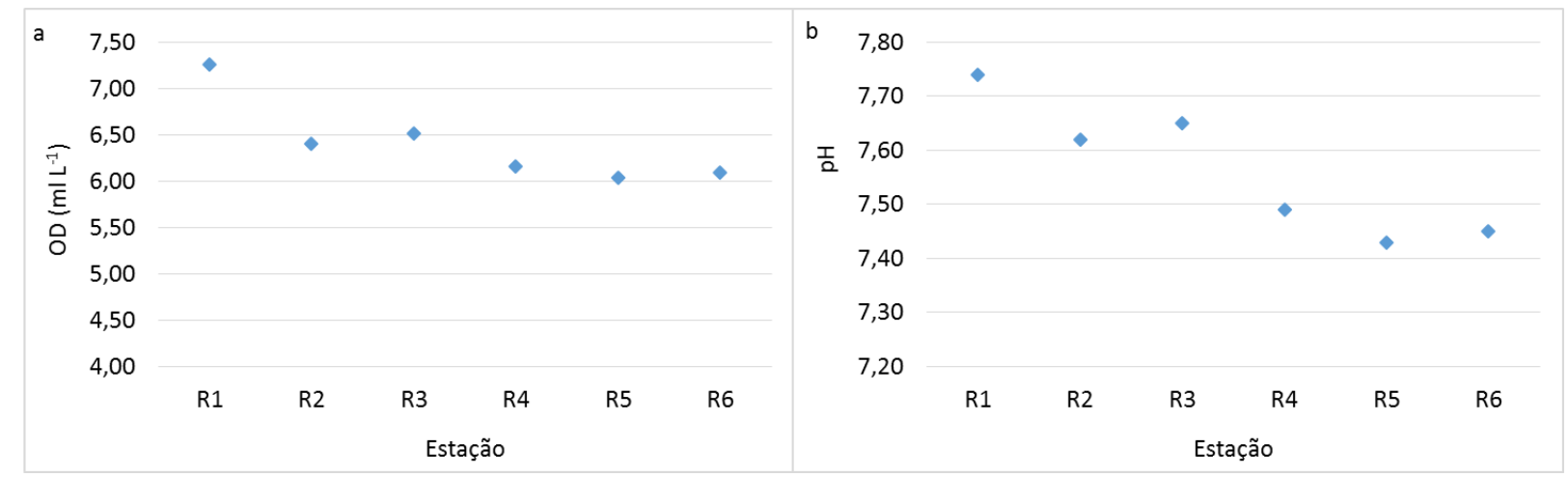

Figura 38. Distribuição espacial de $\mathrm{OD}\left(\mathrm{ml} \mathrm{L}^{-1}\right)$ (a) e pH (b) no Rio Ribeira de Iguape, em Fevereiro 2014.

Quanto aos nutrientes, o N-amoniacal (Fig. 39a) apresentou o menor valor de 0,29 $\mu \mathrm{mol} \mathrm{L} \mathrm{L}^{-1}$ em R1, ponto mais montante ao Rio, enquanto o maior valor encontrado foi de 2,88 $\mu \mathrm{mol} \mathrm{L} \mathrm{L}^{-1}$ na estação R6, a mais próxima ao Valo Grande. Os valores de N-nitrito (Fig. 39b), em quase todas as estações apresentaram o valor de $0,21 \mu \mathrm{mol} \mathrm{L} \mathrm{L}^{-1}$ e estes são valores muito semelhantes aos encontrados na terceira Campanha, sendo todos baixos. 
Os valores de nitrato (Fig. 39c) foram bastante altos nas águas amostradas do Rio Ribeira de Iguape, com o menor valor de $10,33 \mu \mathrm{mol} \mathrm{L}^{-1}$ na $\mathrm{R} 1$ e o maior valor de $13,78 \mu \mathrm{mol} \mathrm{L}$ ${ }^{1}$ tanto para a R4 como para a R5. Os valores de NID foram altos, apresentando o valor mínimo de 10,83 $\mu \mathrm{mol} \mathrm{L}^{-1}$ na estação R1, mais montante ao Rio e, máximo valor de 15,90 $\mu$ mol L $L^{-1}$ na estação R5 (Fig. 39d). Sem dúvida alguma, a forma de nitrato é a mais significante nas águas do Rio Ribeira de Iguape, também no verão, apresentando valores um pouco menores aos encontrados na Campanha anterior.

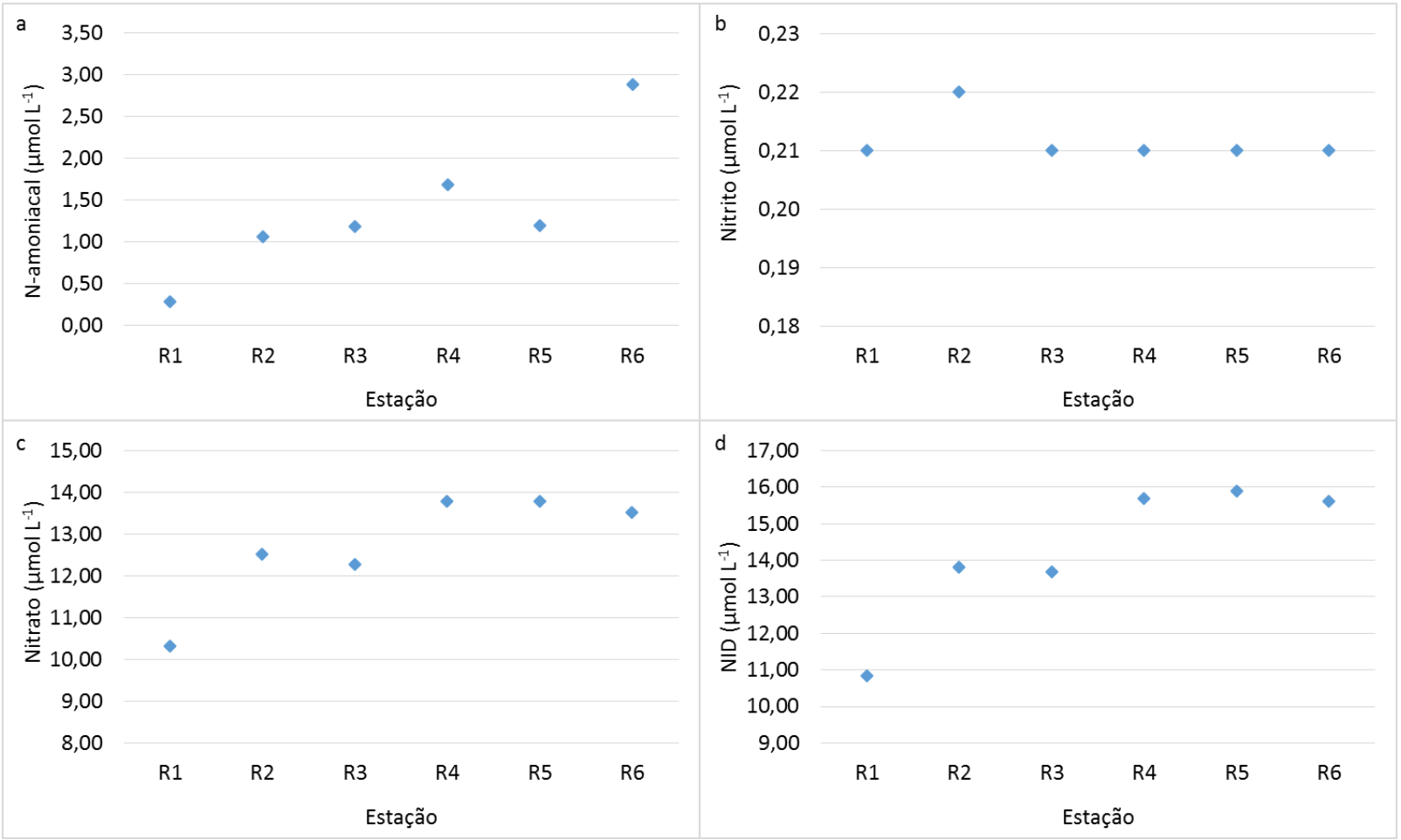

Figura 39. Distribuição espacial de N-amoniacal (a), nitrito (b), nitrato (c) e NID (d), no Rio Ribeira de Iguape, em Fevereiro de 2014.

Os valores de P-fosfato $\left(\mathrm{PO}_{4}^{-3}\right)$ variaram de $3,06 \mu \mathrm{mol} \mathrm{L}{ }^{-1}$ na $\mathrm{R} 2$ a $3,36 \mu \mathrm{mol} \mathrm{L}{ }^{-1}$ na R4 (Fig. 40a), sendo assim, os menores valores encontrados quando comparados às demais campanhas, representando, em média, metade dos valores encontrados nas duas Campanhas anteriores e praticamente quatro vezes menor que valor máximo encontrado na primeira Campanha (R6 com 12,45 $\mu \mathrm{mol} \mathrm{L}{ }^{-1}$ ). A relação NID/P-PO ${ }^{-3}$, de 3,92 a 4,97 foi maior que nas demais Campanhas considerando todas as estações de rio, sendo assim menor valor de $\mathrm{P}_{-} \mathrm{PO}_{4}^{-3}$ (Fig. 40b). 


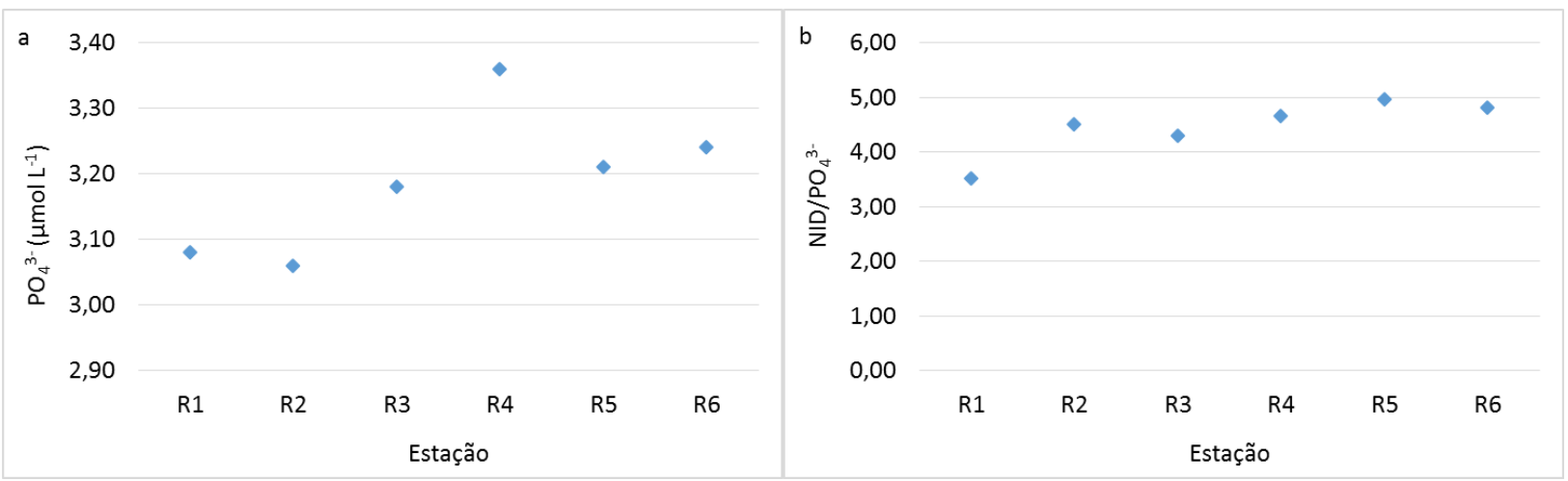

Figura 40. Distribuição espacial de $\mathrm{PO}_{4}^{-3}$ (a) e NID/ $\mathrm{PO}_{4}^{-3}$ (b), nos pontos do Rio Ribeira de Iguape, em Fevereiro de 2014.

Os valores de material em suspensão, matéria orgânica, porcentagem de matéria orgânica e turbidez dos pontos do Rio da quarta Campanha são mostrados na tabela 29.

Tabela 29. Dados hidrológicos e hidroquímicos (0m) das águas a jusante do Rio Ribeira de Iguape, Fevereiro 2014.

\begin{tabular}{|c|c|c|c|c|c|c|c|}
\hline $\begin{array}{c}\text { Fev. } \\
\mathbf{2 0 1 4}\end{array}$ & Est. & $\begin{array}{c}\text { Prof. } \\
(\mathbf{m})\end{array}$ & $\begin{array}{c}\text { MES } \\
\left(\mathbf{m g ~ L}^{-1}\right)\end{array}$ & $\begin{array}{c}\text { MO } \\
\left(\mathbf{m g ~ L}^{-1}\right)\end{array}$ & $\mathbf{\% M O}$ & $\begin{array}{c}\text { Turb. } \\
(\mathbf{n t u})\end{array}$ & $\begin{array}{c}\text { Disco de } \\
\text { Secchi }\end{array}$ \\
\hline \multirow{4}{*}{$\begin{array}{c}\text { Rio } \\
\text { Ribeira } \\
\text { de } \\
\text { Iguape }\end{array}$} & R1 & 0 & 8,20 & 2,80 & 34,15 & 13,90 & 0,80 \\
\cline { 2 - 8 } & R2 & 0 & 12,25 & 3,50 & 28,57 & 10,60 & 0,70 \\
\cline { 2 - 8 } & R3 & 0 & 11,25 & 2,75 & 24,44 & 12,20 & 0,65 \\
\cline { 2 - 8 } & R4 & 0 & 11,33 & 2,67 & 23,53 & 9,91 & 0,50 \\
\cline { 2 - 8 } & R5 & 0 & 14,33 & 5,00 & 34,88 & 14,50 & 0,50 \\
\cline { 2 - 8 } & R6 & 0 & 15,00 & 5,33 & 35,56 & 18,90 & 0,50 \\
\hline
\end{tabular}

Os valores de material em suspensão encontrados estiveram um pouco acima dos encontrados na campanha anterior (setembro de 2013), no entanto, foram bem distintos dos encontrados no verão anterior, cujos valores estiveram acima de $100 \mathrm{mg} \mathrm{L}^{-1}$. Nesta campanha, o ponto com maior valor de MES foi o R6 com 15,00 $\mathrm{mg} \mathrm{L}^{-1}$ e o menor valor encontrado foi no ponto R1, mais a montante do Rio com 8,20 mg L $\mathrm{m}^{-1}$ (Fig. 41a). Com relação à matéria orgânica, os valores nessa campanha foram bem próximos aos valores da campanha anterior e, bem inferiores aos valores encontrados no verão anterior (segunda campanha). $\mathrm{O}$ menor valor encontrado foi no ponto $\mathrm{R} 4 \operatorname{com} 2,67 \mathrm{mg} \mathrm{L}^{-1}$ e o maior ocorreu no ponto $\mathrm{R} 6 \mathrm{com} 5,33 \mathrm{mg} \mathrm{L}^{-1}$ (Fig. 41b), ponto mais próximo ao Valo. A porcentagem de MO foi significativamente menor que na Campanha anterior com o menor valor no ponto R4 com $24,44 \%$ e, maior valor $(35,56 \%)$ ocorreu no ponto R6, ponto mais próximo do Valo (Fig. 41c).

A turbidez teve seu maior valor no ponto R6 (18,90 ntu) e o disco de Secchi teve seu valor variado entre 0,5 e $0,80 \mathrm{~m}$, encontrado no $\mathrm{R} 1$, ponto mais a montante do Rio (Tab. 19). 


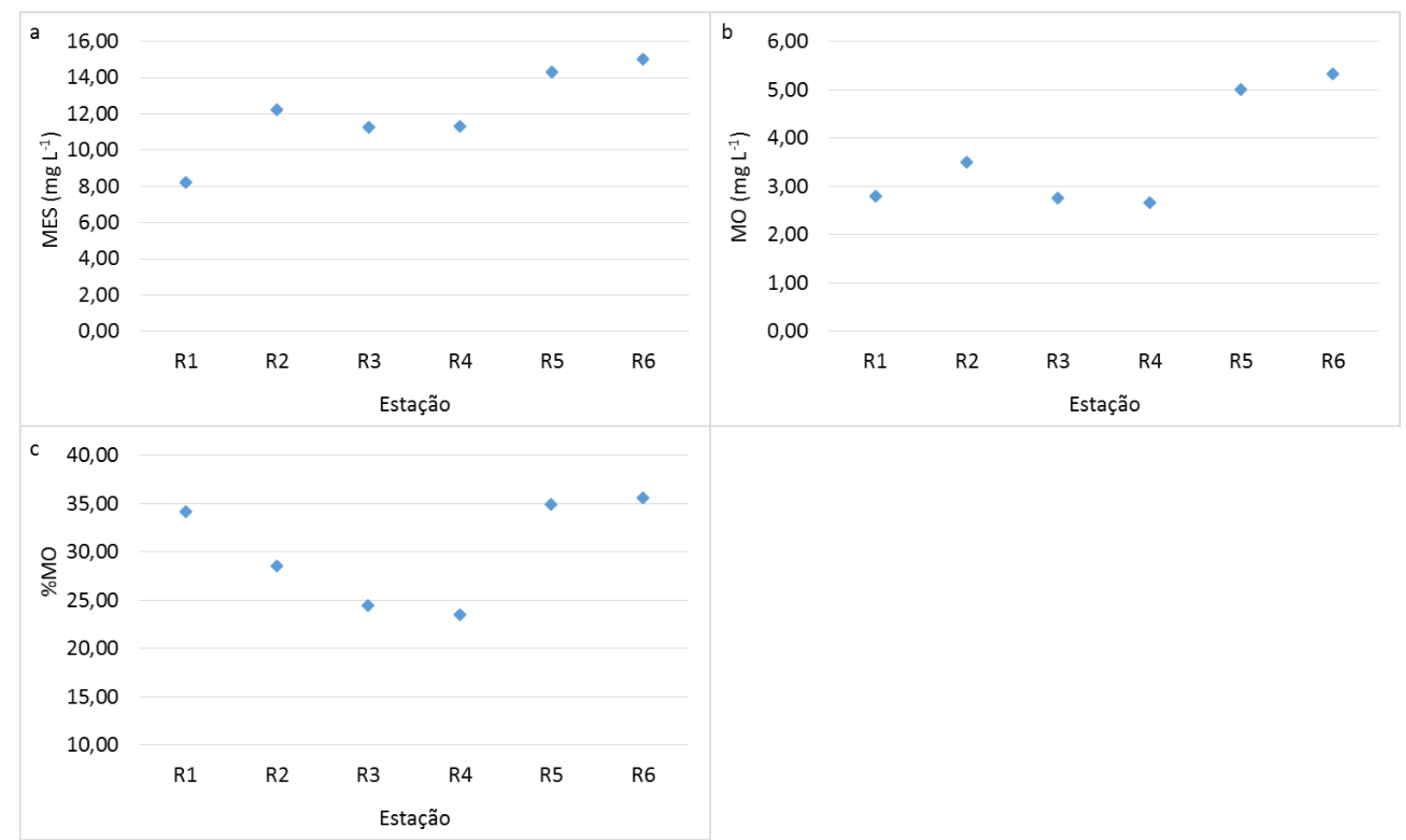

Figura 41. Distribuição espacial do material em suspensão (a), matéria orgânica (b) e porcentagem de matéria orgânica (c) no Rio Ribeira de Iguape, em Fevereiro de 2014.

\subsubsection{Iguape}

Os valores de temperatura na Campanha de Fevereiro 2014, variaram entre 31,70 ${ }^{\circ} \mathrm{C}$ e $32,89{ }^{\circ} \mathrm{C}$, refletindo as altas temperaturas registradas deste verão extremamente quente, sendo a estação 6, setor intermediário, aquela com a temperatura mais alta. A salinidade no setor de Iguape ficou entre 2,52 e 12,35 registradas no ponto $5(0 \mathrm{~m})$ e $(5 \mathrm{~m})$ respectivamente. A salinidade, nos pontos 4 e 5 aproximou-se de 0 , pois estes pontos sofrem influência da água do Rio, via Valo Grande. $\mathrm{O}$ pH mostrou maiores valores nas estações 1 e 2 de Iguape, sob maior influência de água marinha. O OD foi maior nos pontos superficiais das estações 3 e 4 . Os nutrientes nitrogenados e fosfatados apresentaram valores mais altos na estação próxima ao Canal, apresentando valores de NID maiores que 14 na estação 4 (0m e 5m) (Tab.30). 
Tabela 30. Valores de temperatura, salinidade, $\mathrm{pH}$, oxigênio dissolvido, $\mathrm{N}$-amoniacal, nitrito, nitrato, fosfato, nitrogênio inorgânico dissolvido, relação entre nitrogênio inorgânico dissolvido e fosfato em Iguape, no Valo Grande e na estação 6, em Fevereiro de 2014.

\begin{tabular}{|c|c|c|c|c|c|c|c|c|c|c|c|c|}
\hline $\begin{array}{l}\text { Fev. } \\
2014\end{array}$ & Est. & $\begin{array}{l}\text { Prof. } \\
\text { (m) }\end{array}$ & $\begin{array}{c}\text { Temp. } \\
\left({ }^{\circ} \mathrm{C}\right)\end{array}$ & Salin. & pH & $\underset{\left(\mathbf{m L} \mathbf{L}^{-1}\right)}{\mathbf{O D}}$ & $\begin{array}{c}\text { N- am. } \\
\left.(\mu \mathrm{mol} \mathrm{L})^{-1}\right)\end{array}$ & $\begin{array}{c}\mathrm{N}-\mathrm{NO}_{2}^{-} \\
\left(\mu \mathrm{mol} \mathrm{L} \mathbf{L}^{-1}\right)\end{array}$ & $\begin{array}{c}\text { N-NO }{ }^{-} \\
\left(\mu \mathrm{mol} \mathrm{L}{ }^{-1}\right)\end{array}$ & $\begin{array}{c}\text { NID } \\
\left(\mu \mathrm{mol} \mathrm{L}^{-1}\right)\end{array}$ & $\begin{array}{c}\mathbf{P}-\mathrm{PO}_{4}{ }^{3-} \\
\left(\mu \mathrm{mol} \mathrm{L}{ }^{-1}\right)\end{array}$ & $\begin{array}{l}\text { NID/ } \\
\mathrm{PO}_{4}{ }^{3}\end{array}$ \\
\hline \multirow{8}{*}{ Iguape } & 1 & 0 & 32,50 & 8,03 & 7,88 & 5,91 & 1,18 & 0,17 & 1,21 & 2,56 & 1,77 & 1,45 \\
\hline & 2 & 0 & 33,50 & - & 7,87 & 5,90 & 0,19 & 0,12 & 1,88 & 2,19 & 2,02 & 1,08 \\
\hline & 3 & 0 & 31,90 & 2,52 & 7,51 & 6,01 & 0,74 & 0,22 & 4,17 & 5,13 & 2,12 & 2,42 \\
\hline & & 5 & 31,70 & 12,35 & 7,71 & 4,33 & 1,25 & 0,15 & 2,99 & 4,39 & 1,95 & 4,81 \\
\hline & 4 & 0 & 32,70 & 0,05 & 7,38 & 6,07 & 0,75 & 0,22 & 13,27 & 14,24 & 3,21 & 4,44 \\
\hline & & 5 & 31,60 & 0,05 & 7,77 & 5,79 & 0,69 & 0,21 & 13,28 & 14,18 & 3,30 & 4,29 \\
\hline & 5 & 0 & 31,90 & 0,25 & 7,13 & 6,07 & 0,92 & 0,12 & 1,30 & 2,34 & 2,35 & 0,99 \\
\hline & & 5 & 31,81 & 0,35 & 7,06 & 5,50 & 0,70 & 0,12 & 2,88 & 3,70 & 2,22 & 1,66 \\
\hline \multirow{2}{*}{ Interm. } & 6 & 0 & 32,51 & 10,03 & 7,64 & 5,43 & 1,20 & 0,03 & 0,07 & 1,30 & 0,50 & 2,60 \\
\hline & & 5 & 32,89 & 16,54 & 7,77 & 5,27 & 0,18 & 0,03 & 0,06 & 2,08 & 0,77 & 2,70 \\
\hline
\end{tabular}

Na região de Iguape em fevereiro de 2014, os teores dos nutrientes tendem a diminuir com o aumento da salinidade (Fig. 42). O nitrato mostrou valores de 13,27 $\mu$ mol $\mathrm{L}^{-1}(0 \mathrm{~m})$ e $13,28 \mu \mathrm{mol} \mathrm{L}^{-1}(5 \mathrm{~m})$ no ponto 4 , associado ao Canal do Valo Grande e em conformidade com os valores encotrados nos pontos de menor salinidade desta mesma Campanha. Os menores valores de nitrato encontrado foram de $0,07 \mu \mathrm{mol} \mathrm{L}^{-1}(0 \mathrm{~m})$ e 0,06 $\mu \mathrm{mol} \mathrm{L}{ }^{-1}(5 \mathrm{~m})$, ambos associados ao ponto 6 , setor intermediário do sistema. Os maiores teores de fosfato foram de 3,21 $\mu \mathrm{mol} \mathrm{L}-1(0 \mathrm{~m})$ e $3,30 \mu \mathrm{mol} \mathrm{L}^{-1}(5 \mathrm{~m})$ no ponto 4 , no Canal do Valo, com teores mínimos de $0,50 \mu \mathrm{mol} \mathrm{L}^{-1}$ e $0,77 \mu \mathrm{mol} \mathrm{L}^{-1}$ associados ao ponto 6. O amônio apresentou teores mais estáveis em função do aumento da salinidade, apresentando teor máximo de $1,20 \mu \mathrm{mol} \mathrm{L}^{-1}(0 \mathrm{~m})$ e mínimo de $0,18 \mu \mathrm{mol} \mathrm{L}^{-1}(5 \mathrm{~m})$ no ponto 6 .

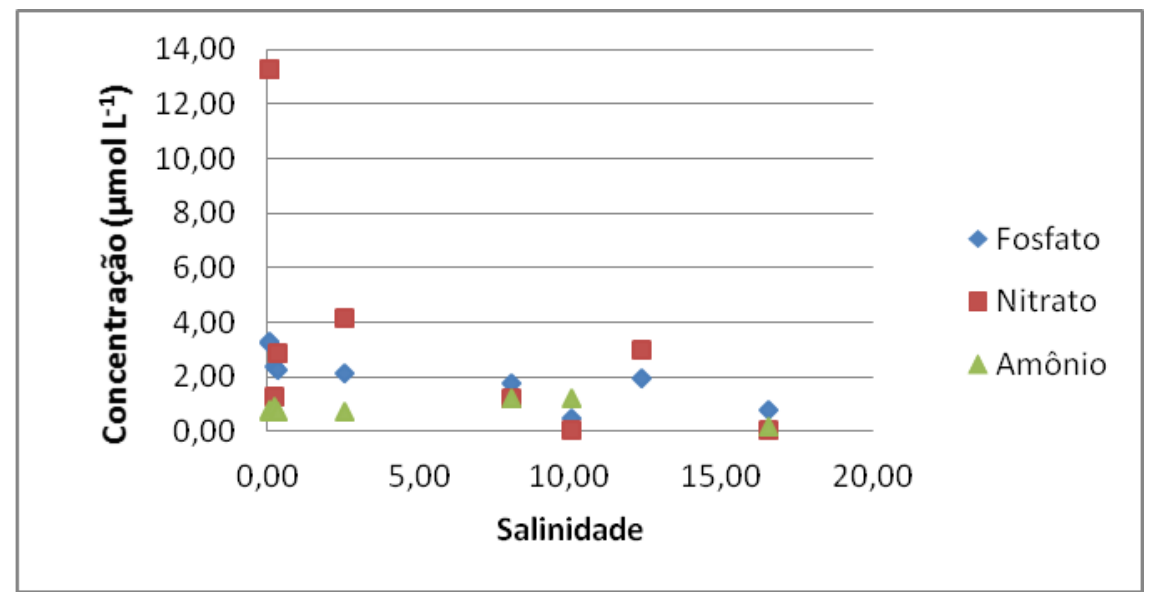

Figura 42. Distribuição de Fosfato, Nitrato e Amônio versus Salinidade, Iguape, em Fevereiro de 2014. 
Com relação ao MES, o maior valor, $51,00 \mathrm{mg} \mathrm{L}^{-1}$, foi encontrado no ponto 4 (5m), acompanhado pelo maior valor de $\mathrm{MO}, 9,40 \mathrm{mg} \mathrm{L}^{-1}$. Os valores mínimos foram 10,20 mg L-1 para o MES (estação 3, 5m) e 1,40 mg L-1 para o MO (estação 6, 5m). O maior valor de \% MO foi encontrado na estação 2 e na estação 5 (5m) de 35,42\%. A turbidez teve um valor máximo de 31,50 ntu e diminuiu sensivelmente na estação intermediária, tendo seu mínimo valor de 3,60 ntu a 0m de profundidade (Tab. 31).

Tabela 31. Valores de material em suspensão, matéria orgânica, \% de matéria orgânica e turbidez, em Iguape, no Valo Grande e no setor intermediário, em Fevereiro de 2014.

\begin{tabular}{|c|c|c|c|c|c|c|}
\hline $\begin{array}{l}\text { Fev. } \\
2014\end{array}$ & Est. & $\begin{array}{l}\text { Prof. } \\
\text { (m) }\end{array}$ & $\begin{array}{c}\text { MES } \\
\left(\mathrm{mg} \mathrm{L}^{-1}\right)\end{array}$ & $\begin{array}{c}\text { MO } \\
\left(\mathrm{mg} \mathrm{L}^{-1}\right)\end{array}$ & $\% \mathrm{MO}$ & $\begin{array}{l}\text { Turb } \\
\text { (ntu) }\end{array}$ \\
\hline \multirow{8}{*}{ Iguape } & 1 & 0 & 14,00 & 3,60 & 26,00 & - \\
\hline & 2 & 0 & 16,00 & 5,67 & 35,42 & - \\
\hline & 3 & 0 & 17,40 & 3,40 & 19,54 & 16,00 \\
\hline & & 5 & 10,20 & 2,80 & 27,45 & 17,40 \\
\hline & 4 & 0 & 16,80 & 3,60 & 21,43 & 15,60 \\
\hline & & 5 & 51,00 & 9,40 & 18,43 & 19,40 \\
\hline & 5 & 0 & 14,67 & 3,67 & 25,00 & 8,14 \\
\hline & & 5 & 16,00 & 5,67 & 35,42 & 31,50 \\
\hline \multirow{2}{*}{ Interm. } & 6 & 0 & 17,40 & 2,40 & 13,79 & 3,60 \\
\hline & & 5 & 13,00 & 1,40 & 10,77 & 7,94 \\
\hline
\end{tabular}

\subsubsection{Cananéia - Ararapira}

Os valores de temperatura na Campanha de Fevereiro de 2014, oscilaram entre $30,70{ }^{\circ} \mathrm{C}$ e $33,45{ }^{\circ} \mathrm{C}$, sendo a estação 10 , no setor Ararapira aquela que apresentou a temperatura mais alta. A salinidade no setor de Cananéia variou entre 22,32 e 28,60. Na estação 10 (Ararapira) a salinidade apresentou valores de 22,43 (0m) e 27,47 (5m), na estação 12 os valores de salinidade foram de 32,36 (0m) e 32,86 (5m). O pH esteve abaixo de 8 apenas na estação 11. O OD apresentou o seu maior teor na estação 7 (Cananéia), com 4,69 ml L-1 e menor na estação $10(5 \mathrm{~m}) \operatorname{com} 3,58 \mathrm{ml} \mathrm{L}^{-1}$. Os nutrientes apresentaram valores baixos, o P-fosfato, na estação $9(0 \mathrm{~m})$, obteve o maior valor encontrado de 0,63 $\mu$ mol L ${ }^{-1}$. O valore de NID foi maior que $1 \mu \mathrm{mol} \mathrm{L} \mathrm{L}^{-1}$ na estação 10 (5m) (Tab. 32). 
Tabela 32. Valores de temperatura, salinidade, $\mathrm{pH}$, oxigênio dissolvido, $\mathrm{N}$-amoniacal, nitrito, nitrato, fosfato , nitrogênio inorgânico dissolvido,relação entre nitrogênio inorgânico dissolvido e fosfato em Cananéia - Ararapira, em fevereiro de 2014.

\begin{tabular}{|c|c|c|c|c|c|c|c|c|c|c|c|c|}
\hline $\begin{array}{l}\text { Fev. } \\
2014\end{array}$ & Est. & $\begin{array}{c}\text { Prof. } \\
\text { (m) }\end{array}$ & $\begin{array}{c}\text { Temp. } \\
\left({ }^{\circ} \mathbf{C}\right)\end{array}$ & Salin. & pH & $\underset{\left(\mathbf{m L ~ L} \mathbf{L}^{-1}\right)}{\text { OD }}$ & $\underset{(\mu \mathrm{mol} \mathrm{L}}{\mathrm{N}-\mathbf{a m})}$ & $\begin{array}{c}\mathrm{N}^{-\mathrm{NO}_{2}}{ }^{-} \\
\left(\mu \mathrm{mol} \mathrm{L} \mathbf{L}^{-1}\right)\end{array}$ & $\begin{array}{c}\mathrm{N}^{-\mathrm{NO}_{3}}{ }^{-} \\
\left(\mu \mathrm{mol} \mathrm{L} \mathbf{L}^{-1}\right)\end{array}$ & $\begin{array}{c}\text { NID } \\
\left(\mu \mathrm{mol} \mathrm{L} \mathbf{L}^{-1}\right)\end{array}$ & $\begin{array}{c}\mathbf{P}^{-P \mathbf{O}_{4}{ }^{3-}} \\
\left(\mu \mathrm{mol} \mathrm{L} \mathbf{L}^{-1}\right)\end{array}$ & $\begin{array}{c}\mathrm{NID} / \\
\mathrm{P}- \\
\mathrm{PO}_{4}{ }^{3} \\
\end{array}$ \\
\hline \multirow{6}{*}{ Cananéia } & 7 & 0 & 32,82 & 23,66 & 8,07 & 4,69 & 0,38 & 0,03 & 0,07 & 0,48 & 0,80 & 0,60 \\
\hline & & 5 & 31,93 & 27,28 & 8,03 & 4,02 & 0,10 & 0,04 & 0,06 & 0,19 & 0,49 & 0,38 \\
\hline & 8 & 0 & 32,80 & 23,57 & 8,07 & 4,63 & 0,25 & 0,03 & 0,07 & 0,35 & 0,64 & 0,55 \\
\hline & & 5 & 31,95 & 26,82 & 8,05 & 4,20 & 0,16 & 0,04 & 0,06 & 0,26 & 0,52 & 0,50 \\
\hline & 9 & 0 & 32,35 & 22,32 & 8,08 & 4,66 & 0,08 & 0,04 & 0,06 & 0,18 & 0,63 & 0,28 \\
\hline & & 5 & 31,68 & 28,60 & 8,04 & 4,05 & 0,26 & 0,06 & 0,14 & 0,46 & 0,48 & 0,95 \\
\hline \multirow{6}{*}{ Ararapira } & 10 & 0 & 33,45 & 22,47 & 8,02 & 4,49 & 0,38 & 0,06 & 0,19 & 0,63 & 0,07 & 9,00 \\
\hline & & 5 & 32,63 & 27,47 & 8,00 & 3,58 & 1,15 & 0,10 & 0,30 & 1,55 & 0,04 & 38,75 \\
\hline & 11 & 0 & 32,60 & 22,16 & 7,94 & 4,38 & 0,83 & 0,04 & 0,11 & 0,98 & 0,07 & 14,00 \\
\hline & & 5 & 32,40 & 25,40 & 7,99 & 4,14 & 0,50 & 0,04 & 0,11 & 0,65 & 0,25 & 2,60 \\
\hline & 12 & 0 & 31,20 & 32,36 & 8,17 & 4,44 & 0,14 & 0,03 & 0,12 & 0,29 & 0,10 & 2,90 \\
\hline & & 5 & 30,70 & 32,86 & 8,18 & 4,61 & 0,34 & 0,04 & 0,11 & 0,49 & 0,09 & 5,44 \\
\hline
\end{tabular}

No que se refere ao MES, o maior valor, $48,80 \mathrm{mg} \mathrm{L}^{-1}$, foi encontrado no ponto 7, profundidade $5 \mathrm{~m}$, sendo acompanhado pelo maior teor de $\mathrm{MO}$ de $14,60 \mathrm{mg} \mathrm{L}^{-1}$, assim como o maior valor de \% MO de 29,92\%. Os valores mínimos destes parâmetros também ocorreram na estação 7, mas na superfície, com valores de 22,60 mg L $\mathrm{m}^{-1}, 4,80 \mathrm{mg} \mathrm{L}^{-1} \mathrm{e}$ $21,24 \%$ respectivamente. A turbidez tem seu menor valor encontrado de 2,14 ntu na estação 10 e seu máximo de 11,10 ntu no ponto 12 a 0m de profundidade (Tab.33).

Tabela 33. Concentrações de material em suspensão, material orgânico em suspensão, porcentagem de material orgânico em suspensão e turbidez, nas águas de Cananéia - Ararapira, em Fevereiro de 2014.

\begin{tabular}{|c|c|c|c|c|c|c|}
\hline $\begin{array}{c}\text { Fev. } \\
\mathbf{2 0 1 4}\end{array}$ & Est. & $\begin{array}{c}\text { Prof. } \\
(\mathbf{m})\end{array}$ & $\begin{array}{c}\text { MES } \\
\left(\mathbf{m g ~ L}^{-\mathbf{1}}\right)\end{array}$ & $\begin{array}{c}\text { MO } \\
\left(\mathbf{m g ~ L}^{-\mathbf{1}}\right)\end{array}$ & $\mathbf{\% M O}$ & $\begin{array}{c}\text { Turb. } \\
(\mathbf{n t u})\end{array}$ \\
\hline \multirow{4}{*}{ Cananéia } & 7 & 0 & 22,60 & 4,80 & 21,24 & 2,51 \\
\cline { 2 - 7 } & & 5 & 48,80 & 14,60 & 29,92 & 2,42 \\
\cline { 2 - 7 } & 8 & 0 & 33,00 & 8,43 & 25,54 & 2,54 \\
\cline { 2 - 7 } & & 5 & 36,29 & 9,29 & 25,59 & 2,36 \\
\cline { 2 - 7 } & & 0 & 32,71 & 8,86 & 27,07 & 2,67 \\
\hline \multirow{5}{*}{ Ararapira } & 10 & 0 & 36,71 & 10,00 & 27,24 & 2,77 \\
\cline { 2 - 7 } & & 5 & 41,17 & 8,83 & 27,46 & 2,14 \\
\cline { 2 - 7 } & 11 & 0 & 29,29 & 10,67 & 25,60 & 2,30 \\
\cline { 2 - 7 } & & 5 & 35,33 & 8,67 & 25,37 & 3,62 \\
\cline { 2 - 7 } & 12 & 0 & 23,14 & 5,29 & 22,83 & 4,22 \\
\cline { 2 - 7 } & & 5 & 47,14 & 11,14 & 23,64 & 4,95 \\
\hline
\end{tabular}

Em Cananéia, na Campanha de Fevereiro de 2014, os teores de fosfato diminuíram em função do aumento da salinidade (Fig. 43). O fosfato também foi o nutriente que teve teores mais altos, com o mínimo de $0,48 \mu \mathrm{mol} \mathrm{L}^{-1}$, em salinidade 28,60 , e máximo de 0,80 
$\mu \mathrm{mol} \mathrm{L}{ }^{-1}$, em salinidade 23,66. O nitrato apresentou valor máximo de $0,46 \mu \mathrm{mol} \mathrm{L}^{-1}$ onde a salinidade é maior. O N-amoniacal mostrou valores baixos, porém os mais representativos na composição do NID.

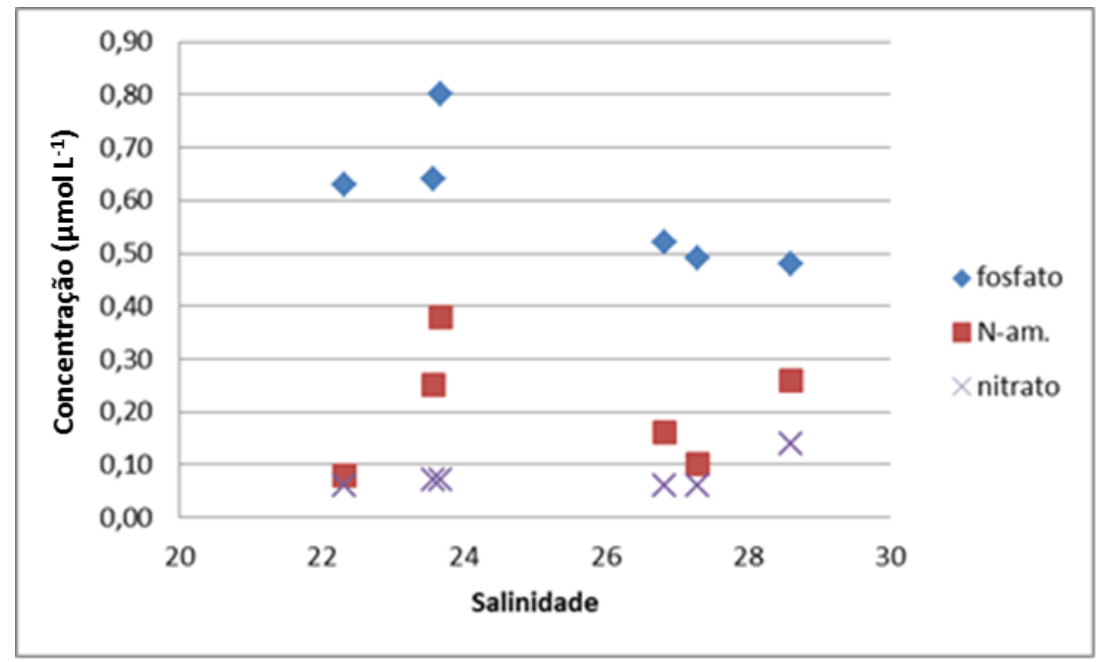

Figura 43. Distribuição de Fosfato, Nitrato e Amônio versus Salinidade, Cananéia, em Fevereiro de 2014.

Na região de Ararapira (Fig. 44), encontram-se águas com salinidade que variam de 22,16 (água salobra) até a salinidade 32,86 (água salina). O N-amoniacal foi o nutriente que teve os maiores teores encontrados em ambas as campanhas de verão, com o teor máximo de $1,15 \mu \mathrm{mol} \mathrm{L} \mathrm{L}^{-1}$ para salinidade 27,47 e mínimo de $0,14 \mu \mathrm{mol} \mathrm{\textrm {L } ^ { - 1 }}$ para a salinidade 32,36. O P-fosfato apresentou maior teor encontrado de $0,25 \mu \mathrm{mol} \mathrm{L}^{-1}$ sob salinidade de 25,40 e sob a salinidade de 32,86 foi de $0,09 \mu \mathrm{mol} \mathrm{L}^{-1}$. Quanto ao N- nitrato, sob a salinidade de 22,47 apresentou o teor de $0,19 \mu \mathrm{mol} \mathrm{L}^{-1}$ e sob a salinidade 32,86 apresentou teor de $0,12 \mu \mathrm{mol} \mathrm{L} \mathrm{L}^{-1}$.

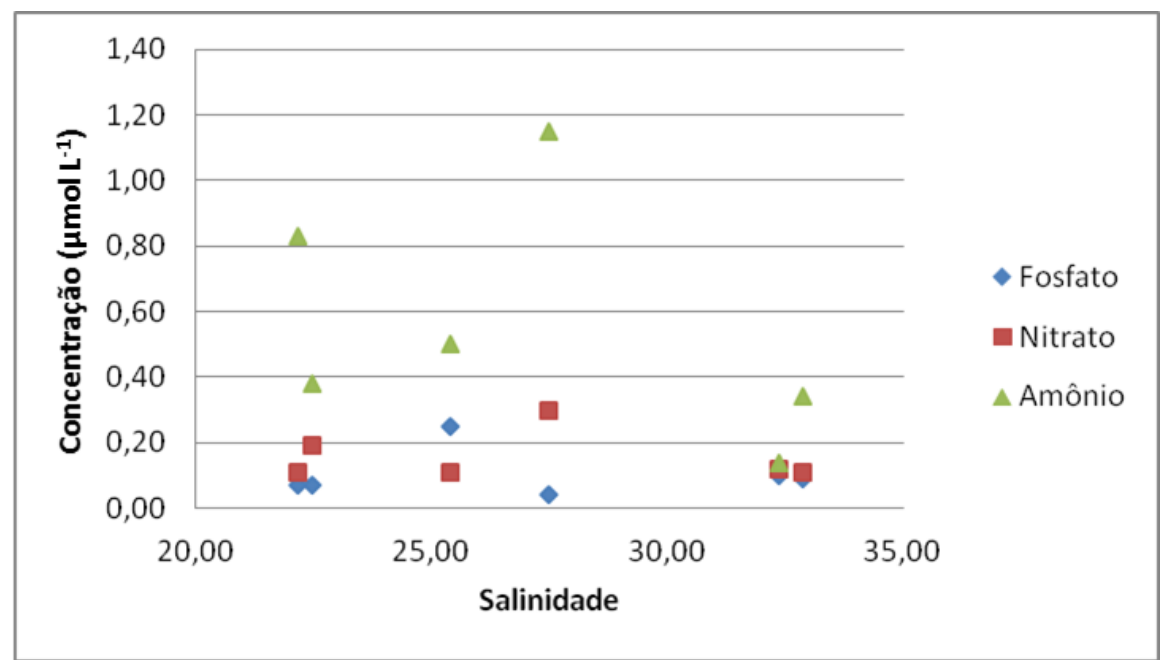

Figura 44. Distribuição de Fosfato, Nitrato e Amônio versus Salinidade. Ararapira, em Fevereiro de 2014. 
A Campanha de Fevereiro de 2014 (Tab. 34) apresentou temperaturas mais elevadas que as Campanhas anteriores, apresentando temperaturas de em média $3^{\circ} \mathrm{C}$, mais elevadas que a Campanha do verão anterior. A salinidade é de água doce nas áreas próximas ao Rio (Rio Ribeira, Valo Grande, estação 5 de Iguape) e vai aumentando em direção à porção sul do sistema, passando de salobra para salina em Ararapira. $\mathrm{O}$ pH aumenta com o aumento da salinidade ficando em torno de 8. O oxigênio dissolvido mostrou valores acima de $6 \mathrm{ml} \mathrm{L}^{-1}$, em algumas estações na porção Norte do sistema e concentrações entre 3,58 $\mathrm{ml} \mathrm{L}^{-1}$ e 4,69 $\mathrm{m} \mathrm{L}^{-1}$ em Cananéia e Ararapira. Quanto ao material em suspensão, os maiores valores encontrados foram no Valo Grande, apresentando teor de 51,00 mg L-1, seguido por Cananéia com teor de 48,80 $\mathrm{mg} \mathrm{L}^{-1}$ e Ararapira com 47,14 $\mathrm{mg} \mathrm{L}^{-1}$. O maior valor de matéria orgânica encontrada foi em Cananéia com 14,60 mg L${ }^{1}$ e a maior porcentagem de matéria orgânica foi encontrada em Iguape com 35,42\%. A turbidez teve seu maior valor registrado em Iguape com 31,50 ntu e o menor valor em Ararapira com 2,30 ntu.

Quanto aos nutrientes nitrogenados, o $\mathrm{N}$-amoniacal apresentou o menor teor de $0,08 \mu \mathrm{mol} \mathrm{L}{ }^{-1}$ em Cananéia e maior valor de $2,88 \mu \mathrm{mol} \mathrm{L}^{-1}$ no R6. O N-nitrito, na porção Sul do sistema e também na estação intermediária, apresentou seu teor mínimo de 0,03 $\mu$ mol $\mathrm{L}^{-1}$ e máximo teor de $0,22 \mu \mathrm{mol} \mathrm{L}^{-1}$ na parte norte do sistema. $\mathrm{O} \mathrm{N}$-nitrato apresentou teores maiores que $10,00 \mu \mathrm{mol} \mathrm{L}^{-1}$ para as estações do Rio e do Valo, com

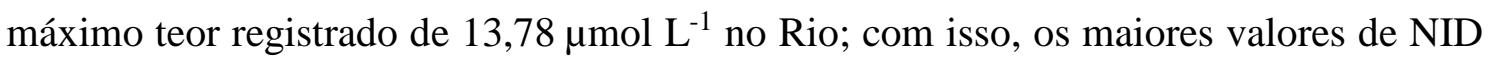
foram encontrados na porção Norte do Sistema, nas porções do Rio e do Valo com teores máximos de $15,90 \mu \mathrm{mol} \mathrm{L} \mathrm{L}^{-1}$ e $14,24 \mu \mathrm{mol} \mathrm{L}^{-1}$, respectivamente. O menor valor de NID registrado foi em Ararapira com $0,29 \mu \mathrm{mol} \mathrm{L}^{-1}$. O P-fosfato também apresentou seus maiores teores registrados na porção norte do Sistema com máximos de $3,36 \mu \mathrm{mol} \mathrm{L}^{-1}$ no Rio e 3,30 $\mu \mathrm{mol} \mathrm{L}-1$ no Valo Grande, e mínimo de $0,04 \mu \mathrm{mol} \mathrm{L}-1$ no Canal do Ararapira. 
Tabela 34. Quadro sinóptico da situação do sistema em Fevereiro de 2014.

\begin{tabular}{|c|c|c|c|c|c|c|}
\hline Fevereiro 2014 & Rio Ribeira & Valo Grande & Iguape & Inter. & Cananéia & Ararapira \\
\hline $\mathbf{T}\left({ }^{\circ} \mathbf{C}\right)$ & $32,50-33,20$ & $31,60-32,7$ & $31,7-33,5$ & $32,51-32,89$ & $31,68-32,82$ & $30,70-33,45$ \\
\hline Salinidade & $0,04-0,05$ & $0,05-0,05$ & $0,25-12,35$ & $10,03-16,54$ & $22,32-28,60$ & $22,16-32,86$ \\
\hline pH & $7,43-7,74$ & $7,38-7,77$ & $7,51-7,87$ & $7,64-7,77$ & $8,03-8,07$ & $7,94-8,18$ \\
\hline $\mathrm{OD}\left(\mathrm{ml} \mathrm{L}^{-1}\right)$ & $6,04-7,26$ & $5,79-6,07$ & $4,33-6,07$ & $5,27-5,43$ & $4,05-4,69$ & $3,58-4,61$ \\
\hline MES $\left(m g L^{-1}\right)$ & $8,20-15,00$ & $16,80-51,00$ & $10,20-17,4$ & $13,00-17,40$ & $22,60-48,80$ & $23,14-47,14$ \\
\hline MO $\left(\mathrm{mg} \mathrm{L}^{-1}\right)$ & $2,67-5,33$ & $3,60-9,40$ & $2,80-5,67$ & $1,40-2,40$ & $4,80-14,60$ & $5,29-11,14$ \\
\hline$\% \mathrm{MO}$ & $23,53-5,42$ & $18,43-21,43$ & $19,54-35,42$ & $10,77-13,79$ & $21,24-29,92$ & $22,84-27,46$ \\
\hline Turb. (ntu) & $9,91-18,90$ & $15,6-19,4$ & $8,14-31,50$ & $3,60-7,94$ & $2,36-2,77$ & $2,30-11,10$ \\
\hline $\mathrm{N}$-am. $\left(\mu \mathrm{mol} \mathrm{L}{ }^{-1}\right)$ & $0,29-2,88$ & $0,69-0,75$ & $0,19-1,25$ & $0,18-1,20$ & $0,08-0,38$ & $0,14-1,15$ \\
\hline $\begin{array}{c}\mathrm{N}-\mathrm{NO}_{2}{ }^{-}\left(\mu \mathrm{mol} \mathrm{\textrm {L } ^ { - }}\right. \\
\left.{ }_{1}\right) \\
\end{array}$ & $0,21-0,22$ & $0,21-0,22$ & $0,12-0,22$ & 0,03 & $0,03-0,06$ & $0,03-0,10$ \\
\hline $\begin{array}{c}\mathrm{N}^{-\mathrm{NO}_{3}}{ }^{-}(\mu \mathrm{mol} \mathrm{L} \\
{ }_{1}\end{array}$ & $10,33-13,78$ & $13,27-13,28$ & $1,21-13,28$ & $0,06-0,07$ & $0,06-0,14$ & $0,11-0,30$ \\
\hline $\mathrm{NID}\left(\mu \mathrm{mol} \mathrm{L} \mathrm{L}^{-1}\right)$ & $10,83-15,90$ & $14,18-14,24$ & $2,19-14,24$ & $1,30-2,08$ & $0,18-0,63$ & $0,29-1,55$ \\
\hline 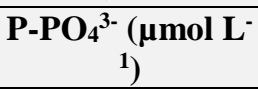 & $3,06-3,36$ & $3,21-3,30$ & $1,77-2,35$ & $0,50-0,77$ & $0,48-0,80$ & $0,04-0,25$ \\
\hline $\mathrm{NID} / \mathrm{P}-\mathrm{PO}_{4}{ }^{3-}$ & $10,83-15,90$ & $4,29-4,44$ & $0,99-4,81$ & $2,60-2,70$ & $0,28-0,95$ & $2,6-38,75$ \\
\hline
\end{tabular}

De um modo geral, a temperatura foi maior no setor do Rio Ribeira de Iguape decrescendo em direção ao Canal do Ararapira. A salinidade foi menor, próxima a zero nos pontos do Rio e foi aumentando em direção ao setor sul. As águas do rio tiveram um maior valor de OD. Os nutrientes mostraram valores maiores na região do Rio e do canal do Valo Grande, assinalando que esta área é mais vulnerável à influência da agricultura e demais atividades antrópicas que ocorrem rio acima. A estação associada ao Canal do Valo Grande apresentou um maior valor de MES, enquanto o maior teor de matéria orgânica e porcentagem de MO foi registrado no ponto 7 (5m) em Cananéia, o maior valor de turbidez foi registrado em Iguape, no ponto $5(5 \mathrm{~m})$ de profundidade (Tab.34).

Assim, as atividades antrópicas têm aumentado o nível dos nutrientes das águas de superfície. O transporte de material pelos rios fornece informação essencial quanto aos processos que ocorrem na zona costeira como o aumento do intemperismo, agricultura intensiva, poluição por agrotóxicos e fertilizantes e também, oferece informações sobre a quantidade e natureza do material que é carreado dos rios para outros corpos d'água como lagos, estuários e oceanos.

\subsubsection{Discussão Parcial}

A figura 45 a mostra faixas de salinidade bem distintas em cada setor. Fevereiro de 2014 surpreende com valores de salinidade maiores no setor intermediário; Agosto de 2012 mostra os maiores valores de salinidade no setor sul. Valores de temperatura foram menores nos períodos de inverno; o pH mostrou mais estabilidade no setor de Cananéia 
e Ararapira, com valores em torno de 8. O OD mostrou maiores valores no inverno, porém no setor de Iguape e entre os dois verões mostra alterações, o que é comum para este parâmetro.

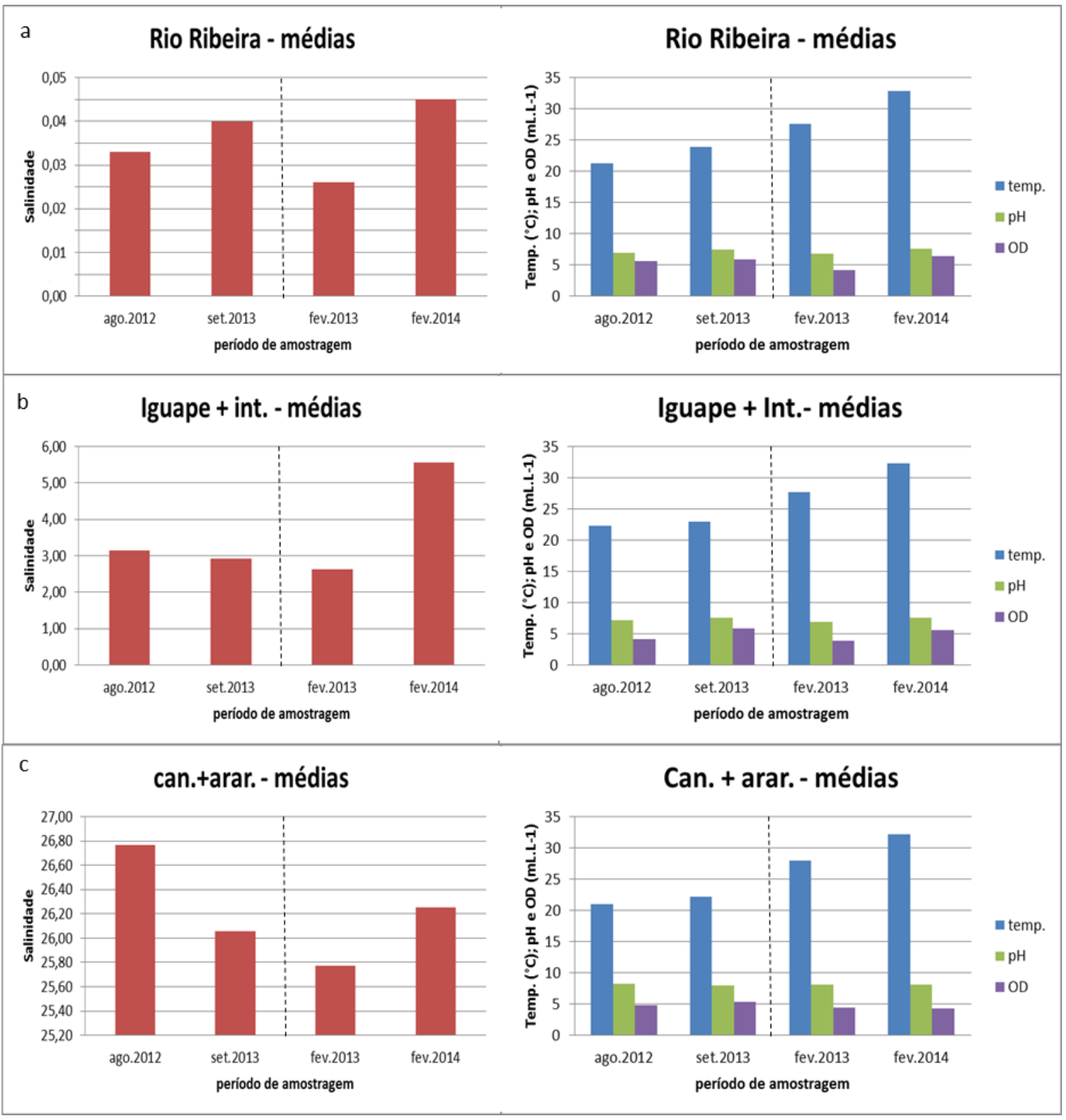

Figura 45. Valores médios dos parâmetros salinidade, temperatura, $\mathrm{pH}$ e OD nos diferentes anos, no setor Rio(a), Iguape (b) e Cananéia-Ararapira (c).

No caso dos nutrientes (Fig. 46), o P- fosfato mostrou valores muito altos no rio e em Iguape sobretudo em Agosto de 2012 e os valores diminuíram no verão. Os valores de $\mathrm{N}$-nitrato foram altos em todas as campanhas no Rio, bem como o $\mathrm{N}$-amoniacal, mantiveram-se altos em Iguape no inverno e no verão 2013. A relação NID/PO ${ }_{4}^{3-}$ só se destacou quando houve baixa efetiva do fosfato, com os maiores valores em CananéiaArarapira nos verões e no inverno de 2012. O material em suspensão apresentou destaque 
no setor Norte no verão 2013, enquanto no sul, mostrou destaque em Setembro de 2013.

Em suma, Fevereiro de 2013 foi bastante chuvoso, o que pode ter interferido em algumas propriedades do sistema, sobretudo no Norte. Agosto de 2012 foi muito seco enquanto Setembro de 2013 não o foi tanto.

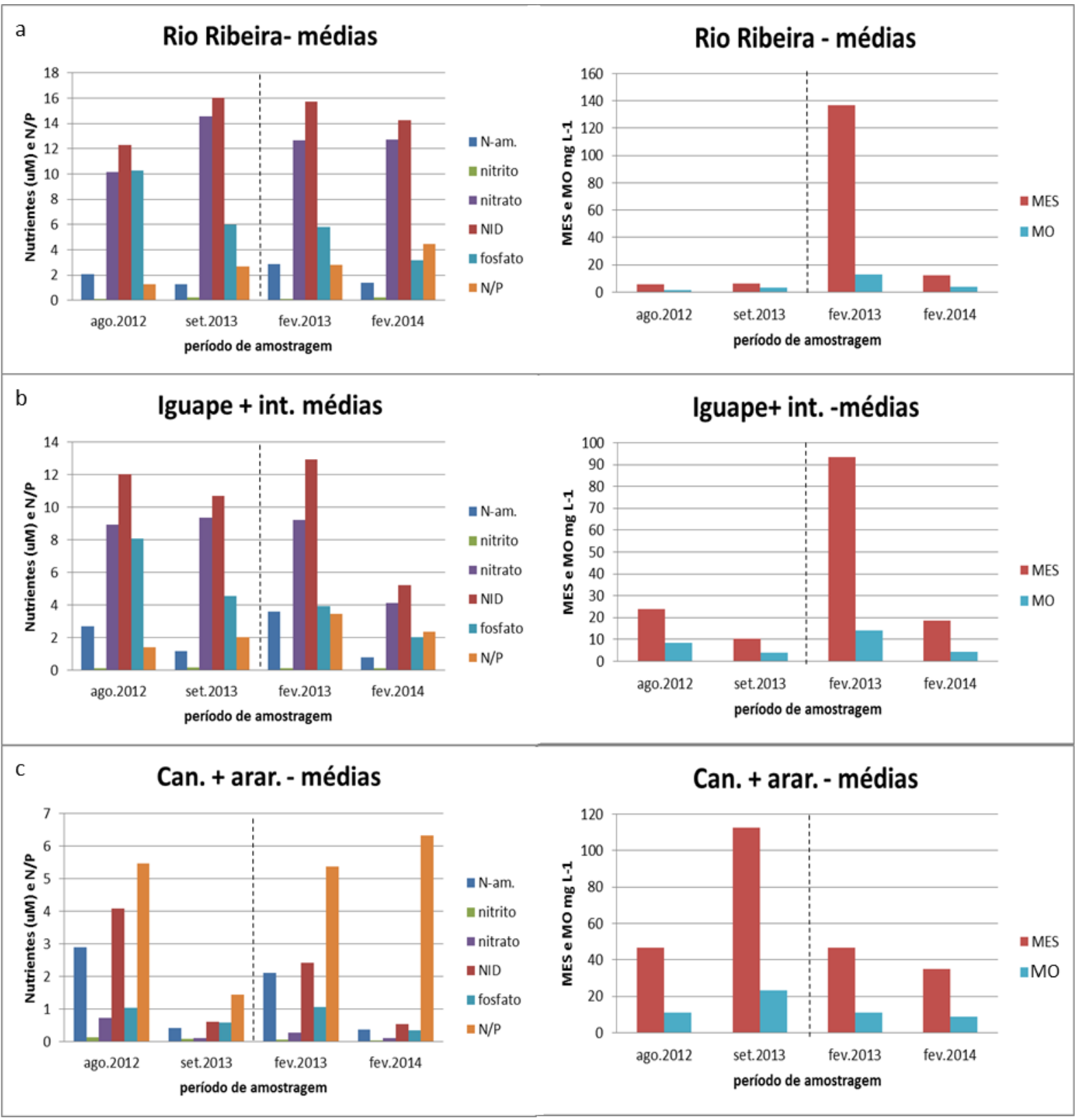

Figura 46. Valores médios dos parâmetros $\mathrm{N}$-amoniacal, nitrito, nitrato, NID, fosfato e razão N/P nos diferentes anos, no setor Rio (a), Iguape (b) e Cananéia-Ararapira (c).

O trabalho realizado por Meybeck (1982) (Tab. 35) mostrou os teores de N-nitrato e P-fosfato em Rios ainda não poluídos, de diferentes regiões (ártica, subárticas, temperadas, tropicais e desérticas). 
Tabela 35. Concentrações de fosfato e nitrato em rios com base no trabalho de Meybeck, 1982.

\begin{tabular}{|c|c|c|c|}
\hline Região & Rios & $\begin{array}{l}\text { Nitrato } \\
\left(\mu g L^{-1}\right)\end{array}$ & $\begin{array}{l}\text { Fosfato } \\
\left(\mu g L^{-1}\right)\end{array}$ \\
\hline Ártica & Kazan e Back & - & 2 \\
\hline Subártica & Iceland & 0,7 & 20 \\
\hline Temperada & $\begin{array}{l}\text { Gloma } \\
\text { Volga }\end{array}$ & $\begin{array}{l}- \\
-\end{array}$ & $\begin{array}{c}6,8 \\
11\end{array}$ \\
\hline Tropical & $\begin{array}{l}\text { Solimões } \\
\text { Negro } \\
\text { Amazonas }\end{array}$ & $\begin{array}{l}1 \\
1 \\
1\end{array}$ & $\begin{array}{c}15 \\
6 \\
12\end{array}$ \\
\hline Desértica & Orange & - & 9,1 \\
\hline
\end{tabular}

Ainda segundo Meybeck (1982), a taxa de exportação do N-nitrato pode variar de menos de $10 \mathrm{~kg} \mathrm{~km}^{-2}$ ano $^{-1}$ nas regiões subárticas (rios: Nelson, Kazan e Back) a $200 \mathrm{~kg}$ $\mathrm{km}^{-2} \mathrm{ano}^{-1}$ nas regiões tropicais úmidas (rios: Sumatra, Borneo, Papua). O nível de fosfato (ortofosfato) foi baixo em águas naturais variando de 1 a $24 \mu \mathrm{g} \mathrm{L}^{-1}$; tais águas foram filtradas (rios do Brasil) e o ortofosfato $\mathrm{P}_{-} \mathrm{PO}_{4}$ foi a forma de fosfato predominantemente encontrada.

Bacias hidrográficas de rios baixos como as dos Rios Don e Ythan na Escócia, sob intensa influência da área de agricultura, tiveram o teor de $\mathrm{N}$-nitrato acrescido acima de $600 \mu \mathrm{mol} \mathrm{L}{ }^{-1}$ e, teor de P-fosfato elevado acima de $5 \mu \mathrm{mol} \mathrm{L}{ }^{-1}$ nos respectivos estuários. Em contrapartida, rios de montanha, com solos minerais pobres, pequena população e baixa agricultura encontrada nas proximidades dos Rios Inverness, Cromarty e Dornoch Firths, mostraram teores bem menores destes nutrientes, com nitrato apresentando teores entre 3 e $8 \mu \mathrm{mol} \mathrm{L}{ }^{-1}$ e fosfato com teores entre 0,07 e $0,28 \mu \mathrm{mol} \mathrm{L}^{-1}$ (Balls, 1994).

A exportação de nutrientes na interface solo água é acrescida em função do uso da terra e este acréscimo é ainda maior quando há o uso de fertilizantes. Dados pretéritos de Young et al. (1996), Mckee et al. (2000), Brodie \& Mitchell (2005), afirmam que em comparação a florestas, as pastagens podem acrescer a perda de nutrientes (nitrato e fosfato) em 10 vezes mais, e plantações, voltadas ao mercado agrícola, consideram esta perda em mais de 20 vezes.

Muitos experimentos agronômicos (Dowdell, 1982; Hilhorst et al., 2001; Delgado, 2002) sugerem que de uma forma geral, as culturas agrícolas usam apenas $50 \%$ do $\mathrm{N}$ aplicado. O N excedente será perdido via volatilização (amônia), denitrificação e lixiviação (Boumans et al. ,2005). 
Segundo Khatik et al., (2011), em trabalho conduzido na Índia, em Jalgaon, distrito de Maharashitra, área sob intenso cultivo de bananas, onde se avaliou o teor residual do nitrato em solo e o posterior movimento horizontal e descendente deste no perfil do solo atingido águas subterrâneas, revelou teores encontrados na água de 16,8 mg $\mathrm{L}^{-1}$ a $79,7 \mathrm{mg} \mathrm{L}^{-1}$. De acordo com o autor, em muitos países tropicais, pouca informação é validada ou padronizada quanto à quantidade de aplicação de nutrientes/fertilizantes em culturas agrícolas e a subsequente poluição dos cursos d’água adjacentes a estas terras.

O impacto negativo desta falta de informação talvez deva-se à crença que o uso de fertilizantes ainda esteja abaixo do nível alarmante nestes países e portanto não poluem o ambiente (Olarewaju et al.,2009).

Outro trabalho (Mitchel et al., 2009) conduzido na Austrália, comparando três Rios (Tully, Murray e Hull), no período de 1987-1995, no qual foram analisadas concentrações de N-nitrato em diferentes áreas de cultivo (cana de açúcar, banana) e de usos da terra, confirmou-se que o N-nitrato apresenta um pico de aporte, em especial no início de estação de chuvas. Ao comparar culturas distintas como a cana-de-açúcar e a banana, notou-se que a cultura da banana era responsável pelo grande aporte de nitrato para o Rio, cerca de $25 \%$ maior (teor de nitrato encontrado de $46 \mu \mathrm{g} \mathrm{L}^{-1}$ ), em função da época de adubação e proximidade da chuva. Quanto aos aportes em relação às outras formas do N (N-amoniacal, N-nitrito) e ao P (P-fosfato), estes não foram tão significativos quanto o N-nitrato. A estimativa de exportação de $\mathrm{N}$-nitrato para o rio Tully que cobre uma área de $1683 \mathrm{~km}^{2}$ (Brodie et al., 2001), em áreas de cana-de-açúcar e banana, foi de aproximadamente $502 \mathrm{~T}$ ano $^{-1}$ (Mitchel et al, 2009).

Outro trabalho também conduzido na região do rio Rio Tully (Faithful \& Finlayson, 2005), mostrou que altas concentrações de aporte de nutrientes nitrogenados ocorreram via escoamento das culturas de banana, chegando a um fluxo de 9,2 kg/Nnitrato e $0,8 \mathrm{~kg} / \mathrm{P}$-fosfato, após uma única e intensa tempestade.

A região estuarina da baixada Santista, que está sob forte influência das indústrias apresentou teores de $\mathrm{N}$-nitrato acima de $90 \mu \mathrm{mol} \mathrm{L}{ }^{-1}$ e teores de P-fosfato acima de 24 $\mu \mathrm{mol} \mathrm{L}{ }^{-1}$ segundo Braga et al. (2000).

No trabalho atual, as estações de Rio apresentaram uma alta concentração de nutrientes, tanto para o $\mathrm{N}$-nitrato que teve seu valor máximo de $10,37 \mu \mathrm{mol} \mathrm{L}{ }^{-1}$ como para o P-fosfato que teve o seu maior e bastante alto valor de $12,45 \mu \mathrm{mol} \mathrm{L}^{-1}$. O N-amoniacal teve valores altos nas estações mais próximas ao Valo Grande, corroborando com o fato 
que $70 \%$ da vazão do rio é vertida para esta área, sendo assim, a salinidade é típica de água fluvial ficando entre 0,03-0,04.

Dados do relatório de águas superficiais da CETESB (2013), mostram que os teores médios de N-nitrato encontrado nos pontos de coleta e monitoramento do Rio Ribeira do Iguape (RIIG02500, RIIG02900 e RIIG02995) (Fig. 41) mostraram valores entre $0,23 \mathrm{mg} \mathrm{L}^{-1}\left(16,4 \mu \mathrm{mol} \mathrm{L}{ }^{-1}\right)$ e $0,26 \mathrm{mg} \mathrm{L}^{-1}\left(18,5 \mu \mathrm{mol} \mathrm{L}^{-1}\right)$, no ano de 2013 , e dados pretéritos de 2008-2012, mostraram teores médios de $0,29 \mathrm{mg} \mathrm{L}^{-1}$ a $0,32 \mathrm{mg} \mathrm{L}^{-1}(20,5 \mathrm{a}$ $\left.22,8 \mu \mathrm{mol} \mathrm{L}{ }^{-1}\right)$. O N-amoniacal apresentou teores médios para o ano de $2013 \mathrm{de} 1 \mathrm{mg} \mathrm{L}^{-}$ ${ }^{1}\left(71,4 \mu \mathrm{mol} \mathrm{L}{ }^{-1}\right)$, enquanto que a média dos quatro anos anteriores (2008-2012) foi de 0,54 mg L $\mathrm{m}^{-1}$ a $0,55 \mathrm{mg} \mathrm{L}^{-1}\left(39,3 \mu \mathrm{mol} \mathrm{L}^{-1}\right)$. Com relação ao fósforo, este apresentou no ano de 2013 teores médios de $0,15 \mathrm{mg} \mathrm{L}^{-1}$ e $0,16 \mathrm{mg} \mathrm{L}^{-1}\left(5,1 \mu \mathrm{mol} \mathrm{L} \mathrm{L}^{-1}\right)$ para os pontos RIIG02995 e RIIG02900 e teores médios de $0,19 \mathrm{mg} \mathrm{L}^{-1}$ e $0,26 \mathrm{mg} \mathrm{L}^{-1}\left(6,1 \mu \mathrm{mol} \mathrm{L}^{-1}-\right.$ $8,4 \mu \mathrm{mol} \mathrm{L}{ }^{-1}$ ) para os 4 anos anteriores (2008-2012). Cabe ressaltar que no ponto monitorado do Rio Jacupiranga (JAPI021000) (Fig. 41), foram encontrados teores de fósforo de $3,8 \mathrm{mg} \mathrm{L}^{-1}\left(12,2 \mu \mathrm{mol} \mathrm{L}{ }^{-1}\right)$ no ano de 2013 e $2,4 \mathrm{mg} \mathrm{L}^{-1}\left(7,7 \mu \mathrm{mol} \mathrm{L}^{-1}\right)$ em média para o período de 2008-2012. Os valores médios de OD foram de 5,9 $\mathrm{mg} \mathrm{L}^{-1}$ (RIIG02995), 6,2 $\mathrm{mg} \mathrm{L}^{-1}$ (RIIG02900) e 7,0 mg L'-1 (RIIG02500) para o ano de 2013, e teores médios de 7,1 mg L-1 (RIIG02995), 6,4 $\mathrm{mg} \mathrm{L}^{-1}$ (RIIG02900) e 6,0 mg L-1 (RIIG02900) para o período de 2008-2012.

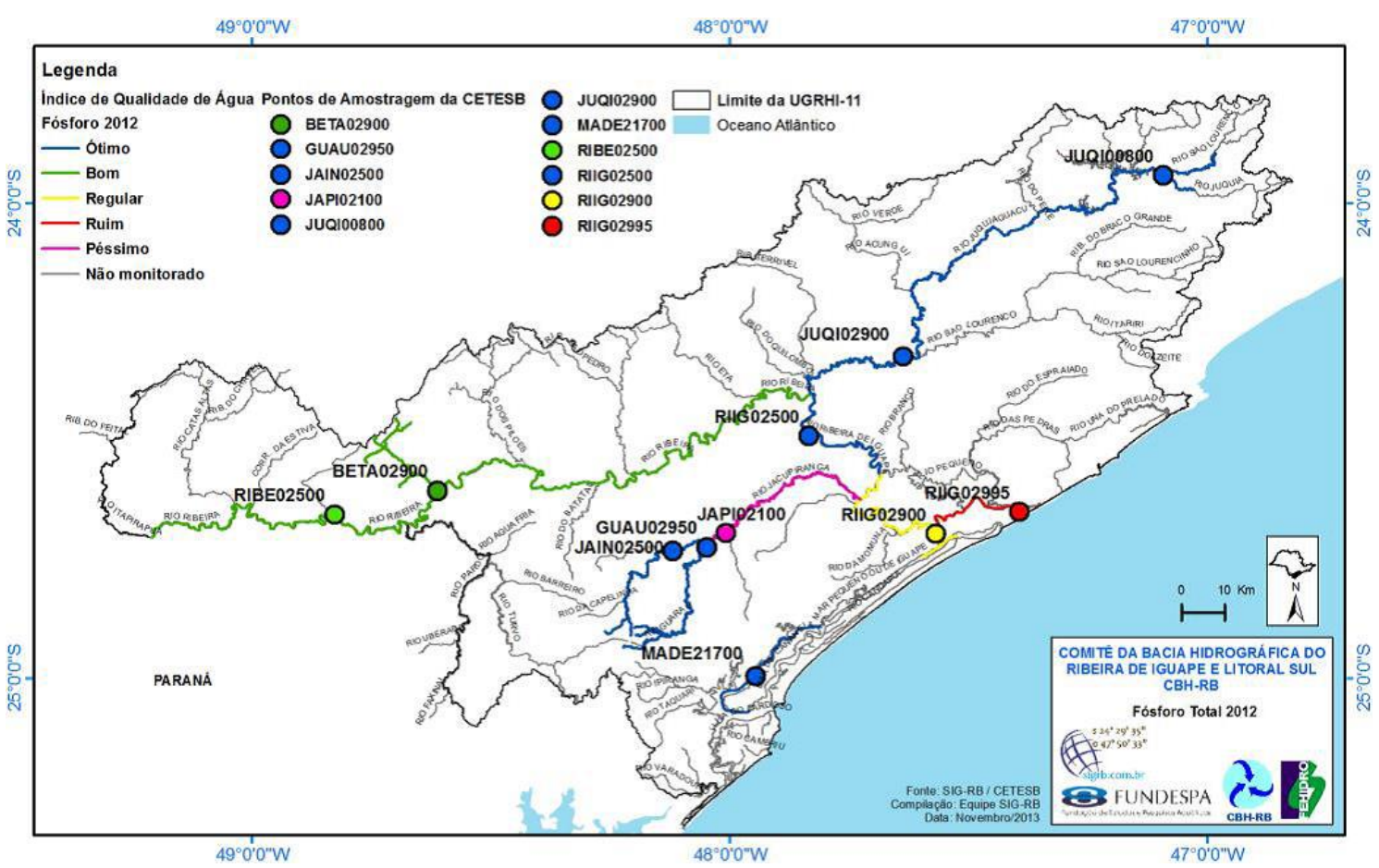

Figura 47. Mapa referente ao indicador E.01 (1) - Fósforo total. Fonte: CETESB ,2013 
Um trabalho conduzido na extensão do Rio Ribeira, desde o seu início em Cerro Azul (PR) e Rio Branco do Sul, até a desembocadura no Oceano (BRASIL DAS ÁGUAS, 2007) apresentou dados que estão na tabela 36.

Tabela 36. Valores de $\mathrm{pH}$, oxigênio dissolvido, $\mathrm{N}$-amoniacal, N-nitrito, N-nitrato, N-total, Pfósforo, fósforo total em Registro e no Canal do Valo Grande, Novembro de 2006. Fonte:

BRASIL DAS ÁGUAS (2007) e estudo atual.

\begin{tabular}{|c|c|c|c|c|c|c|c|c|c|c|}
\hline $\begin{array}{l}\text { Ponto de } \\
\text { coleta }\end{array}$ & Mês/ano & LAT./LONG. & $\mathrm{pH}$ & OD & $\begin{array}{c}\mathrm{N}- \\
\text { amon }\end{array}$ & $\mathrm{N}$-nitrito & N-nitrato & $\mathrm{N}$ (total) & P-fosfato & $\mathrm{P}$ (total) \\
\hline Unidade & & & & $m L^{-1}$ & $\mu g L^{-1}$ & $\mu \mathrm{gL}^{-1}$ & $\mu g L^{-1}$ & $\mu g L^{-1}$ & $\mu g L^{-1}$ & $\mu g L^{-1}$ \\
\hline Registro* & 2006 & $\begin{array}{l}24^{\circ} 49^{\prime} 3 / \\
047^{\circ} 49^{\prime} 4\end{array}$ & 5,9 & 7,2 & 63,3 & 5,65 & 337,93 & 447,26 & 2,54 & 26,91 \\
\hline $\begin{array}{l}\text { Canal do } \\
\text { Valo } \\
\text { Grande* }\end{array}$ & 2006 & $\begin{array}{l}24^{\circ} 48^{\prime} 2 / \\
047^{\circ} 337\end{array}$ & 5,25 & 6,3 & 59,3 & 7,25 & 358,81 & 358,81 & 55,24 & 239 \\
\hline Unidade & & & & $m L^{-1}$ & $\begin{array}{c}\mu \mathrm{mol} \\
\mathrm{L}^{-1}\end{array}$ & $\mu \mathrm{molL}^{-1}$ & $\mu \mathrm{molL}^{-1}$ & $\mu \mathrm{molL}^{-1}$ & $\mu \mathrm{molL}^{-1}$ & $\mu \mathrm{molL}^{-1}$ \\
\hline Registro* & 2006 & $\begin{array}{l}24^{\circ} 49^{\prime} 3 / \\
047^{\circ} 49^{\prime} 4\end{array}$ & 5,9 & 7,2 & 4,5 & 0,4 & 24,13 & 31,94 & 0,08 & 0,86 \\
\hline $\begin{array}{l}\text { Canal do } \\
\text { Valo }\end{array}$ & & $24^{\circ} 48^{\prime} 2 / 04$ & & & & & & & & \\
\hline Grande* & 2006 & $7^{\circ} 337$ & 5,25 & 6,30 & 4,23 & 0,51 & 18,49 & 25,62 & 1,78 & 7,7 \\
\hline & Ago./2012 & $\begin{array}{c}24^{\circ} 40,588 / \\
47^{\circ} 34,933\end{array}$ & 6,84 & 5,45 & 2,26 & 0,10 & 10,07 & 12,43 & 11,95 & nd \\
\hline $\begin{array}{l}\text { Rio } \\
\text { Ribeira R3 }\end{array}$ & Fev./2013 & $\begin{array}{c}24^{\circ} 40,588^{\prime} 4 \\
7^{\circ} 34,933 \\
\end{array}$ & 6,75 & 4,11 & 2,41 & 0,06 & nd & nd & 5,78 & nd \\
\hline & Set./2013 & $\begin{array}{c}24^{\circ} 40,588 / \\
47^{\circ} 34,933\end{array}$ & 7,62 & 5,71 & 2,30 & 0,23 & 14,17 & 16,7 & 5,82 & nd \\
\hline & Fev./2014 & $\begin{array}{c}24^{\circ} 40,588 / \\
47^{\circ} 34,933 \\
\end{array}$ & 7,65 & 4,11 & 2,41 & 0,21 & 12,28 & 13,68 & 3,18 & nd \\
\hline Registro & Nov./2013 & & 7,49 & nd & 1,86 & 0,22 & 14,59 & 17,01 & nd & nd \\
\hline
\end{tabular}

Os resultados dos teores dos parâmetros analisados na tabela acima, corroboram com a premissa que entre a cidade de Registro e Iguape, ou seja, na porção final do Rio, há um aporte maior de fosfato que provavelmente seja oriundo da afluência do Rio Jacupiranga, que é o Rio que passa próximo a área de exploração da rocha de fosfato em Cajati e deságua no Rio Ribeira do Iguape. Cabe ressaltar que os pontos de Registro e do Canal do Valo, são bem próximos aos pontos da coleta de Registro feita em final de outubro de 2013 e do ponto 4 do projeto FEBIOGEOQUIM -CNPq. 


\subsection{Aspectos indicativos de contribuições antrópicas no Baixo Ribeira}

\subsection{1. Área estimada da bananicultura nas margens do Rio (Registro - Iguape)}

Neste trecho, foram observadas além da bananicultura (objeto de estudo), áreas de pasto, cultivo de chá e núcleos urbanos.

No caso da bananicultura, primeiramente foram identificadas as áreas de plantações de banana, as quais foram subdivididas em lotes, demarcadas com o uso de polígonos e calculadas com o uso do programa Google Earth Pro®. Para o cálculo de áreas totais, somente foi levada em conta a área de plantio, eliminando-se ruas, sedes e pontos sem cultivo que puderam ser visualizados no interior dos lotes.

Desta forma, foram identificadas 29 áreas (Fig. 48) e estas foram subdivididas em lotes. Foi feita uma estimativa de quantas plantas cada lote/área poderia possuir levando em conta diferentes densidades (mínimo de 1300 plantas/ha, máximo de 2500 plantas/ha), também foi feita uma estimativa da distância de determinados pontos destas áreas (lotes mais próximos à margem) para o Rio, pois as plantações possuem limites diretos e/ou muito próximos à margem do Rio. 


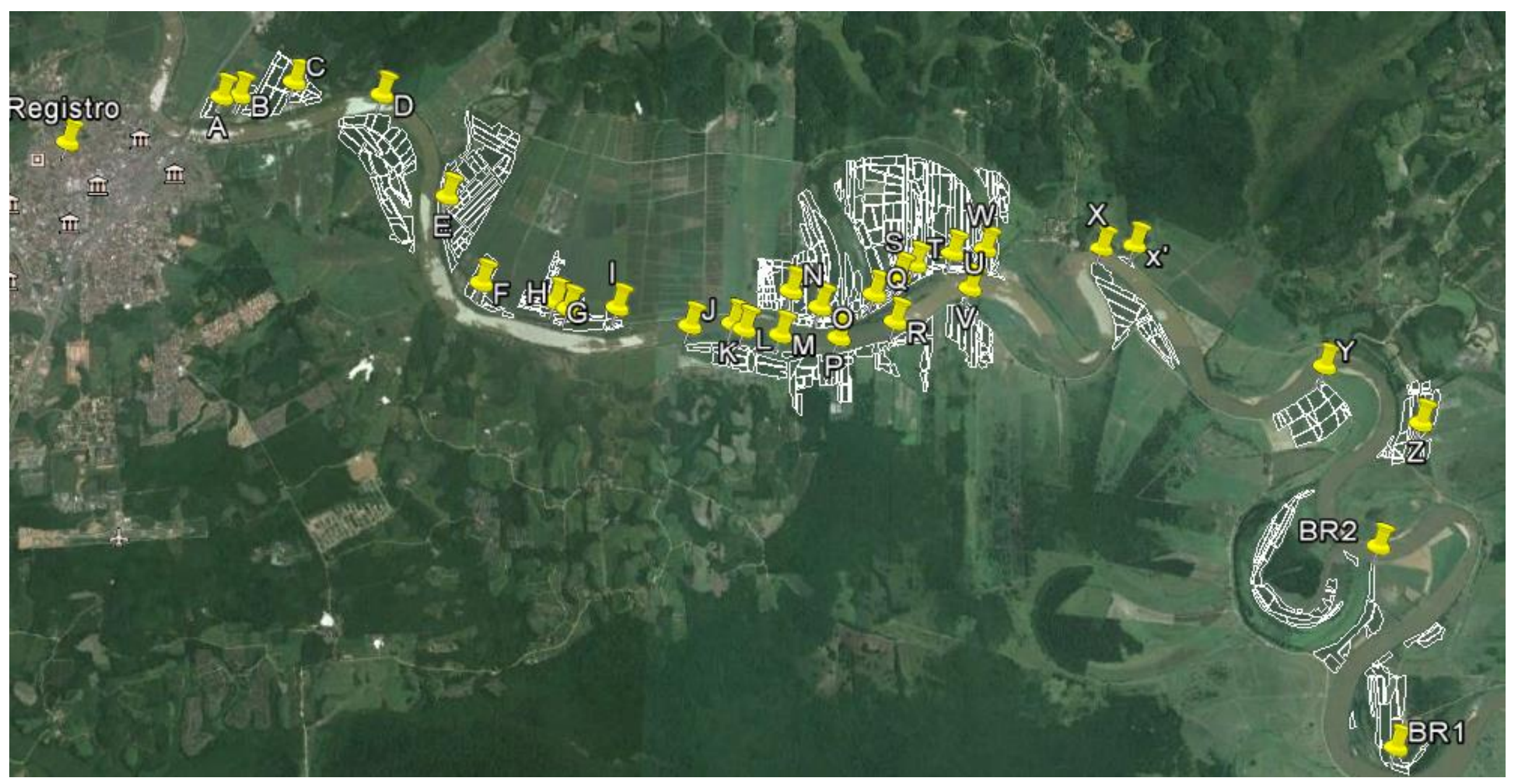

Figura 48. Desenho amostral das áreas/setores de bananiculturas localizadas nas margens do Rio Ribeira entre as cidades de Registro e Iguape (SP) (GOOGLE EARTH PRO-11/01/2015). 


\subsubsection{Caracterização de cada área/lote}

A área A está localizada próxima a rodovia Regis Bittencourt (BR-116) e junto (176 m) à margem esquerda do rio Ribeira (Lat. 24²9'15,29"S, Long. 4749'56,11"W). Esta área (dividida em dois lotes) apresentou uma metragem total estimada de $35.574 \mathrm{~m}^{2}$, ou seja, com um pouco mais que 3,5 hectares, que dependendo da densidade do cultivar, seja este de 1300 plantas/ha, 1500 plantas/ha, 1800 plantas/ha, 2000 plantas/ha ou 2500 plantas/ha poderá apresentar de 4600 a 8900 plantas (Fig. 49).

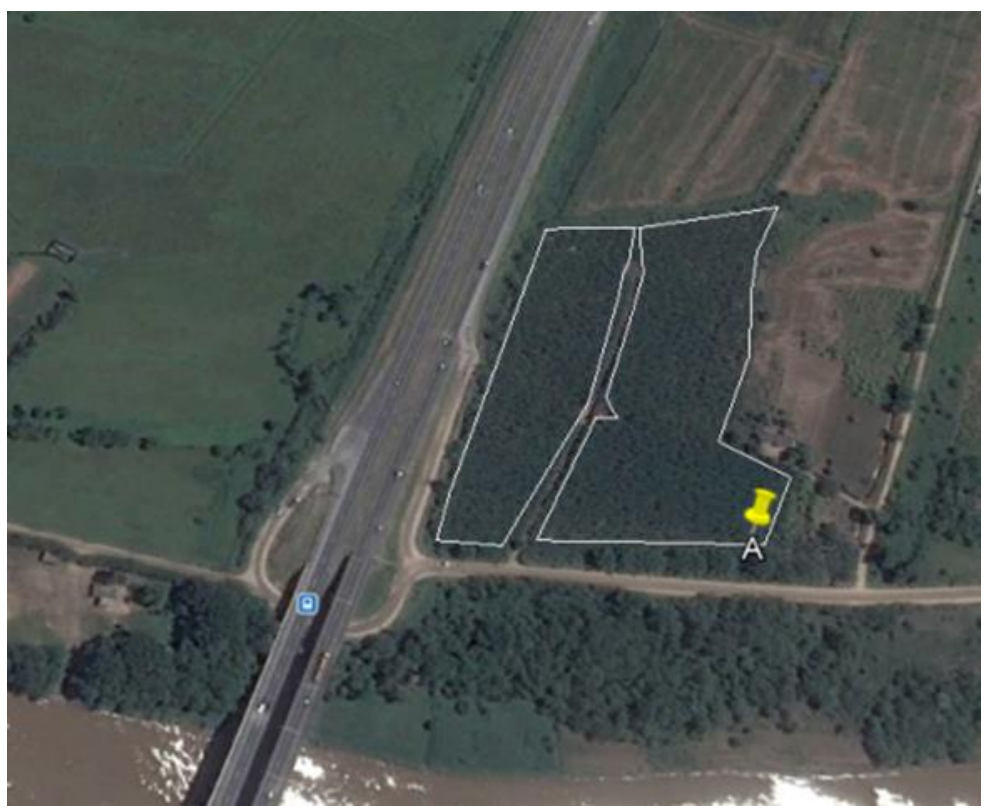

Figura 49. Localização e delimitação da área $\mathrm{A}$ de plantação de banana na região entre Registro e Iguape (SP), (utilização do GOOGLE EARTH PRO-11/01/2015).

As áreas B (Lat. 2429'14,54"S, Long. 4749'48,74"W) e C (Lat. 24²9'9,14"S, Long. 4749'26,64"W) (Fig. 50) localizam-se à margem do Rio apresentando cultivares a uma distância mínima aproximada de 116 m e 107 m do Rio respectivamente. A área B foi dividida em 19 lotes, apresentando aproximadamente 26 ha de área plantada, enquanto a área $\mathrm{C}$, dividida em 9 lotes, apresentou aproximadamente 7 ha em área plantada. A área B pode ter, portanto, de 36 mil a 65 mil plantas, e a área $\mathrm{C}$ de 9 mil a 17 mil plantas, dependendo da densidade do cultivar. 


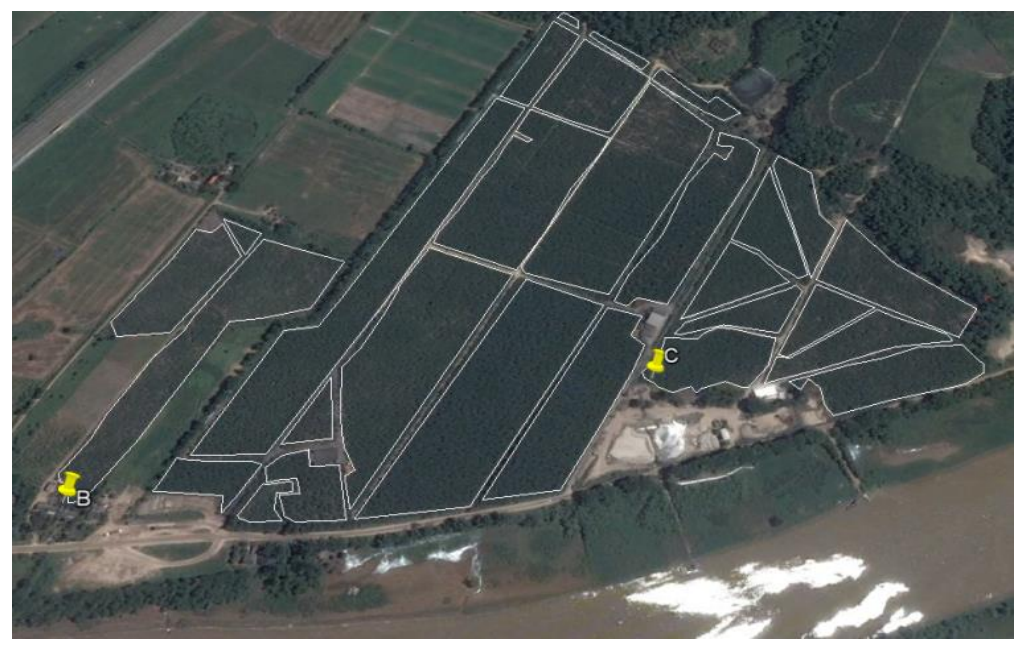

Figura 50. Localização e delimitação das áreas B e C (utilização do GOOGLE EARTH PRO$11 / 01 / 2015)$.

A área D (Lat. 24²9'13,67"S, Long. 4748'50.43"W) (Fig. 51) está localizada à

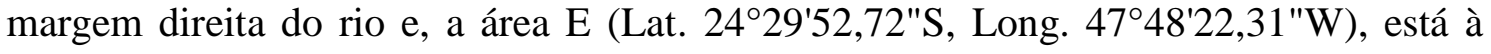
margem esquerda do Rio Ribeira do Iguape. A distância de algumas plantas da área D para o Rio, em determinados pontos chega a menos de 40 metros e em outros, a distância está em torno de $80 \mathrm{~m}$. O setor/área E apresentou plantas com distância de 60 a $90 \mathrm{~m}$ do Rio Ribeira. A área D, dividida em 35 lotes, apresentou uma área plantada estimada em aproximadamente 71 ha e a E, com 51 lotes, um pouco mais que 63 ha em área plantada. O número de plantas para a área $\mathrm{D}$ pode variar de 92 mil a 177 mil, e para a área $\mathrm{E}$, o número de plantas pode variar de 82 mil a 157 mil, dependendo da densidade de plantas por hectare.

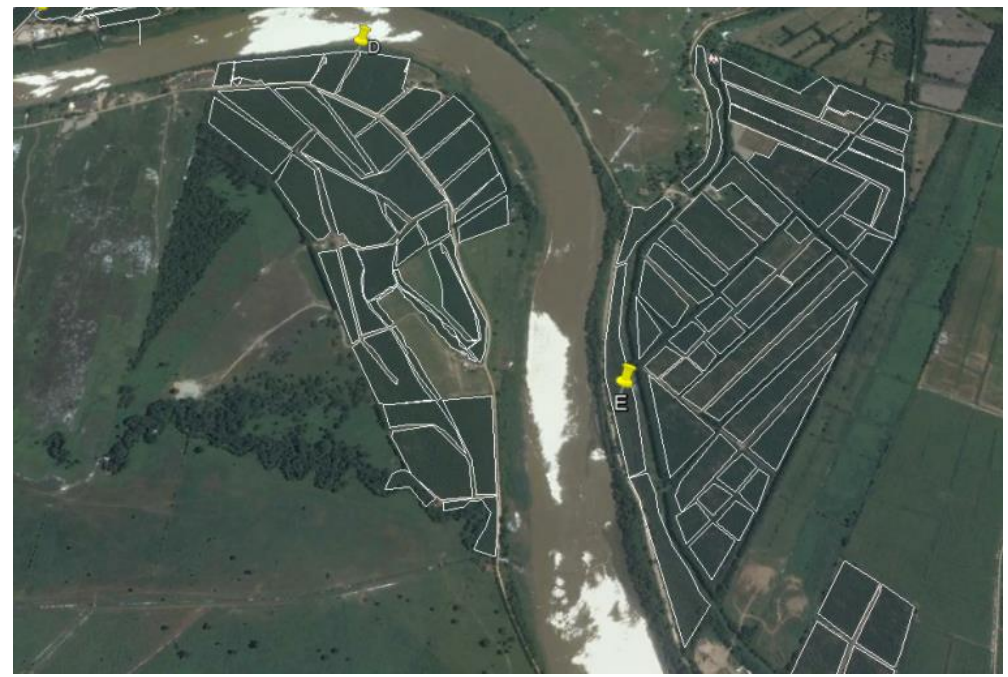

Figura 51. Localização e delimitação das áreas D e E (utilização do GOOGLE EARTH PRO$11 / 01 / 2015)$.

As áreas F (Lat. 2430'25,62"S, Long. 4748'7,23"W), G (Lat. 24³0'32,29"S,

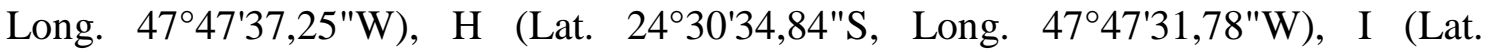


24³0'34,15"S, Long. 4747'11,94"W) (Fig. 52), localizadas à margem esquerda do rio apresentaram as seguintes medidas:

A área $\mathrm{F}$ (dividida em oito lotes), com aproximadamente 12 ha de área plantada, possui algumas plantas na distância de 110 - 130 metros do Rio. Nessa área, há capacidade de ter de 15 mil a 30 mil plantas dependendo da densidade. Cabe ressaltar que em alguns lotes da área $\mathrm{F}$ foram observadas algumas partes de lotes sem plantas totalizando aproximadamente $10 \%$ da área total.

A área $\mathrm{G}$ (24 lotes) com aproximadamente 14 ha de área plantada, algumas plantas encontram-se em uma distância de 64 - 140 metros do Rio, com 17 a 34 mil plantas, dependendo da densidade de plantas por hectare. Foram observadas partes de lotes com ausência de plantas em aproximadamente $8-10 \%$ da área total

A área $\mathrm{H}$ (4 lotes) com aproximadamente 8,6 ha de área, apresenta algumas plantas à distância de 55 metros do Rio, com capacidade de 11 mil a 22 mil plantas dependendo da densidade de plantas por hectare.

A área I (4 lotes) com aproximadamente 2,4 ha de área plantada, possui algumas plantas a uma distância de 106 metros do Rio, a área pode ter de 3 mil a 6 mil plantas dependendo da densidade de plantas por hectare.

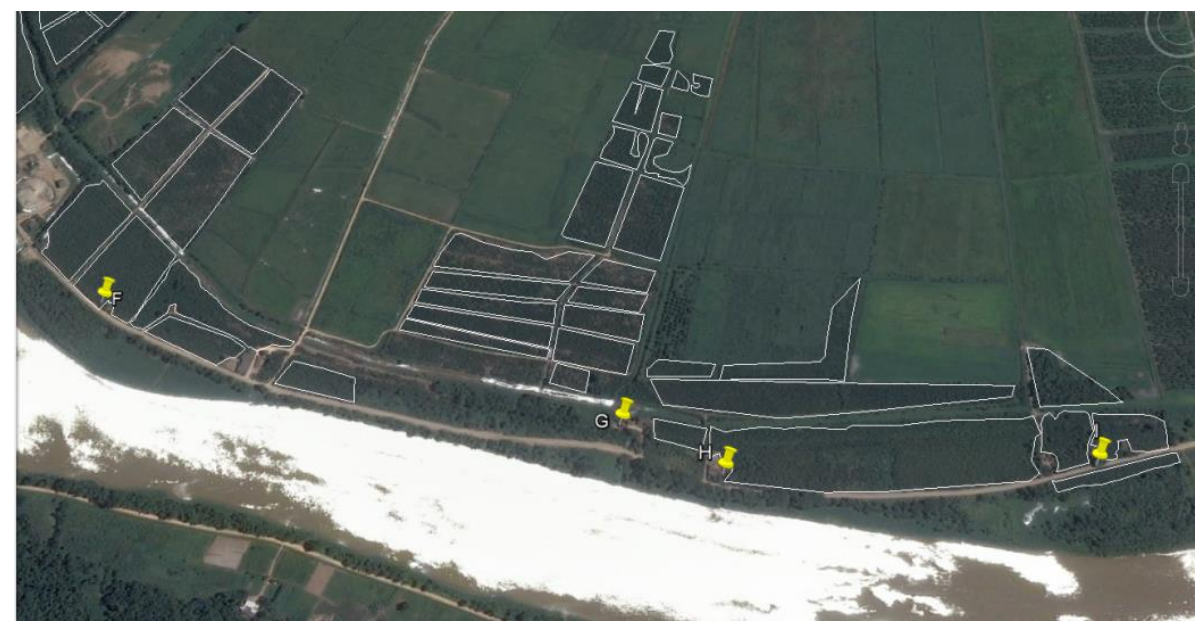

Figura 52. Localização e delimitação das áreas F, G, H e I (utilização do GOOGLE EARTH PRO-11/01/2015).

Localizadas à margem direita do Rio Ribeira do Iguape as áreas J (Lat. $24^{\circ} 30^{\prime} 40,64^{\prime \prime S}$, Long.4746'42,39"W), K (Lat. 24³0'39,54"S, Long. 4746'25,00"W), L

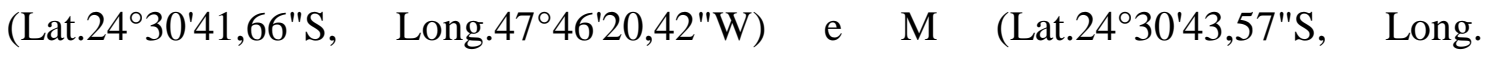
$47^{\circ} 46$ '5,69"W) (Fig. 52) obtiveram medidas estimadas descritas a seguir. 
A área $\mathrm{J}$ (dividida em 5 lotes) apresentou aproximadamente 14 ha em área plantada, podendo ter de 18 mil a 35 mil plantas, dependendo da densidade do cultivo, a distância da plantação ao rio é menor que $50 \mathrm{~m}$.

A área $\mathrm{K}$ (3 lotes), com um pouco mais que 1,5 ha em área plantada, pode ter de 2 mil a 4 mil plantas dependendo da densidade do cultivo, alguns pontos desta área localizam-se a uma distância de 120 m da margem do Rio Ribeira do Iguape.

A área L (com 7 lotes) apresentou área plantada estimada em 6,5 ha, podendo ter de 8 mil a 16 mil plantas dependendo da densidade do cultivar, atingindo uma distância para o rio de $157 \mathrm{~m}$. Observou-se ausência de plantas em aproximadamente 5\% do total deste setor.

A área M (4 lotes) apresentou área plantada de 8 ha, estimou-se a presença de 10 mil a 20 mil plantas em função da densidade do cultivar, a distância para o rio é de aproximadamente $170 \mathrm{~m}$.

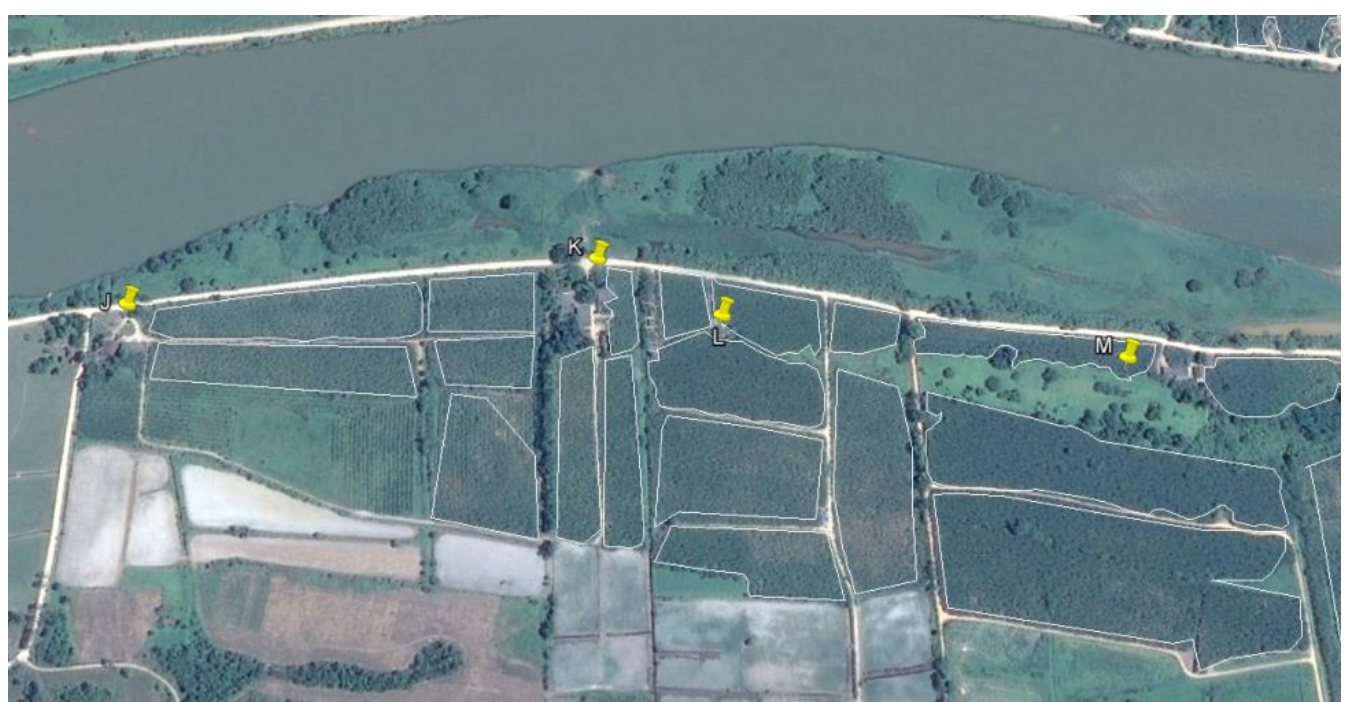

Figura 53. Localização e delimitação das áreas J, K, L e M (utilização do GOOGLE EARTH PRO-07/02/2015)

Localizadas à margem esquerda do Rio Ribeira as áreas N (Lat. 24³0'27,05"S,

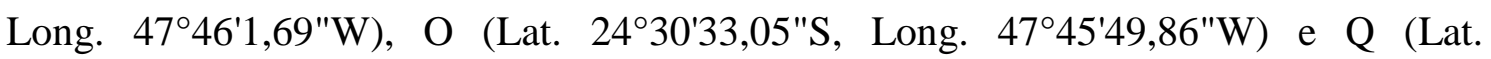
2430'28,00"S, Long. 4745'27,88"W) (Fig. 54), constaram das seguintes medidas:

A área $\mathrm{N}$ foi dividida em 27 lotes, apresentou aproximadamente 17 ha em área plantada, portanto podendo portar de 22 mil a 42 mil plantas em função da densidade do cultivar, a distância estimada para o rio é de $160 \mathrm{~m}$.

A área $\mathrm{O}$ foi dividida em 30 lotes, apresentou uma área plantada de aproximadamente 52 ha, no entanto, deve-se dar um desconto de $15 \%$ do total da área, devido à ausência de plantas. A capacidade de ocupação de plantas nessa área é de 67 mil 
a 130 mil dependendo da densidade. A distância de determinado ponto da área para o Rio foi menor que $30 \mathrm{~m}$.

A área Q foi dividida em 11 lotes, apresentou uma área plantada de aproximadamente 10 ha, observou-se a falta de plantas em $20 \%$ deste setor, com capacidade total de ocupação de 13 mil a 25 mil plantas dependendo da densidade do cultivar, a distância medida até o Rio foi de menos que $144 \mathrm{~m}$.

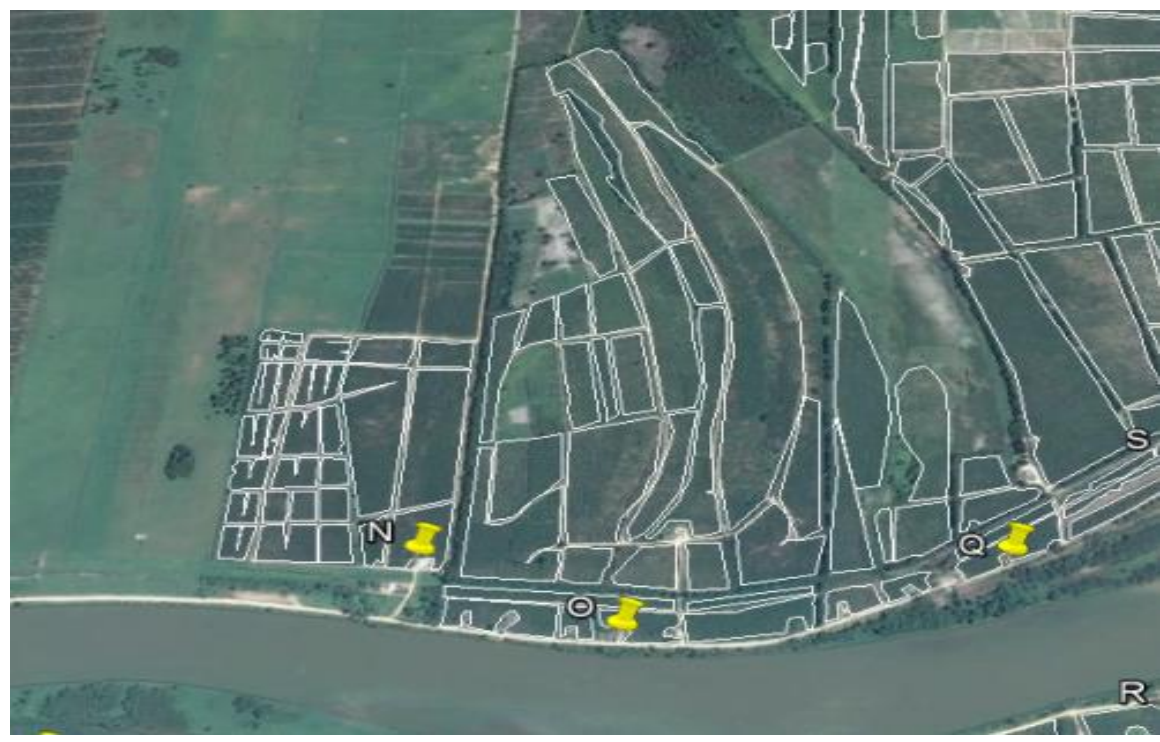

Figura 54. Localização e delimitação das áreas N, O e Q (utilização do GOOGLE EARTH 07/02/2014).

Localizadas à margem direita do Rio Ribeira do Iguape as áreas P (Lat.

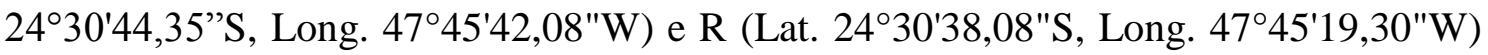
(Fig. 55) apresentaram as seguintes medidas:

A área $\mathrm{P}$ foi dividida em 26 lotes, apresentou uma área plantada de aproximadamente 37 ha, o que confere a essa área a presença de 48 mil a 94 mil plantas dependendo da densidade do cultivar, observou-se falta de plantas em aproximadamente $10 \%$ da área total. A distância de determinado ponto desta área para o Rio é de aproximadamente $78 \mathrm{~m}$.

$\mathrm{A}$ área $\mathrm{R}$ foi dividida em 16 lotes, obtendo-se aproximadamente 15 ha em área plantada, a ocupação pode ser de 19 mil a 38 mil plantas, dependendo da densidade da plantação. Foi observada ausência de plantas em $2 \%$ da área total. A distância do Rio é de aproximadamente $45 \mathrm{~m}$. 


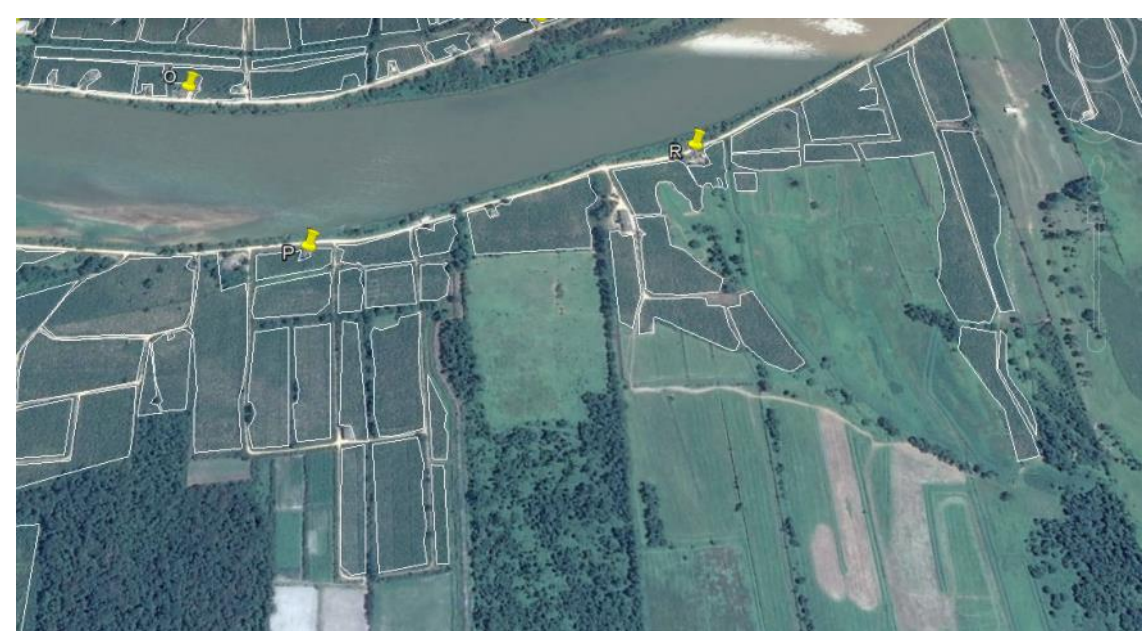

Figura 55. Localização e delimitação das áreas P e R, margem direita do Rio (utilização do GOOGLE EARTH -07/02/2014).

Localizadas à margem esquerda do Rio Ribeira do Iguape as áreas S (Lat.

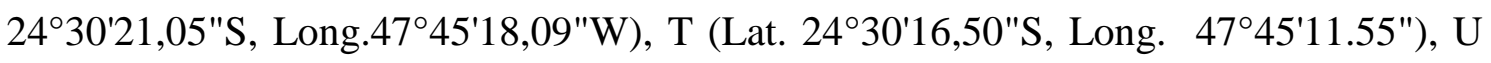

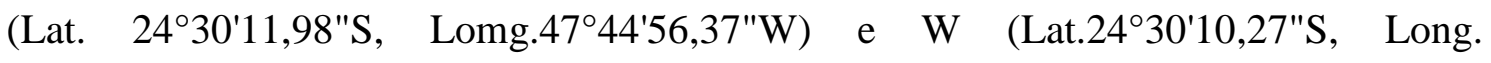
4744'43,06"W) (Fig. 56) apresentaram as seguintes medidas:

A área $\mathrm{S}$ foi dividida em 41 lotes, apresentou aproximadamente 72 ha em área plantada, o que possibilita uma ocupação total de 79 mil a 93 mil plantas dependendo da densidade do cultivo, foi observada a falta de plantas em mais ou menos $15 \%$ da área total. A plantação apresentou uma distância de mais ou menos $240 \mathrm{~m}$ do Rio.

A área $T$ foi dividida em 25 lotes, apresentou por volta de 24,5 ha em área plantada podendo comportar de 31 mil a 61 mil plantas em função da densidade do cultivo, o ponto medido para a distância do Rio apresentou aproximadamente $256 \mathrm{~m}$.

A área $U$ foi dividida em 41 lotes, com uma área plantada de quase 50 ha, podendo comportar de 64 mil a 124 mil plantas dependendo da densidade da plantação, alguns lotes encontram-se bem próximos ao Rio, a uma distância de menos que 30 metros.

A área $\mathrm{W}$, foi dividida em 30 lotes, apresentou uma área plantada de aproximadamente 21 ha, portanto podendo ter de 27 mil a 52 mil plantas dependendo da densidade da plantação, apresentando uma distância de aproximadamente $35 \mathrm{~m}$ do Rio. 


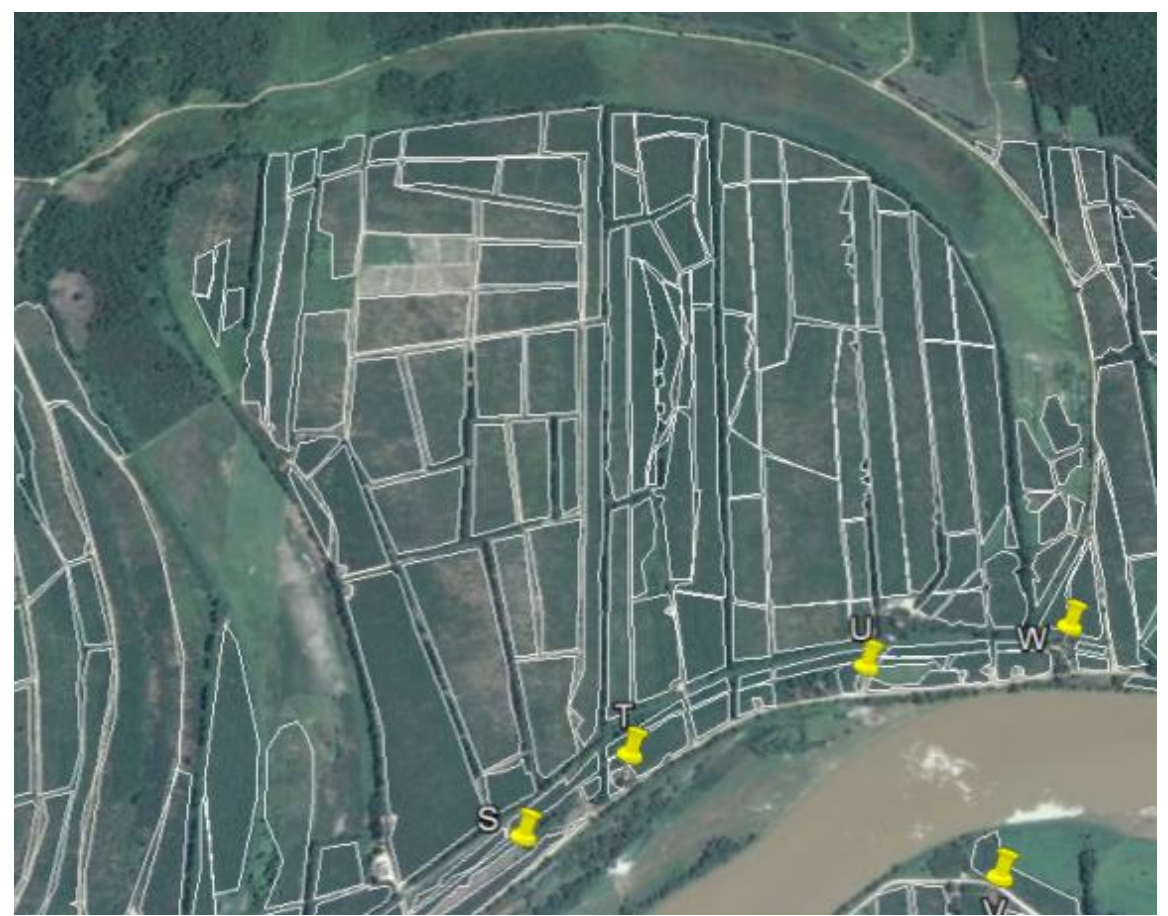

Figura 56. Localização e delimitação das áreas $S, T, U$ e W à margem esquerda do Rio (utilização do GOOGLE EARTH PRO-07/02/2014).

Localizada à margem direita do Rio Ribeira do Iguape, a área V (Lat. 24³0'25,24"S, Long. 4744'49,15"W) (Fig. 57) em alguns lotes, próximos à margem, apresentou distância do Rio variando entre 5,50 e até $200 \mathrm{~m}$. A área total medida foi de aproximadamente 22 ha, podendo possuir de 29 mil a 56 mil plantas.

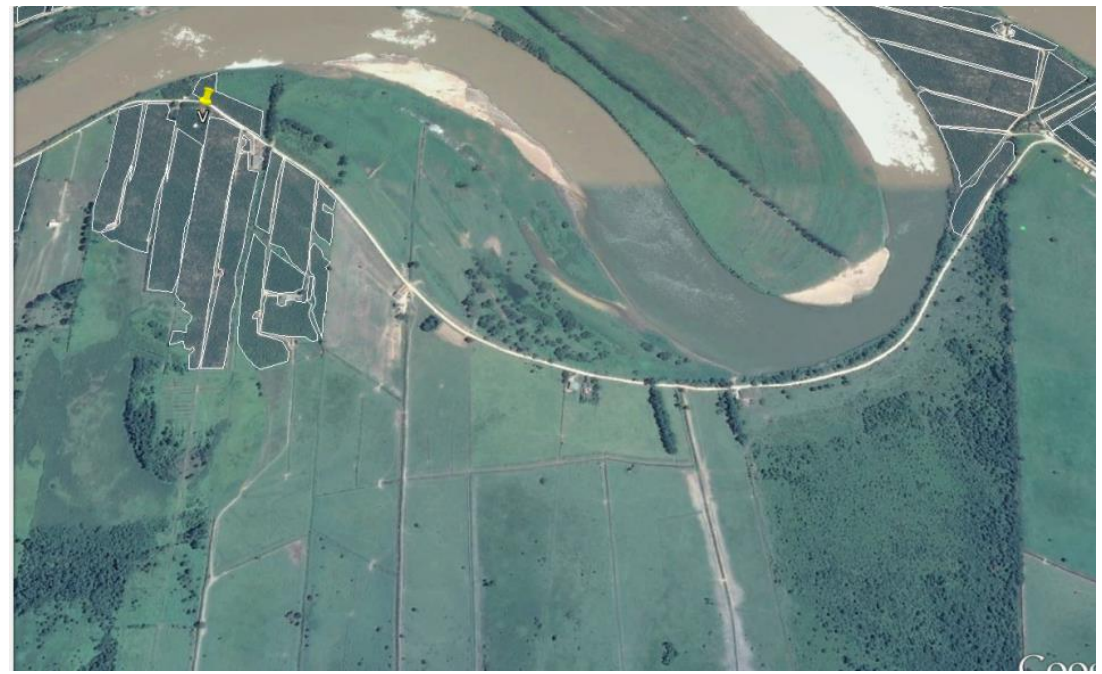

Figura 57. Localização e delimitação da área V à margem direita do Rio (utilização do GOOGLE EARTH PRO -07/02/2014)

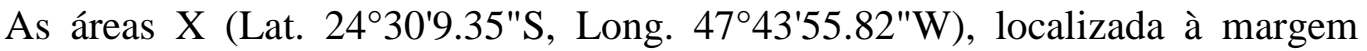
direita do Rio e X' (Lat.24³0'7.97"S, Long. 4743'42.30"W) (Fig. 58), localizada à margem esquerda do Rio apresentaram as seguintes medidas: 
A área $\mathrm{X}$ foi dividida em 19 lotes e apresentou uma área total estimada em aproximadamente 30 ha, podendo portar de 39 mil a 75 mil plantas, conforme a densidade da plantação, alguns pontos apresentaram distância menor que 30m do Rio, sendo que $20 \%$ da área total mostrou ausência de bananeiras. A área $X^{\prime}$ apresentou área total de aproximadamente 1/3 ha, podendo comportar de 907 a 1700 plantas em função da densidade do cultivar, esta área assim como alguns lotes da área X, apresentaram distâncias do Rio menores que 30 m.

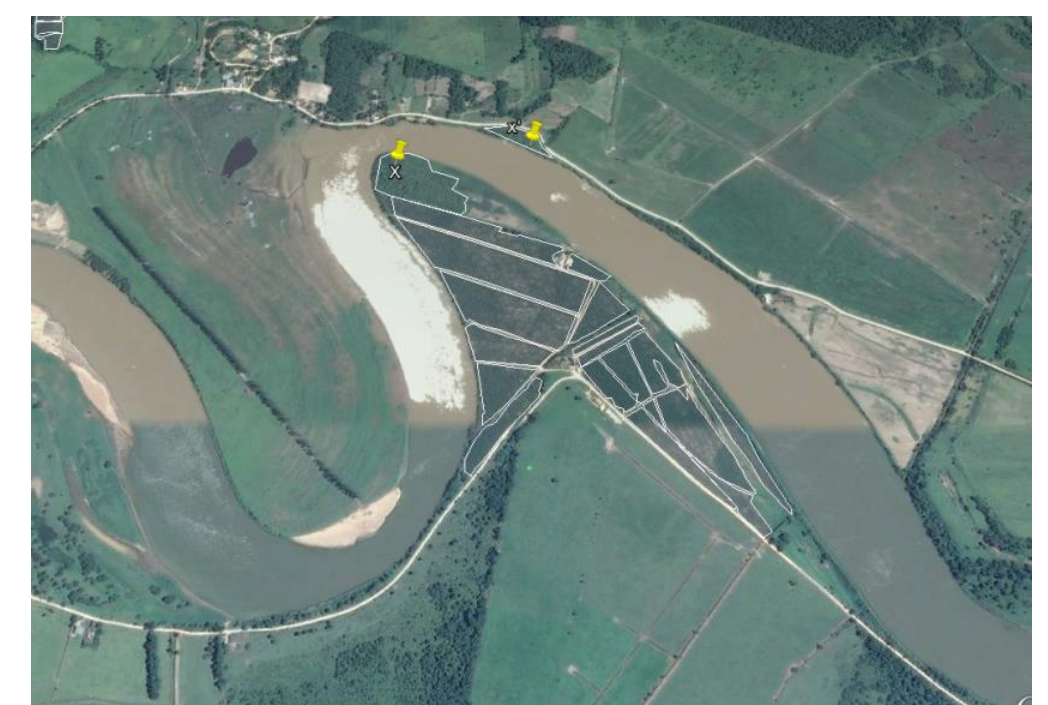

Figura 58. Localização e delimitação das áreas $X$ e X' nas margens direita e esquerda do Rio (utilização do GOOGLE EARTH PRO -07/02/2014).

As áreas Y (Lat. 2430'53,09"S, Long.4742'25,96"W), localizada à margem direita do Rio e Z (Lat.24³1'13,74"S, Long. 4741'47,58"W), localizada à margem esquerda do Rio (Fig. 59) apresentaram as seguintes características:

A área Y foi dividida em 20 lotes, com aproximadamente 32 ha de área plantada, podendo conter de 41 mil a 80 mil plantas, dependendo da densidade do cultivar, apresentou uma falta de plantas de mais ou menos $5 \%$ da área total e distância de alguns lotes da margem do Rio menores que 30m.

A área Z, composta por 25 lotes, apresentou uma área plantada de aproximadamente 24,5 hectares, podendo conter cerca de 32 mil a 62 mil plantas. Alguns lotes estão localizados bem próximos ao Rio, distanciados a menos de $20 \mathrm{~m}$ deste. 


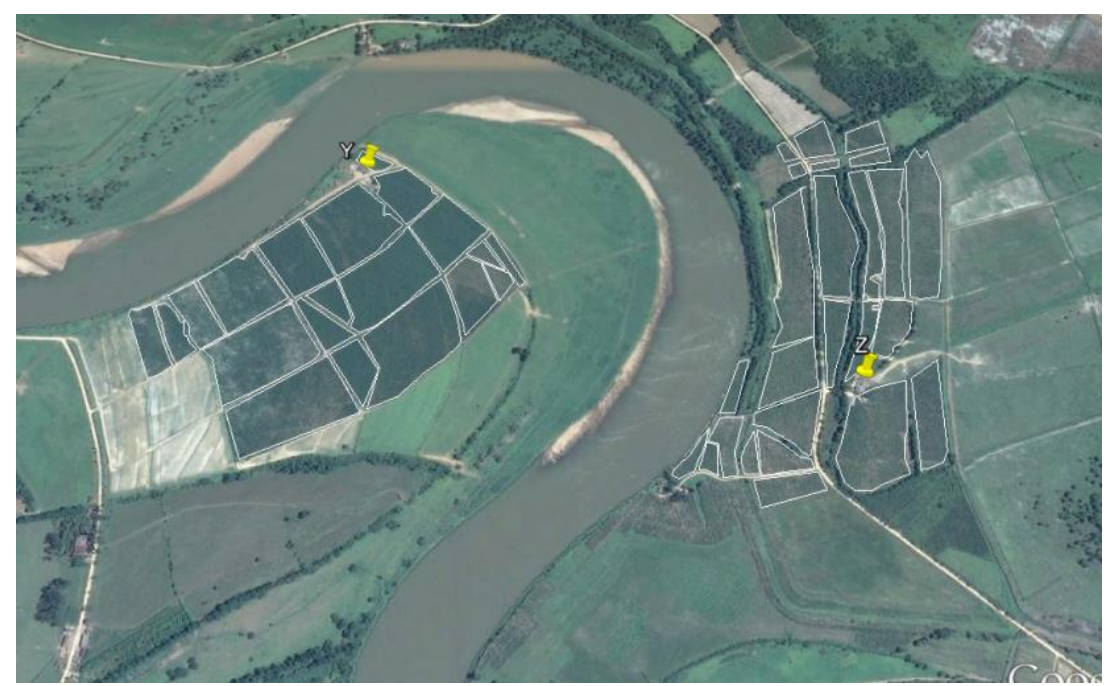

Figura 59. Localização e delimitação das áreas $\mathrm{Y}$ e $\mathrm{Z}$ às margens direita e esquerda do Rio respectivamente (utilização do GOOGLE EARTH PRO -07/02/2014).

A área BR2 (Lat. 24³2'0.07"S, Long. 47²4'5.46"W), à margem direita do Rio (Fig. 60), foi dividida em 32 lotes, apresentando uma área total mensurada em aproximadamente 54 ha, podendo possuir de 70 mil a 135 mil plantas. Alguns lotes localizam-se a menos de 45 metros do Rio.

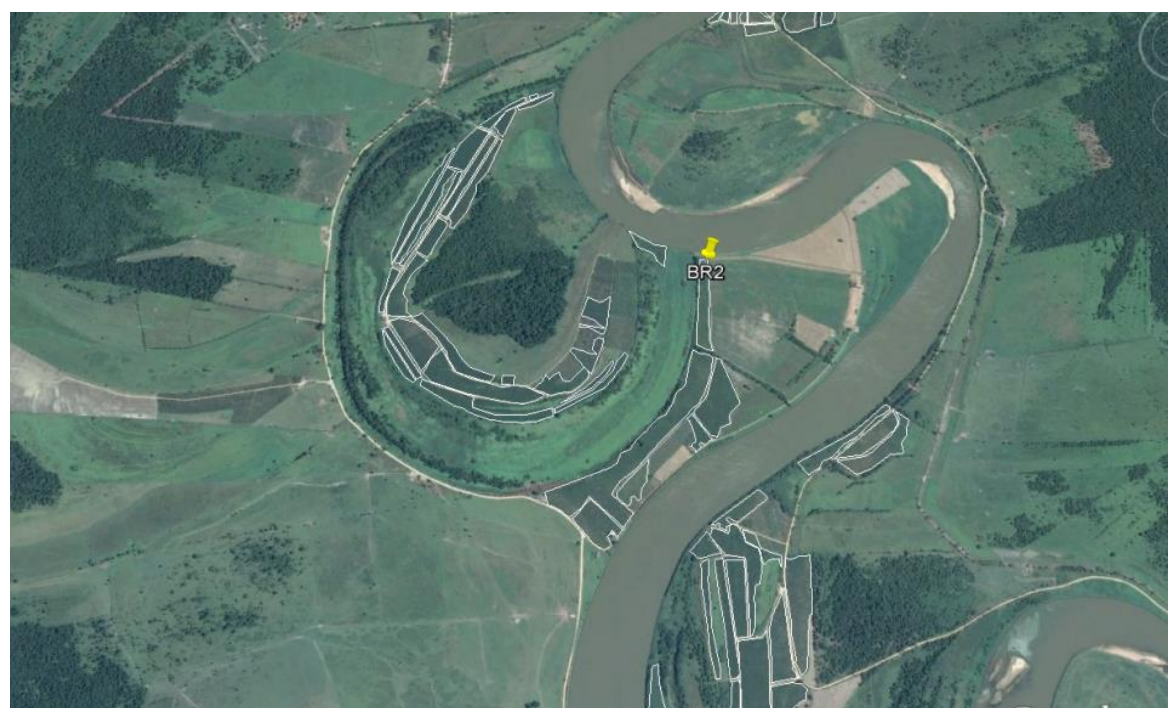

Figura 60. Localização e delimitação da área BR2 margem direita do Rio (utilização do GOOGLE EARTH PRO -07/02/2014).

A área BR1 (Lat. 2433'13,57"S, Long. 47²4'0,16"W) (Fig. 61), com 21 lotes apresentou uma área total de $36,5 \mathrm{ha}$, podendo possuir aproximadamente de $47 \mathrm{mil} \mathrm{a} 91 \mathrm{mil}$ plantas dependendo da densidade do cultivar. Alguns lotes mantêm distancia de mais ou menos 60 metros do Rio. 


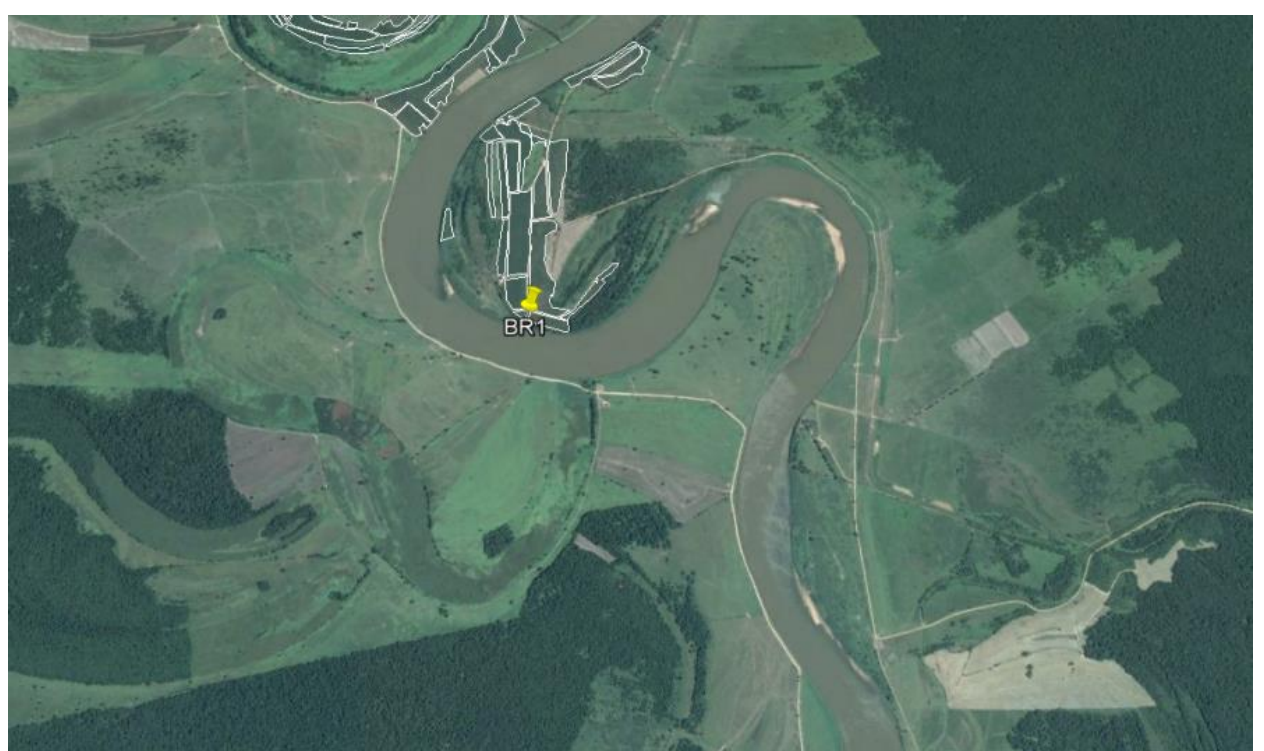

Figura 61. Localização e delimitação da área BR1, à margem esquerda do Rio (utilização do GOOGLE EARTH PRO -07/02/2014).

O ponto referente à Barra do Rio Jacupiranga (Fig. 62) está localizado na Lat. $24^{\circ} 37^{\prime} 14,59^{\prime \prime}$ S e Long. $47^{\circ} 43^{\prime} 49,48^{\prime \prime} \mathrm{W}$.

A distância entre a área A (próxima à ponte de Registro) e a área BR1 é de aproximadamente 26 km (distância percorrida ao longo do Rio Ribeira do Iguape).

A distância entre a área $\mathrm{A}$ (próxima à ponte de Registro) e a Barra de Jacupiranga é de 40 km (distância percorrida ao longo do Rio Ribeira do Iguape).

A distância entre a área $\mathrm{A}$ (próxima à ponte de Registro) e a e a estação R1 (ponto de coleta mais a montante do rio) é de $68 \mathrm{~km}$.

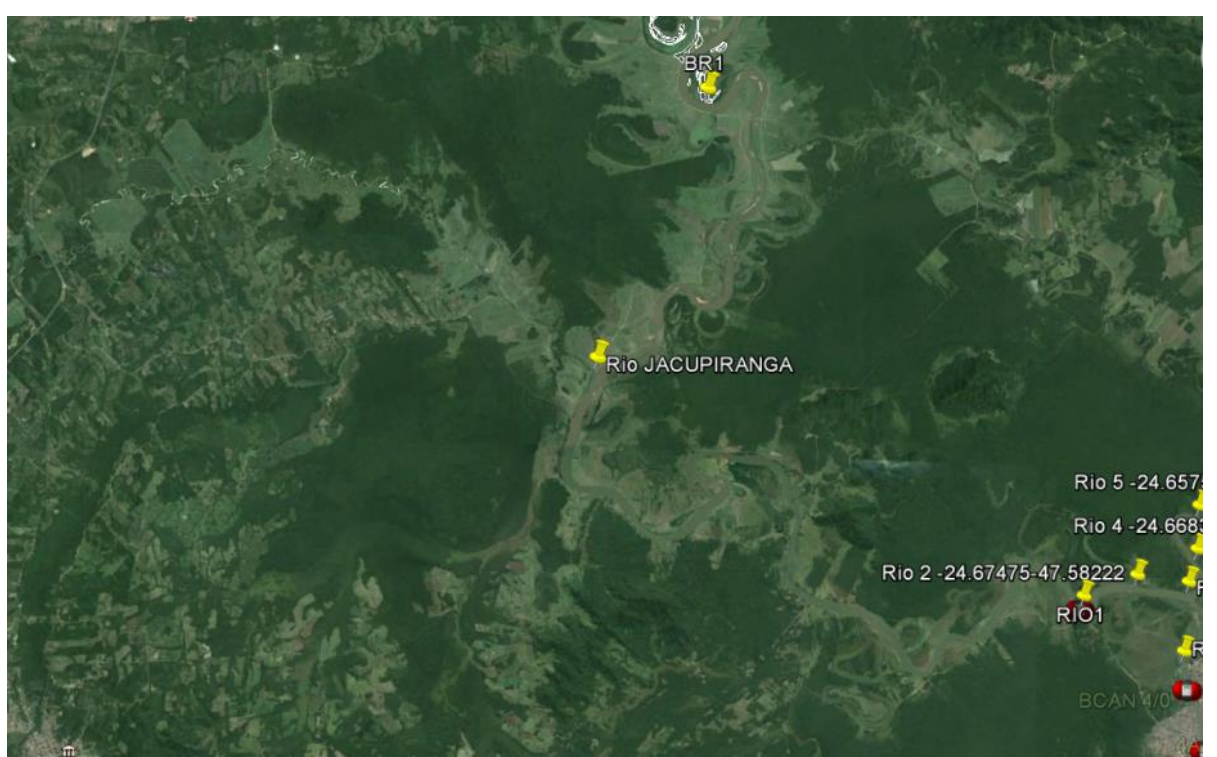

Figura 62. Localização e delimitação da área BR1, chegada do afluente Jacupiranga e pontos de coleta no Rio Ribeira do Iguape - Projeto FEBIOGEOQUIM e INCT-TMCOcean (utilização do GOOGLE EARTH PRO -07/02/2014). 
De um modo geral, as áreas cultivadas delimitadas neste estudo possuem tamanhos diferentes e acabam contribuindo de modo diferenciado ao sistema hídrico com o excesso de N-nitrato e P-fosfato. A figura 63 mostra o tamanho de cada área delimitada.

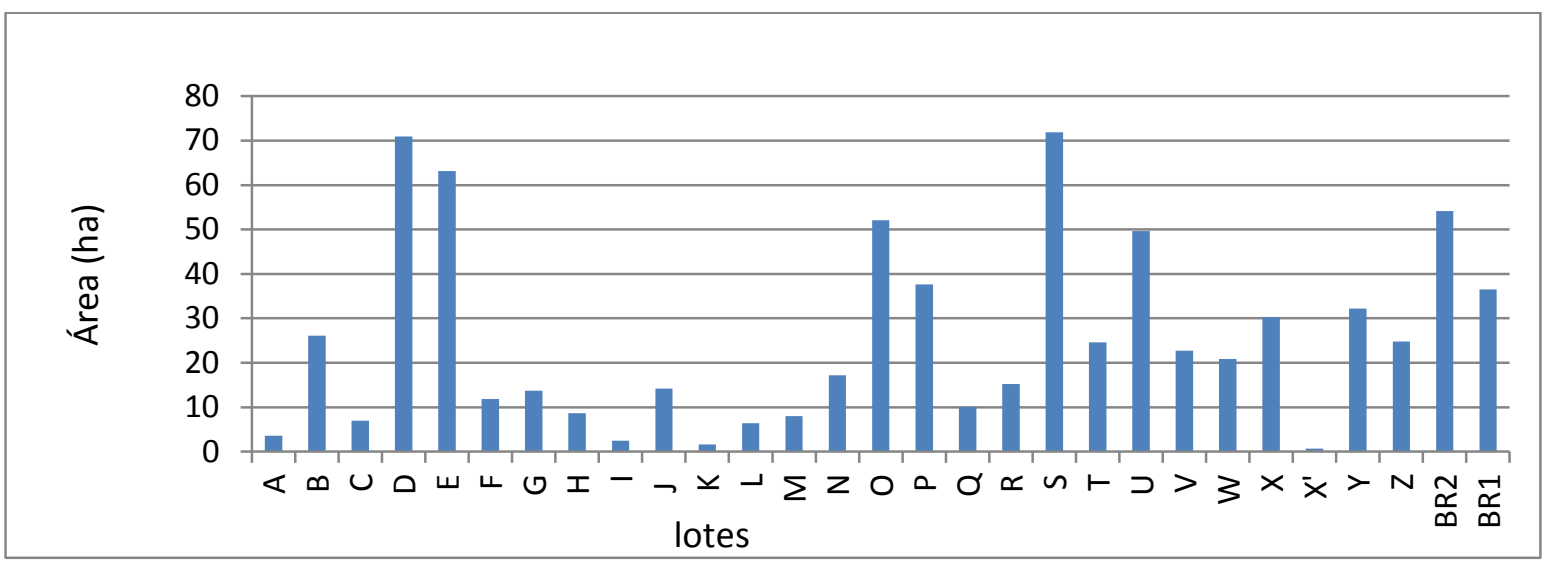

Figura 63. Tamanho das áreas ocupadas pela bananicultura delimitadas neste estudo entre Registo e Iguape (SP).

\subsubsection{Cultivo da banana e potencial de lixiviação de $N$ e $P$ ao Rio Ribeira do Iguape}

Os dados referentes à área total amostrada, o número de plantas/hectare (densidade), adubo nitrogenado aplicado ao ano, quantidade de $\mathrm{N}$ por planta, quantidade total de adubo $\mathrm{N}$ aplicada na área e perda estimada de N (30\%) ao ano, encontram-se na tabela 37 .

Tabela 37. Área plantada total, densidade de plantas/ha, total de plantas, quantidade de $\mathrm{N}$ aplicado por planta, total de $\mathrm{N}$ aplicado, perda estimada (30\%) de N /ano.

\begin{tabular}{|c|c|c|c|c|c|c|}
\hline $\begin{array}{l}\text { Área } \\
\text { (ha) }\end{array}$ & $\begin{array}{l}\text { Densidade* } \\
\left(\text { plantas ha }^{-1} \text { ) }\right.\end{array}$ & $\mathbf{N}^{\circ}$ plantas & $\begin{array}{c}\text { N/ano } \\
\left(\mathrm{kg} \mathrm{ha}^{-1} \mathbf{a n o}^{-1}\right)\end{array}$ & $\begin{array}{l}\text { N/planta*** } \\
\text { (kg/planta) }\end{array}$ & $\begin{array}{c}\text { Total N } \\
\text { (t) }\end{array}$ & $\begin{array}{c}\text { Perda estimada } \\
\text { de } \mathbf{N} * * * \\
\left(\mathbf{t} \mathbf{a n o}^{-1)}\right) \\
\end{array}$ \\
\hline 744,5 & 1800 & 1.340 .100 & $130-270$ & 0,11 & 147,4 & 44,22 \\
\hline
\end{tabular}

Portanto, ao longo do trecho do Rio estudado, entre as cidades de Registro e Iguape, foi estimada uma área de plantio de bananas de aproximadamente 744,5 ha e, considerando uma densidade média de 1800 plantas por hectare (CATI, 2008), calculase um total de 1.340 .100 plantas. Com a aplicação de fertilizantes nitrogenados estimada de 130 a 270 t ha $^{-1}$ ano $^{-1}$ para esta Região e, tomando-se a média de adubação de $\mathrm{N}$ de 200 $\mathrm{kg} \mathrm{ha}^{-1} \mathrm{ano}^{-1}$, calcula-se aproximadamente um total de $0,11 \mathrm{~kg}$ de adubo por planta ao ano, portanto um total de 147,4 t de adubo nitrogenado nesta área. Considerando-se uma perda 
de $30 \%$, tem-se um total de 44,22 t de $\mathrm{N}$ perdida ao ano e que pode chegar ao Rio, ou seja, aproximadamente $3,7 \mathrm{t}$ de $\mathrm{N}$ por mês.

Com relação ao adubo fosfatado, os dados para cálculo de perda de fosfato, encontram-se na tabela 38 .

Tabela 38. Densidade de plantas e estimativa de perda de P (fosfato).

\begin{tabular}{|c|c|c|c|c|c|c|}
\hline $\begin{array}{l}\text { Área } \\
\text { (ha) }\end{array}$ & $\begin{array}{l}\text { Densidade* } \\
\left(\text { planta ha }^{-1}\right)\end{array}$ & $\mathbf{N}^{\circ}$ plantas & $\begin{array}{c}\text { P/ano } \\
\left(\mathrm{kg} \mathrm{P} \mathrm{ha}^{-1} \text { ano }^{-1}\right)\end{array}$ & $\begin{array}{l}\text { P/planta*** } \\
\text { (kg/planta) }\end{array}$ & $\begin{array}{c}\text { Total P } \\
\text { (t) }\end{array}$ & $\begin{array}{r}\text { Perda de P } \\
\left(\text { ano }^{-1}\right)^{* *}\end{array}$ \\
\hline 744,5 & 1800 & 1.340 .100 & $40-120$ & 0,04 & 53,6 & 5,36 \\
\hline
\end{tabular}

Assim, para esta mesma área, com relação à adubação fosfatada, considerando a aplicação aproximada de $80 \mathrm{~kg} \mathrm{ha}^{-1}$ ano $^{-1}$, estima-se uma aplicação de 53,6 t ao ano e com uma perda relativa de 5,36 t ao ano, ou seja, aproximadamente 446,6 kg de P ao mês.

No entanto, é muito importante considerar a dinâmica destes nutrientes a partir de sua aplicação e os processos físico-químicos sofridos por eles na interface solo, atmosfera, água.

\subsubsection{Perda de $N$ e $P$ no solo, sob o cultivar de bananas}

O solo sob o cultivar da banana perde nutrientes através da lixiviação ( $\mathrm{K}$ e N), erosão $(\mathrm{N}, \mathrm{K}$ e $\mathrm{P})$, volatilização $(\mathrm{N})$, denitrificação $(\mathrm{N})$ e, além disso, o $\mathrm{N}$ também é removido devido à colheita da cultura e escoamento superficial. Tais processos acentuamse em áreas tropicais costeiras. Volatilização é a perda gasosa de N, sob a forma de ureia, isto ocorre quando há falta de chuva e/ou irrigação suficiente para dissolver e lavar a ureia para dentro do solo. Denitrificação é a perda gasosa de N, quando o solo está morno e alagado.

\subsubsection{Processo de lixiviação do nitrato}

O nitrato encontra-se frequentemente livre na solução do solo, pois seus íons $\left(\mathrm{NO}_{3}{ }^{-}\right)$não são adsorvidos pelos componentes das frações inorgânicas do solo, portanto se deslocam com uma maior facilidade, podendo ser absorvidos pelas raízes e translocados às folhas ou lixiviados aos mananciais subterrâneos (Correa et al., 2006). Dynia e Camargo (1999) enfatizam que a lixiviação do N-nitrato é um fenômeno físico, favorecido pela baixa energia envolvida no processo de adsorção e pela alta solubilidade do nitrato em água. Com isso, os íons de nitrato não permanecem aderidos ao solo, ficando em uma solução com a água e sendo carreados, podendo atingir águas de superfície e subsuperfície. 
O N-nitrato é a principal forma de nitrogênio associada à contaminação da água em função das atividades agrícolas. Segundo Resende (2002), isso ocorre por este componente ser fracamente retido nas cargas positivas dos colóides, tendendo a permanecer em solução, principalmente nas camadas superficiais do solo, as quais acentuam a carga eletronegativa da fase sólida, repelindo o nitrato. Na solução do solo, este elemento fica muito vulnerável ao processo de lixiviação, podendo haver ao longo do tempo, um considerável aumento de seus teores em água profunda. Para esse autor a intensidade do processo contaminante vai depender principalmente das quantidades de nitrato adicionada ao solo, da permeabilidade do solo, das condições climáticas (pluviosidade e irrigação) e da profundidade do lençol freático.

O processo de nitrificação ocorre sob condições normais no solo, onde se estabelece um aumento da disponibilidade e absorção do nitrogênio pelas plantas, aumento das perdas de N-nitrato por denitrificação e devido ao efeito poluidor do Nnitrato mineral. Esse processo (nitrificação) pode ser definido como uma oxidação biológica em que o amônio proveniente da mineralização da matéria orgânica do solo ou de fertilizantes amídicos ou amoniacais é convertido a nitrato pelos microorganismos do solo.

Tal processo divide-se em duas fases: na primeira fase, as bactérias do gênero Nitrossomonas agem na formação de nitrito e na segunda, a formação de nitrato ocorre por ação da bactéria Nitrobacter, tais bactérias são quimioautotróficas, fixando $\mathrm{CO}_{2} \mathrm{com}$ a energia obtida nessas duas reações, as quais são obrigatoriamente aeróbicas.

\subsubsection{O P-fosfato no solo}

A exigência da cultura de banana em relação ao fósforo (fosfato) é bem menor, quando comparada à demanda por adubação nitogenada e potássica. Trabalhos conduzidos na região salientam que não há carência deste nutriente em amostras foliares nos cultivares (Godoy et al., 2006).

Segundo Lehmann et al. (2003), o P-fosfato diferentemente do N-nitrato é imóvel na maioria dos solos, porque ele precipita e é adsorvido na superfície dos minerais, portanto a lixiviação é praticamente insignificante, exceto em solos extremamente arenosos e orgânicos (Wild, 1988). Trabalho conduzido em áreas com cultivares de banana na região Registro, Pariquera-Açu e Jacupiranga, identificaram solo do tipo Gleissolo háplico para propriedades encontradas na área de Registro e solos Latossolo 
Amarelo e Cambissolo Háplico para propriedades encontradas em Pariquera-Açú e Jacupiranga, respectivamente (Godoy et al ,2012).

Uma estimativa de perda de nutrientes ( $\mathrm{N}$-nitrato e P-fosfato) em cultivares de bananas encontra-se na tabela 39.

Tabela 39. Estimativa da perda de nutrientes $(\mathrm{N}$ e $\mathrm{P})$ da bananeira por enxurrada, drenagem e adubação (tabela adaptada de Godefroy et al., 1970; 1975).

\begin{tabular}{ccccc}
\hline Nutriente & $\begin{array}{c}\text { Perdas } \\
\left(\text { kg ha }^{-1} \mathbf{a n o}^{-1}\right)\end{array}$ & Drenagem & Enxurrada & $\begin{array}{c}\text { Perdas } \\
\text { Adubação }\end{array}$ \\
\hline N-n & 219 & $>90 \%$ & $<10 \%$ & $55 \%$ \\
$\mathbf{P}$ & 1,8 & $50 \%$ & $50 \%$ & $10 \%$ \\
\hline
\end{tabular}

Bérgamo (2000) apresentou o valor de máxima vazão do Rio Ribeira de Iguape como $1751 \mathrm{~m}^{3} / \mathrm{s}$, mínimo de $99 \mathrm{~m}^{3} / \mathrm{s}$ e um valor médio de $774 \mathrm{~m}^{3} / \mathrm{s}$, enquanto que o $\mathrm{CBH}$ RB (2013) indica vazão média do Rio Ribeira de Iguape de $526 \mathrm{~m}^{3} / \mathrm{s}$. Fevereiro de 2013 houve o maior índice de precipitação (184mm) e, a amostragem de agosto de 2012 correspondeu ao período mais seco $(11 \mathrm{~mm})$. Desta forma, tem-se ideia dos dois extremos de lixiviação e drenagem que podem ocorrer na região de estudo e que pode ser usado para estimar o transporte de $\mathrm{N}$ e $\mathrm{P}$, com base nos valores de concentração de nitrato e fosfato obtidos na porção final do Rio Ribeira conforme a tabela 40.

Tabela 40. Estimativa de transporte de $\mathrm{N}$ e P pelos rios no inverno e verão, de acordo com as concentrações determinadas na estação Rio mais a Jusante, R3 e em Registro (Novembro,

2013). Apresentam-se também resultados de Cunha, 2010, obtidos no Rio Jacupiranga.

\begin{tabular}{|c|c|c|c|c|c|c|c|c|c|c|}
\hline & $\begin{array}{c}\text { Precip. } \\
\text { (mm) }\end{array}$ & $\begin{array}{l}\text { Vazão } \\
\left(\mathbf{m}^{3} / \mathbf{s}\right)\end{array}$ & $\begin{array}{l}\text { N-Nitrato } \\
\left(\mu \mathrm{mol} \mathrm{L}^{-1}\right)\end{array}$ & $\begin{array}{l}\text { P-Fosfato } \\
\left(\mu \mathrm{mol} \mathbf{L}^{-1}\right)\end{array}$ & \begin{tabular}{|c|} 
Carga de $\mathrm{N}-$ \\
nitrato \\
$\left(\mathrm{g} \mathrm{s}^{-1}\right)$
\end{tabular} & $\begin{array}{c}\text { Carga de P- } \\
\text { fosfato } \\
\left(\mathrm{g} \mathrm{s}^{-1}\right)\end{array}$ & $\begin{array}{c}\text { Transporte } \\
\text { N-total } \\
\left(\mathrm{t} \text { ano }^{-1}\right)\end{array}$ & $\begin{array}{c}\text { Transporte } \\
\text { P-total } \\
\left(\mathbf{t} \text { ano }^{-1}\right)\end{array}$ & $\begin{array}{c}\text { Carga } \\
\text { N-agric. } \\
\left(t \text { ano }^{-1}\right)\end{array}$ & $\begin{array}{c}\text { Carga } \\
\text { P-agric. } \\
\left(t_{\text {ano }}^{-1}\right)\end{array}$ \\
\hline \multirow{2}{*}{ Verão } & \multirow{2}{*}{$1.372,8$} & \multirow{2}{*}{$\begin{array}{c}774 * \\
526 * *\end{array}$} & $\begin{array}{c}12,62 \\
(2013)\end{array}$ & $\begin{array}{c}6,45 \\
(2013)\end{array}$ & $\begin{array}{c}136,8 * \\
93,03 * *\end{array}$ & $\begin{array}{c}154,3 * \\
104,9 * *\end{array}$ & $\begin{array}{c}4318 * \\
2935 * *\end{array}$ & $\begin{array}{c}4869 * \\
3310 * *\end{array}$ & \multirow{6}{*}{44,22} & \multirow{6}{*}{5,36} \\
\hline & & & $\begin{array}{l}12,28 \\
(2014)\end{array}$ & $\begin{array}{c}3,18 \\
(2014)\end{array}$ & $\begin{array}{c}133,2 * \\
90,52 * *\end{array}$ & $\begin{array}{c}76,22 * \\
51,83 * *\end{array}$ & $\begin{array}{c}4201 * \\
2856 * *\end{array}$ & $\begin{array}{c}2405^{*} \\
1635^{* *}\end{array}$ & & \\
\hline \multirow{2}{*}{ Inverno } & \multirow{2}{*}{$1.403,3$} & \multirow{2}{*}{$\begin{array}{c}774 * \\
526^{* *}\end{array}$} & $\begin{array}{l}10,07 \\
(2012)\end{array}$ & $\begin{array}{c}11,95 \\
(2012)\end{array}$ & $\begin{array}{c}109,2 * \\
74,23 * *\end{array}$ & $\begin{array}{c}286,4 * \\
194,8 * *\end{array}$ & $\begin{array}{l}3445 * \\
2342 * *\end{array}$ & $\begin{array}{c}9038,13 * \\
6144 * *\end{array}$ & & \\
\hline & & & $\begin{array}{c}14,17 \\
(2013)\end{array}$ & $\begin{array}{c}5,82 \\
(2013)\end{array}$ & $\begin{array}{c}153,6^{*} \\
104,5^{* *}\end{array}$ & $\begin{array}{c}139,4 * \\
94,81 * *\end{array}$ & $\begin{array}{c}4847 * \\
3296 * *\end{array}$ & $\begin{array}{c}4400 * \\
2991 * *\end{array}$ & & \\
\hline Nov. 2013 & - & & 18,17 & 4,49 & $\begin{array}{c}197,0 * \\
134,0 * *\end{array}$ & $\begin{array}{c}107,74 * \\
73,2 * *\end{array}$ & $\begin{array}{l}6216^{*} \\
4226^{* * *}\end{array}$ & $\begin{array}{l}3397 * \\
2309 * *\end{array}$ & & \\
\hline $\begin{array}{c}\text { Cunha } \\
(\text { out } / 2010)\end{array}$ & & 42 & $\begin{array}{c}37,1 \\
\left(0,52 \mathrm{mg} \mathrm{L}^{-1}\right)\end{array}$ & $\begin{array}{c}193 \\
\left(6 \mathrm{mg} \mathrm{L}^{-1}\right)\end{array}$ & 21,84 & 252 & 679,31 & 7838,30 & & \\
\hline
\end{tabular}

* Vazão (Bérgamo, 2000)

** Vazão (Relatório CBH-RB, 2013) 
A tabela 40 mostra a alta quantidade de nutrientes (N-nitrato e P-fosfato) que são aportados ao Rio. As cargas de N-nitrato nos dois verões, $12,62 \mu \mathrm{mol} \mathrm{L}^{-1}$ e $12,28 \mu \mathrm{mol}$ $\mathrm{L}^{-1}$ (fev. 2013 e fev.2014, respectivamente) foram muito parecidas, já que nessa época chuvosa, a adubação da banana é evitada pelos agricultores, para que não haja uma grande perda por lixiviação. Em virtude disso, a época de adubação programada pelos agricultores da região para a cultura da banana ocorre, de forma gradual, nos meses de fevereiro a maio e de agosto a novembro (Godoy et al., 2012). Pode-se estabelecer uma relação com os maiores teores de nitrato encontrados na água em setembro e em novembro.

Tomando-se como referência os valores máximos e mínimos do transporte total de nutrientes pelo rio (colunas 8 e 9 da tabela 40), calculados com base na vazão média obtida pela CETESB (2013), pode-se inferir que o transporte mensal de N pode variar entre 192,40 t mês ${ }^{-1}$ e 260,25 t mês ${ }^{-1}$, e de P entre 134,53 t mês ${ }^{-1}$ e 505,56 t mês ${ }^{-1}$.

Observa-se pela tabela 40 que a quantidade estimada de nitrogênio perdido pela bananicultura (30\%) e transportado pelo rio, na área amostrada entre Registro e Iguape, com valor de 44 toneladas por ano, corresponde a cerca de 1,6\% do total de nitrogênio que flui ao longo de todo o percurso do Rio.

Ao se observar os dados para fósforo na tabela 40, destaca-se que o teor de fósforo varia muito mais de uma amostragem para outra quando comparado ao N. Os teores mais elevados de fósforo obtidos neste trabalho correspondem à amostragem abaixo do Jacupiranga que transporta efluentes provenientes da mineração de rocha fosfatada do município de Cajati. Os valores mais elevados, 8918 toneladas por ano, são comparáveis aos determinados no Rio Jacupiranga por Cunha (2010) de 7838 toneladas de fósforo por ano.

A quantidade estimada de $10 \%$ de P-fósforo perdido pela bananicultura na área amostrada entre Registro e Iguape e transportado pelo rio resultou em 5,36 toneladas de fósforo ao ano. Isto equivale em média a cerca de $0,15 \%$ do total de fósforo que flui ao longo de todo o percurso do Rio.

O fosfato tem uma demanda menor pela cultura, de acordo com Godoy et al. (2012), pois a planta na região dificilmente carece deste nutriente. Como já relatado, os compostos de fósforo são mais retidos no solo que os de nitrogênio, resultando em um menor aporte do fósforo para o rio. O alto teor de fósforo encontrado, igual a 11,95 $\mu \mathrm{mol}$ $\mathrm{L}^{-1}$, pode ser atribuído ao fosfato oriundo do afluente Jacupiranga que recebe uma contribuição via indústria (exploração da rocha fosfática em Cajati). Lembrando que o 
Rio Jacupiranga deságua no Rio Ribeira do Iguape a uma distância de mais ou menos 30 $\mathrm{km}$ do ponto R3. 


\section{CONCLUSÃO}

- Os valores de nitrato apontam a contribuição antrópica ao longo de todo o trabalho, pois os valores de concentração são bastante altos, com maiores concentrações observadas em agosto de 2012. Isto indica que a lixiviação é constante e os processos de retenção são poucos, a perda desse insumo pela agricultura merece reflexão para aumento da eficiência no uso.

- Os valores de P-fosfato, na maioria dos pontos do sistema norte, esteve entre 9 e $10 \mu \mathrm{mol} \mathrm{L-}{ }^{1}$, sendo realmente muito altos para serem explicados apenas pela lixiviação de áreas de cultivo e aporte de esgoto doméstico. Deve haver contribuição por aporte vindo de outra atividade antrópica, sendo apontada a possível contribuição oriunda da atividade de exploração de minérios contendo P-fosfato (Jacupiranguito, apatita utilizados na produção de ácido fosfórico, obtenção de fosfocálcio, suplemento mineral em rações animais).

- A diluição dos parâmetros pela entrada de água salgada, pobre em nutrientes, no setor norte é muito sutil, pois há domínio de água doce no sistema norte, em função da vazão do Rio via Valo Grande. Deste modo, a diluição é pouco efetiva para levar os valores de $\mathrm{N}$ e $\mathrm{P}$ aos limites naturais apontados para aquele sistema. Pode-se observar uma diluição mais adequada no meio do sistema, junto à estação intermediária, já nas proximidades da Ilha de Cananéia.

- A influência da precipitação, como no caso de Agosto de 2012 que foi muito baixa, não provocou uma redução acentuada nas concentrações, sobretudo de $\mathrm{P}$, o que confirma a contribuição por fontes extras, além da lixiviação. No caso do N, como no verão de 2013, quando a precipitação foi intensa, os valores altos de $\mathrm{N}$ podem estar associados ao transporte por lixiviação.

- No verão 2013, os valores de P foram cerca de 50\% menores do que na amostragem anterior mostrando uma contribuição industrial menos efetiva, ou melhor, que a diluição possa ter sido mais efetiva no período. Quanto à carga de material em suspensão (MES) ela acusou maior intensidade no período chuvoso e, o material fosfatado poderia estar principalmente na forma particulada. No caso do inverno 2013, os valores também diminuíram mais 50\% em relação a agosto de 2012, sendo observados os maiores valores da relação N/P devido ao aumento do nitrato e diminuição do fosfato. $\mathrm{O}$ $\mathrm{N}$-amoniacal, mostrou valores bastante estáveis em quase todos os períodos, exceto em 
setembro de 2013, quando a amostragem ocorreu no final do inverno. Esta forma de nitrogênio diminuiu provavelmente devido ao consumo no início do bloom fitoplanctônico de primavera, pois o $\mathrm{N}$-amoniacal é a forma de $\mathrm{N}$ preferencialmente assimilada.

- Os valores de carga de matéria orgânica e disponibilidade de oxigênio dissolvido mostram pontos onde o oxigênio tem valores menores, mas nenhum dado de forte hipóxia (exceto a estação 2 da primeira campanha), de modo que os valores de OD são aceitáveis indicando apenas locais onde a decomposição da matéria orgânica é mais intensa e os processos de circulação são menos efetivos. Os valores de $\mathrm{pH}$ abaixo de 8 só foram observados no norte do sistema, acompanhando a menor capacidade de tamponamento de águas doce e salobras, e passa a valores em torno de 8 no sistema sul.

- À medida que a salinidade atinge valores maiores que 5, os teores de $\mathrm{N}$ e $\mathrm{P}$ diminuem, atingindo valores normais para o sistema estuarino com pouca influência antrópica.

- Observando o período de Setembro de 2013, final de inverno e início de primavera, os valores de MES, no sistema sul, foram altos, porém devem estar associados à produção de matéria orgânica fitoplanctônica ou à ressuspenção de sedimentos.

- Considerando as áreas com plantações de bananas no trecho a jusante do Ribeira do Iguape, entre os municípios de Registro e Iguape, foi estimada uma área plantada de aproximadamente 744,5 hectares. Então, para o desenvolvimento do cultivar seriam necessários $200 \mathrm{~kg}_{\text {de }} \mathrm{N} \mathrm{ha}^{-1} \mathrm{ano}^{-1}$ e $80 \mathrm{~kg} \mathrm{ha}^{-1} \mathrm{ano}^{-1}$ de $\mathrm{P}$, sendo que a mobilidade e a retenção destes elementos são diferenciadas. A alta mobilidade do $\mathrm{N}$ influencia de modo evidente o sistema hídrico, pois os valores foram constantemente altos. O P tem maior retenção no solo, portanto somente a lixiviação de áreas do plantio marginal não é suficiente para explicar os altos valores encontrados no sistema hídrico, o que corrobora com a existência de uma entrada adicional à agricultura e esgoto deste elemento.

- O aporte do $\mathrm{N}$ e do P ao sistema hídrico vindo do plantio e do cultivo da banana, considerando uma perda de $10 \%$ para o $\mathrm{P}$ e de $30 \%$ para o $\mathrm{N}$, e tomando como referência um valor médio de vazão do Rio Ribeira de Iguape, mostra um potencial acentuado de transporte/exportação tanto de $\mathrm{P}$ quanto de $\mathrm{N}$ para o sistema marinho, o que pode influenciar os processos biogeoquímicos na região costeira, até mesmo provocando a eutrofização. Esse transporte estimado está na ordem de $5 \mathrm{t} \mathrm{ano}^{-1}$ para $\mathrm{P}$ e $44 \mathrm{t}_{\text {ano }}{ }^{-1}$ para 
$\mathrm{N}$, quando considerada a vazão média do rio, o que é preocupante, diante de outros valores mundiais.

- O desbalanceamento da entrada de P-fosfato na relação N:P indica a forte influência antrópica na região provocada não só pelo desvio do Rio Ribeira de Iguape pelo Valo Grande, como sobretudo pela carga calculada de nutrientes que isto representa para o complexo estuarino-lagunar de Cananéia Iguape. A carga antrópica de nutrientes pode eventualmente atingir o setor sul (Cananéia) já que os processos de diluição só foram verificados de forma efetiva nas proximidades da Ilha de Cananéia.

- Enfim, pode-se concluir que na região de estudo, a contribuição antrópica no sistema Norte é efetiva em termos de $\mathrm{N}$ e $\mathrm{P}$ provenientes da agricultura e que no caso do $\mathrm{P}$ há um suplemento muito importante provavelmente vindo da exploração mineral do fósforo que deve ser avaliada em planos de manejo e conservação ambiental. 


\section{REFERÊNCIAS BIBLIOGRÁFICAS}

AMINOT, A. \& CHAUSSEPIED, M. Manuel des analyses chimiques en milieu marin. CNEXO. Brest. 395p. 1983.

BALLS, P.W. Nutrient inputs to estuaries from nine scottish east coast rivers: influence of estuarine processes on inputs to the North Sea. Estuarine Coastal and Shelf Science. v. 39, n.4, p.329-352. 1994.

BARRERA -ALBA,J.J. Dinâmica metabólica e transporte de propriedades no sistema estuarino-lagunar de Cananéia- Iguape. Tese (Doutorado). Instituto Oceanográfico, Universidade de São Paulo, SP. 216p. 2004.

BERBEL, G.B.B. Estudo do fósforo sedimentar e de suas especiações químicas em dois sistemas costeiros e Plataforma Continental Sudeste (Brasil) e Baía do Almirantado (região antártica) considerando suas relações biogeoquímicas. Tese (Doutorado). Instituto Oceanográfico, Universidade de São Paulo, SP. 283p. 2008.

BÉRGAMO, A.L. Característica da hidrografia, circulação e transporte de sal: Barra de Cananéia, sul do Mar de Cananéia e Baía do Trapandé. Dissertação (Mestrado). Instituto Oceanográfico, Universidade de São Paulo. São Paulo-SP. 254p. 2000.

BONÁS, T.B. Aplicação de índice mineralógico como apoio na avaliação de reservas da mina de fosfato de Cajati-SP. Dissertação (Mestrado). Instituto de Geociências, Universidade de São Paulo, São Paulo-SP. 77p. 2007.

BOUMANS, L.J.M.; FRATERS, D. \& VAN DRECHT, G. Nitrate leaching in agriculture to upper groundwater in the sandy regions of the Netherlands during the 1992-1995 period. v.102, p. 225-241. 2005.

BRAGA, E. S. Estudo dos nutrientes dissolvidos nas águas da Enseada das Palmas, Ilha Anchieta (Ubatuba-SP), com ênfase às formas nitrogenadas e contribuição dos aportes terrestres e atmosféricos. Dissertação (Mestrado). Instituto Oceanográfico, Universidade de São Paulo, SP. 207p. 1989.

BRAGA, E. S. Nutrientes dissolvidos e produção primária do fitoplâncton em dois sistemas costeiros do Estado de São Paulo. Tese (Doutorado). Instituto Oceanográfico, Universidade de São Paulo. São Paulo, SP. 2v. 1995.

BRAGA, E.S. Determinação automática de nitrato. In: WAGENER, A.R.L. \& CARREIRA, R. Métodos analíticos de referência em Oceanografia Química. Rio de Janeiro, MMA/SMA. Cap. 6, p. 27-29. 1998.

BRAGA, E. S. Bioquímica Marinha e efeitos de poluição nos processos bioquímicos. $2^{a}$ ed. São Paulo, SP. FUNDESPA. 108p. 2002.

BRAGA, E. S.; BONETTI, C.V.D.H.; BURONE, L. \& BONETTI-FILHO J. Eutrophication and bacterial pollution caused by industrial and domestic wastes at the Baixada Santista Estuarine System -Brazil. Marine Pollution Bulletin. v.40, n.2, p.165-173. 2000. 
BRAGA, E. S. \& CHIOZZINI, V. G. Nutrientes dissolvidos no complexo estuarino lagunar de Cananéia-Iguape: influência do Valo Grande no setor sul (1992 e 2005). In: BRAGA, E. S. Oceanografia e mudanças globais. Universidade de São Paulo. São Paulo, SP. p. 573-582. 2008.

BRAGA, R. Planejamento regional no Estado de São Paulo: A experiência do Vale do Ribeira nas décadas de 1970 e 1980. Tese (Doutorado). Faculdade de Filosofia, Letras e Ciências Humanas, Universidade de São Paulo, SP. 226p. 1998.

BRASIL. Lei n ${ }^{\circ} 4771$, de 15 de setembro de 1965. Institui o novo Código Florestal. Diário Oficial da União, Brasília, DF. Seção 1, p. 9529. 16 set. 1965.

BRASIL DAS ÁGUAS. Relatório Rio Ribeira. Projeto Brasil das Águas - Sete Rios. 70p. 2007. Disponível em: www.brasildasaguas.com.br.

BRODIE, J., CHRISTIE, C., DEVLIN, M., HAYNES, D., MORRIS, S., RAMSAY, M., \& YORKSTON, H. Catchment management and the Great Barrier Reef. Water Science and Technology. v. 43, n.9, p. 203-211. 2001.

BRODIE, J.E. \& MITCHELL, A.W. Nutrients in australian tropical rivers: changes with agricultural development and implication for receiving environments. Marine and Freshwater Research. v.53, n.3, p.279-302. 2005.

BRUNINI, O. Exigências climáticas e aptidão agroclimática da bananicultura. In: Anais do Simpósio Brasileiro sobre Bananicultura. FCAVJ, Jaboticabal, SP. p.99-117. 1984.

CATI. Coordenadoria de Assistência Técnica Integral. Levantamento censitário de unidades de produção agrícola do Estado de São Paulo (LUPA). 2008. Disponível em: www.cati.sp.gov.br/projetolupa.

CBH-RB. Comitê da Bacia Hidrográfica do Ribeira de Iguape e Litoral Sul. Caderno de informações sobre a bacia da Unidade de Gerenciamento de Recursos Hídricos $n^{\circ} 11$. 28p. 2008-2011. Disponível em: www.sigrb.com.br.

CBH-RB. Comitê da Bacia Hidrográfica do Ribeira de Iguape e Litoral Sul. Relatório de situação dos recursos hídricos da UGRHI 11. 659p. 2008. Disponível em: www.sigrh.sp.gov.br.

CBH-RB. Comitê da Bacia Hidrográfica do Ribeira de Iguape e Litoral Sul. Relatório de situação dos recursos hídricos da UGRHI 11. 60p. 2011. Disponível em: www.sigrh.sp.gov.br.

CBH-RB. Comitê da Bacia Hidrográfica do Ribeira de Iguape e Litoral Sul. Relatório de situação dos recursos hídricos da UGRHI 11. 82p. 2013. Disponível em: www.sigrh.sp.gov.br.

CBH-RB. Comitê da Bacia Hidrográfica do Ribeira de Iguape e Litoral Sul. Relatório de situação dos recursos hídricos da UGRHI 11. 82p. 2013. Disponível em: www.sigrh.sp.gov.br.

CETEC. Centro Tecnológico da Fundação Paulista de Tecnologia e Educação. Situação dos recursos hídricos do Ribeira de Iguape e Litoral Sul. São Paulo, SP. 213 p. 1999. 
CETESB. Companhia Ambiental do Estado de São Paulo. Qualidade das águas superficiais em São Paulo. 2013. Disponível em: www.cetesb.sp.gov.br. Acesso em: 25 de agosto de 2014.

CHIOZZINI, V.G.; MALUF, J.C.C.; TORRES, J.L.R. \& BRAGA, E.S. Variabilidade sazonal (inverno-verão) das especiações químicas de nitrogênio no complexo estuarino- lagunar de Cananéia-SP. In: BRAGA, E.S. (org.). Oceanografia e Mudanças Globais, Universidade de São Paulo. São Paulo - SP. p. 629-647. 2008.

CORREA, R. S.; WHITE, R. E.; WEATHERLEY, A. J. Risk of nitrate leaching from two soils amended with biosolids. Water Resources, v. 33, n. 4, p. 453-462. 2006.

CUNHA, C.A.G. A sub-bacia do Rio Jacupiranga: análise dos aspectos sócio econômicos e ambientais como subsídio para o manejo sustentável da região do Vale do Ribeira, São Paulo. Tese (Doutorado). Escola de Engenharia de São Carlos, Universidade de São Paulo. São Carlos - SP. 251p. 2010.

CUNHA, M. L. Determinação de resíduos de pesticidas em sedimentos dos principais rios do Pantanal Mato-grossense por CG/EM. Dissertação (Mestrado). Instituto de Saúde Coletiva, Universidade Federal de Mato Grosso, (MT). 86p. 2003.

CUNHA, D.G.F. \& CALIJURI, M.C. Comparação entre os teores de matéria orgânica e as concentrações de nutrientes e metais pesados no sedimento de dois sistemas lóticos do Vale do Rio Ribeira do Iguape-SP. Revista de Engenharia Ambiental. v.5, n.2, p. 24-40. 2008.

DAEE/IPT-SIBH. Departamento de Águas e Energia Elétrica (DAEE)/Instituto de Pesquisas Tecnológicas (IPT) - Sistema Integrado de Bacias Hidrográficas (SIBH). São Paulo, DAEE/IPT, 2004.

DELGADO, J.A. Quantifying the loss mechanisms of nitrogen. Journal of Soil and Water Conservation. v.57, n.6, p.389-398. 2002.

DIEGUES, A.C. Pesca e marginalização no litoral paulista. Dissertação (Mestrado). Faculdade de Filosofia, Letras e Ciências Humanas, Universidade de São Paulo, São Paulo, SP. 201p. 1973.

DOWDELL, R.J. \& MIAN, M.H. Fate of nitrogen applied to agricultural crops with particular reference to denitrification (and discussion). Philosophical Transactions B. v. 296, n.1082, p.363-373.1982.

DYNIA, J.F. \& CAMARGO, O.A. Nitrate retention in a variable-charge soil, as influenced by phosphate fertilizing and liming. Pesquisa Agropecuária Brasileira. v.34, p.141-144. 1999.

EMBRAPA. Empresa Brasileira de Pesquisa Agropecuária. Cultivo da banana para o ecossistema dos tabuleiros costeiros. 2003. Disponível em: http://sistemasdeproducao.cnptia.embrapa.br. 
EMBRAPA. Empresa Brasileira de Pesquisa Agropecuária. Produção de bananas no Brasil em 2011. 2011. Disponível em: www.cnpmf.embrapa.br. Acesso em $14 / 04 / 2013$.

ESCHRIQUE, S.A. Estudo do balanço biogeoquímico dos nutrientes dissolvidos principais como indicador da influência antrópica em sistemas estuarinos do nordeste e sudeste do Brasil. Tese (Doutorado). Instituto Oceanográfico, Universidade de São Paulo, São Paulo, SP. 229 p. 2011.

FAITHFUL, J. \& FINLAYSON, W. Water quality assessment for sustainable agriculture in the Wet Tropics - A community-assisted approach. Marine Pollution Bulletin. v. 51, n.1, p. 99-112. 2005.

GEOBRÁS. Complexo Valo Grande, Mar Pequeno e Rio Ribeira de Iguape. Relatório Geobrás S/A, Engenharia e Fundações para o Serviço do Vale o Ribeira do Departamento de Águas e Energia Elétrica (DAEE), São Paulo - SP, 2 v., 1966.

GRASSHOFF, K., EHRHARDT, M. \& KREMLING, K. Methods of seawater analysis. 2nd ed. Weinhein, Verlag Chemie. 419p. 1983.

GODEFROY, J.; MULLER, M. \& ROOSE, E. Estimation des pertes par lixiviation des elements fertilisants dans un sol de bananeraie de basse Cote d'Ivoire. Fruits. v. 25, n. 6, p. 403-423. 1970.

GODEFROY, J.; ROOSE, E.J. \& MULLER, E. Estimation des pertes par les eaux de russellement et de drainage dos elements fertilisants dans un sol de bananeraie d sud de la Côte d'Ivoire. Fruits. v.30, p.223-235. 1975.

GODOY, L.J.G.; GOÇALO, S. G.; MENDONCA, J.C. \& BERNARDO, A. Variação sazonal da concentração de nutrientes em folhas de bananeiras, no Vale do RibeiraSP. Semina: Ciências Agrárias. v. 33, p. 1367-1380. 2012.

GODOY, L.J.G.; NOMURA, E.S. \& MORAES, W.S. Nutrição e adubação da cultura da banana. Informações Agronômicas. n. 116, p. 14-19. 2006.

HILHORST, G.J.; OENEMA, J. \&VAN KEULEN, H. Nitrogen management on experimental dairy farm 'De Marke'; farming system, objectives and results. Wageningen Journal of Life Science. v.57; p.135-151. 2001.

ITAL. Instituto de Tecnologia de Alimento. Bananas: cultura, matéria-prima, processamento e aspectos econômicas. 3ed. Campinas, SP. 320p. 1990.

KATO, K. Chemical investigations on the hydrographical system of Cananéia lagoon. Boletim do Instituto Oceanográfico. v. 15, n. 1, p. 1-12. 1966.

KHATIK, V.A.; SARODE, D.B.; JADHAV, R.N.; INGLE, S.T. \& ATTARDE, S.B. Assessment on residual soil nitrate of intensively fertilized banana farms of Jalgaon region. Malaysian Journal of Soil Science. v.15, p.87-99. 2011.

KUNIOSHY, L.S. Bioacumulação de elementos traço e expressão de micronúcleos em Cathorops spixii (biomotor) como ferramentas de avaliação da influência antrópica em dois setores do complexo estuarino lagunar de Cananéia- Iguape, São Paulo, Brasil. 
Tese (Mestrado). Instituto Oceanográfico, Universidade de São Paulo. São Paulo, SP. 127p. 2011.

LAHAV, E. \& TURNER, D.W. Fertilizing for high nutrition banana: Banana nutrition. International Potash Institute (IPI) Bulletin 7. 62p. 1983.

LEHMANN, J.; KERN, D.; GERMAN, L.; MCCANN, J.; MARTINS, G. C. \& MOREIRA, A. Soil fertility and production potential. In Amazonian dark earths. Springer Netherlands. p. 105-124. 2003.

MALUF, J.C.C. Estudo dos metais traço (Zinco,Cádmio e Chumbo) em duas regiões do complexo estuarino lagunar de Cananéia- Iguape(SP) sob diferentes pressões antrópicas. Dissertação (Mestrado). Instituto Oceanográfico, Universidade de São Paulo. São Paulo, SP. 125p. 2009.

MCKEE, L.J.; EYRE, B.D. \& HOSSAIN, S. Transport and retention of nitrogen and phosphorus in the sub-tropical Richmond River estuary, Australia - a budget approach. Biogeochemistry. v.50, p.241-278. 2000.

MEDINA, J.C.; BLEINROTH, E.W.; MARTIN, Z.J.; TRAVAGLINI, D.A.; OKADA, M.; QUAST, D.G.; HASHIZUME, T.; RENESTO, O.V.; MORETTI, V.A. Banana da cultura ao processamento e comercialização. ITAL, Campinas (SP). 197p. 1978.

MEYBECK, M. Carbon, nitrogen, and phosphorus transport by world rivers. American Journal of Science. v. 282, p. 401-450. 1982.

MITCHEL, A., REGHENZANI, J., FAITHFUL, J., FURNAS, M., \& BRODIE, J. Relationships between land use and nutrient concentrations in streams draining a'wettropics' catchment in northern Australia. Marine and Freshwater Research. v. 60, n.11, p.1097-1108. 2009

MOMMAERTS, J.; ADAM, Y.; D’HONDT, P. \& JACQUES, T.G. A modeling approach to the effects of waste disposal in the southern bight to North Sea. In: Physical chemical process and wastes in the ocean. CONNOR, T.P.; BURT; W.V. \& DUEDALL, I.W. (eds). Oceanic Process in Marine Pollution Series. v.2, p 47-57.1987.

MOREIRA, R. Cultura da bananeira. EMATER - Belo Horizonte, MG. 68p. 1979.

MOREIRA, R.S. Banana: teoria e prática de cultivo. Fundação CARGILL, Campinas (SP). 335p. 1987.

OLAREWAJU, O.E.; ADETUNJI, M.T.; ADEOFUN, C.O. \& ADEKUNLE, I.M. Nitrate and phosphorus loss from agricultural land: implications for nonpoint pollution. Nutrient Cycling in Agroecosystems. v.85, p.79-85. 2009.

PINO, F.A.; FRANCISCO, V.L.F.S.; PEREZ, L.H.; AMARO, A.A. A cultura da banana no Estado de São Paulo. Informações Econômicas. v.30, n.6, p. 46-76. 2000.

RESENDE, A.V. Agricultura e qualidade da água: contaminação da água por nitrato. EMBRAPA Cerrados, Planaltina (DF). 29p. 2002. 
ROSS, J.L.S. A Morfogênese da Bacia do Ribeira do Iguape e os Sistemas Ambientais. São Paulo, Geousp - Espaço e Tempo, n. 12. 2002. Disponível em: http://www.usp.br/geografia. Acesso em 10 out. 2012.

SANCHEZ, S.S. \& SANCHEZ, L.E. Mineração de fosfato em Cajati e o desenvolvimento local. In: FERNANDES, F.R.C; ENRIQUES, M.A.R.S.; ALAMINO, R.C.J. Recursos minerais e sustentabilidade territorial. p. 163-197. 2011.

SEADE. Fundação Sistema Estadual de Análise de Dados. Região administrativa de Registro. Diagnóstico para ações regionais da Secretaria de Emprego e Relações do Trabalho do Estado de São Paulo. 19p. 2010.

SONAL, T \& KATARIA, H.C. Physical-chemical studies of water quality of Shahpura Lake, Bhopal (M.P) with special reference to pollutio effects on ground water of its fringe áreas. Current World Environment. v. 7, n. 1, p. 139-144. 2012.

SOTO, M. Bananos: cultivo y comercialización. 2ed. San José: LIL. 674p. 1992.

SSRH. Secretaria de Saneamento e Recursos Hídricos. Estado de São Paulo. Plano regional integrado de saneamento básico para UGRHI-11. 136p. 2009.

STEIN, C.E. Estudo do papel da Spartina alterniflora como espécie bioindicadora de contaminação por elementos traço no Complexo -Estuarino Lagunar de CananéiaIguape, São Paulo, Brasil. Tese (Mestrado). Instituto Oceanográfico, Universidade de São Paulo. São Paulo, SP. 133p. 2011.

STRICKLAND, J.D.H. \& PARSONS, T. R. A practical handbook of seawater analyses. Ottawa: Fisheries Research Board of Canada. 311p. (Bulletin: Fisheries Research Board of Canada, n. 167). 1968.

TEIXEIRA, C. Estudo quantitativo da produção primária, clorofila $\alpha$ e parâmetros abióticos em relação à variação temporal (Lat.23 ${ }^{\circ}$ 30S-Long. $45^{\circ} 06 \mathrm{~W}$ ). Tese (Livre Docência). Instituto Oceanográfico, Universidade de São Paulo.243p.1980.

TEIXEIRA, L.A.J. Tópicos de nutrição e adubação de bananeira. In: Anais da XIII Reunião Itinerante de Fitossanidade do Instituto Biológico. Registro, SP. p. 66-79. 2005.

TRÉGUER, P. \& LE CORRE, P. Manuel d'analysis des sels nutritifs dans l'eau de mer. 2ed. Brest, Université de Bretagne Occidentale. 110 p. 1975.

WILD, A. Plant nutrients in soil: phosphate. Russell's soil conditions and plant growth. $11^{\text {th }}$ ed., p. 695-742. 1988.

YOUNG, W.J.; MARSTON, F.M. \& DAVIS, R.J. Nutrient export and land use in australian catchments. Journal of Environmental Management. v. 47, n.2, p. 165-183. 1996. 